(Aus dem physiologischen Institut zu Jena.)

\title{
Ueber die Athmung der Reptilien und Vögel.
}

Von

\section{Erngt Siefert.}

Hierzu Tafel III, IV u. V und 8 Textfiguren.

\section{Einleitung.}

Die Physiologie hat, der lange ausschliesslich herrschenden Richtung folgend, die in der vorliegenden Abhandlung erörterten Thatsachen und Fragen bisher nur immer flüchtig gestreift und fast ausschliesslich die Säugethiere und Amphibien (Frosch) berïcksichtigt. Es würde überflisssig sein, hier auf den Werth einer vergleichenden Untersuchung hinzuweisen, durch welche allein ein tieferes Verständniss der einschlägigen Probleme angebahnt wird.

Erfreulicher Weise macht sich neuerdings mehr und mehr das Bestreben geltend, den Kreis physiologischer Thatsachen zu erweitern und den Schlussfolgernngen durch Ausdehnung der Untersuchungen auf möglichst zahlreiche und verschiedene Objekte eine breitere und sicherere Unterlage zu geben.

Freilich steht das Ziel, die Physiologie zu dem Range einer vergleichenden Wissenschaft zu erheben und so den Vorsprung, den die Anatomie als vergleichende Forschung längst gewonnen hat, wieder einzuholen, zur Zeit noch in weiter Ferne, und wir sind im Wesentlichen noch darauf angewiesen, nene Thatsachen zu sammeln. Nichts destoweniger ist, diesem Bestreben bereits eine stattliche Zahl wichtiger physiologischer Arbeiten zu verdanken, und auch die vorliegende Untersuchung entsprang in erster Linie dem Wunsche, einen Beitrag zur vergleichenden Physiologie der Athmung zu liefern und die sehr fühlbare Lücke wenigstens in allgemeinen Zügen auszufüllen, welche zwischen den zwei durch weite Differenzen von einander gesehiedenen Gruppen der Amphibien einerseits, der Säugethiere und Vögel anderseits besteht. 


\section{Die experimentelle Methodik.}

Was die Methoden betrifft, deren ich mich bei meinen Untersuchungen bediente, so darf ich um so schneller darüber hinweggehen, als es sich durchaus um keine neuen, sondern lediglich um Uebertragung alter, lange angewandter und erprobter Methoden auf die hier in Betracht kommenden Fälle handelt. Es kam darauf an, gr a p h i s c h entweder die Druckschwankungen in den Lungen oder die der Inspiration und Exspiration entsprechenden Gestaltveränderungen des Thorax zu verzeichnen.

Entweder setzte ich durch eine Kopfkappe oder durch eine Trachealcanüle einen Marey'schen Tambour in geeigneter Weise mit den Luftwegen des Thieres in Verbindung oder benutzte, wenn die Bewegungen des Thorax graphisch dargestellt werden sollten, einen Fühlhebel, dessen Ausschläge ein hinreichend treues Bild der Bewegung nach Richtung und zeitlichem Verlauf lieferten.

Diese Methode leistete mir auch ferner bei der Beobachtung der Kehl- und Schluckathmung der Reptilien gute Dienste. Bei Vögeln benutzte ich oft auch eine kleine Vorrichtung nach Art der Cardiographen. Eine halbkugelige Messingkapsel, deren Durchmesser ca. fünf Centimeter beträgt, steht durch eine Oeffnung in ihrem Scheitel mit einem Tambour in Verbindung; unten ist sie durch eine elastische Kautschukmembran abgeschlossen, welche dem Theile der Brust- oder Bauchwand, dessen Exkursionen aufgezeichnet werden sollen, durch einen einfachen Bandapparat lose angeschmiegt wird.

Mehr iber die angewandten Methoden zu sagen, dürfte wegen ihrer allgemeinen Bekanntheit kaum erforderlich sein; gewisse Versuchsanordnungen, ebenso wie die operative Technik bei Blosslegung von Nerven u. A. wird, soweit es nöthig erscheint, in den betreffenden Abschnitten selbst eine kurze Darstellung finden.

\section{Haupttheil.}

Die Athmung der Reptilien.

A. Allgemeines.

Ich wende mich nach diesen kurzen Vorbemerkungen zul speciellen Behandlung unseres Themas und beginne mit der Be- 
sprechung der Reptilienathmung, da hier die Verbältnisse in vieler Beziehung einfacher liegen, als bei den Vögeln.

Man wird es der vorliegenden Untersuchung gewiss mit Recht zum Vorwurf machen dürfen, dass nur eine sehr geringe Anzahl von Vertretern der Klasse Berïcksichtigung finden konnte und eigentlich nur die Eideehsenathmung eingehender studirt wurde. Die mannigfachen Schwierigkeiten, geeignetes Versuchs-Material zu beschaffen, sowie die Kürze der mir zur Verfügung stehenden Zeit mag dies wenigstens einigermaassen entschuldigen. In letzterer Beziehung sei erwähnt, dass die Untersuchung im Frühling des vorigen Jahres in der Absicht begonnen wurde, die Versuche womöglich auch in den Wintermonaten fortzusetzen. Indessen musste hiervon bald Abstand genommen werden, indem der normale Athmungstypus der Eidechsen bei Eintritt der kalten Jabreszeit selbst bei in warmen Räumen gehaltenen Thieren so eingreifende Aenderungen erfährt, dass alle Bemühungen, über diese Schwierigkeiten hinwegzukommen, sich alsbald als aussichtslos erwiesen. Es scheint fast, als ob die normaler Weise dem Winterschlaf verfallenden Thiere auch dann tief greifende Veränderungen der Erregbarkeit des Nervensystems erlitten, wenn durch künstliche Wärmezufuhr die unmittelbare Veranlassung zum Eintritt jenes lethargischen Ruhezustandes vermieden wird.

Es ist mir wenigstens nicht in befriedigender Weise gelungen, unter diesen Umständen einen auch nur annähernd so regelmässigen Athmungstypus zu erzielen, wie er für dieselben Thiere im Sommer charakteristiseh ist.

Die Beschränkung der Untersuchung auf nur noch wenige andere Vertreter der Klasse wird man gewiss umsomehr bedauern miissen, als die gewaltigen Differenzen in der anatomischen Organisation der verschiedenen Reptilienformen es gerade hier besonders wïnschenswerth erscheinen lassen mussten, möglichst viele der physiologisch so sehr von einander abweichenden Ordnungen zu berücksichtigen.

Neben einheimischen Eidechsenarten (L. agilis, viridis) habe ich nur noch die Ringelnatter als Repräsentanten der Ophidier herangezogen und bemühte mich ferner auch, die lange und viel umstrittene Frage nach dem Modus der Schildkrötenathmung einer befriedigenden Lösung entgegenzuführen.

Meine ursprüngliche Absicht, die einzelnen Ordnungen in 
möglichst gleichmässiger Weise bei allen in Betracht kommenden Fragen zu berïcksichtigen, musste ich leider bald aufgeben aus Gründen, welche, wie es scheint, auch dafür maassgebend gewesen sind, dass die Reptilienathmung bisher nur so selten in den Kreis wissenschaftlicher Betrachtung gezogen wurde.

Es liegt dies wohl hauptsächlich an der ausserordentlichen Trägheit und zugleich Unregelmässigkeit der Athmung bei den meisten dieser Thiere unter selbst ganz normalen Verbältnissen, wodurch selbstredend das Studium aller Veränderungen, welche durch irgend einen Eingriff etwa hervorgerufen werden sollen, oft kaum überwindlichen Schwierigkeiten begegnet.

Alles dies steigert sich noch wesentlich, wenn die Thiere zum Zwecke des Versuches unter irgend ungewöhnliche Bedingungen gebracht werden; die vordem schon wenig regelmässige Athmung gewinnt dann oft einen gänzlich atypischen Charakter. Dies gilt vor Allem von Schildkröten.

Eine Schildkröte (ich benuitzte fast ausschliesslich Emy s e uropaea), der man, ohne sie auch nur fixirt zu haben, eine Kopfkappe überstülpt, lässt oft minutenlang warten, bis endlich eine oder eine Reihe von noch dazu meist ganz atypischen Athembewegungen erscheinen, in der Regel in Form heftiger Exspirationsstösse, die so rasch aufeinanderfolgen, dass der Hebel während ihrer Dauer gar nicht mehr in die Ruhelage zurücksinken kann, sondern dass die Athmungen sich aufeinander superponiren und zwar in so unregelmässiger Weise, dass eine Analyse solcher Curven kaum möglich wird.

Dazu kommt noch, dass die Thiere gleichzeitig allerlei Abwehr- und Fluchtbewegungen ausführen, die sich namentlich bei tracheotomirten Individuen oft ebenfalls an den gezeichneten Curven ausprägen. Nach einem solchen Anfall sistirt dann meist die Athmung wieder für längere Zeit, bis endlich eine neue Folge unregelmässiger Respirationsstösse die Pause unterbricht. Dieser einer Untersuchung offenbar wenig förderliche Zustand kann unter Umständen stundenlang andauern, bis endlich eine längere Reihe wenigstens annähernd regelmässiger Athmungen für das ermiidende Zuwarten belohnt.

Auch die relativ geringe Erregbarkeit der centralen Apparate macht sich oft, namentlich bei Nervenreizungen, in unangenehmer Weise bemerkbar. 
Leichte Vagusreize z. B., die bei Warmblïtern schon eine entschiedene Beeinflussung der Athmung bewirken, zeigen sich hier meist ganz erfolglos, und erst bei sehr starken Reizen kann man gewisse Veränderungen konstatiren, die aber bei der andauernden Unregelmässigkeit und besonders bei der oft kolossalen Pausenlänge von mehr als problematischem Werthe sind, und von denen man meist nicht mit Sicherheit angeben kann, ob sie wirklich Folgen einer reflektorischen Erregung sind, oder ob es sich nur um zufällige Erscheinungen handelt.

Eine gewisse Regelmässigkeit in Frequenz und Rhythmus der Athembewegungen ist eben unbedingtes Erforderniss fiur die Untersuchung aller durch ein Experiment etwa gesetzter Veränderungen, und da es mir bei diesen Thieren fast nie gelang, diese nothwendige Vorbedingung zu erfüllen, stand ich bald von den Versuchen ab und zog Schildkröten und Schlangen, von denen ziemlich das Gleiche gilt, nur noch insoweit in den Kreis der Betrachtungen, als es galt, die rein mechanischen Verhältnisse der Athmung festzustellen.

Glizklicherweise gestalten sich die Versuchsbedingungen bei den von mir benutzten $\mathrm{S}$ a u rier n bei Weitem günstiger.

Die beweglichen, munteren Eidechsen zeigen, namentlich unter dem Einflusse warmer Sonnenstrahlen, eine ausserordentlich lebhafte und regelmässige Athmung, so dass sie in dieser Beziehung allen berechtigten Anforderungen an ein Untersuchungsobjekt entsprechen, umsomehr, als sie auch am leichtesten in beliebiger Menge beschafft werden können.

\section{B. Historisches.}

Wie ich schon Eingangs erwähnt babe, ist die vorhandene Literatur über die Athmung der Reptilien eine relativ äusserst dürftige. Fast alle älteren einseblägigen Arbeiten stellen morphologische Gesichtspnnkte in den Vordergrund und beriucksichtigen die Physiologie nur insoweit, als es durch direkte Beobachtung möglich war, sich über die grob mechanischen Vorgänge Aufschluss zu verschaffen.

Pa ul Bert(1) ist meines Wissens der erste, der hierbei die graphische Methode, jenes gerade hier so wichtige Hulfsmittel der Forschung, in seinen 1870 erschienenen „Leçons sur la physiologie comparée de la respiration" in ausgedehntem Maasse an- 
wandte und in dem betreffenden Kapitel seines Buches auch einige Athmungs-Curven von Schildkröten, Ringelnattern, Eidechsen und einigen anderen Vertretern der Klasse mittheilt. Da seine Beobachtungen an verschiedenen Stellen der vorliegenden Abhandlung noch ausfübrlich zu berïcksichtigen sein werden, so verzichte ich hier auf eine nähere Darlegung der wichtigen und in gewissem Sinne grundlegenden Arbeit des französischen Forschers.

Ausser dem Bert'schen Werke existiren in der Literatur nur sehr wenige die Athmung der Reptilien betreffende Arbeiten, die im Folgenden kurz aufgeführt sind.

Mehr durch die Sonderbarkeit der Auffassung, als durch wirklichen. Werth ausgezeichnet ist eine Arbeit von Emil Blanc hard (2).

Ansgehend von der durch $\mathrm{M}$ il ne - E d ward s experimentell nachgewiesenen Hautathmung der Batracbier und gestiitzt auf eine fernere Behauptung des französischen Forschers, dass auch bei den Sauriern während des Sommers die Lungenathmung zur Unterhaltung des Lebens ungenügend werden sollte, sucht Blanchard durch eine vergleichende, anatomische Untersuchung des Integumentes verschiedener Reptilien (besonders $\mathrm{S}$ e in $\mathrm{ken}$ und $0 \mathrm{ph}$ idier) den Nachweis za erbringen, das trotz des Schuppenpanzers dieser Thiere eine wirksame Hautathmung anatomisch möglich wäre.

„Les écailles," sagt er, „formées par plusieurs lames superposées, sont pourvues de canaux anastomosés dans leur partie moyenne et ouverts à la base, et en outre, d'espaces lacuneux d'un aspect argenté. L'aspect argenté est dû à la présence d'air engagé et dans les canaux et dans les espaces lacuneux." Da er alle Schuppen umscheidet findet von einer äusserst feinen und sehr durchgängigen Membran, so glaubte er der Anwesenheit ron Luft in diesem zierlich angeordneten Canalsystem eine wichtige respiratorische Funktion zuschreiben zu müssen, um so mehr, als beim Eintauchen der Schuppen oder auch des ganzen Thieres in Wasser oder Eisensalzlösungen die Hohlräume bald mit diesen Flüssigkeiten sich füllten und so die grosse Permeabilität der umhüllenden Membranen gesichert schien. Obwohl mit den Scinken in engen organischen Beziehungen stehend, fand er bei Anguis fragilis das complicirte Kanalnetz nur in sehr vereinfachten Verhältnissen vor, und gerade dieser Umstand schien ihm ein Beweis für die 
Anpassungsfähigkeit dieser Thiere an die jeweiligen Lebensbedingungen.

Die Blindschleiche hält sich am liebsten an feuchteren Orten auf and schien daher des Canalnetzes der Schuppen eher entbehren za können, als die dürren, trocknen Boden bevorzugenden Scinken.

Auch die Haut der Lacerten besitzt nach B lanchard in hohem Grade die Fähigkeit, Wasser und Luft aufunehmen.

Bei Varanus (Polydaedalus) niloticus seien zwar die Hautschilde an sich ungeeignet, in respiratorischem Sinne zu funktioniren; aber da sie an ihren Enden durch eine zarte Membran aneinander befestigt sind, und da anch hier ein Kanalsystem sich findet, so kann ein Gasaustausch eintreten, während andererseits gerade die sonstige Impermeabilität der Schuppen eine zu schnelle Verdampfung verhindern würde.

So liessen sich nach $\mathrm{Bl}$ a $\mathrm{n} \mathrm{ch}$ ard aus einer vergleichend anatomischen Untersuchung der Haut der Reptilien in der That interessante biologische Rückscblïsse ziehen, wenn leider nicht die ganze Arbeit auf den phantasievollen Deduktionen jenes Forschers bernhte, die einer nüchternen Kritik nicht standhalten können.

L e y d i g (3) wies später nach, dass alle jene Lacunen und Kanäle, denen Blanchard eine so hohe physiologisehe und biologische Bedeutung beimaass, ganz mit Bindegewebe erfullt sind, welches Pigment, Nerven und Blutgefässe enthält, die der Ernährung des Hautorgans dienen.

Dagegen ist die Haut der Saurier in der That an manchen Stellen pneumatisch, wie Leydig behauptet, spurweise nur an den Gesichtstheilen, deutlicher an den Rändern der Bauchschuppen, wo der Luftgehalt für die Betrachtung mit auffallendem Licht am Rande der Schuppen einen regelmässigen Silberstreifen erzeugt.

Diese wirklich pneumatischen Räume scheint uibrigens Blanchard gar nicht gekannt zu haben; aber auch für sie weist wohl mit vollem Recht Leydig die Ansicht zurück, dass sie irgend eine Rolle bei der Athmung spielen; schon das Verbalten der Blutgefüsse spricht gegen die Annahme einer respiratorischen Funktion; ibre Existenz aber erklärt sich einfach als begleitende Erscheinung der Metamorphose gewisser Gewebstheile.

Noch weniger Anspruch auf eine ernstliche wissenschaftliche Kritik dürfte eine Arbeit von J. Julien (4) erheben können, 
zumal sie aus einer Zeit stammt, in der bereits von $\mathrm{B}$ ert die wesentlichsten Verhältnisse der Reptilienathmung experimentell festgestellt waren.

Da die Lungen der Reptilien eine mächtig entwickelte glatte Muskulatur besitzen, hinter der oft das Netzwerk der elastischen Fasern sehr zuriicktritt, so glaubt Julien ihr eine der wichtigsten Rollen bei der Athmung dieser Thiere zuschreiben zu dürfen.

„Ils n'avalent pas l'air comme les batraciens, mais quand ils respirent, les faisceaux musculaires se contractent, comme le ferait le coeur lui-même, l'air est expulsé et après la contraction il entre dans les poumons grâce à l'élasticitè du thorax aidée sans aucun doute par l'action des muscles élevateurs des côtes; les contractions des muscles thoraciques n'entrent pour rien dans cette exspiration, qui n'est absolument due qu'à la contraction des muscles intrinsèques des poumons. Il paraît peu probable d'ailleurs, que ces muscles pulmonaires soient soumis à la volonté de l'animal; ils me semblent devoir fonctionner comme les muscles de l'iris, qui se contractent à l'insu de l'animal, et selon l'intensité de la lumière. Quand on regarde respirer un de ces lézards, on voit, que le second temps respiratoire, c'est à dire le plus long, est l'expiration, suivie immédiatement d'une inspiration brusque.... Cette observation s'applique à l'expiration chez tous les reptils munis de poumons" setzt er apodiktisch hinzu.

Ich würde dieser Arbeit sicherlich keine Erwähnung gethan haben, da sie so vollkommen auch der oberflächlichsten Beobachtung widerspricht, hätte sie nicht in Bronn's „Klassen und Ordnungen des Thierreiches" (5) Eingang und sogar anerkennende Erwähnung gefunden; Kritik an ihr zu üben dürfte indessen wohl überflüssig sein, da die völlige Grundlosigkeit der darin vertretenen Anschauungen im Laufe der folgenden Untersuchungen klar genug zu Tage treten wird.

Es bleiben noch 2 kleine Abhandlungen von Heinemann (6 und 7) und eine von Lange $\mathrm{adorff}(8)$ zu erwähnen.

Was den Inhalt der ersteren betrifft, so ist derselbe wieder so innig mit dem Gedankengang der vorliegenden Untersuchungen verquickt, dass ich auf eine besondere Erörterung an dieser Stelle wohl verzichten kann.

L a $\mathbf{n g e n d}$ orff bringt einige wenige Curven von normal respirirenden Eidechsen und Blindschleichen, reproduzirt ausserdem 
einige Curven aus den Bert'schen Untersuchungen und schliesst mit der Feststellung einer spinalen Athmung, die durch zwei Curvenausschnitte belegt wird.

Im Uebrigen ist die ganze Arbeit wesentlich in der Absicht geschrieben, neues Beweismaterial für $L$ a $n g$ e n $d$ orf f's bekannte Decentralisationslehre zu erbringen, wie schon die gesperrt gedruckten Schlussworte zeigen, dass, auf alle Fälle so bewiesen ist, dass bei der Eidechse spinale Athemcentren bestehen, die ohne Hilfe des Kopfmarkes automatisch zu funktioniren and längere Zeit hindurch die Athembewegungen zu erbalten im Stande sind".

Ausser dieser Angabe, auf die ich später noch eingehender zurïckkomme, enthält die Arbeit nur noch eine Zuriickweisung der Bert'schen Behauptung, dass den Sauriern die Fähigkeit, die Luft zu schlucken, >öllig abginge, und constatirt, was ïbrigens $\mathrm{H}$ e in e m a $\mathrm{n}$ s schon früher behauptete, die Existenz beider Respirationsmodi bei dieser Reptilienklasse.

Eine mehr eingehende Behandlung, namentlich von Seite französischer Forscher, hat die Athmung der Schildkröten gefunden, obgleich gerade hier die widersprechendsten Ansichten geäussert wurden, die auch zur Zeit noch unvermittelt gegeníberstehen. Es wird dies begreiflich, wenn man die besonderen Schwierigkeiten berïcksichtigt, welche bei diesen von einem festen Panzer umhüllten Thieren dem Studium der Athembewegungen entgegenstehen.

Die Schildkröten wurden früher hinsichtlich ihres respiratorisehen Mechanismus auf eine Stufe mit den Fröschen gestellt; der unnachgiebige Panzer schien eine irgend erbebliche Erweiterung des Thorax kaum zuzulassen; und da man ausserdem eigenthümliche undulatorische Bewegungen der Kehlhant jederzeit leicht beobachten kann, so war der Gedanke an eine durch rhythmische Mundbodenkontraktionen bedingte Schluckathmung sehr naheliegend.

Zwei französische Forscher, Coiter und Varnier, wollten sogar gesehen haben, dass eine Schildkröte, deren Brustpanzer man gespalten bat, trotzdem, wie ein Frosch, ihre Lungen aufblasen kann.

Alle diese Behanptungen wurden in sehr einfacher und überzeugender Weise durch Haro (9), Panizza (10) und weiterhin durch Weir-Mitchel (11) u. A. widerlegt. Es zeigte sich E. Pfïger, Archir f. Physiologie. Ba. 64 . 
von Allem, dass eine Durchtrennung der Trachea die Athmung keineswegs aufhebt.

Vielmehr lässt sich mittels einer eingelegten Caniile hier ganz ebenso eine graphische Verzeichnung der respiratorischen Bewegungen ermöglichen, wie bei anderen Reptilien (Eidechsen, Schlangen).

Dass demnach die Schildkröten eine Saugat hmung besitzen, kann nicht zweifelbaft sein; fraglich bleibt nur der Mechanismus, weleher derselbenzu Grunde li egt.

Sehr eigenthiumliche Anschauungen äusserte Haro (9) in einer ziemlich ausführlichen Abhandlung über das Problem.

Er erwähnt, dass synchron mit der Athmung Bewegungen der Kehlmuskeln, des Kopfes und der Vorderextremitäten erfolgen, bei deren Verhinderung die schlaffe Haut an der Basis der letzteren wulstig hervorgetrieben wird. Dass es sich hierbei nm Luft handelt, ergiebt sich daraus, dass bei starkem Zurïckdrängen der Beine Luft unter einem blasenden Geräusch entleert wird, worauf die Wülste collabiren.

Ha ro beschreibt dann einen grossen, mindestens ein Drittel der Brustbauchböhle einnehmenden Luftsack, welcher von einer dichten, porzellanartig undurchsichtigen Membran gebildet werden soll, die nach Trennung des Rüeken- und Bauchschildes und vorsichtigem Abpräpariren des letzteren zu Tage tritt und die Baucheingeweide und Lungen umschliesst.

In ganz bestimmter Reihenfolge soll nun zuerst dieser Luftsack sich füllen, dann die Lunge, und zwar nicht durch eine einzige Inspiration, sondern durch mehrere (funf bis sechs) kurze, nicht durch Exspirationen unterbrochene Einathmungsbewegungen. Die Exspiration wäre meist ein-, selten zweizeilig.

Sticht man den Luftsack an, so entweicht nach Haro Luft mit hörbarem Geräusch; er bleibt dann dauernd collabirt, während die Lunge nach wie vor ihre Volumenschwankungen ausfihht. Verschliesst man das Loch dadureh, dass man es mit dem Finger zuklemmt, so tritt sofort das periodische An- und Abschwellen des Luftraumes wieder auf.

Wenn das Thier schreitet, so ist jede Bewegung der Glieder begleitet von einer leichten Exspiration, gefolgt von einer kurzen Inspiration; in der Ruhe sind die einzelnen respiratorischen 
Akte durch Intervalle von ein bis zwei Minuten voneinander ge. trennt.

Die Erweiterung und Verengerung des Brustbauchraumes lässt Haro durch Ausstrecken resp. Einzieben des Kopfes und der Extremitäten bewerkstelligt werden.

Ausserdem kämen noch zwei Muskelpaare in Frage, ein hinteres exspiratorisch wirksames, und ein vorderes, das bei der Inspiration mitwirke. Diese sebr unklaren and wenig überzengenden Behauptungen erfuhren in der Folge durch Pannizza eine strenge und verdiente Kritik.

Er bestätigt zunächst das Vorhandensein einer thorakalen Saugathmung bei den Schildkröten, bestreitet abel mit aller Entschiedenheit die Existenz einer "poche aérienne".

Pannizza brachte eine Wassersehildkröte nach vorsichtiger Entfernung des Bauchschildes mit Ausnahme des Kopfes unter Wasser. Nachdem das Thier einige Respirationsbewegungen gemacht hatte, während derer die betreffende Membran (d. i. das Peritoneum) rhythmisch sich dehnte und wieder zusammensank, wurde der angebliche Luftsack angeschnitten; es trat keine L uft heraus; im Gegentheil drang das Wasser durch die Oeffnung in die Bauchböhle und beeinträchtigte dadurch die Athmung wesentlich.

Am todten Thiere wurden dann, ebenfalls unter Wasser, Anfblasungsversuche angestellt, wobei auch nicht eine Luftblase aus dem angeschnittenen Sacke (d. b. der Bauchhöhle) in die Flüssigkeit austrat.

Um die Natur der von Haro beschriebenen eigenthümlichen Luftwiilste des subcutanen Bindegewebes zu erforschen, die in der That bei der künstlichen Aufblasung und auch bei jeder Inspiration zu beobachten sind, brachte er ein Thier unter Wasser, blies die Lunge auf und schnitt dann mit dem Messer auf eine der Hautblähungen ein; keine einzige Luftblase stieg in der Flüssigkeit empor. Nach $\mathrm{P}$ a $\mathrm{n} \mathbf{n}$ i z a entstehen die Wülste einfach durch die Contraktion der Muskeln und durch die Ausdehnung der Lungen, welche mit sich die correspondirenden Hautstellen emporheben und eine Intumescenz vortäuschen.

Das Gefühl aber, das man bei der Palpation hat, und das scheinbar durch die Elastizität von unter der Haut befindlicher Luft be- 
dingt wird, wäre auf die weiche Gewebsschichte zurückzuführen, welche sich zwischen Haut und Muskulatur vorfindet.

Während $\mathrm{H}$ a ro behauptete, dass nach der Incision seiner „poche aérienne" die Lungen gänzlich unbeeinflusst bleiben und sich wie vorher rhythmisch futllen und entleeren, konnte $\mathrm{Pannizza}$ beobachten, dass nach Excision eines nur kleinen Stückes aus der fraglichen Membran, und wenn er verbinderte, dass die Baucheingeweide sich vor die kïnstliche Oeffnung legten, ein daternder Collaps der Lungen eintrat; eine vor die Trachealöffnung gebrachte Flaumfeder liess auch nicht die Spur eines ein- oder austretenden Luftstromes erkennen.

Mit Recht fragt $P$ a n $\mathrm{n}$ i z $\mathrm{z}$ a ferner: „pourquoi l'auteur, parlant des poches aérienues, n'a pas indiqué les points de communication, et pourquoi il a pu être conduit $\dot{a}$ les admettre, puisque les poumons dans la Tortue sont isolés et ne communiquent pas même avec la membrane, qui les entoure?"

Während demnach die Haro'sche Anschaung sich als grobe Täuschung erwies, machte Milne-Edwards einen sehr eigenartigen Versuch, die Differenzen in den Versuchsergebnissen beider Autoren zu erklären. Ich darf den Passus vielleicht hier wörtlich wiedergeben.

„En répétant sur la petite Tortue d'Europe les expériences du premier de ces naturalistes, H a ro, j'ai souvent vu l'air inspiré par l'animal se répandre dans les lacunes souscutanées et s'échapper au-dehors par les ouvertures, que je pratiquais à la peau, vers le haut de l'épaule; mais dans d'autres cas je n'ai vu rien de semblable et je me suis assuré, que l'air était complétement emprisonné dans les poumons. Cela m'a déterminẻ à examiner avec plus de soin les voies par lesquelles, dans les expériences, ce fluide avait passè de l'appareil respiratoire dans le reste du corps et je me suis aperçu, que ce phénomène dépendait d'un état pathologique du poumon, qui présentait des perforations, dont le nombre, la grandeur et la position variaent. Qnelquefois les bords de ces ouvertures paraissaient ulcérés, d'autres fois ils étaient bien cicatricés et, suivant toute apparence, leur présence dépendait de quelque affection analogue à la phthisie pulmonaire."

Wir dürfen uns demungeachtet wohl ohne Bedenken Pannizza anschliessen.

Hinsichtlich der bei der Athmung betheiligten Muskelkräfte 
macht dieser Forscher schon auf die Beweglichkeit des Schultergürtels aufmerksam und ist geneigt, in der Art der Anheftung der vorderen Extremität an die die Brustbauchhöhle umschliessende Membran durch ein zellreiches Gewebe die denkbar guinstigsten Bedingungen für eine thorakale Athmung zu erblicken; die fraglichen auxiliären Athmungsmuskeln, welche $\mathrm{Haro}$ an den Innenwänden des Cavum thoraco-splanchnicum annimmt, ignorirt $\mathrm{Pa} n \mathrm{n}$ i z z a völlig.

In seinen bereits mehrfach citirten Leçons beschäftigt sich auch $\mathrm{P}$ aul Bert ziemlich eingehend mit dem Athmungsmodus der Schildkröten, den er mittels der graphischen Methode untersuchte. Da uns seine diesbezüglichen Angaben später noch ausführlich zu beschäftigen haben werden, so begnüge ich mich hier mit einer kurzen Wiedergabe der Anschaungen, zu welchen Bert hinsichtlich der mechanischen Verhältnisse der Schildkrötenathmung gelangt ist.

H a ro glaubte sich, wie schon erwähnt, berechtigt, den Bewegungen der Extremitäten und des Kopfes die Hauptrolle im Mechanismus der Athmung and beim Zustandekommen der intrapulmonalen Druckschwankungen zuschreiben zu durfen, und auch P. Bert ist geneigt diesem Umstande eine nicht unwesentliche Bedeutung beizumessen, da er bemerkte, dass eine auf dem Rücken liegende Schildkröte bei jeder Inspiration den Hals und die 4 Extremitäten vorstreckte und bei der Exspiration wieder zurïckzog. Dass es sich dabei aber böchstens um ein unterstitzendes Moment handeln kann, dürfte nicht zweifelhaft sein.

Schon Townson (12) hatte gesehen, dass die Athmung fortdauert, wenn der Kopf und die Beine unbeweglich fixirt werden, und die Versuche, welche P. Bert in dieser Richtung anstellte, führten durchaus zu dẹ gleichen Ergebniss.

Wenn nur die vorderen Extremitäten und der Hals ad maximum gedehnt werden, so ist ein Einfluss auf die Athmung überhaupt nicht ersichtlich; dasselbe ist der Fall, wenn man diese Körpertheile frei lâsst und dafür die hinteren Extremitäten extendirt; "maintenant," so fährt Bert weiter fort, "nous tirons à la fois, énergiquement, et nous fixons dans une extension vraiment effrayant les quatre pattes et la tête de la Tortue. Elle n'en continue pas moins de respirer, mais ici, l'amplitude a manifestement diminué, la durée du mouvement, au contraire, a augmenté, car la pause interexpiratoire a duré plus d'une minute." 
Drängte dagegen Bert die beiden Vorderbeine und den Kopf kräftig in die Schaale zurück, so wird dadurch vor Allem die inspiratorische Phase der Athmung beeinträchtigt und kann sogar gänzlich fehlen, wie die von Bert mitgetheilten Curven (Fig. 57 p. 295) unmittelbar erkennen lassen.

Gleichzeitig fühlt man in jedem Moment, der einer Inspiration entspricht, in den fixirten Gliedern eine Tendenz zur Entfaltung; die zu überwinden einen gewissen Kraftaufwand erfordert.

Der gleiche Erfolg (aktive Exspiration, fehlende Inspiration) lässt sich auch beobachten, wenn alle 4 Extremitäten und der Kopf möglichst tief unter die Schaale zurückgedrängt werden.

Hieraus folgert nun Bert, dass die Athembewegungen (wenigstens Exspiration) zwar noch erfolgen können, wenn jede Bewegung des Kopfes und der Beine unmöglich gemacht wird, dass aber andererseits diese letzteren bei sehr angestrengter Athmung fördernd mitwirken.

Da Bert hieraus die Pflicht erwuchs, die eigentlich specifischen Respirationsmuskeln näher zu kennzeichnen, so legte er bei einem eben getödteten Thiere durch Resektion des Bauchschildes die schon mehrfach besprochene aponeurotische Membran blos, in die muskuläre Faserzilge, welche sich am Carapax inseriren, eingesprengt sind.

Townson, Duvernoy (13) und Weir-Mitchel haben sie als exspiratorische Muskeln betrachtet, doch gelang es Bert, bei elektrischer Reizung der Fasern nur schwache Wirkungen zu erzielen, allerdings anch in exspiratorischem Sinne. Dagegen gab ein Muskel (?), „large, aplati, mince, situé en arrière, entre la carapace, le couplier sternal et le membre postérieur", dessen inspiratorische Wirkung theils geleugnet, theils zugestanden war, bei elektrischer Reizung einen ausgesprochenen inspiratorisehen Effekt. Der Strom war schwach genug, um Stromschleifen auf andere als die in Frage kommenden Muskeln ausschliessen zu können.

Schliesslich wäre noch eine mir leider im Original nicht zugänglich gewesene Arbeit von F ano (14) aus dem Jahre 1888 zu erwähnen, der auch bei den Schildkröten eine reichliche, in $\mathrm{Ab}$ hängigkeit von den Vagi stehende Lungenmuskulatur fand und dieser einen eigenartigen und bedeutungsvollen Platz in der Athmang: dieser Thiere zuerkennt. Ob mit Recht, dafür werden wir uns später zu entscheiden haben. 
Man sieht, dass es ungeachtet ziemlich zahlreicher Arbeiten zur Zeit kaum möglich erscheint, die zum Theil unverständlichen, zum Theil widersprechenden Angaben über die Athmung der Schildkröten von einem einheitlichen Gesichtspunkt aus zu beurtheilen, ohne zuvor durch neue Untersuchungen eine sichere Grundlage gewonnen zu haben.

\section{Die Eupnoe der Reptilien.}

Um zunächst den normalen Athmungstypus der Eidechsen festzustellen, empfiehlt es sich am meisten, dem nicht narkotisirten Thier eine passende Kopflkappe anzulegen, die in bekannter Weise mit einem Marey'schen Tambour verbunden wird. Auf diese Weise sind denn auch die meisten der ausgewählten Curvenbeispiele gewonnen worden. In einzelnen Fällen handelt es sich dagegen um tracheotomirte Thiere, was dann immer besonders vermerkt ist.

Die erstere Methode hat den grossen Vortheil, dass hierbei jeder operative Eingriff vermieden wird; und da die Thiere dann ansserdem gewöbnlich sehr bald in eine Art von hypnotischen $\mathrm{Za}$ stand verfallen, so war es meist auch nicht nöthig, sie besonders zu fixiren, wodurch sonst leicht in Folge reflektorischer und psychischer Beeinflussung Störung der Athmung hätte erfolgen können:

Man erhält unter diesen Umständen oft so lange Reihen völlig regelmässiger Respirationen, deren Grundtypus auch bei verschiedenen Individuen immer: so ähnlich blieb, dass man sie wohl mit einiger Berechtigung als den graphischen Ausdruck normaler Athembewegungen betrachten darf.

Wenn man ein Thier beobachtet, das ruhig athmend sich sonnt, so sieht man leicht, dass die Muskulatur des Halses, der Mundhöhle und des Thorax in bestimmter charakteristischer Weise sich bewegt.

Momentan erfolgt eine Einziehung der genannten Partien, am stärksten am Brustkorb, viel schwächer und oft nur einer fibrillären Zuckung ähnlich, am Boden der Mundböhle bemerklich, der eben so plötzlich eine kräftige Hervorwölbung folgt, die ihrerseits sofort wieder einer schwächeren Einwärtsbewegung Platz macht. Dann folgt eine Pause von mehreren Sekunden - unter Umständen kann die Zeit der Athemrube sich auch erbeblich re- 
duziren bezw. beträchtlich verlängern - worauf dasselbe rhythmische Spiel von nenem beginnt.

Wir sehen also schon durch die blosse Beobachtung, dass die Exspiration und die Inspiration, die bei Säugethieren unter normalen Verhältnissen ohne Pause aufeinanderfolgen, sich bei den Eidechsen auf $d r e i$ Phasen vertheilen, dass sich ausserdem zwischen je 2 Respirationen eine Zeit der Rube einschiebt, die gewöhnlich unverhältnissmässig viel länger ist, als die Zeit einer aktiven Athembewegung. Dieses Verhalten, das sich schon mit dem Auge ohne Schwierigkeiten konstatiren lässt, tritt noch viel eklatanter bei graphischer Darstellung hervor.

Fig. 1, Taf, III zeigt einen Ausschnitt einer derartigen Curve, die in der bereits geschilderten Weise mittels einer Kopfkappe von einer ruhig athmenden Eidecbse gewonnen wurde. Die absteigenden Schenkel entsprechen hierbei der Inspiration; die aufsteigenden der Exspiration.

Man sieht, wie jedesmal die Curve steil ansteigt, um sofort wieder abzusinken, indem eine rasche Inspiration der vorausgehenden, jede Athmung einleitenden (aktiven) Exspiration folgt.

In der grossen Mehrzahl der Fälle sinkt der Schreibhebel unter das Niveau der Ruhelinie, von der die Exspiration ausging, um sich dann etwas langsamer wieder zu erheben, bis schliesslich genau die Linie (resp. Thoraxlage) wieder erreicht ist, von der die ganze Athembewegung ihren Ausgang nahm.

Nun folgt die Ruhepause, während welcher der Schreibstift eine horizontale Linie verzeichnet, bis eine abermalige kräftige aktive Exspiration eine neue Athembewegung einleitet (Fig. 4, Taf. III). Es zeigt sich, dass im Sommer der Rhythmus im Allgemeinen ein ziemlich gleichmässiger ist, dass die Inspiration und Exspiration bei verschiedenen Versuchsthieren annähernd die gleiche Amplitude und den gleichen zeitlichen Verlauf darbieten, und dass auch die Pausen im Grossen und Ganzen gleiche Dauer zeigen.

Freilich, die ausserordentliche Regelmässigkeit, die man bei Säugethieren (und auch Vögeln) in der Regel zu beobachten Gelegenheit hat, findet man bei Poikilothermen nur selten in gleicher Weise ausgeprägt, und wenn man die Curven überblickt, die sämmtlich von verschiedenen Individuen stammen, wird man leicht er- 
kennen, dass diese Unregelmässigkeiten sämmtliche Phasen betreffen können.

Hinsichtlich der Frequenz lässt sich eine, auch nur annähernd constante Zahl kanm feststellen. Es spielen hier eben die äusseren Einflüsse, und vor Allem die Temperaturverhältnisse eine ungleich wichtigere Rolle als bei Homoiothermen.

Auch scheinen individuelle, uncontrolirbare Verschiedenheiten der Erregbarkeit der nervösen Centralorgane von grösstem Einfluss zu sein.

Nach Paul Bert, welcher eine beträchtliche Zahl statistischer Erhebungen über die Häufigkeit der Athembewegungen bei den verschiedenen Thierklassen mittheilt, würde bei L acerta 0 cella ta (die im Allgemeinen weit grössere Dimensionen erreicht, als die von mir untersuchten Species) als Durchschnittszahl der Respirationen etwa zwölf pro Minute anzusehen sein. Doch war es ihm schon aufgefallen, dass gerade bei den Reptilien die Aufstellung solcher Durchschnittszahlen auf grosse Schwierigkeiten stösst. "Les moindres circonstances", sagt er, „des differences minimes de température, le sommeil et la veille, la colère et la peur, font aisément passer du simple ou double le nombre de leurs mouvements respiratoires; en telle sorte qu'il faudrait, pour obtenir des résultats sérieusement discutables, une masse énorme d'observations."

Diese Thatsache batte auch ich in reichlichem Maasse zu beobachten Gelegenheit, und wenn ich auch im Sommer im Allgemeinen als Norm zehn bis zwanzig Athmungen feststellen konnte, kamen doch oft genug Fälle vor, wo diese Zahl selbst bis auf vier pro Minute herunterging, und ebenso andere, wo in derselben Zeit vierzig, ja selbst sechzig Respirationen gezählt wurden.

Im Allgemeinen scheint auch bei den Reptilien der Satz ebenso wie bei dẹ Säugethieren und Vögeln Gültigkeit zu baben, dass die Zahl der Athembewegungen in einem gewissen Verhältniss steht zu der Grösse der Thiere, indem auch hier kleinere Species im Allgemeinen rascher und energischer athmen.

Die Durchschnittszahl zwölf für Lacerta oc ella ta wäre demnach entschieden zu niedrig gegriffen bei Lacerta agilis oder viridis. Indessen würden vergleichende Beobachtungen an möglichst zablreichen Vertretern der Klasse erforderlich sein, um hier weitere Verallgemeinerungen zu ermöglichen. 
Die schwankende Frequenz der Respirationen ist es daher vor Allem, durch welche den Curvenreihen ein gewisser Character von Irregularität aufgeprägt wird. Dazu kommt noch die Verschiedenheit der einzelnen Athmungen in Bezug auf Form und Verlauf, was bei Vergleichung der Curven ohne Weiteres hervortritt. In der Regel combinirt sich geringe Frequenz mit grösserer Amplitude und umgekehrt.

Aeusserst variabel ist vor Allem die Tiefe der Inspiration, und kann der unterhalb der Ruhelinie gelegene Curvenabschnitt kleiner (Fig. 1, Taf. III) gleich, oder selbst grösser sein, als der oberhalb befindliche, exspiratorisch aufsteigende Theil der Curve (Fig. 2, Taf. III). Nur selten (Fig. 3) erscheint bei Eidechsen der aktive Theil der Inspiration gar nicht ausgeprägt, indem nach Vollendung der aktiven Exspiration der Schreibstift nur wieder bis zum Niveau der Ruhelinie herabsinkt, während dies bei Schlangen sehr häufig beobachtet wird, was P. Bert veranlasste, die Pause zwischen je zwei Athmungen in diesem Falle für eine inspiratorische zu halten, wodurch ein eigenthümlicher Gegensatz im Athmungstypus der Sa urier und $0 p$ h i d i e r gegeben sein würde.

Zu der gleichen Anschauung sind auch P. Regnard und R. Blanchard bei ibren Untersuchungen an Eidechsen und Ringelnattern gelangt (Compt. rend. de la soc. de biol. 1880, 7. Serie, II, p. 197, p. 180 and p. 259). Für die letzteren würde hiernach der folgende Athmungsmodus als Regel zu betrachten sein: ,On remarque, que l'inspiration est très brusque et se fait d'un seul coup. Puis il existe une pause inspiratoire variable, mais généralement assez longue, à laquelle succède quelquefois une expiration directe. Le plus souvent, au milieu de la pause inspiratoire, il se produit un commencement d'exspiration, qui divise la pause inspiratoire en deux parties et le tracé en deux étages."

Meine eigenen Beobachtungen stimmen, wie gleich hier bemerkt sein mag, in keiner Weise zu diesen Angaben und haben in allen Fällen eine fast vollkommene Uebereinstimmung im Athmungstypus der Eidechsen und Schlangen ergeben.

Sonderbarer Weise beschreiben iubrigens dieselben Autoren auch bei Lacertaviridis eine inspiratorische Pause von beträchtlicher Dauer. "L'inspiration est brusque; la pause 
ins p ir a t o i r e peut durer de $10-15$ secondes; e'est en général pendant l'exspiration que l'ocelusion de la glotte se produit, ce qui divise ce temps en deux parties. Le rythme est donc le suivant: inspiration brusque, panse inspiratoire, petite expiration, longue pause et exspiration definitive." Ich bin leider nicht in der Lage, diese meinen eigenen Befunden durchaus widersprechenden Beobachtungen, deren Unrichtigkeit sich aus dem Folgenden zur Genüge ergeben wird, irgend deuten zu können.

Eines ist unter allen Umständen constant in dem wechselvollen Bilde der Reptilien-Athmung: Di e Lage des S c hreibhebels während der Zeit der A themruhe.

Mögen die Excursionen des Thorax im Verlauf der einzelnen Respirationsbewegungen noch so verschieden sein, während der Pause schreibt der Hebel stets im gleichen Niveau; die exspiratorische Anfangserhebung setzt stets in derselben Höhe ein, und wenn man diese Punkte mit einander verbindet, wird man finden, dass diese Linie in allen Fällen eine gerade ist. Bisher wurde, wie die vorstehend erwähnten Angaben der Autoren zeigen, diese auffallende Erscheinung in ziemlich verschiedener Weise aufgefasst und gedeutet.

Paul Bert weist auf gewisse Veränderungen hin, welche sich während der ruhigen Athmung am Kehlkopfe ausprägev. Betrachtet man bei aufgesperrtem Munde den Kehlkopfeingang (glottis) eines athmenden Thieres, so findet man ausser den später noch zu berïcksichtigenden, stempelartig nach vorn und rückwärts gerichteten Bewegungen, das die Athemspalte wäh rend der ganzen Dauer jeder Pause geschlossen bleibt und sich erst öffnet, sobald wieder eine aktive Exspiration als erste Phase der neu einsetzenden Atbmung beginnt. Hierin erblickt P. Bert zugleich die Erklärung der Pause, von der er annimmt, dass sie einer Thoraxlage in halber Exspirationsstellung entspricht, so dass also während dieser Zeit die Lungen noch theilweise inspiratorisch gebläht bleiben.

Die aktive Exspiration wïrde demnach nicht in einem Zuge, sondern in zwei Zeiten erfolgen, die durch ein Stadium von einander getrennt sind, während dessen durch aktiven hermetischen Verschluss der Athemspalte dem weiteren Ausströmen von Luft ein Ziel gesetzt wird, bis endlich früher oder später das Hinderniss weicht und die unterbrochene Exspiration vollendet werden kann. 
P. Bert gibt für diese Erklärung bei Eidechsen keinerlei experimentelle Beweise und erwähnt nur, dass beim $\mathrm{Ca}$ iman, wo in der Regel 2 nnmittelbar aufeinanderfolgende Athmungen, jede bestehend aus einer (aktiven) Exspiration und einer unmittelbar sich anschliessenden, etwa gleich grossen Inspiration, durch eine lange, wie er meint, inspiratorische Ruhepause getrennt erscheinen (1. c. Fig. 66), diese letztere sich sofort in eine exspiratorische verwandelt, wenn durch Einführen eines Röhrchens in die Athemspalte der Verschluss der Glottis gehindert wird.

Meine Vermuthung, dass es zwischen dem Athemtypus der Crocodile einerseits, der Eidechsen und Schlangen andererseits kaum principielle Unterschiede geben würde, bestätigte sich, als ich. kurz vor Beendigung dieser Arbeit Gelegenheit hatte, einen Alligator lueius auf seine Athmung hin zu untersuchen. Die beigegebene Curve (Fig. 5 Taf. III) des trach e otomirten Thieres lässt die volle Identität mit denen anderer Reptilien deutlich genug erkennen, und auch die Form der Keblkopfbewegungen ist dieselbe wie bei Eidechsen. Damit wird die gegentheilige Ansicht Bert's hinfällig.

Von einer mit Aether narkotisirten Ringelnatter theilt P. Bert (1. e. Fig. 60, 2) eine mittels einer Kopfkappe gewonnene in Figur
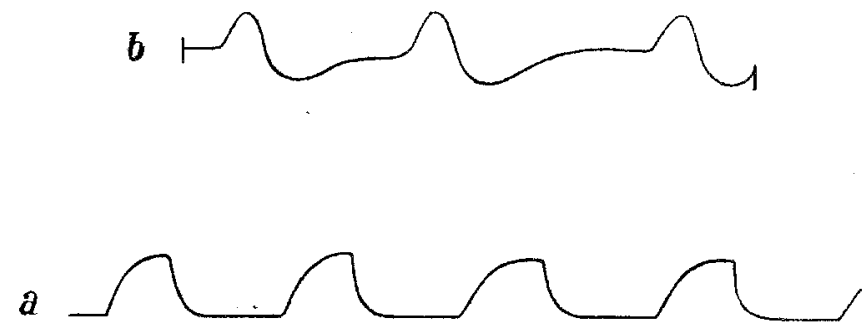

Fig. 1.

1 a reproduzirte Athmungscurve mit, an welcher, durch längere Pausen getrennt, aktive Exspirationen hervortreten, worauf der Schreibstift einfach zur Rubelage zurückkehrt (passive Inspiration). Die Pausen hier für inspiratorische zu halten, liegt meines Erachtens um so weniger Grund vor, als eine andere (Fig. $1 \mathrm{~b}$ ), von einer tracheotomirten Schlange herrührende Curve (1. c. Fig. 59, 2) durchaus mit der normalen Eidechsenathmung übereinstimmt, für die das Unzutreffende der Bert'schen Auffassung sich aus dem Folgenden ergeben wird. Die Pause ist eben weder eine inspira- 
torische, noch eine in halber Exspirationsstellung erfolgende, sondern es handelt sich einfach um ein kürzeres oder längeres Verweilen in der Ruhelage, von der aus sowohl aktive Exspiration wie aktive Inspiration erfolgen können, welch' letztere aber bisweilen gänzlich fehlt.

Ich selbst habe mittelst der Kopfkappe von Ringelnattern zahlreiche Athmungscurven gewonnen, welche sich in keiner Weise von jenen unterscheiden, welche die Eidechsen unter gleichen Umständen lieferten (Fig. 6, Taf. III) und nur viel häufiger insofern rudimentär erscheinen, als die aktiv inspiratorische Phase fehlt. Es darf hiernach als sicher gelten, dass der normale Athmungstypus der Schlangen in allen wesentlichen Punkten mit dem der Eidechsen übereinstimmt.

Eine Besonderheit, durch welche Athmungseurven von tracheotomirten Schlangen sich häufig auszeichnen, besteht in ziemlich regelmässigen kleinen Wellen, welche während der Dauer der Pausen hervortreten und dem betreffenden Curvenabschnitt ein eigenthümlich saccadirtes Aussehen verleihen. Es ist diese Erscheinung zurückzufuhren auf eigenthümliche wellenförmig von vorne nach hinten fortschreitende Contraktionen der Rumpfmuskulatur (Intercostales), die wohl einer besseren Vertheilung der Luft in der langgestreckten Lunge dienen dürften. In Folge des während jeder Pause eintretenden Glottisverschlusses können sich die dadurch bedingten intrapulmonalen Druckschwankungen bei Verzeichnung der Athmung mittels der Kopfkappe nicht ausprägen.

Es wurden diese Wellenbewegungen bei Schlangen bereits von Schlegel (16) in seinem Essay sur la physionomie des serpents, Amsterdam 1837, beschrieben: Er giebt an, mehr als 30 derartige peristaltisch fortschreitende Contraktionswellen gesehen zu haben. Ich selbst konnte, wie auch P. Bert, bei Ringelnattern nie mehr als höchsten 4-6 constatiren und stimme mit dem letzgenannten Forscher auch darin iuberein, dass dabei nur die exspiratorisch wirkenden Muskeln, nicht wie Schlegel will, die Inspiratoren in Thätigkeit treten.

Bei den Eidechsen wird die Grundlage des Kehlkopfes durch ein verhältnissmässig einfaches Knorpelgerüst gebildet, über welchem 2 Muskelsysteme in longitudinaler und circulärer Richtung ausgespannt sind, von denen das eine (Compressor laryngis) der Verenergung, das andere (M. dilatator) der Erweiterung des Organes 
dient. Während, wie schon erwähnt, P. Bert den Glottisverschluss während der Athempause durch aktive Muskelwirkung bedingt sein lässt und in diesem Umstande eben die Ursache jener rhythmisch wiederkehrenden Stillstände erblickt, leugnet He inemann (1. c.) den aktiven Charakter des ganzen Vorganges und bezieht den Verschluss der Athemspalte auf die elastischen Eigenschaften der bei den Sauriern schon ziemlich entwickelten Giesskannenknorpel, welche bei der Erschlaffung der dilatatorisch wirkenden Glottiserweiterer einfach in ihre Ruhestellung zurïckspringen.

Indessen wird für diese Behauptung keinerlei Beweis erbracht, und dürfte der stets vorhandene Constrictor doch wohl bei der Verengerung betheiligt sein, was ich allerdings auch nicht mit Bestimmtheit behaupten kann, da die Kleinheit der Verhältnisse bej den von mir untersuchten Species eine sichere Entscheidung sehr erschwert.

Wenn Heinemann aber sagt: „Die Möglichkeit einer Ruhepause in den respiratorischen Bewegungen hat Bert ganz richtig darauf zurückgeführt, dass der Keblkopfeingang während derselben vollständig geschlossen ist, iiber den Mechanismus dieses Verschlusses aber ist er zu einer unrichtigen Anschauung gekommen", so muss ich mich für das gerade Gegentheil aussprechen.

Die Bert'sehe Annahme einer Ruhepause, die nur durch den laryngealen Verschliessungsmechanismus ermöglicht werden könnte, ist entschieden unberechtigt, seine Anschau ung über die Artdes Verschlusses dürte dagegen wohl den Thatsachen entprechen.

Wie erwähnt, nimmt Bert an, dass bei jeder Athmung die Exspirationsbewegung des Thorax in ihrem Verlanfe temporär durch die plötzlich einsetzende Contraction des Constrictor laryngis unterbrochen wird; dieser momentan eintretende Verschluss sistirt sofort das weitere Austreten der Ausathmungsluft. Die Exspirationsmuskulatur verharrt dann im contrahirten Zustande, obne dass aber hierdurch auch nur der geringste respiratorische Effekt erzielt wird, da die circulären Fasersysteme des Larynx in diesem gegensätzlichen Kampfe mit den exspiratorischen Kräften des Thorax das Uebergewicht behalten; der Weg wird erst wieder frei, sobald der Tonus des Constrictor laryngis nachlässt; indem 
dann zugleich der antagonistische Dilatator in Wirksamkeit tritt, erfolgt nun eine plötzliche rasche Exspiration.

So stellt sich nach Bert das Bild der normalen Reptilien. athmung dar, so will auch Heinemann in seiner mehrfach erwähnten Arbeit den Vorgang aufgefasst wissen, nur dass er an Stelle der aktiven Thätigkeit des Constrictor laryngis die elastische Kraft des durch die Dilatatoren torquirten Giesbeckenknorpels setzen zu müssen glaubt.

Wie immer dieser Verschluss der Athemspalte nun auch bedingt sein mag, soviel ist sicher, dass er sehr fest und widerstandsfähig ist. Comprimirt man bei einem Thier, welches in längeren Pausen athmet, den Thorax während eines solchen Ruhestadiums möglichșt kräftig, so gelingt es nur ganz ausnabmsweise, und vielleicht auch hier nur in Folge schon eingetretener spontaner Eröffnung des Kehlkopfeinganges, den Widerstand zu überwinden. Meist zeichnet der Schreibhebel des Marey'schen Tambours auch bei stärkster Compression eine horizontale Linie (bei Anwendung der Kopfkappe), bis wieder eine spontane aktive Exspiration erfolgt.

Von diesem Gesichtspunkte aus würde daher die Bert'sche Theorie ganz wohl zu Recht bestehen können und liesse sich ein berechtigter Einwand kaum machen.

Indessen ist die ganze Annahme eines hemmenden Eingreifens der Kehlkopfmuskulatur in den Rhythmus der Athembewegungen von vorneherein so unwahrscheinlich, dass man sich zu ihrer Annahme gewiss nur unter der Voraussetzung ganz zwingender Gründe entschliessen könnte.

Heineman n (17) hat seiner Zeit eine Arbeit veröffentlicht, in der er die Innervationsstörungen schildert, die nach Vagisektion bei den Fröschen eintreten. Er fand hierbei, dass, wenn die Durchtrennung oben am Kopfe ausgeführt wurde, d. h. oberhalb jener Stellen, wo der den Glottisverengerer versorgende "obere" und der den Glottiserweiterer innervirende "untere" Nervenast den Hauptstamm verlässt, die Glottis dauernd verschlossen blieb. Dies bedeutet soviel, dass beim Frosch, wenn die Thätigkeit wirksamer Muskelkräfte ausgeschlossen wird, die Cadaverstellung in einem Verschluss des Kehlkopfes besteht. Er konnte deshalb mit Recht für gewisse Fälle den Verschluss der Glottis auf elastische Momente zurickfubren. Diese Thatsache mag es hauptsächlich gewesen 
sein, die ihn dazu verfuhhte, auch beim lebenden Thiere das Vorhandensein eines aktiven Kehlkopfverschlusses zu leugnen. Lässt sich sehon iber diese Verallgemeinerung seiner Beobachtung streiten, so war es jedenfalls ganz unberechtigt, sie ohne Prüfung auch als für die Reptilien geltend anzusehen; in seiner bereits citirten Abhandlung sagt er nämlich: "Dies" - (die Auffassung des Glottisverschlusses als einer Kraftäusserung von seiten des Thieres) - „ist übrigens gar nicht der Fall, wie ich es schon früher ausführlich für den Frosch dargethan habe".

Das Unzutreffende dieser Behauptung lässt sich sehr einfach erweisen.

Lähmt man durch Durchschneidung des N. glossopharyngeus und vagus die Muskulatur des Kehlkopfes, so bleibt der Kehlkopf dauernd geöfnet, die Cadaverstellung des Larynx besteht demnach bei den Eidechsen nicht in einem Verschluss, sondern vielmehr in einer Oeffnung des Aditus laryngis. Diese Oeffnung ist freilich nicht immer deutlich zu beobachten und mag sich der oberflächlichen Betrachtung manchmal entziehen, indem bei einem todten Thier oder bei einem Individuum mit gelähmter Kehlkopfmuskulatur oft nur ein schmaler Spalt bemerkbar ist. In der Mehrzahl der Fälle aber ist die Glottisöffnung deutlich sichtbar, und immer gelingt es wenigstens mit der Lupe, sie absolut sicher nachzuweisen.

Sehr iberzeugend gestaltet sich der Befund, wenn man ein so präparirtes Thier mittels der Kopfkappe mit einem Tambour verbindet. Während nämlich bei einem normalen Thier, wie schon erwähnt, auch die stärkste Thoraxcompression den activen Glottisverschluss nicht zu durchbreehen vermag, erfolgen hier schon bei leichtestem Druck entsprechende Bewegungen des Schreibhebels, ein klarer Beweis, dass in diesem Falle von einem elastischen Verschluss des Kehlkopfes nicht die Rede sein kann.

Sprechen schon diese Beobachtungen deutlich genug gegen die Heinemann'sche Hypothese, so lässt sich die Unrichtigkeit derselben anch noch durch andere Thatsachen leicht erhärten. Präparirt man den Kehlkopf nämlich vorsichtig frei von der Zunge und dem Os hyoideum und löst auch die Trachea von ihren bindegewebigen Verbindungen mit den Nachbarorganen los, so beobachtet man ebenfalls eine Oeffnungsstellung der Glottis, die freilich nicht dauernd gleich bleibt, sondern im Rhythmus 
der Athembewegungen bald erweitert, bald etwas verengert erscheint.

Dieser Befund erklärt sich leicht durch folgende anatomische Betrachtung: Tief unten am Halse zweigt vor Abgabe seiner Rami pulmonales und cardiaci vom Vagus ein kleiner Nervenast ab, der seitlich an der Trachea und ihr eng verbunden emporläuft, um an der Kehlkopfmuskulatur sich zu verzweigen, nachdem er mit einem zweiten, aus dem Glossopharyngeus entspringenden und die Keblkopfmuskeln versorgenden Zweige eine Verschmelzung eingegangen ist. Da auch dieser letztere Nerv, wie Fischer (18) überzeugend nachgewiesen hat, trotz seines weitaus häufigeren $\mathrm{Ur}$ sprunges aus dem Glossopharyngeus in Wahrheit als Vagusast angesprochen werden muss, so kann man beide Nerven als $\mathrm{N}$. laryngeus superior und inferior s. recurrens in direkte Parallele mit den analogen Vaguszweigen bei den höheren Wirbelthieren setzen.

Ferner ist die anatomische Thatsache zu constatiren, dass der M. dilatator sowohl mit seinem Ursprung, als seiner Insertion auf die Kehlkopfknorpel beschränkt bleibt, indem er vom Seitentheil des unteren Randes der Cartilago thyreo-ericoidea entspringt und sich, den Compressor bedeckend, mit ziemlich gerade aufwärts verlanfenden Fasern an der Haut des Stimmladeneinganges und des Giessbeckenknorpels, den er nach aussen zieht, inserirt. Der Compressor dagegen ist nur in wenigen Fällen - Chamaeleo, Anguis etc. - auf den Kehlkopf beschränkt, meist entspringt er entweder vom Zungenbein selbst oder von einem rundlichen Bande, dem Lig. hyo-thyreoideum (Henle), das den Larynx an die Spitze des Zungenbeinkörpers befestigt. Fiihrt man demnach die Isolirung von Kehlkopf und Trachea in der oben angegebenen Weise aus, so wird nicht nur der M. Compressor von seinem Ursprung getrennt, sondern es wird auch jener Glossopharyngeusast, der in der Gegend der ersten Knorpelringe an die Luftröhre herantritt, durchschnitten.

Da man aber unter diesen Verbältnissen eine dauernde Erweiterung constatiren kann, die nur gradweise Aenderungen im Rhythmus der Athembewegungen erfährt, aber sofort constant wird, wenn auch die Trachea und mit ibr der N. laryngeus inferior durchtrennt wird, so scheint daraus hervorzugehen, dass dieser Vaguszweig die dilatirenden Fasern entbält. Durchtrennt 
man nur den einen $N$. laryngeus inferior, so macht - bei Ausschaltung der Constrictorfunktion - nur die noch innervirte Hälfte ihre Excursionen. Der Luftstrom bewirkt auch nicht die geringste selbst dem bewaffneten Auge bemerkbare Erweiterung der gelähmten Larynxhälfte.

Legt man andererseits eine Canüle in die Trachea ein, während die $\mathrm{N}$. laryngei inf. noch erhalten sind, so bleibt das rbythmische Spiel der Athemspalte dauernd erhalten.

Hieraus geht unmittelbar hervor, dass der exspiratorische Luftstrom an sich keinerlei Rolle bei der Oeffnung des Kehlkopfeinganges spielt.

Die beiderseitige Durchtrennung des N. laryngeus superior allein bringt keine nennenswerthen Aenderungen hervor. So lange die Athembewegung dauert, bleibt, wie sonst auch, die Glottis geöfnet, worauf sie sich, während der Ruhepause, allerdings nicht vollständig, schliesst.

Aus den vorstehend erörterten Thatsachen ergeben sich im Wesentlichen folgende Schlussfolgerungen :

1) Der Cadaverstellung des Kehlkopfes entspricht Oeffnung: der Glottis, die während der aktiven Athmung durch Contraktion des M. dilatator laryngis wesentlich verstärkt wird.

2) Während der Athempause erfolgt ein völliger Glottisverschluss, wesentlich bedingt durch die Innervation des M. constrictor glottidis. Glottisschluss kann man übrigens auch jederzeit durch Reizung der Larynxschleimhaut erzielen, was sich offenbar leichter durch die Annahme reflektorischer Erregung des M. compressor, als durch eine reflektorische Hemmung der Contraktion des dilatator erklären lässt.

3) Die Nervenfasern für den M. dilatator verlaufen im $N$. laryngeus inferior, die für den Constrictor im N. laryngeus superior; es entspricht dies genau den Innervationsverhältnissen beim Frosche.

Die Bert'sche Ansicht von dem Zustandekommen der normalen Athempausen durch zeitweiligen, rhythmisch wiederkehrenden Glottisverschluss lässt sich nun in höchst einfacher Weise widerlegen.

Lähmt man die Glottis in der angegebenen Weise mittels Durchschneidung des Glossopharyngeus und Vagus, oder schaltet man den Kehlkopf von vornherein ganz aus durch Einlegen einer 
Trochealkanüle, oder führt man endlich eine conisch zugespitzte Glasröhre bei einem narkotisirten Thiere direct in die Glottis ein, so lisst sich bei Verzeichnung der Athembewegungen mittels eines Marey'schen Tambours stets zeigen, dass die typische Form der Curven dadurch nicht im Mindesten geändert wird. Nach wie vor erfolgt die Exspiration zweizeitig, beide Phasen (die passive und active) getrennt durch eine mehr oder weniger lange Pause.

Dies könnte offenbar nicht der Fall sein, und müssten von den normalen wesentlich verschiedene Respirationscurven entstehen, wenn die Theorie von P. Bert richtig wäre. Der Umstand, dass die Pausen in ganz gleicher Weise auch bei dauernd offener Glottis und bei völliger Muskelruhe des Thorax eintreten, beweist, dasses sich um wirkliche Rubepausen im strengsten Wortsinne handelt, während deren keinerlei aktive Maskelkräfte in Wirksamkeit treten und der Thorax sich in seiner elastisehen Gleichgewiehtslage (Cadaverstellung) befindet. P. Bert scheint bei Eidechsen keine Athmungscurven mittels der Trachealkanüle aufgenommen zu haben, wohl aber bei Schildkröten. Die absolute Identität der Bilder, die er hier bei tracheotomirten Thieren und bei Anwendung der Kopfkappe fand, ist ihm zwar aufgefallen - ,vous voyez même", sagt er, "que la forme primitive a été conservée" -, doch hat er es nicht versucht, für diese Thatsache eine Erklärung zu geben. Dagegen behauptet er beim Caiman in der That, nach Einführung eines Röhrehens in die Glottis eine Umkehr der Curvenform beobachtet zu baben.

Die mitgetheilte Curve, die mir allerdings wenig beweisend erscheint, nsignifie évidemment," sagt P. B e rt (l. c. p. 308), "que le Caiman, sa glotte étant maintenant ouverte, ne peut plus rester gonflé; son repos en inspiration devient nécessairement un repos en exspiration." Ohne eigene Versuche ist es natürlich kaum möglich, an dieser Behauptung Kritik zu üben, indessen möchte ich doch die Vermuthung aussprechen, dass auch die Wassereidechsen in dieser Beziehung wohl kaum eine Ausnahme von den anderen Reptilien (Schlangen, Eidechsen, Schildkröten) bilden dürften, für welche die Behauptung von B e r t sicher nicht zutrifit.

Der schlagendste Beweis für die Richtigkeit unserer An- 
nahme, dass die Athempause der Cadaverstellung des Thieres entspricht, liegt aber wohl in folgender Erfahrung:

Man präparirt bei einer Eidechse, die in Bauchlage fixirt ist, und deren Luftwege durch eine Tracbealkaniule oder Athemkappe mit dem Registrir-Apparat in Verbindung stehen, die Muskulatur des Nackens ab und führt nach Blosslegung der Wirbelsäule unter die letztere die schmale Branche einer Scheere.

Hat das Thier nun auf der rotirenden Trommel eine Reihe von Athembewegungen verzeichnet, so schliesst man durch einen einzigen kräftigen Scheerenschlag die Branchen und führt so eine momentane Trennung der spinalen Athemmuskelcentren von ihrem dominirenden Centralorgan in der Med. oblongata herbei.

Hier, wie bei den Säugethieren, sistirt sofort und dauernd die Athembewegung, und obne Krämpfe erfolgt, wiewobl erst nach langer Zeit, der Tod des Thieres.

Bei Säugethieren steigt, wie $\mathrm{G}$ a d zuerst erkannte, nach einem derartigen Eingriff der zeichnende Schreibhebel rasch zur Exspirationsstellung empor, deren bisherige maximale Höhe er nicht nur erreicht, sondern mehr oder minder beträchtlich überschreitet, sodass oberhalb des Niveaus der früheren exspirat orischen Curvenscheitel eine gerade Linie verzeichnet wird. Dies bedeutet offenbar, dass bei Säugethieren, wo die Exspiration in der Regel nur passiv durch die elastischen Kräfte des Thorax bewirkt wird, die inspiratorischen Muskeln normaler Weise niemals wirklich ganz erschlaffen, sondern auch am Ende der Exspiration noch in einem gewissen Tonus verharren, so dass der Thorax zukeiner Zeit die eigentliche $\mathrm{R}$ u h e lage e in $\mathrm{n}$ i $m \mathrm{~m}$ t. Die Athembewegungen erfolgen nicht von der Cadaverstellung des Thorax aus, sondern von einer Thoraxlage, die die Folge eines erst im Tode sich lösenden dauernden inspiratorischen Tetanus ist.

Ganz anders gestaltet sich dagegen das Resultat, wenn man denselben Versuch an einem Reptil anstellt. Mag die Rüekenmarksdurchtrennung im Augenblicke einer ex-oder inspiratorischen Thoraxbewegung erfolgen, mag der Hebel sich in diesem Momente ober- oder unterhalb der Ruhelinie befinden, immer steigt oder fällt er sofort zum Niveau derselben und zeichnet auch weiterhin eine Linie, die die directe Verlängerung der vorausgegangenen respiratorischen Ruhepausen darstellt. 
Hiermit ist aber unweigerlich bewiesen, dass die Athempanse, wie schon auf Grund der früheren Versuche wahrscheinlich war, in der That der Cadaverstellung des Thorax entspricht, dass sie einer Periode der Unthätigkeit des Athemcentrums ihre Entstehung verdankt, während welcher weder in- noch exspiratorische Impulse ausgesendet werden.

Analysiren wir jetzt von diesem Standpunkte aus den Verlauf der Athembewegungen der Eidechsen und Schlangen, so haben wir es offenbar zu thun mit einer von der elastischen Gleichgewichtslage ausgehenden, durch aktive Muskelcontraktionen bewirkten, rhythmischen Verengerung und Erweiterung der die Lungen umschliessenden Leibeshöhle; jede Phase besteht meist aus 2 Theilen, einem aktiven und einem passiven, den Anfang macht in der Regel die aktive Exspiration, der Schreibhebel erhebt sich mehr oder weniger weit über die Ruhelage; nun schliesst sich unmittelbar bei Ersehlaffung der exspiratorisch wirkenden Muskeln eine inspiratorische Bewegung an, der Schreibstift sinkt zur Ruhelage zurïck; nur selten bleibt es bei einer solchen (passiven) Inspiration, der dann die Pause unmittelbar folgt (Fig. 3, Taf. III); meist erfolgt eine a kti ve Inspiration und die Curve erhält daher auch einen unterhalb der Ruhelinie gelegenen Abschnitt, dessen zweite Hälfte (der aufsteigende Ast) als passive Exspiration zu deuten ist. Die Exspiration ist also in der That zweizeitig, die trennende Pause ist aber weder eine in- noch eine exspiratorische, sondern sie entspricht einer wirklichen $R u h e$ des respiratorischen Apparates.

Wie schon die von P. Bert mitgetheilten Curven zeigen, mit denen die von mir selbst erhaltenen durchaus übereinstimmen, gestaltet sich auch bei den Schildkröten der Verlauf der Athembewegungen bei graphiseher Verzeichnung mittels der Kopf kappe oder von der Trachea aus ganz analog dem eben geschilderten, und nur in Bezug auf Tiefe und Frequenz machen sich selbstverständlich Unterschiede bemerkbar.

Mit Rücksicht auf die zu Grunde liegenden mechanischen Verhältnisse ist es bemerkenswerth, dass, wie schon in der Einleitung hervorgehoben wurde, die Ausprägung der aktiv inspiratorischen Phase, d. h. des unterhalb der Ruhelinie gelegenen Curvenabsehnittes, zwar nicht dureh Fixation der Vorderextremitäten in Extensionsstellung, wohl aber durch kräftiges Zurïckdrängen der- 
selben wesentlich beeinträchtigt, ja selbst gänzlich unterdrïckt werden kann.

D. Ueber die bei der Athmung thätigen Mnskelgrappen und den Mechanismus der Thoraxbewegungen.

Hinsichtlich der Athmung des Frosches war früher allgemein die Ansicht verbreitet, dass dieselbe bedingt wäre einmal durch die Contraktion des Mundbodens, die bei gleichzeitig verengten Nasenlöchern die Luft in die geöffnete Glottis hineinpresst, und zweitens durch die Contraktion der Bauchmuskeln, welche bei ebenfalls offenem Kehlkopfeingang die Exspiration bewirken sollte.

Die erstere Thatsache ist heute so unumstösslich sichergestellt, dass ein Zweifel daran wohl nicht aufkommen kann, die zweite dagegen wird neuerdings von $\mathrm{K} n$ oll (19) und La $\mathrm{n}$ ge nd orff (20) als irrthümlich bestritten. Da nämlich durch Ausbohrung des Rückenmarkes und Tamponirung des Spinalkanales der Rhythmns der Atbmung ein ungestörter bleibt, so war hiermit der Annahme eines Einflusses der Bauchmuskulatur auf die Exspiration der Boden entzogen. Dieselbe wird vielmehr unter normalen Verhältnissen durch andere Momente bedingt, auf die wir hier nicht näher einzugehen brauchen. Allerdings sollen bei vagotomirten (17) oder lungenlosen Fröschen (21) aktive Bauchmuskelcontraktionen vorkommen, die, wie $\mathrm{L}$ a $\mathrm{g}$ ge n d o rff nachweist, antomatischen Ursprungs zu sein scheinen 1 ).

Ich erwähne diese Dinge hier deshalb, weil, wenn man von den Schildkröten, wo besondere Verhältnisse obwalten, absieht, auch bei den Reptilien die Muskulatur der Bauchdecken noch nicht in das Spiel der Athembewegungen eintritt.

Um bei Eidechsen zu prüfen, welche Muskeln eigentlich bei der Bewegung des Thorax in erster Linie betheiligt sind, schlug ich folgendes Verfahren ein:

Vom ganzen Rumpfe wurde die Haut abpräparirt, sodass vom Brustbein an bis zu den unteren Extremitäten die nackte Muskelfläche vorlag. Sehr schön konnte man jetzt die Bewegungen der

1) Beobachtungen an einem grossen amerikanischen Ochsenfrosch zeigten mir allerdings, dass von Zeit zu Zeit zwischen den passiven uscillatorischen Bewegungen der Flanken auch aktive Contraktionen der Bauchmuskeln erfolgen. 
Rippen verfolgen, die, wie durch geheimnissvolle Kräfte getrieben, ihre Excursionen vollführen.

Von eigentlichen Muskelcontraktionen lässt sich nämlich an den kleinen Versuchsthieren wenig hemerken; die blasse Farbe und die Schwierigkeit, die einzelnen Muskeln scharf von einander zu unterscheiden, macht es kaum möglich, die respiratoriseh wirksamen Muskeln von denen zu trennen, die in Ruhe verharren oder nur passiv mitbewegt werden, sei es, dass sie, wie die Schultergürtelmuskulatur, ihre eine Fixation am Brustkorb finden und in Folge dessen seinen Exkursionen folgen müssen, sei es, dass sie, wie die Banchmuskeln, durch die beim Gaswechsel stattfindenden Raumveränderungen in der Pleuroperitonealhöhe passiv nach aussen gedrängt oder nach innen gezogen werden.

P. S ibs o n (22) hat seiner Zeit, von der Ueberlegung ausgehend, dass jeder aktiv sich contrahirende Muskel auch dann verkürzt erscheinen wird, wenn seine Insertionspunkte passiv einander genähert werden, durch Aufblasen und Aussaugen der Lungen an todten Reptilien, Vögeln und Säugethieren zu ermitteln versucht, welche Muskeln im einen und welche im anderen Falle verkuirzt erschienen, und zog daraus Schliusse auf deren normale physiologische Funktion.

Ohne den Werth dieser Methode bestreiten zu wollen, war ich doch bestrebt, der Frage womöglich direct auf experimentellem Wege beizukommen und versuchte zunächst durch successive Ausschaltung von Muskelgruppen zum Ziele zu gelangen.

Ich hatte vorher schon beobachtet, dass, ohwohl fast die ganze Seitenwand des Leibes mit Rippen in ibren Weichtheilen ausgestattet ist, nur die mit dem Sternum verbundenen echten Rippen im Rhythmus der Athmung aktiv bewegt werden, während die viel zahlreicheren falschen Rippen, die nicht zu einer Verbindung mit dem Brustbein gelangen, sich nur bei sehr ausgiebigen Respirationen passiv mitbewegen. Wenn so auch keine anatomische Sonderung zwischen Brust- und Bauchraum existirt, so ist doch im physiologischen Sinne eine Pleura- and eine Abdominalhöhle wohl zu unterseheiden, eine Sonderung, die bei den Sauriern auch dadurch schon äusserlich ihren Ausdruck findet, dass das parietale Blatt des abdominalen Cölomtheiles tief schwarz gefärbt ist, während der Abschnitt, der die Lungensäcke enthält, durch eine zarte Rosafärbung sich auszeichnet. 
Wenn ferner auch bei den Sauriern und Ophidiern keine abgeschlossenen Brustfellsäcke existiren, so bildet doch die Leber einen ziemlich sicheren Verschluss gegen die Bauchhöhle hin, und man kann durch breite Incisionen die letztere öffnen, ohne hierdurch einen Collaps der Lungen herbeizuführen. Zieht man dagegen die Leber aus ihrer normalen Lage heraus, sodass an ihr vorbei die Luft in die kopfwärts gelegenen Theile der Leibeshöhle hineingelangen kann, so ziehen sich mit der Ausgleichung des intrathorakalen Druckes die Lungen sofort zusammen.

Nach Analogie des Typus der aktiven Exspiration bei Sängethieren würde man vielleicht von vornherein geneigt sein, die kräftigen Ausathmungsbewegungen der Eidechsen ebenfalls auf die Contraktion der Bauchmuskulatur zurieckzuführen, die auch hier durch den Rectus, den Transversus und die beiden Obliqui abdominis repräsentirt wird. Dies wird aber schon unwahrscheinlich durch die blosse Inspection, welche gar keinen Anhaltspunkt für diese Annahme bietet, indem an der abdominalen Muskulatur auch nicht die geringsten aktiven Bewegungsvorgänge zu constatiren sind. Experimentell konnte ich leicht den Nachweis durch folgende Operation führen:

Ich öffnete die Banchböhle durch einen Schnitt in der Mittellinie und führte unter Schonung der Eingeweide beiderseits Schnitte längs der letzten mit dem Brustbein in Verbindung stehenden Rippe bis zur Wirbelsäule, welche schliesslich auch noch durchtrennt wurde, sodass die beiden Rumpfbälften nur noch durch den unversehrt gelassenen Darmkanal zusammenhingen. Die Athmung verlief demungeachtet gänzlich ungestört weiter und die Exspiration erfolgte so rasch und kräftig wie bisher.

Ein weiterer Schnitt oberhalb des Schultergürtels in der ganzen Circumferenz des Halses gefuhrt, setzt dann auch alle jene Muskeln ausser Wirksamkeit, die, höher oben entspringend, an den Rippen inseriren.

Auch dies beeinträchtigt die Athembewegungen nicht in merklicher Weise. Daran wird schliesslich auch nichts geändert, wenn noch die Vorderextremitäten exarticulirt und so die Sehultergürtelmuskeln ausgeschaltet werden.

Die zu diesem Versuche benutzte Eidechse hatte nach diesen Eingriffen nur noch die intercostale und die Muskulatur des Riuckens zur Verfügung. Ich bemiuhte mich dann, auch noch die 
letztere so weit als möglich zu entfernen, indem ich mit Scheere und Messer die Wirbelkörper frei präparirte und alle die Intercostales etwa noch deckenden Muskelreste sorgfältig entfernte. Speciell als Inspiratoren kommen dann höchstens noch die Levatores costarum in Betracht, die übrigens nach Gegen b a u r (23) der intercostalen Gruppe beigezählt werden müssen, und deren Bedeutung für die Bewegung der Rippen, wie insbesondere auch S i b s on (l.c.) für die Schlangen hervorhebt, kaum zweifelhaft sein kann. Hier liegen die Verhältnisse hauptsächlich in Folge des Fehlens eines Brustbeines überhaupt sehr einfach.

Wie Figur 2 unmittelbar erkennen lässt, werden durch die Verkürzung der von den Wirbelkörpern entspringenden und schräg nach abwärts zu den Rippen verlaufenden Levatoren jene nicht nur nach vorn und oben gehoben, sondern auch nach aussen gedreht, so dass sich ibre vorderen freien Enden von einander entfernen, und dadurch die Rumpfhöhle sowohl in der Richtung von vorn nach hinten, wie auch von rechts nach links erweitert wird. Bei

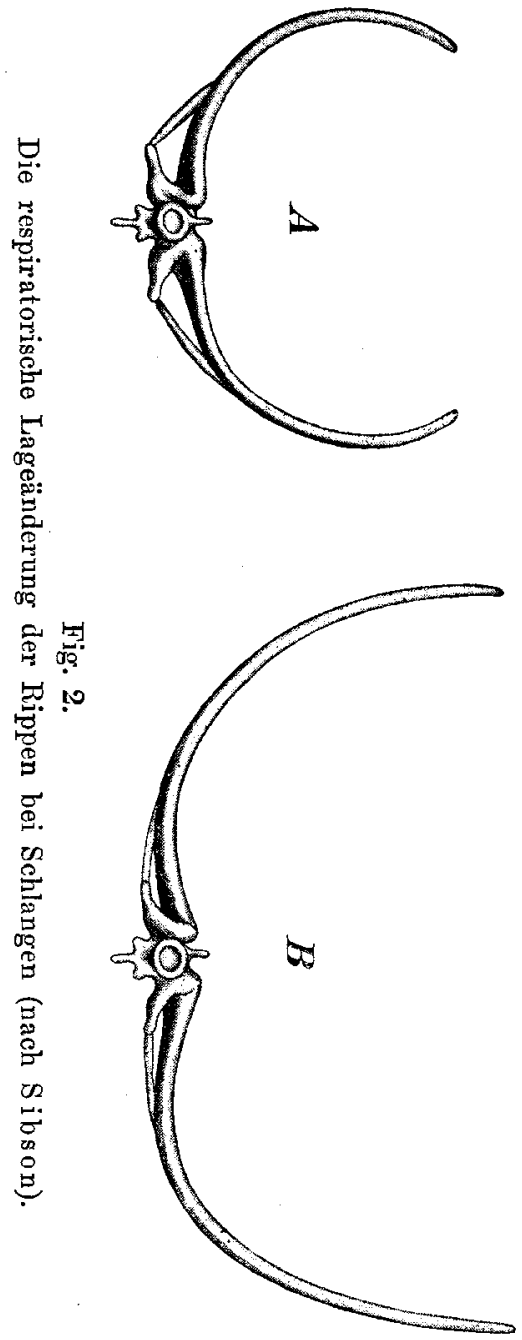
den S e blangen, wo das System der Intercostalmuskeln am mächtigsten entwickelt erscheint, und wo in Folge der einfachen anatomischen Verhältnisse auch ihre funktionellen Beziehungen am durchsichtigsten sind, kommen zu den Rippenhebern auch noch besondere (exspiratorisch wirkende) Ruickzieher hinzu; hinsichtlich der Wirkung entsprechen ihnen bei sämmtlichen Sauriern gewisse 
Muskeln („Retrahentes costarum"), welche „innerlich, ventral von den Nervenstämmen neben der Wirbelsänle liegen, von den Wirbelkörpern entspringen und schräg kopf- und seitwärts anfsteigend sich mit platten Zacken an die Innenfläche der nächst vorderen Rippe heften, dicht neben dem Ursprung des M. transversus abdominis."

(H o f $\mathrm{mann}$, in Bronn's Klassen und Ordnungen IV. Bd. III, Abth. 2, p. 619.)

Mit den eben genannten Muskeln zusammen spielen $d \mathbf{a}$ her zweifellos die Intercostales externi und interni die wiehtigste Rolle bei der Athmung der mit Rippen versehenen Reptilien.

Mit ihnen und ihrer Wirkungsweise müssen wir uns jetzt noch etwas eingehender beschäftigen.

Bau und Lage der Rippen bei den Reptilien, sowie die Art ihrer Bewegungen bei der Athmung verhalten sich vielfach anders als bei den Säugethieren (vergl. Fig. 3). Hier liegen im Allgc-

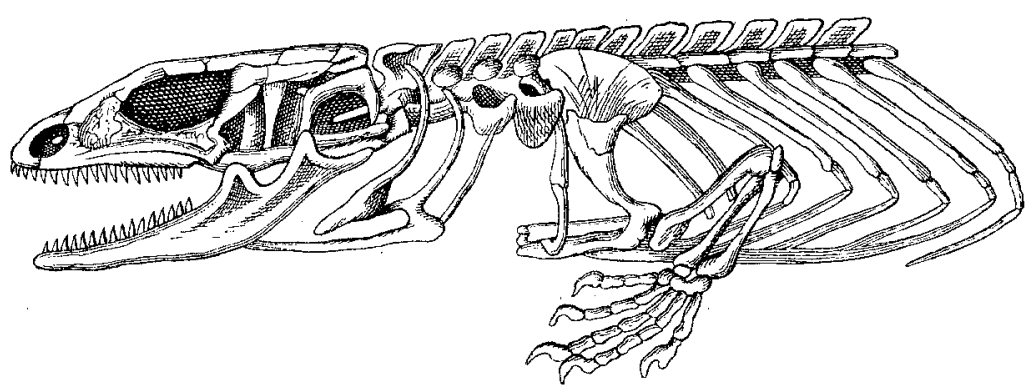

Fig. 3.

Kopf und Brustkorb einer Eidechse (Lacerta) in Seitenansicht (nach Vogt und $\mathrm{Yung}$ ).

meinen je zwei zusammengehörige Rippen annähernd in einer Ebene, die, vom ersten Rippenpaar abgesehen, umso mehr nach vorn und abwärts geneigt erscheint, je weiter nach riuckwärts gelegene Rippen man ins Auge fasst.

An der ersten Rippe setzt sich bekanntlich beim Menschen diese Neigung vollständig, an der zweiten fast vollständig bis zum Sternum fort, an den folgenden bis zur zehnten geht sie an der Vorderfläche des Thorax wieder in eine dem Rippenknorpel angehörige Aufwärtssteigung über (24). Die Drehung jeder Rippe erfolgt um eine Axe, die naheza mit der Axe des Rippenhalses 
zusammenfällt, sodass mit Rücksicht auf die geneigte Lage des Rippenkörpers jeder Punkt desselben sich bei der Hebung in horizontaler Richtnng von der Wirbelsäule entfernen, bei der Senkung dagegen sich ihr nähern muss.

In Folge der Richtung der Drehungsaxe von vorn und innen nach aussen und hinten und zugleich von innen und oben nach aussen und unten wird demnach der Brustkorb bei der inspiratorischen Hebung der Rippen nicht nur in der Richtung von vorn nach hinten, sondern in noch viel höherem Grade von rechts nach links erweitert (resp. bei exspiratorischer Senkung verengert), indem die seitlichen Punkte der Rippen bei der Hebung zugleich nach aussen und bei der Senkung nach innen rücken müssen.

Selbstverständlich muss wegen des Zusammenhanges der Rippen unter einander und mit dem Sternum auch dieses letztere an ihren Bewegungen Theil nehmen.

Dadurch ist natürlich die Breite der Excursionen der einzelnen Rippenpaare, beziehungsweise die Beweglichkeit des ganzen Brustkorbes eine verhältnissmässig recht beschränkte, und sie würde ohne die so ausgiebige, durch das $\mathrm{Zw}$ erchfell vermittelte, Erweiterung im Längsdurchmesser den Bedürfnissen der Athmung kaum auf die Dauer genügen können. Es ist daher auch rerständlich, dass bei allen mit Rippen versehenen Wirbelthieren, denen ein Zwerchfell fehlt, oder wo es nur rudimentär entwickelt erscheint, für eine weit ansgiebigere Beweglichiseit der ersteren gesorgt sein muss, wie wir es in der That bei Reptilien und Vögeln finden.

Der weitaus grössten Beweglichkeit erfreuen sich die Rippen der Schlangen, welche hier nicht nur der Athmung, sondern zugleich der Locomotion zu dienen bestimmt sind (vergl. S i b s o n 1. c. p. 502 f.). Die zusammengehörigen Paare der vorn nicht durch ein Brustbein zusammengesehlossenen Rippen liegen (die Schlange in. Vertikalstellung gedaclit) je in einer von hinten und oben nach vorn und unten geneigten Ebene, die bei der inspira. torischen, durch die Levatores costarum und die Intercostales externi vermittelten Hebung sich mehr der Horizontallage nähert.

Die beistehenden, der schon oft citirten trefflichen Abhandlung von Sibson entlehnten schematischen Figuren (Fig. 4 A, B) sind geeignet, nicht nur diese Art der Bewegung, sondern auch 
die Wirknngsweise der dabei in Action tretenden Muskeln zu rersinnlieben.

Man sieht, dass hei Inspirationsstellung sowohl die durch die Linien (1) dargestellten Levatores, wie auch die Intercostales

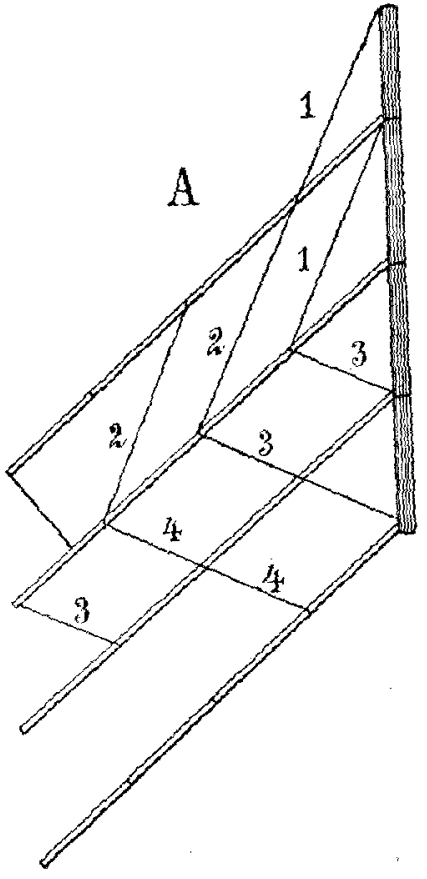

Fig. 4.

Schema der Rippenbewegung der Reptilien (nach Sibson).

externi (2) verkiurzt erscheinen, und dass der Abstand je zweier Rippen von einander erheblich zunimmt. Es ist klar, dass auf diese Weise der Darchmesser der Rumpfhöhle in der Richtung von vorn aach hinten beträchtlich vergrössert wird.

Darch die Levatores costarum werden aber die Rippen zagleich auch nach auswärts gedreht, sodass, im Quersolnitt gesehen, der von innen umschlossene Flächenraum in Inspirationsstellung viel grösser ist, und die Rumpfböhle auch in seitlicher Richtung beträchtlich erweitert wird (Fig. 2).

Wesentlich anderen Verhältnissen begegnen wir bei den Sa ariern, indem sich bier ein Theil der Rippen mit dem Brustbein verbindet.

Bei Lacerta kann man nach dem Verhalten der Rippen 3 Gruppen von Rückenwirbeln nnterscheiden, 5 Sternalwirbel, 
deren Rippen sich an dem schildförmigen Sternum festsetzen; 8 Dorsalwirbel, deren falsche Rippen sieh um die Bauchhöhle herumkrümmen, aber frei enden, und 8 Lendenwirbel, deren nach hinten stets kleiner werdende Rippen nicht an den Seiten herabsteigen, sondern die Bauchhöhle nur von oben her decken; die letzten Rippen bestehen nur aus einem Knochenstabe mit einem Knorpelende, während die falschen und wahren Rippen aus 3 Stücken zusammengesetzt sind; einem oberen, an dem entsprechenden Wirbel eingelenkten, das schief nach hinten und unten gerichtet ist, einem schief nach vorn und oben gerichteten abdominalen Stück und einem kleinen verbindenden Mittelstiick (Fig. 3).

Durch diese Gliederung jeder einzelnen Rippe wird offenbar die Beweglichkeit des ganzen Bogens sehr wesentlich erhöht und der Brustkorb viel mehr geeignet gemacht, dem Zug der bewegenden Muskeln in ausgiebigem Maasse zu folgen, als es bei Säugethieren der Fall ist.

Vor Allem ist aber durch das zwischen dem vertebralen und dem sternalen (abdominalen) Abschnitt jeder wahren Rippe beweglich eingeschaltete Mittelstiick die Möglichkeit gegeben, dass bei der inspiratorischen Hebung der Rippen sich auch der nach unten (hinten) hin immer stumpfer werdende Winkel, welchen beide Theilstücke miteinander bilden, noch wesentlich vergrössert.

Es ist klar, dass hierdurch eine viel ausgiebigere Bewegung des Brustbeines nach vorn bewerkstelligt werden kann, als bei Säugethieren, wo es sich nur um eine verhältnissmässig geringe Hebung des Sternums nach vorn und oben handelt. In noch viel ausgeprägterer Weise kommt übrigens dieser Umstand, wie wir sehen werden, bei der Athmung der Vögel in Betracht. Die Erweiterung des Thorax in seitlicher Richtung, welche bei den Schlangen durch einfaches Auseinanderweichen der ganz freien vorderen Rippenenden bewirkt wird, erscheint bei den Sauriern dadurch sehr begïnstigt, dass je 2 zusammengehörige Rippenbogen nicht, wie bei den Säugethieren, annähernd (sofern man wenigstens nur den knöchernen Theil der Rippen berücksichtigt) in einer Ebene liegen, sondern dachförmig zusammenstossen, indem der Rippenbogen jeder Seite in einer steil nach abwärts abfallenden Ebene liegt, die mit der der anderen Seite einen nach oben spitzen Winkel einschliesst.

Es ist unmittelbar ersichtlich, dass unter diesen Umständen 
schon eine geringe Hebung der Rippen zu einer sehr ausgiebigen Erweiterung des Thoraxraumes in seitlicher Richtung führen muss, was sich ubrigens in jedem Falle auch leicht durch die blosse Inspection des lebenden, athmenden Thieres erkennen lässt, vor allem beim. Chamäleon; wo sich die Form und Lage der Rippen bei einer tiefen Inspiration schon ätisserlich an der Haut sebr deutlich ausprägt.

Während bei den Säugethieren die obersten Rippen (besonders die erste und zweite, an welche sich die Scaleni inseriren) die ausgiebigsten Bewegungen ausführen, verhält es sich bei den Sauriern gerade umgekehrt, indem hier die oberen falschen Brustrippen fast völlig in Ruhe bleiben, während gerade die unteren am meisten aus ihrer Ruhelage herausgedreht werden und bei der Hebung verhältnissmässig umfangreiche Bogenlinien beschreiben ${ }^{1}$ ).

Wie schon erwähnt, sind die Levatores und Intercostales die hauptsächlich betheiligten Muskeln; von den letzteren wirken die Interni exspiratorisch, die Externi inspiratorisch.

Es handelt sich hier um kurze, von Rippe zu Rippe gehende Muskelfasern, die in sich kreuzender Richtung angeordnet sind. In Fig. $4 A$ und $B$ sind die Ersteren durch die Linien (3), die Letzteren (Externi) durch 2 versinnlicht. (4) entspricht Maskeln, welche den Schlangen eigenthümlich über eine Rippe wegziehen, in ihrer Wirkung natürlich ganz den Intercostales interni gleichen.

Die äusseren Intercostalmuskeln nehmen bei den Sauriern lateralwärts eine mehr und mehr dem Verlauf des äusseren schiefen Bauchmuskels parallele Richtung an und erstrecken sich nur bis zu der Stelle, wo die vertebralen und sternalen Stücke der Rippen aneinanderstossen; die Interni nehmen ziemlich rasch die für sie charakteristische vom Riicken und Schwanz nach dem Bauch und Kopf zu gehende Faserrichtung an und erstrecken sich im Gegensatz zu den Externi bis an das distoventrale Ende der Sternalstiicke der Rippen, erreichen im Brustkorb also die Mittellinie.

Es ist daher klar, dass die inspiratorische Erhebung sich vorwiegend an denjenigen Theilen der Rippen geltend machen wird, welche mit Intercostales externi ausgestattet sind, d. h. vorzugs-

1) Nach Sibson und $\mathrm{M}$ i I n e-E d w a $\mathrm{rds}$ (26) sind auch die Scaleni als Inspiratoren aufzufassen. Eine grössere respiratorische Bedeutung dürfte ihnen kaum zukommen. 
weise bis zu der Stelle, wo die Rippen die für sie so charakteristische scharfe Krümmung nach vorn und oben erleiden, während umgekehrt die Strecke, innerhalb deren von diesem Punkte bis zum Brustbein die Interni allein vorhanden sind, exspiratorisch sich verengert. In dieser Phase der Athmung legen sich hier die Rippen fast völlig zusammen, so dass man kaum noch ron Zwischenrippenränmen sprechen kann. Gleichzeitig verengern sich auch die lateralen Abschnitte ein wenig und senkt sich das Brustbein tiefer herab, jedoch weniger nach unten, als vielmehr nach innen.

Es tritt auf diese Weise die funktionell verschiedeneWerthigkeit der beiden Arten von Zwischenrip penm uskeln sehr klar und überzengend hervor, wie denn iiberhaupt die ganze grosse Bedeutung des Systemes der Inter- costales erst in solchen Füllen klar zu erkennen ist, wo der bei Säugethieren so wichtige Hülfsmuskel des Zwerchfelles fehlt.

Hier war bekanntlich die Rolle der Intercostalmuskeln lange Zeit ein Zankapfel der Physiologen, und seit dem berübmten Streit zwischen $\mathrm{Hamberger}$ und $\mathrm{Haller}$ (53) ist die Frage nicht ganz von der Tagesordnung wissenschaftlicher Streitfragen geschwunden. Leugnete doch selbst ein Forscher von der Bedeutung $\mathrm{Henle}$ 's jeglichen aktiven Einfluss der in Rede stehenden Muskeln auf die Athmung und schrieb ibnen nur insofern eine gewisse indirekte Bedeutung zu, als sie eine inspiratorische Einziehung resp. eine exspiratorische Ausbuchtung der Intercostalräume verhindern, dieselben also gegen Schwankungen des Druckes resistenter machen sollten.

Wenn nun auch die Bedeutung dieses Umstandes keineswegs geleugnet werden soll, so geht doch für die Reptilieñ die aktive und zwar ganz wesentliche Rolle der Intercostales ans den vorstehenden Untersuchungen klar genug hervor, und es liegt, soweit ich sehe, kein Grund vor, der von einer Verallgemeinerung dieses Befundes auf die Säugethiere abhalten mïsste.

Insbesondere scheint aber auch die vielfach angezweifelte inspiratorische Bedentung der Externi und die exspiratorische Wirkung der Interni durch die bei den Sanriern zu beobachtende Art der räumlichen Vertheilung beider Muskelarten auf verschiedene Rippenabschnitte iber jeden Zweifel sicher gestellt.

Bei Hunden, deren Athmungstypus durch das häufige Vorkommen aktiver Exstirpationen ausgezeichnet ist, haben übrigens 
Martin and Hartwe 11 direkt durch Beobachtung am lebenden Thier sich davon ïberzeugen können, dass die Interni sich während der exspiratorischen Phase wirklich contrahiren.

Auch die Versuche, welche L a b o r de (Compt. rend. de la soc. biol. 1884 8. Serie. I. p. 305) über den Erfolg der elektrischen Reizung der Intercostales an der Leiche eines enthaupteten Verbrechers anstellte, lieferten durchans der $\mathrm{Hamb}$ erger'schen Theorie entsprechende Resultate (27).

Immerhin wird man aber zugeben miissen, dass in Folge des Vorhandenseins eines Zwerchfelles und des in der Regel mehr passiven Charakters der normalen Exspiration die Rolle der Intercostales bei den Säugethieren eine vergleichsweise nur untergeordnete sein dürfte.

Eine ganz besondere Ausnahmestellung nehmen unter den Reptilien die Schildkröten hinsichtlich ihres respiratorischen $\mathrm{Me}$ chanismus ein, indem hier ja bewegliche Rippen, welche der Erweiterung der die Langen einschliessenden Höhle dienen könnten, gänzlich fehlen und der Körper ausserdem zum grössten Theil in einen starren, meist gänzlich unbeweglichen Panzer eingeschlossen ist. Dass demungeachtet eine leicht nachweisbare echte Saugathmung (neben einer in der Regel kaum in Betracht kommenden Schluckathmung) besteht und normaler Weise fast allein wirksam ist, kann auf Grund der bereits mitgetbeilten fremden und eigenen Erfahrungen nicht bezweifelt werden. Auch wurden früher bereits die vielfach nicht ganz klaren Ansichten erwähnt, welche von verschiedenen Autoren hinsichtlich des hier wirksamen respiratorischen Muskelmechanismus geäussert worden sind.

Dass durch einen solchen eine Erweiteruing resp. eine Verengerung der Leibeshöhle herbeigeführt werden muss, ist selbstverständlich absolut erforderlich, wenn Luft angesaugt oder ausgetrieben werden soll, es sei denn, dass man, wie dies thatsächlich auch für andere Reptilien behauptet worden ist, den Langen selbst eine so hoch entwickelte selbständige Contraktilität zuschreiben wollte.

Jede auch nur oberflächliche Betrachtung einer Schildkröte zeigt sofort, dass für eine Ausweitung der Leibeshöhle nur an den Stellen Raum bleibt, wo sich die Extremitäten mit dem Rumpfe verbinden, und eine schlaffe dehnbare Haut die Lücken zwischen Rücken- und Bauchschild ausfüllt. Es ist denn auch nichts ein- 
facher, als sich davon zu iberzeugen, wie bei jeder Inspiration diese Partien stark ausgebuchtet, bei jeder Exspiration dagegen nach innen eingezogen werden. Am deutlichsten tritt dies hervor, wenn man eines der Hinterbeine gewaltsam ausreckt und dann die so frei liegende Stelle der Leibeswand betrachtet. Man gewinnt hierbei durchaus den Eindruck, das namentlich die exspiratorische Einziehung durch eine Contraktion unmittelbar darunter gelegener Muskeln bewirkt wird, während die inspiratorische Verwölbung mehr den Eindruck eines passiven Vorganges macht.

Es ist auch nicht schwer, sich schon auf diese Weise davon zu iuberzeugen, dass aktive Bewegungen der Extremitäten und des Kopfes für das Zustandekommen dieser zweifellos der Athmung dienenden Volumänderungen der Leibeshöhle keineswegs erforderlich sind, indem sich dieselben anch dann vollziehen, wenn alle vier Beine in möglichst extendirter Stellung fixirt werden, wie dies ubrigens schon $\mathrm{P}$. B e r t feststellte.

Auf der anderen Seite ist aber auch zuzugeben, dass, wenn aus irgend welchem Grunde die Athmung eine sehr angestrengte wird, die Mithülfe der Extremitäten durch Vorstrecken bei der Einathmung, Einziehen bei der Exspiration in der Regel sehr deutlich hervortritt. Näherer Aufschluss über den respiratorischen Mechanismus und insbesondere die betheiligten Muskeln lässt sich nur nach Entfernung des Bauchschildes gewinnen, eine Operation, die ohne erheblichen Blutverlust und ohne Eröffnung der Leibeshöhle leicht ausführbar ist. Man braucht nur mittels der Knochenzange die eine seitliche Brïcke zwischen Rïcken- und Bauchschild zu entfernen und dann durch flache Schnitte mit dem Messer die Bauchwand immer dicht längs der Innenfläche des Brustschildes abzulösen. In der Regel athmet dann das Thier eine Zeit lang gar nicht, und nur durch starke (elektrische oder mechanische) Reize gelingt es, eine oder mehrere Athembewegungen auszulösen. Dabei überzeugt man sich leicht, dass bei jeder Exspiration die Bauchdecken sich abflachen und seitlich mehr oder weniger eingezogen werden, während bei der Inspiration vor Allem der sehr eigenthümlich angeordnete und äusserst bewegliche Schultergïrtel betheiligt $\mathrm{zu}$ sein scheint.

Die ersterwähnte Bewegung, wobei natürlich die Leibeshöhle verkleinert und Luft aus den Lungensäcken ausgetrieben wird, ist ohne jeden Zweifel auf die Contraktion der platten membranartigen E. Palüger, Archiv f. Physiologie. Bd.64. 
B a chm askeln, vor Allem des Transversus und Obliquus abdominis, zu beziehen, deren ganze Anordnung durchaus auf eine solche Rolle hinweist. Ein Blick auf eine der trefflichen Abbildungen in der klassischen Monographie von $\mathrm{B} \mathrm{o} \mathrm{ja} \mathrm{n} \mathrm{u} \mathrm{s} \mathrm{(28)} \mathrm{lässt}$ hierüber kaum einen Zweifel bestehen.

Der erstere Muskel entspringt von der inneren Fläche des Rückenschildes, von dem seine Fasern in einer langgestreckten krummen Linie abgehen, deren Convexität in der Regel nach vorn und innen (gegen die Wirbelsäule) gekehrt ist. - Von lier aus laufen die Fasern im Allgemeinen unter dem Brustschild schräg nach aussen und hinten und gehen in eine dünne Aponeurose über, welche wie die Muskelfasern selbst dem Bauchfell dicht anliegt und die in der binteren Hälfte des Rumpfes gelegenen Eingeweide seitwärts und von unten her umfasst. In der Mittellinie verbindet sie sich mit der Aponeurose des gleichen Muskels der anderen Seite und heftet sich hinten am Schambein an.

Auch die Fasern des Obliquus entspringen in einer bogenförmigen Linie, die nach aussen von dem M. testo-iliacus in dem Winkel gelegen ist, welcher das Rückenschild mit dem Bauchschild verbindet. Sie laufen convergent nach unten und innen und setzen im Allgemeinen einen nur wenig breiten, bogenförmigen Streifen zusammen, dessen unterer innerer Rand in eine Aponeurose übergeht, die mit jener des Transversus bald verschmilzt.

Fraglich ist die funktionelle Bedeutung des M. diaphragmaticus, eines den Schildkröten ganz eigenthümlichen Muskels, dessen Ursprung und Verlauf, wie ich glaube, am ehesten auch auf eine exspiratorische Wirkung hindentet.

Derselbe besteht aus zwei dünnen auf beide Seitenhälften des Körpers vertheilten, einander symmetrischen Schichten von Muskelfasern, von denen jede in der vorderen Hälfte der Rumpfböhle, theils von der Wirbelsäule, theils in deren Nähe von einer oder zweien ihnen entsprechenden Rippen entspringt, von da zwischen dem Carapax (Rückenschild) und der Lunge ihrer Seitenhälfte nach aussen und unten verläuft und anf diesem Wege in eine Aponeurose übergeht, die sich unter der Lunge um das Bauchfell herumschlägt und an dem Herzbeutel endigt (Hofman $\mathrm{n}$, Bronn's Classen und Ordnungen VI. Bd., III. Abth. I, p. 111).

Nach dem Verlauf der Fasern muss man schliessen, dass sie 
bei ihrer Contraktion die von ihnen theilweise umfasste Lunge comprimiren.

Wenn schon die blosse Betrachtung der genügend freigelegten Bauchdecken die exspiratorische Bedeutung der vorgenannten Muskeln ganz unzweifelhaft erscheinen lässt, so gelingt es durch Anwendung der graphischen Methode hiefuir einen noch augenfälligeren Beweis zu liefern. Verbindet man bei einer in der früher beschriebenen Weise hergerichteten Schildkröte die Trachea mit einem M a r e y'schen Tambour en registrateur, so kann man sich erstlich leicht davon überzeugen, dass synchron mit jeder exspiratorischen Hebelbewegung nach aufwärts die Bauchdecken sich abflachen und einziehen, während andererseits auch in der Ruhezeit eine exspiratorische Hebelbewegung von allerdings geringerem Umfange dirch künstliche elektrische Reizung der muskulösen Seitentheile der Bauchwand erzeugt werden kann.

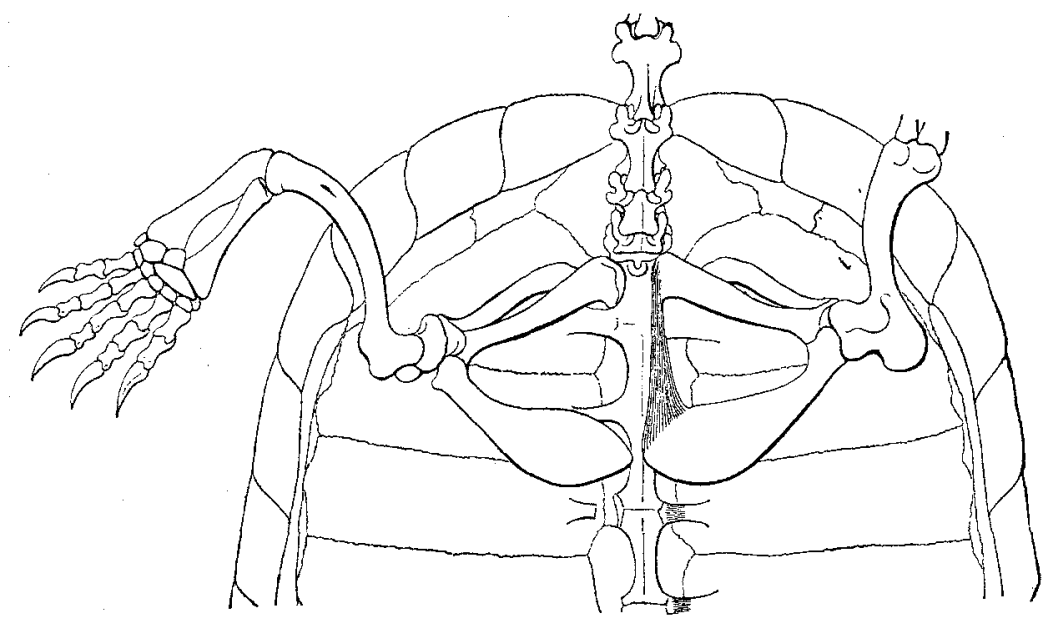

Fig. 5 .

Schultergürtel einer Schildkröte (nach Bojanus).

Nicht so unmittelbar gewinnt man über den Mechanismus der Inspiration Aufschluss.

Auf die Bedeutung des Schultergürtels weisen mehrfache Umstände hin. Vor allem die anatomischen Verhältnisse und seine ausserordentliche Beweglichkeit.

Es lassen sich am Schultergürtel der Schildkröten (Fig. 5) drei Stiicke unterscheiden, von welchen eines dorsalwärts, die beiden anderen ventralwärts gerichtet sind. Das erstere, schmal 
und stabförmig, ist als Scapula aufzufassen, während̉ die Bedeutung des vorderen Schenkels des ventralen Abschnittes noch strittig ist und von den Einen (Gegenbaur, F ii r bringer) als Procoracoïd, von Anderen ( $\mathrm{H}$ o $\mathrm{f} \mathrm{m}$ a $\mathrm{n} \mathbf{n}$ ) als Clavicula angesprochen wird. "Der betreffende Knochen wird an seinem medialen breiteren Ende, das dem der anderen Seite sehr nahe liegt, dúrch Bandmasse mit den Plastron verbunden. An seinem lateralen schmäleren Theile verwächst er ohne Naht mit dem Schulterblatte und mittels Naht mit dem Coracoüd, welches den hinteren Schenkel des ventralen Abschnittes und zugleich den breitesten Knochen des Schultergürtels darstellt. Medial, wo es sich in ein Knorpelstïck (Epicoracoird) fortsetzt, ragt es frei in die Leibeshöhle, ohne das Brustbild zu berïhren. Coracoïd und Procoracoïd erscheinen medianwärts durch ein längeres oder kürzeres Band mit einander verbunden, welches den zwischen beiden Knochen gelegenen Raum zu einer Oeffnung abscbliesst (Ligam. epicoracoïdeum F ü r b ring er).

Ohne auf eine Beschreibung der zahlreichen den Schultergürtel bewegenden Muskeln näher einzugehen, sei hier nur auf den für die inspiratorische Funktion wichtigsten Umstand hingewiesen, dass auch unabhängig von irgend erheblichen Bewegungen der Vorderextremität der Schultergürtel innerhalb weiter Grenzen verschiebbar ist. Löst man bei einer Sehildkröte das Bauchschild von hinten aus nur soweit ab, dass seine Verbindung mit dem Procoracoïd nicht gelöst wird, während die beiden Coracoïde ganz freiliegen, so wird man sich leicht überzeugen, dass jede spontane oder durch Reizung sensibler Theile ausgelöste Inspiration von einer mehr oder weniger beträchtlichen Verschiebung der letztgenannten Knochen begleitet ist, indem die medialen Ränder der Epicoracoïdknorpel, welche sich gewöhnlich fast berïhren, auseinanderweichen, sodass die Längsaxen beider Knochen einen minder stumpfen oder selbst spitzen Winkel miteinander einschliessen und in extremen Fällen einander fast parallel laufen. Dies letztere ist besonders dann der Fall, wenn es, wie meist nach Eröffnung der Leibeshöhle, zu sehr forcirten Inspirationen kommt, wobei uibrigens immer anch die Vorderbeine mehr oder weniger stark ausgestreckt werden. Dieselbe Bewegung der Coracoïde erfolgt natiurlich auch dann, wenn man die Vorderextremitäten gewaltsam zwischen dem Panzer hervorzieht.

Es ist ohne weiteres klar, dass jede solehe Bewegung zu 
einer entsprechenden Erweiterung der Leibeshöhle führen muss, da ja die dorsale Fläche des ventralen Abschnittes des Schultergiurtels direct an die Leibeswand angeheftet ist.

Könnte hieribber noch ein Zweifel bestehen, so würde er durch die Thatsache beseitigt, dass der Hebel eines mit der Trachea verbundenen Mar e y'schen Tambours regelmässig im inspiratorischen Sinne bewegt wird, wenn bei völlig unter den Panzer zurückgezogenen Vorderbeinen die Coracoïde passiv nur wenig von einander entfernt werden. Ueberaus starke Ausschläge erbält man aber, wenn die Verschiebung in derselben Richtung bedeutender ist, oder wenn man dieselben noch durch Vorziehen der Beine unterstiutzt.

Auch durch elektrische Reizung der an der Dorsalffäche des Coracoïd sich inserirenden Muskeln, durch deren Contraktion die betreffende Bewegung bewirkt wird, lässt sich der gleiche inspiratorische Effekt erzielen.

Es darf demnach, wie ich glaube, als bewiesen gelten, das bei den Schildkröten der so eigenthümlich gebaute Schultergürtel für den Athemmechanismus vonderallergrössten Bedeutung ist und speciell die aktive Inspiration vermittelt, gewiss eine sehr eigenartige, wohl hauptsächlich durch den Mangel der Rippen bedingte funktionelle Anpassung dieses Skelettabsebnittes, für die sich in der Wirbelthierreihe wohl kaum noch ein Analogon finden duirfte.

Dazu kommt noch die weitere nicht minder merkwürdige Thatsache, dass a uch dureb Bewegungen des Beckens eine inspiratorische Erweiterung der Leibeshöhle bedingt wird von nicht minderem Umfang, wie durch die geschilderten Versehiebungen des Schultergürtels. Bei Ablösung des Bauchschildes von hinten her durchschneidet man eine miichtige sich an jenem mit breiter Fläche ansetzende Muskelmasse (Fig. 6), welche das Becken mit dem Plastron verbindet und aus zwei Hälften besteht, deren eine vom $O$ s pubis nach vorne, die andere nach hinten gebt. Die vordere Hälfte (Attrahens pelvis $\mathrm{B}_{0} \mathrm{j}$ a $\mathrm{n} \mathrm{u} \mathrm{s}$ ) liegt unter der gemeinschaftlichen Aponeurose der beiden exspiratorisch wirkenden Bauchmuskeln (Obliquus und Transversus abdominis) und zieht, wie man leicht sieht, das Becken nach vorn, während die Fasern der hinteren Bälfte (Retrahens pelvis Bojanus) das- 
selbe nach unten und hinten bewegen. Der ganze sebr kräftige Muskel wird neuerdings als $M$. rectus abdominis bezeichnet (vgl. $\mathrm{H}$ of $\mathrm{mann}$ in Bronns Classen und Ordnungen VI. Bd., III. Abth. I, p. 110). In Folge der Verbindungen des Beckens mit der Bauchwand muss nun jede Abwärtsbewegung des ersteren die Leibeshöhle erweitern und inspiratorisch wirken, wie sich in der

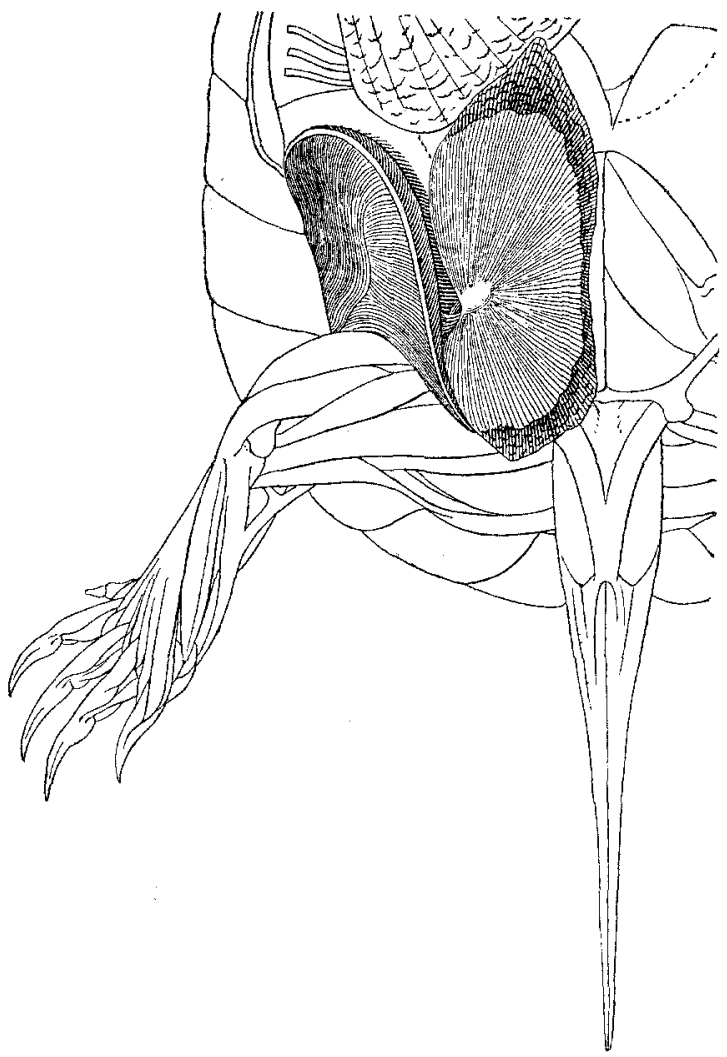

Fig. 6.

Der M. retrahens pelvis einer Schildkröte (nach Bojanus).

That leicht zeigen lässt, wenn man an einer tracheotomirten mit einem Mar e y'schen Tambour verbundenen Schildkröte derartige Bewegungen passiv ausführt. Man findet selbst die kleinsten Verschiebungen schon wirksam und gewinnt auf diese Weise eine Vorstellung, welche bedeutende Wirkungen im angedeuteten Sinne die Contraktion eines so mächtig entwickelten Muskels zur Folge haben muss. Es erscheint demnach sicher gerechtfertigt, auch ihn als einen Inspirationsmuskel der Schildkröten zu bezeichnen. 
Aehnliche Beobachtungen hat ubbrigens auch schon $\mathrm{Char}$ bon elle-Salle (37) gemacht, die er in folgenden Sätzen zusammenfasst:

„Il y a chez les Chéloniens deux sortes d'agents moteurs affectés au service de la respiration: d'une part les muscles proprement dits (diaphragme; transverse, et oblique de l'abdomen); d'autre part les muscles moteurs des ceintures thoracique et pelvienne; les deux ordres de puissances motrices ont dans l'ensemble des phenomènes des parts fort inégales, suivant que l'on considère une tortue terrestre on une tortue aquatique. Dans la première les muscles propres de la respiration sont rudimentaires et les ceintures jouent le plus grand rôle. Chez la seconde, les muscles respiratoires, bien développés, ont une importance au moins égale à celles des ceintures. Des deux ceintures, e'est la thoracique, qui par ses mouvements exerce la plus grande influence sur le renouvellement de l'air dans les poumons ${ }^{1}$ ). ${ }^{\text {" }}$

\section{E. Die Dyspnoe der Reptilien.}

Die eigenartigen dyspnoischen Erscheinungen sind bei Eidechsen ganz ausserordentlich schön zu beobachten, weil sie Störungen im respiratorischen Gaswechsel gegenüber ungemein resistent sind, und weil sich der Ablauf der Erscheinungen, der bei Warmbliutern sich innerhalb kürzester Zeit vollzieht, hier auf eine halbe Stunde und länger ausdehnt, sodass man die Entwickelung vom ersten Auftreten dyspnoischer Symptome bis zur völlig entwickelten Asphyxie sehr bequem verfolgen kann.

Leitet man dauernd Wasserstoff durch ein mit doppelt durchbohrtem Gummistöpsel rerschlossenes Glasgefäss von circa 1 Liter Voluminhalt, in dem sich eine Eidechse befindet, so tritt zunächst keinerlei bemerkenswerthe Veränderung an dem ruhig sitzenden Thier hervor, und nur die unregelmässige Athmung, wobei Gruppen in sich wieder ungleich kräftiger Respirationen von langen Pausen unterbrochen werden, deutet vielleicht auf ein gewisses Lnbehagen des Thieres hin. Innerhalb jeder Gruppe von Athmungen nimmt die Stärke derselben im Sinne einer aufsteigenden Treppe zu.

1) Einige unwichtigere Arbeiten s. Litteraturverzeichniss $38-42$ incl. 
Allmählich stellt sich dann eine durch lange Pausen unterbrochene Atbmung ein, wobei die einzelnen Respirationen merklich schwächer sind, als unter normalen Verbältnissen. Das Thier liegt während dessen mit geschlossenen Angen lethargisch am Boden. Dieser Zustand wird bisweilen unterbrochen durch ein plötzliches Erwachen des Thieres, welches sich an den Wänden des Glases emporrichtet und durch energische Fluchtversuche sich ans seiner Lage zu befreien sucht. Der ganze Erregungszustand ist begleitet von rasch sich folgenden Respirationen. In der Folge äussert sich die fortschreitende Dyspnoe ähnlich, wie auch bei Fröschen unter gleichen Bedingungen, durch weites Aufsperren des Maules bei jeder neuen Inspiration, während die Pausen fortwährend an Länge zunehmen.

Gleichzeitig contrahiren sich die langen Muskeln des Rückens und Halses, wodurch der Kopf nach rickwärts gerissen und in dieser Stellung eine Zeitlang fixirt wird. Erst ganz allmählich im Laufe der nächsten Athempause lässt der Krampf nach und der Kopf sinkt wieder in seine horizontale Lage zurtick.

Auch das Auftreten von energischen Schluckathmungen und Kehlbewegungen darf als ein Symptom der Dyspnoe gelten. Anfangs zeigen sich letztere nur selten, eine bis zwei zwischen je zwei Athmungen, dann aber in steigernder Anzahl, sodass schliesslich immer fünf bis zehn Kehlbewegungen sich zwischen je zwei Thoraxbewegungen einschieben.

Erst nach einer Stunde etwa tritt ein Zustand gefährlicher Somnolenz auf; die Athmungen sind sehr verflacht, erfolgen nur in Intervallen von 1-2 Minuten; auch die Zahl der Kehlbewegungen wird allmählich immer geringer, und die Reizerscheinungen an der Rücken- und Kiefermuskulatur werden schwächer bis zum fast völligen Verschwinden. Das Thier, das bisher beim Umschïtteln des Behälters reflektorische Athembewegungen zeigte, reagirt jetzt nicht mehr in dieser Weise, und um es nicht unnütz zu opfern, wird das Experiment unterbrochen. Die erste Bewegıng in freier Luft ist eine tiefe Inspiration, gefolgt von einer langen Pause. Ganz allmählich beginnen hierauf die Athmungen frequenter zu werden, während die Schluckbewegungen an Zahl abnehmen und schliesslich ganz fortfallen. Nach wenigen Minuten hat sich ein wahrer respiratorischer Sturm entwickelt, wobei die Athemfrequenz mehr als vierzig in der Minute erreichen kann. Das 
Thier liegt während dieser Zeit ganz rubig da, die Reflexerregbarkeit ist erloschen und tritt erst ziemlich spät wieder hervor.

Ganz ähnliche Erscheinungen lassen sich auch in dem Falle beobachten, wenn Eidechsen in eine Kohlensäureatmosphäre gebracht werden; doch entwickelt sich das geschilderte Bild der dyspnoischen Athmung im Allgemeinen wesentlich rascher.

Charakteristisch ist in beiden Fällen, abgesehen von vorübergehenden Reizerscheinungen, welehe niemals so beherrschend in den Vordergrund treten, wie bei den Warmblïtern, und sicb auch viel weniger an dem eigentlichen Athemmuskelapparat, als vielmehr an accessorischen Muskelgruppen äussern, ein allmähliches Schwächerwerden der einzelnen Respirationen, sowie eine mit der fortschreitenden Dyspnoe immer zunehmende Verlängerung der Pausen, die schliesslich mehr als eine Minute andauern können (Taf. III, Fig. 7-10).

Niemals kommt es bei Kaltblïtern zu jenen heftigen Erstickungserscheinungen, welche unter dem Bilde tonischer und klonischer Krämpfe die Dyspnoe der Säugethiere und Vögel so charakteristisch auszeichnen; ganz allmählich wird die Reflexerregbarkeit schwächer und schwächer, um schliesslich zu erlöschen.

Jedenfalls ist sicher, dass von einer durch Sauerstoffmangel oder Kohlensäureintoxikation bedingten Reizung nervöser Centren bei den Reptilien nicht im selben Sinne die Rede sein kann, wie bei den Warmblütern.

Dies zeigt sich in gleicher Weise bei plötzlicher Unterbrechung der Cireulation durch Ausschneiden des Herzens oder Eröffnung grosser Gefässstämme. Es verdient besonders bemerkt zu werden, dass periodisches Athmen, wie es bei Fröschen unter analogen Verhältnissen von Luchsinger (29), Langendorff (30) and Anderen (31) beobachtet wurde, an Eidechsen niemals hervortritt. Auch hierbei konnte ich immer nur eine zunehmende Verlängerung der Athempausen bei gleichzeitiger Abschwächung der einzelnen Respirationen bis zum völligen Verschwinden constatiren.

Im Allgemeinen widerstanden die Thiere derartigen Eingriffen nicht so lange, wie der einfachen Gas-Dyspnoe, und selten überlebte eine Eidechse die Herzexstirpation länger als eine Stunde. 
Wie es scheint, büsst das Athmungscentrum im Verlaufe der sich entwickelnden Asphyxie seine Erregbarkeit später ein als die spinalen Reflexcentren; denn ich konnte wiederholt beobachten, dass Reizung sensibler Theile noch eine deutliche reflektorische Athembewegung auslöste, während spinale Reflexe an Extremitätenmuskeln nicht mehr hervortraten.

In Kürze sei bier noch der Wirkung der Wärme und Kälte, sowie der Anästhetica (Aether, Chloroform) auf die Athmung gedacht.

Starke Abktihlung lässt sich in einfachster Weise dadurch erzielen, dass man einen mit kleinen Eisstiickchen gefüllten Gummibeutel lose um das Thier herumlegt. So erhielt ich Abkühlungen bis gegen $0^{0}$, wobei im Allgemeinen ganz ähnliche Folgeerscheinungen hervortreten, wie bei der Gas-Dyspnoe oder Anämie, nur mit dem Unterschied, dass unter diesen Umständen die concommittirenden Athembewegungen des Kopfes etc. fehlen.

Es handelt sich hier um die reinste Form einer allmählich wachsenden centralen Erregbarkeitsabnahme.

Eine sehr auffallende Erregbarkeitssteigerung des Athmungscentrums wird dagegen, wie zu erwarten war, durch Erwärmung bedingt, was sich leicht dadurch erreichen lässt, dass man die Eidechse in ein von beliebig erwärmter Luft durchströmtes Glasgefäss bringt, während gleichzeitig die Athembewegungen graphisch verzeichnet werden.

Schon vor längerer Zeit sind von A ckermann (32), Gad (33) und seinen Schiulern (34) Beobachtungen mitgetheilt worden, die auf bemerkenswerthe, bei Säugethieren zu beobachtende Unterschiede in der Erscheinungsform der Gas- und Wärmedyspnoe hinweisen und deren principielle Trennung mit Erfolg befüworten. Niemals aber tritt bei Warmblïtern die Differenz dieser beiden Arten der Dyspnoe so deatlich hervor, wie wir es bei den Reptilien in jedem Falle leicht beobachten können.

Ist bei Dyspnoe in Folge von O-Mangel oder Kohlensäurevergiftung eine allmählich fortschreitende Lähmung und Erregbarkeitsabnahme der centralen Apparate vor allem charakteristisch, so findet bei künstlicher Erwärmung des Versuchsthieres gerade umgekehrt eine enorme Steigerung der Funktionen des Athemapparates statt, die sich vor allem in einer sehr erheblichen Beschleunigung der Athmung äussert. Die Frequenz kann in extre- 
men Fällen die normale Zahl um das Drei-, ja selbst Fünffache ïbersteigen (Taf. III, Fig. 11-13). In dieser Hinsicht stimmen meine Ergebnisse durchaus mit dem bei Säugethieren im $\mathrm{Zu-}$ stande der "cephalischen Wärmedyspnoe" beobachteten Verhalten ïberein.

Dieser Umstand ist es hauptsächlich mit gewesen, der Gad und seine Schüler zu einer principiellen Trennung der verschiedenen Dyspnoeformen veranlasste; denn bei jener ebenfalls typischen Form, die man bei Säugethieren erhält, wenn man die Einathmungsluft durch die Ausathmungsluft verschlechtert, findet man die Frequenz wenig oder gar nicht vermehrt, ja nach Langendo r ff(35) tritt sogar, wenn man die zuführenden Luftwege comprimirt, eine nicht unbeträchtliche $\operatorname{Ver} \mathbf{l a n g s a m u n g}$ der respiratorischen Frequenz unter bestimmten Bedingungen ein. Hält man diese Beobachtungen mit den Resultaten, wie sie uns die Betrachtung der verschiedenen Dyspnoeformen bisher geliefert hat, zusammen, so ergiebt sich in der That, dass die erwähnte Trennung durchaus berechtigt ist, und dass die Wärmedyspnoe wohl kaum auf eine durch den erhöbten Stoffwechsel bedingte Kohlensäureanhäufung zurückzuführen ist, sondern wesentlich anderen Faktoren ihre Entstehung verdankt.

Wenn wir jeden Erregungsvorgang im gewöhnlichen Wortsinne als Hand in Hand gehend mit einem gesteigerten Zerfall der lebendigen Substanz ansehen dürfen und die lebhaftere Zersetzung (Dissimilation) geradezu als die eigentliche Ursache der zu beobachtenden Reizerfolge bezeichnen müssen, so erscheint es fast selbstverständlich, dass innerhalb gewisser Grenzen jede Erhöhung der Temperatur auch eine entsprechende Steigerung der centralen Nervenfunktionen wird bedingen müssen.

Dass also das Respirationscentrum (insbesondere der Kaltblüter) lebhafter d.h. rascher reagirt, wenn die Temperatur steigt, ist eine Erscheinung ganz gleicher Ordnung, wie etwa die Zunahme der Frequenz der Herzaktion oder der Flimmerbewegung unter gleichen Verbältnissen.

$\mathrm{Zu}$ erklären bleibt nur die auffallende Differenz zwischen Warm- uud Kaltbliutern in Bezug auf das Verhalten der Athmung bei O-Entziehung (Anämie) oder bei der Einwirkung von reiner $\mathrm{CO}_{2}$.

Es will mir scheinen, dass hier in erster Linie der unzweifel- 
haft sehr verschiedene zeitliche Verlauf in der Entwickelung der Stoffwechseländerungen in Betracht kommt, welche durch jene Eingriffe nothwendig bedingt werden und als die eigentliche Ursache der centralen Nervenreizung im einen wie im anderen Falle anzusehen sind.

Die Lebhaftigkeit aller Stoffwechselprozesse und das grosse 0-Bedürfniss bei homoiothermen Thieren verbürgt sicher auch ein sozusagen plötzliches Anschwellen der Reizursache zu wirksamer Höhe, wenn eine jener Schädlichkeiten zu wirken beginnt, während die bekannte ausserordentliche Resistenz der Amphibien und Reptilien gegen jede O-Beschränkung oder Entziehung voraussetzen lässt, dass die dadurch bedingten Veränderungen der centralen Nervensubstanz nur ganz allmählich zunehmen und daher im Allgemeinen nicht reizauslösend wirken werden, wie dies ja bekanntlich anch bei direkter künstlicher Reizung von Nerven und Muskeln gilt (Einschleichen des Stromes etc.).

Das Athmungscentrum bildet in dieser Beziehung keine Ausnahme, indem dyspnoische centrale Reizerscheinungen bei Poikilothermen überhaupt fehlen, oder sich wenigstens nicht merklich äussern. So vermisst man auch stets eine centrale wirksame Erregung der Hemmungsfasern des Herzens und ebensowenig treten jemals Erstickungskrämpfe im Bereich der quergestreiften Stammesmuskulatur auf. Es wäre nicht unmöglich, dass Beides sich vielleicht doch erreichen liesse, wenn durch künstliche Steigerung. der Temperatur der Versuchsthiere die Empfindlichkeit der erregbaren Theile und anch der Ablauf aller Stoffwechselprozesse wesentlich beschleunigt würde.

Eine schon der normalen Reptilienathmung zukommende Eigenthümlichkeit ist ein häufiges Auftreten periodischer Athmung (Fig. 11, Taf. III), wie es auch bei Amphibien und Säugethieren unter den versehiedensten Bedingungen und in den mannigfachsten Combinationen beobachtet worden ist. Knoll (44) hat bei Kăninchen die Beobachtung gemacht, dass sie oft unmittelbar nach der Fixation auf dem Vivisektionsbrett eine periodische Athmung, oder vielleicht besser "periodische Athemschwankung" unter dem Einfluss des psychischen Shokes zeigen, und ich kann diese Beobachtung auch für die Reptilien bestätigen.

Aber auch unter ganz normalen Verhältnissen, selbst an im 
Freien beobachteten Thieren ${ }^{1}$, tritt sie häufig genug in Erscheinung, und zwar in der Regel in Form einer "ansteigenden Treppe" (Fig. 14 u. 15). Die Perioden selbst sind stets sehr kurz, zwei bis fünf Athmungen, die, nur durch kurze Pausen getrennt, mit immer zunehmender Amplitude, namentlich des exspiratorischen Curvenschenkels, einander folgen. Seltener setzen sich die Gruppen aus Athmungen gleicher Intensität zusammen. Die Erstickung, die bei Amphibien und Säugethieren die wichtigste Entstehungsursache der periodisehen Athmung ist, erweist sich bei den Reptilien, wie bereits oben mitgetheilt, als gänzlich einflusslos, dagegen tritt die Erscheinung fast regelmässig in einem bestimmten Stadium der Wärmedyspnoe hervor; meist sind es dann zwei (Fig. 11), seltener drei Respirationen, die je eine kleine Gruppe zusammensetzen.

Der Temperaturgrad, bei welchem periodisches Athmen, wenn auch nicht immer, so doch häufig entsteht, scheint zwischen dreissig und vierzig Grad zu liegen; später, bei weiterer Steigerung der Wärmezufuhr, verschwindet das Phänomen meist wieder vollständig.

Interessante Ergebnisse erhält man auch oft, wenn auf die nervösen Centralorgane gleichzeitig zwei antagonistische Momente, wie z. B. Kohlensäure und gesteigerte Wärme, einwirken.

Gad (33) hat derartige Versuche an Kaninchen ausgefiihrt, indem er nach Herabsetzung der centralen Erregbarkeit durch Vergiftung mit Chloralhydrat Wärmedyspnoe erzeugte; er fand, dass in diesem Falle die Wirkung des Chlorals vollständig ïbercompensirt wurde und die typische Form der cephalischen Würmedyspnoe zum Vorschein kam.

Lässt man bei Eidechsen, die aus einem mit Kohlensäure gefüllten Glaskolben respiriren, gleichzeitig den Körper von heisser Luft umspülen, so tritt eine beträchtliche Steigerung der respiratorischen Frequenz ein und zwar um so stärker, je intensiver und schneller die Erwärmung von statten geht; hieran schliesst sich ein Stadium, wo die Respiration annähernd normale Frequenz zeigt, bei beträchtlich verringerter Tiefe, worauf nach kurzer Zeit eine typische Gasdyspnoe folgt, die dann auch fernerhin ausschliesslich bestehen bleibt.

1) Mosso hat am wachenden und schlafenden Menschen ebenfalls periodische Athmungen gesehen. 
Wenn man aber die Wärme erst zu einer Zeit einwirken lïsst, in der die Gasdyspnoe bereits völlig entwickelt ist, so sind die Folgewirkungen viel weniger ausgeprägt.

Es tritt wohl eine deutliche Verkürzung der Pause ein, aber eine typische Wärmedyspnoe ist nicht mehr zu erzielen, auch wenn man die zuströmende Luft bis auf $60^{\circ}$ temperirt. Die Erregbarkeit lat eben bereits zu sehr gelitten und kann sich bei der weiter andauernderi Einwirkung der Lähmungsursache auch unter dem Einfluss der Wärme nicht mehr erholen.

Jedenfalls beweist dieser Versuch schlagend, dass in der That die genannten beiden Formen der Dyspnoe sich in gewissem Sinne antagonistisch verhalten, indem sie sich bis zu einem gewissen Grade gegenseitig aufheben können, sodass je nach dem Zustande, in dem sich das Centralorgan befindet, entweder die eine oder die andere das definitive Uebergewicht erbalten kann.

Ich schliesse nun hier noch die Beschreibung der respiratorischen Aenderungen an, die als Folgeerscheinung von Aetherinhalationen auftreten, da sie eine ausserordentliche Aehnlichkeit mit der Wärmedyspnoe aufweisen. Auch hier tritt eine mit Verminderung der Tiefe einhergehende Steigerung der Frequenz charakteristisch hervor, wenn anch die erstere vielleicht nicht so intensiv sich ausprägt, die letztere dagegen noch weit höhere Grade erreicht. Die Aethervergiftung bewirkt regelmässig eine so kolossale numerische Steigerung der Respirationen, wie man sie sonst niemals zu beobachten Gelegenheit hat. Die Pausen manifestiren sich nur noch durch eine leichte Ungleichmässigkeit im exspiratorischen Schenkel der Curve und die Glottisränder, die man leicht durch Sperren des Mundes sichtbar macht, gelangen kaum noch dazu, einander zu berühren, und vibriren förmlich hin und her.

Die Eidechsen erweisen sich im Allgemeinen ausserordentlich resistent gegen den Aether, und es gehört eine ziemlich lange Zeit der Einwirkung dazu, um ein völliges Erlöschen der Reflexerreg. barkeit herbeizuführen, andererseits verschwindet die Narkose sehr rasch wieder. Ich ging in der Regel so vor, dass ich ein Thier tief narkotisirte und es dann mit einem Luftbehälter verband, der mehrere Cubikcentimeter Aether enthielt; durch die Verdunstung desselben wurde die Narkose lange erhalten, sodass ich Stunden 
hindurch die Veränderung der Athmung beobachten konnte. Leider ist für Schlangen und Schildkröten der Aether sowie auch das Chloroform als Anästheticum wenig brauchbar, was umsomehr zu bedauern ist, als man sonst hierdurch ein Mittel in die Hand bekommen würde, den trägen und unregelmässigen Rhythmus in einen für das Experiment besser verwerthbaren umzugestalten. In der Regel sterben die Thiere, bevor es soweit gekommen ist.

Die beigegebenen Curvenbilder (Fig. 16 und 17, Taf. III) sprechen so deutlich, dass es unnütz wäre, in eine detaillirte Beschreibung der Erscheinungen der Aethernarkose einzutreten; nur eine sehr eigenthümliche Erscheinung, welche der Athmung durchaus den Charakter einer ausgesprochenen Periodizität verleiht, muss hier noch eine etwas eingehendere Darstellung finden.

Man beobachtet nämlich in bestimmten, zwar individuell recht verschiedenen, aber im einzelnen Falle ziemlich constanten Intervallen (im Allgemeinen immer zwischen zwanzig bis vierzig Respirationen) folgende auffallende Erscheinung: Plötzlicb bläht sich das Thier weit auf, indem eine tiefe Inspiration erfolgt; der Schreibstift sinkt unter das Niveau der vorausgegangenen inspiratorischen Scheitel herab, um eben so rasch zu einem die gewöhnliche exspiratorische Curvenhöhe um das Doppelte, ja selbst Dreifache übersteigenden Niveau emporzuschwingen (Fig. 16 und 17 Taf. III); hierauf sinkt die Curve sehr allmählich zur Ruhelinie ab.

Noch bevor diese aber wirklich erreicht ist, setzt oft eine neue schwache Exspiration ein, der sich eine Inspiration anschliesst. Jene ist oft nur wenig deutlich ausgeprägt und markirt sich an der Curve oft nur als kleiner, nach oben convexer Höcker (Fig. 17), was besonders dann der Fall ist, wenn bei Beginn der neuen Exspiration der Hebel noch weit von der Ruhelage entfernt ist.

Hierauf folgt nun eine Reihe von Athembewegungen, die langsamer verlaufen, geringere in- und exspiratorische Amplituden aufweisen und anfangs noch Andeutungen von Pausen erkennen lassen (Fig. 16).

Ganz allmählig aber ändert sich dies Verbalten; die Pausen nehmen ab bis zum völligen Verschwinden, während die Frequenz erheblich zunimmt. Die ganze Curvenreihe erhält so wieder den Charakter einer langgezogenen, aufsteigenden Treppe, bis plötzlich eine neue tiefe Inspiration erfolgt und damit jene eigenthümliche Athmungsform einsetzt, die für die Aethernarkose so ausserordent- 
lich charakteristiseh ist. Die Zahl der Atbmungen, welche je eine Periode bilden, ist im Beginn der Narkose im Allgemeinen grösser und lässt sich ausserdem durch Temperatursteigerung sehr beträchtlich vermindern (Fig. 17).

\section{F. Vagusdurchschneidung, Vagusreizung und ihr Einflass anf die Athmung.}

Der Vagus entspringt von der Seitenfläche des verlängerten Markes, in den meisten Fallen in seinem Wurzelgebiet nur schwer von den Aesten des Accessorius Willisii zu trennen, in selteneren auch noch mit den Ursprüngen des Hypoglossus vereinigt. Auch in seinem weiteren Verlauf bleibt der Vagus nur selten vollkommen frei, da in der Regel früher oder später eine Verbindung mit dem Glossopharyngeus, oder dem Hypoglossus, bisweilen auch mit beiden statt hat.

Mit dem Halstheil des Sympathikus ist er in den meisten Fällen nur durch feine Nervenschlingen verbunden; nur selten verschmelzen die von vorn herkommenden sympathischen Elemente gänzlich mit ihm, um später von seinem Stamme sich wieder zu trennen. In diesem Falle fehlen erklärlicher Weise alle Verbindungszweige.

Was die Aeste des Vagus und den Ort ihrer Abzweigung aus dem Hauptstamm anbetrifft, so lassen sie sich praktisch in zwei Kategorien trennen, je nach ihrer Lagebeziehung zu dem ron Vo g $l$ und Ben $\mathrm{tz}$ gleichzeitig entdeckten Ganglion trunci Nervi vagi, das als ovale, glatte, röthlich-weisse Intumescenz kurz vor dem Eintritte des N. vagus in die Brusthöhle in der Nähe des Herzens liegt und durch eine starke Nervenschlinge mit dem ersten oder zweiten Brustganglion des Sympathicus in Verbindung steht.

Die den Kehlkopf und den Schlund innervirenden Zweige zeigen grosse Neigung, sich von den ïbrigen Elementen des Nerven schon sehr frühzeitig zu trennen, indem sie Organe zu versorgen haben, die ziemlich weit nach vorn, i. e. kopfwärts liegen, während der eigentliche Verbreitungsbezirk der ibrigen Theile des Vagus erst von der Brusthöhle an beginnt. So ist schon friiher darauf hingewiesen worden, dass der Ramus laryngeus superior (der indessen zugleich auch meistens die Schlundfäden enthält und deshalb richtiger nach B e $\mathrm{n}$ t z' Vorgang als Nervus laryngopharyngeus anfgefasst wird) häufig in der Form eines Verstär- 
kungsastes aus der Bahn des Vagus schon sehr früh in diejenige des Glossopharyngeus übertritt, um aus dem letzteren wieder in Form eines seiner Aeste auszutreten.

Ferner finden sich bei allen Sauriern Nervenzweige des Vagus, die von hinten her an der äusseren Seite der Luftröhre bis zum Kehlkopf heraufsteigen und sich mit dem Ramus recurrens der Säugethiere und Vögel vergleichen lassen. Bald jenseits, bald diesseits des Ganglion trunci entspringend, in der Regel einfach, seltener zwei, auch drei isolirte Aeste, legen sie sich an die Aussenseite der Luftröhre an und treten schliesslich in intime Beziehung zum Nervus laryngeus superior, wie bereits frïher kurz geschildert.

Auch ihre physiologische Funktion haben wir bereits kennen gelernt, und möchte ich an dieser Stelle nur betonen, dass die bisLerige Anschauung der Anatomen, die im Nervus laryngeus superior den ausschliesslichen Muskelnerven des Kehlkopfes, im Nervus recurrens dagegen einen rein sensiblen die Scheimhaut des Organes versorgenden Nerven erblickte, einer physiologischen Prüfung gegenüber nicht stand halten konnte.

Nach dem Ramus recurrens sind die Zweige an die Speiseröhre diejenigen Aeste, die zuerst nach der Bildung des Ganglion trunci aus dem Stamme des Vagus hervorzutreten pflegen. Nur in sehr seltenen Fällen wiederholen sie den auch ausnahmsweise stattfindenden Ursprung des Rames recurrens diesseits des Ganglions; ebenso selten sind sie schon vom Ursprung des Vagus an von diesem getrennt und in einem besonders verlaufenden Nervus laryngo-pharyngeus vorbanden. Sie verbreiten sich an die Speiseröhre und lassen sich nach hinten bis zum Magen, nach vorn häufig bis zum Schlunde verfolgen.

(Bei meinen Versuchsobjekten, L a c e ta $\mathrm{vir}$ id is und muralis, entspringen diese Aeste ebenso, wie der Nerrus recurrens nach hinten vom Ganglion trunci, das sich nicht allza tief am Halse vorfindet.)

Schliesslich wären noch die Zweige an das Herz, die Lungen und den Magen zu erwähnen, die erst nach der Bildung des Ganglion trunci vom Vagus abtreten. Ihre Zahl ist ausserordentlich schwankend, bei den verschiedenen Arten sehr wechselnd in ihrer Form, eine geflechtartige Verbindung mit dem Sympathikus bisher nicht beobachtet. 
Merkwuirdig ist, dass verschiedene Autoren pulmonale Endäste überhaupt nicht erwähnen; ihre Existenz ist jedenfalls, wenn anatomisch noch nicht gesichert, durch die folgenden physiologischen Untersuchungsergebnisse als bewiesen anzusehen.

Bei den Schlangen und Schildkröten finden sich im Allgemeinen dieselben eben für die Saurier dargelegten Verhältnisse; ich kann deshalb daruber hinweggehen.

Die meisten der bier angefübrten anatomischen Daten sind der ausgezeichneten Arbeit von $\mathrm{F}$ is $\mathrm{ch}$ e $\mathrm{r}$ ïber die Hirnnerven der Saurier entlehnt.

Was die Methode der Freilegung des Vagus betrifft, so muss ich erwähnen, dass sie mit einigen Schwierigkeiten verbunden ist, besonders, wenn man ein genügend grosses Stïck zur Ausfilihrung von Reizversuchen sich verschaffen muss. Durch längere Uebung kann man es indessen ziemlich bald erreichen, schnell und sicher die betreffende Operation auszuführen, bei der man sich am besten einer Stativlupe bedient.

Von grossem Vortheil ist es ferner, stets vorbereitend die Tracheotomie auszuführen, weil man auf diese Weise am bequemsten das Thier mit dem Registrirapparat in Verbindung setzen kann. Man fixirt das Thier am besten in Rückenlage auf einem gewöhnlichen Froschbrett und spaltet durch einen medianen Schnitt die Haut vom Brustbein an bis zu der Stelle, wo die dünnen Hörner des Zungenbeines in dem schmalen Körper zusammenstossen. Dieser Punkt wird leicht gefunden durch den Widerstand, den der Knochen der vorsichtig geführten Scheerenbranche entgegensetzt. Hierauf führt man zwei weitere Schnitte, den einen längs des Schlüsselbeines, den anderen vom Hyoid nach der Stelle, wo das Trommelfell als ovale Membran in den Knochen eingespannt ist, sowohl wach rechts wie nach links und präparirt sorgfältig die Haut ab, und zwar möglichst weit nach hinten zu. Man geht hieranf in der Medianebene zwischen den Sterno-hyoidei ein und indem man mit zwei Pincetten das Bindegewebe zerreisst und die Muskeln auseinanderschiebt, bekommt man bald die Trachea zu Gesicht, siebt den feinen Nervus recurrens, der an ibr entlang. nach oben verläuft und eine ihm seitlich verbundene grosse Vene, vor deren Durchschneidung man sich hüten muss, da sie eine lästige Blutung verursacht. Nunmehr fasst man die Trachea mit einer feinen Pincette, hebt sie nach oben etwas hervor und schlitzt sie 
senkrecht zu ihrer Längsaxe auf, oder führt überhaupt keine eigentliche Tracheotomie aus, sondern verlängert den Medianschnitt unter Durchtrennung des Zungenbeinkörpers nach vorne, drückt hierauf mit einer in der linken Hand gehaltenen Pincette den Boden der Mundhöhle und die Znnge nach unten und löst die Trachea durch einen $\mathrm{Zug}$ nach binten und oben in Verbindung mit dem Kehlkopf herans. Es gelingt dies nach Durchschneidung des Zungenbeines und bei der nur lockeren Fixation des Larynx an die Zunge un. schwer, eventuell muss man mit Scheere und Pincette nachhelfen. Man hat so obne erbebliche Blutung die Trachea in ibrer ganzen Länge zur Verfügung und erleichtert sich ganz wesentlich das Einführen einer Kanüle in den breiten, sich konisch verjüngenden Kehlkopfeingang.

Auf alle Fälle ist es unumgänglich nöthig, die Trachea möglichst weit vorne zu öffnen, weil man sonst mit dem Einlegen der Kanüle gar zu grosse Schwierigkeiten hat. Als letztere genïgt eine einfache Glasröhre, die ziemlich stark sich verjüngt, und die man möglichst weit einführt, indem man die Trachea mit einer Pincette an ihr emporschiebt. Die Kanüle hält dann so fest, dass sie auch ohne Unterbindung fixirt bleibt.

Das Loch in der Luftröhre klafft beständig und ermöglicht es den Thieren, auch ohne eine Dauerkaniile tagelang gänzlich ungestört zu respiriren.

Weit schwieriger gestaltet sich die Auffindung des Vagus selbst; hier ist Uebung wichtiger als jede Beschreibung. Vortheilhaft erscheint es, die Operation zuerst an einem in Alkobol gehärteten Präparate auszuführen, weil man sich in dem festen Gewebe bei einem erstmaligen Versuche bedeutend besser zurechtfindet.

Das Thier, das vorher mit gespreizten Extremitäten in Rïckenlage fixirt war, wird jetzt in Seitenlage gebracht, indem die obere Extremität der Seite, deren Vagus blossgelegt werden soll, über den Kopf nach oben gesehlagen wird. Dann wird ein Faden durch den Oberkiefer gezogen und der Kopf dadurch festgestellt, gleichzeitig aber der Hals, der an und für sich recht kurz ist, möglichst gespannt.

Auf diese Weise macht man sich das Operationsfeld zugänglich.

Man suche nun den Vagus in einer Richtung, die ungefähr 
einer vom Trommelfell aus nach einem zwei Millimeter vom medialen Claviculaende entfernten Punkte gezogenen Linie entspricht, indem man mit Pincette und stumpfem Skalpell mehr als mit Scheere und Messer unter möglichster Schonung der Muskeln in der angegebenen Richtung in die 'Tiefe dringt. Meist wird es so gelingen, sich bald den Nerven zugänglich zu machen; anderenfalls muss man dies durch Anlegen von Muskelfenstern oder direkter Entfernung muskulösen Gewebes (der M. trapezius kommt hier fast ausschliesslich in Frage) zu erreichen suchen.

Die schliesslich freigelegte Parthie gewährt folgenden Anblick. Unter dem Trommelfelle erscheint ein Gewirr von Nervenzweigen des Glossopharyngeus, Vagusäste, deren Ursprung noch höher oben liegt, Nervenzweige, die zu den Muskeln des Halses verlaufen; darüber, in der Gegend dieses Nervengewirres beginnend, streben die langen und kurzen Hörner des Zungenbeines als dünne silberglänzende Fäden nach vorn und medial.

Die Mehrzahl der Nervenstämmchen schlägt sich nach vorne um, um die muskulären Gebilde des Kopfes, besonders die Zunge und den Mundboden zu innerviren, ein kleinerer Theil aber steigt nach unten und medialwärts, unter ihnen der Vagus, der schon durch die dentlich sichtbare Anschwellung seines Ganglion trunci von den Nerven des Cervicalmarkes immer deutlich unterschieden werden kann.

Auf der ganzen sichtbaren Strecke verläuft der Stamm ohne Abgabe von Aesten, und man müsste die Clavicula und die ersten Rippen reseciren, wollte man den Abgang des Ramus recurrens und die visceralen Endäste zu Gesicht bekommen. Meist an seiner lateralen Seite, seltener ibn deckend, folgt eine sehr grosse, durch Bindegewebe ihm fest angeheftete Vene seinem Verlanfe.

Vor dem Vagus sieht man in zierlichem Bogen zwei pulsirende Arterien emporsteigen, die bald dirergiren, die Arteria subclavia und carotis communis.

Bei der Sektion des Nerven habe ich stets als Ort der Durchschneidung eine Stelle unterhalb des Ganglion trunci gewählt, was namentlich bei Reizversuchen nnumgänglich nothwendig ist, wenn man ein für die anzulegenden Elektroden ausreichendes Nervenstïck gewinnen will.

Bei der Vagisektion isolirt man entweder den Nerv ein kleines Stückchen von der Vene, führt den Arm einer feinen 
Scheere unter ihm hinweg und durchschneidet dann, oder man unterbindet Vene und Nerv doppelt und durchtrennt zwischen der Ligatur.

Letzteres Verfahren ist fast stets vorzuziehen, wenn man den Nerv freipräpariren muss, da dieses sonst kaum ohne gleichzeitige Verletzung des Gefässes oder des Nerven gelingt.

Hinsichtlich der Folgen der Vagusdurchschneidung bei Reptilien hat P. B ert in seinem oft citirten Werke nur wenige Angaben gemacht.

Er bildet von einer vagotomirten Schildkröte herrührende Athmungscurven $a b$, welehe nur eine Verlängerung und Vertiefung der einzelnen Respirationen erkennen lassen.

Indessen sind, wie ich mich mehrfach zu überzeugen Gelegenheit hatte, gerade diese Thiere wegen der ausserordentlichen Unregelmässigkeit auch ihrer normalen Athmung am allerwenigsten geeignet, irgend welche experimentell herbeigeführte Störungen mit Sicherheit erkennen zu lassen. Es ist dies um so mehr zu bedauern, als gerade hier der Vagus ausserordentlich leicht auf eine lange Strecke zusammen mit der auch hier ihn begleitenden grossen Vene freigelegt werden kann, und zwar ohne irgend welche Verletzung.

Sehr constante und charakteristische Folgewirkungen lassen sich dagegen nach Vagisektion bei E i d e ch se n beobachten.

Die einseitige Vagusdurchschneidung ist in ihren Erfolgen etwas wechselnd, wenigstens was die Dauer und die Intensität der durch sie bedingten Erscheinungen betrifft. Regelmässig ist der unmittelbare Effekt eine oft sehr lange Pause, die durch starke sensible Reize sich unterbrechen lässt, indem hierdurch eine einmalige rasche Athembewegung ausgelöst wird.

Nach Ablauf der Pause, die oft die Dauer einer Minute erreicht, folgen meist noch in unregelmässigem Rhythmus verlangsamte Athmungen meist rudimentärer Art, indem nicht, wie auch sonst bisweilen, die aktiv in spirator is ehe Theilphase in Wegfall kommt, sondern gerade umgekehrt die aktiv exs pi rat oris che (Fig. 18 Taf. III). Aber auch in der Folge, wenn die einzelnen Athmungen bereits wieder einen ganz normalen Charakter angenommen haben, bleibt als charakteristisch die ausserordentlich geringe Frequenz bestehen (Fig. 19). In Bezug auf die Form der einzelnen Curven sei noch erwäbnt, dass auch nach dem Wieder- 
auftreten der aktiven Exspirationen die inspiratorische Phase häufig verzögert ist, wodurch der Gipfel des betreffenden Curvenabschnittes oft mehr abgerundet erscheint, als unter normalen Verbältnissen.

Unter allen Umständen nehmen aber die im Gefolge der einseitigen Vagusdurchschneidung auftretenden Störungen um so mehr $a b$, je längere Zeit nach der Operation verflossen ist, und schliesslich erfolgt in allen Fällen die Restitutio ad in tegram.

Oft findet man schon am nächsten Tage die normale Frequenz wieder hergestellt, in anderen Fällen macht sich noch am dritten bis füften Tage eine leichte Verlangsamung bemerkbar, oder ist selbst noch dentlich ausgeprägt.

Dieser letztere Umstand macht es wahrscheinlich, dass wir in der Verlangsamung der Athmung weniger eine Reiz- als eine Ausfallserscheinung vor uns haben. Wenn sie allmählich verschwindet und einer normalen Frequenz wieder Platz macht, so ist dies auf gewisse regulatorische Vorgänge im Organismus zurückzuftihren, indem der intakte Vagus, der vielleicht überall bei den Vertebraten b e ide Lungen versorgt, die Funktion des ausgefallenen selbständig übernimmt. Diese Erscheinungen einer rascher oder langsamer sich vollziehenden Compensation zeigen Reptilien, Vögel und Säugethiere in durchaus gleicher Weise.

Da uernde Ausfalls ers chein unge n treten dagegen regelmässig nach d oppelseitiger Vagotomie auf. Bezüglich der Form der einzelnen Athmung herrscht fast vollkommene Uebereinstimmung mit den bereits geschilderten Folgewirkungen der Durchschneidung nur eines Nerven. Als untersebeidendes Merkmal muss dagegendieganzauffallende Verlängerung der Pausen hervorgehoben werden, deren Dauer oft um das Dreifache jene bei einfacher Vagusdurchtrennung ibertrifft ${ }^{1}$ ).

Dass es sich hier wirklich um $\mathrm{d}$ a $\mathbf{u}$ ernde Veränderungen handelt, lässt sich gerade in diesem Falle sehr sicher nachweisen, da die Thiere sich gegen den schweren Eingriff ausserordentlich

1) Manchmal beobachtet man, meist kurze Zeit nach der Operation, dass zwei, ja selbst drei Athembewegungen unmittelbar auf einander folgen, worauf dann die folgende Athempause besonders gedehnt erscheint. 
resistent zeigen und ohne besondere Vorsichtsmaassregeln eine Woche und länger am Leben erhalten werden können, ohne dass irgend eine merkliche Veränderung im Verhalten der Athmung zu beobachten wäre.

Gewiss kommt es vor, dass einmal eine leichte Verkürzung der Pausen zur Beobachtung gelangt, ebenso oft aber kann man an späteren Tagen eine entschieden noch gesteigerte Verlangsamung constatiren, und sicher sind diese Abweichungen bedingt durch zufällige andere Momente, Aenderungen in der Aussentemperatur, im psychischen Verhalten u. A.

Es kann daher wohl auch kaum davon die Rede sein, die geschilderten Folgewirkungen der Vagusdurchschneidung auf einen dadurch bedingten dauernden Reizzustand zu beziehen, da ein solches Verhalten ohne jede Analogie sein würde.

Was P. Bert von seiner Schildkröte zu berichten weiss, seheint freilich meinen Versuchsresultaten direkt zu widersprechen. Ich lasse den betreffenden Passus hier wörtlich folgen:

Les Oiseaux et les Reptiles survivent longtemps à la section des nerfs pneumogastriques. Mais il est interessant de noter, que les troubles respiratoires, qui sont consécutifs à cette opération, sont du même ordre que chez les mammifères. Seulement il semble, que leur maximum d'intensité suit immédiatement la section; dans les jours postérieurs, la respiration se rapproche davantage du type normal. Il en est tout autrement chez les mammifères.

Die von P. B ert mitgetheilten 5 Curven einer vagotomirten Schildkröte, welche an mehreren aufeinanderfolgenden Tagen aufgenommen wurden, lassen sämmtlich die charakteristische Verlangsamung dentlich erkennen. Dagegen finden sich für seine Behauptung einer fortschreitenden Besserung keinerlei Belege.

Auf Grund meiner eigenen Erfahrungen muss ich die Möglichkeit einer solchen durchaus bezweifeln.

So lange ich auch immer die vagotomirten Thiere beobachtet habe, nie ist mir eine A enderang des darch die Nervendurebsehneidung bedingten Athmungstypus im Sinne einer Wiederherstellang des normalen Rhyt h m us rorgek om men.

Berïcksichtigt man die so ungemein zahlreichen und doch so wenig übereinstimmenden Untersuchungen über den Einfluss der centralen Vag u sreiz u g auf die Athmung bei Säugethieren, 
so wird man kaum mit besonderen Erwartungen an derartige Versuche bei Reptilien herantreten. Ich habe solche zunächst mit Hülfe tetanisirender Induktionsströme ${ }^{1}$ ) angestellt, die sich, wie spätere Erfahrungen an Vögeln lehrten, viel weniger geeignet erweisen, als der unterbrochene Kettenstrom.

Bei Schlangen, welche behufs Präparation des Vagus nur schwer in genügender Weise fixirt werden können, behauptet P. Bert als Reizerfolg sowohl in- wie exspiratorische Pausen gesehen zu haben.

„J'ai experimenté sur les couleuvres; mais les tracés obtenus sont entachés d'une cause d'erreur difficile à éviter, quand on tient à conserver l'animal, je veux parler de petites fuites d'air, autour de la muselière employée. (Diesem Umstand legt B e r t uiberhaupt eine unverständlich hohe Bedeutung bei; die Schwierigkeit liegt in ganz anderen bereits geschilderten Verhältnissen.) Je me contenterai de vous dire, que j'ai chez ces animanx, comme chez les Oiseaux, obtenu un arrêt complet de la respiration, au moment même où je portais l'excitant électrique sur le nerf. J'ai donc eu arrêt en inspiration et en exspiration; l'animal dans ces cas restait complétement immobile. Une fois, il demeura ainsi gonflé en inspiration moyenne pendant quatre minutes, durant lesquelles le levier trace toujours dans la même ligne. Je désire, à cause de ce fait étrange, vous montrer ce tracé, sous le bénéfice de l'observation déjà faite.

Ich selbst habe mehrfach solche Versuche an tracheotomirten Ringelnattern angestellt, wobei die "petites fuites" natürlich nieht in Betracht kommen konnten, ohne aber jemals eine Athempause in In- oder Exspirationsstellung zu sehen. Vielmehr erfolgten sie, wenn iiberbaupt, stets bei Ruhelage. Doch möchte ich hieraus keineswegs folgern, dass Resultate, wie sie von P. B e r t beschrieben wurden, nicht doch unter gewissen Umständen zu erzielen wären. Freilich sprechen meine gleich zu erwähnenden zahlreicheren Erfabrungen an Eidechsen nicht eben sehr zu Gunsten einer solchen Annahme. Ich fand hier bei Vagusreizung eine in der Regel sehr ausgeprägte Pausenbildung, während deren de r

1) Mechanische Reizung, durch sanftes Reiben mittelst eines Glasstabes, durch Quetschung mit einer Pincette, oder durch centripetal angelegte Schnittserien erzeugt, geben der Reizung mit dem Induktionsstrom analoge Resultate. 
Thorax unter allen Umständen in Cadaverstell u $\mathrm{ng}$ verbarrte.

Bei Säugethieren (und wie vorläufig bemerkt sei, auch bei Vögeln) ist bekanntlich die Intensität der zur Reizung benutzten Ströme von sebr wesentlicher Bedentung für den jeweils hervortretenden Erfolg.

Pa a l Bert versuchte, hierauf gestützt, eine Theorie zu begründen, die es ermöglichen sollte, die Erfolge der centralen Vagusreizung zu beherrschen. Eine schwache Erregung, sagt er, beschleunige die Respiration, eine stärkere verlangsame sie und bringe sie endlich zum Stillstande. Dieser Satz hat sich schon längst als in seiner Allgemeinheit unrichtig herausgestellt; ebenso wenig ist es aber den zahlreichen Bemühungen späterer Forscher geglitckt, Bedingungen zu finden, unter denen mit Sicherheit bald die eine oder die andere, die anregende oder die hemmende Wirkung eintritt; "vergeblich", um die Eingangsworte einer neueren mit dieser Frage sich beschäftigenden Arbeit Langendorff's (46) zu citiren, „hat man die Stärke des Stromes und den Ermiidungszustand des Nerven, wie die Athemphase, in der der Reiz hereinbrieht, für den Erfolg verantwortlich zu machen gesucht; vergeblich hat man den Zustand des Centralnervensystems, sehwächere oder tiefere Narkose, Apnoe und Dyspnoe, Vorhandensein oder Fehlen gewisser Hirnabsehnitte berücksichtigt, hat man das Thier erwärmt und abgekühlt".

"Sogar dem Geseblecht der Versuchsthiere hat man einen bestimmenden Einfluss zugeschrieben (47). Jahre lang hat man sich sogar darïber in Zweifel befinden müssen, ob bei reinen Reizversuchen neben der inspiratorischen überhaupt eine exspiratorische Vaguswirkung existire, ob letztere nicht nur auf Versuchsfehler zurückzuführen sei.

So suchen denn nenere Autoren den Grund des wechselnden Erfolges in der "Individualität" des Thieres (48) oder in einer gewissen "Stimmung des Centralnervensystems" (49), ein nicht sehr ermuthigendes Zugeständniss, das es ganz natürlich erscheinen lässt, wenn der neueste Forscher (49) auf diesem Gebiete ausspricht, dass man niemals erwarten dürfe, von der centralen Vagusreizung eine bestimmte Wirkung zu erhalten, und dass man sich, besonders bei Schulversuchen, hüten müsse, den Reizeffekt vorhersagen zu wollen". 
Wenn dies alles nun für die Sängethiere, und, wie später nachgewiesen werden wird, auch für die Vögel durchaus richtig ist, so scheint dagegen die Erregung des Vagus bei Reptilien durch den Induktionsstrom immer konstante Resultate zu liefern, wenn meine an circa 20 Versuchsthieren gemachten Erfahrungen Anspruch auf eine derartige Verallgemeinerung machen dürfen. Hier ist es ziemlich gleichgültig, wie stark der Strom ist, oder in weleher Phase man den Reiz einbrechen lässt; Individualität, Stimmung des centralen Nervensystems spielen anscheinend keine wesentliche Rolle (Fig. 20, 21 Taf. III).

Das Räthselvolle in dem Effekte der Vagusreizung durch den Induktionsstrom wird dadurch freilich eher noch gesteigert; denn wir stehen damit der auffallenden Thatsache gegeniiber, das A usschaltung und Reizung eines Nerven denselben äusseren Erfolg haben.

Ich habe die Reizversuche stets bei erhaltenem Vagus der anderen Seite ausgefiuhrt, weil die bei doppelseitiger Vagisektion auftretende kolossale respiratorische Verlangsamung die Uebersichtlichkeit der Erfolge allzusehr beeinträchtigt.

Giebt man die Unwabrscheinlichkeit eines durch den Schnitt gesetzten dauernden Reizzustandes zu, so bleibt nur die Annahme eines Ueberwiegens der Erregung athmungshemmender im Vagus verlanfender Fasern iubrig. Dass ausserdem noch andere antagonistisch wirkende Fasern im selben Nervenstamm anzunehmen sind, ergiebt sich fraglos aus dem Erfolg. der Durchschneidung und den dadurch bedingten Ansfall "physiologischer" Reize.

In mehreren Fällen konnte ich übrigens nach der Reizung des centralen Vagusstumpfes mit dem unterbrochenen Kettenstrom und zwar sowohl bei auf- wie absteigender Richtung sehr ausgeprägte exspiratorische Wirkungen erzielen (Fig. 22, Taf. III), die im Allgemeinen mit wachsender Stromesintensität an Stärke zunehmen. Ein Unterschied in der Wirkung der Stromrichtung war nur insofern zu constatiren, als der aufsteigende Strom bei geringer Intensität stärkere Wirkung hervorbrachte, als der absteigende; doch glich sich diese Differenz schon bei Anwendung mittelstarker Ströme rasch aus. Der beigegebene Curvenausschnitt zeigt den Erfolg der Reizung in charakteristischer Weise. Der Hebel steigt sofort zu einer die normalen Exspirationsscheitel oft erbeblich iibersehreitenden Höhe empor, auf der er sich längere oder kür. 
zere Zeit hält, um dann ganz allmählich abzusinizen; bei längerer Dauer der Reizung kann der exspiratorische Tetanus völlig aufhören, indem der Thorax in eine der Gleichgewichtslage entsprechende oder wenigstens stark angenäherte Stellung zurickkehrt. Im Moment, wo der Stromkreis geöffnet wird, erfolgt eine als „negative Nachwirkung“ aufzufassende tiefe Inspirationsbewegung, die oft weit unter die normalen Inspirationsscheitel herabreicht, worauf die Respiration, ohne dass etwa Störungen in der Frequenz beobachtet werden könnten, almählich zur Norm zurückkehrt. Bemerkenswerth ist, dass dieser Effekt bei Reizung in allen Athemphasen erzielt wird.

Ich bin weit entfernt davon, zu glauben, dass inspiratorische Vaguseffekte bei Eidechsen überhaupt nicht zu erzielen wären. Auf das Vorhandensein inspiratorischer Vagusfasern deutet vielleicht die erwähnte negative Nachwirkung hin, wenn man mit Meltzer annehmen will, dass sie ebenfalls als Reizwirkung aufzufassen ist, die aber erst dann in Erscheinung tritt, wenn die Erregung der exspiratorischen Fasern bereits abgeklungen ist. Auch lässt sich in diesem Sinne vielleicht die Beobachtung Couvreur's (38) verwerthen, der am Caiman ausgeprägte inspiratorische Effekte bei Vagusreizung erbielt. Vor allem aber muss es als a priori wahrscheinlich gelten, dass die Beziehungen des $\mathrm{N}$. vagus zum Athemapparat bei allen Wirbelthierklassen im Wesentlichen tibereinstimmende sind.

Gesichert würde die Frage dann sein, wenn Versuche nach Analogie der Hering-Breuer'schen an Säugethieren auch bei Reptilien von gleichen Erfolgen begleitet wären. Meine Bemühungen in dieser Richtung lieferten leider keine ganz eindentigen Resultate.

Zuweilen kann man eine dentliche inspiratorische Oeffnung des Kehlkopfes bei jeder Aussaugung sehen, was im Sinne der Hering-Bre u er'schen Selbststeuerungstheorie za verwerten wäre; in anderen Fällen ist das Resultat aber durchaus negativ. Aufblasung bedingt zumeist andauernde Hemmung, die auch nach Sistirung der Lungendehnung oft noch erheblich lange Zeit anhält. In einem Falle jedoch trat unmittelbar nach jeder Aufblähung eine beträchtliche Beschleunigung der $\mathrm{Ath} \mathrm{m} \mathrm{ung}$ auf, die durch reine Exspirationsbewegungen ohne ansehlies- 
sende aktive Inspiration ausgezeichnet war, während die Aussaugung resultatlos blieb.

Bindende Schlüsse lassen sich aus diesen Beobachtungen natïrlich nicht ziehen; doch erscheint es mir als durchaus wahrscheinlich, dass ein genaueres Studium in dieser Richtung zu Ergebnissen fübren dürfte, die sich zu den Beobachtungen bei Vögeln und Säugethieren in Parallele setzen liessen.

Ehe ich den Abschnitt iber Vagusausschaltung und Vaguserregung schliesse, möchte ich noch einige kurze Bemerkungen iiber den Einfluss sensibler Nerven auf die Athmung anschliessen, da meine Beobachtungen sich in wenigen Sätzen erledigen lassen.

Bei ruhig und regelmässig athmenden Eidechsen rufen leichte Hautreize, wie Anblasen der Haut, Betupfen derselben, Erschiitterungen des Thieres u. s. w. in der Regel eine momentane Steigerung der Athemthätigkeit hervor, wobei, wie die graphische Verzeichnung leicht erkennen lässt, namentlich die exspiratorische Phase betheiligt erscheint, indem der Hebel weit über die normalen Curvenzipfel emporschnellt.

In minderem Grade erscheint auch die Inspiration verstärkt.

Bei sehr schwachen Reizen ist oft nur eine einzige Respirationsbewegung in dem beschriebenen Sinne abgeändert, worauf nach einer in der Regel etwas kürzeren Pause, als der Norm entspricht, seltener nach einer längeren Athemruhe, der regelmässige Typus zurïckkehrt.

Lässt man den Reiz zu Beginn einer Pause einwirken, so wird dieselbe stets coupirt; die Steigerung der motorischen Aktion ist um so beträ.chlicher, je näher der Moment des Reizes an den Eintritt einer neuen Respirationsbewegung heranriickt, und im Allgemeinen am stärksten, wenn er während der ex-oder inspiratorischen Phase einbricht, was wohl durch Veränderungen der centralen Anspruchsfähigkeit bedingt sein dürfte, die offenbar nach Ablauf einer Athembewegung am geringsten ist und erst im Verlauf der Athemruhe wieder ansteigt.

Bei Anwendung stärkerer Reize (kräftiges Kneifen der Haut, Berührung mit einem erhitzten Glasstabe u. dgl.) treten bisweilen stärkere reflektorische Hemmungswirknngen hervor, obschon in der Mehrzahl der Fälle auch dann den geschilderten ähnliche Reizerfolge zu beobachten sind.

Lässt man starke Reize öfters hintereinander an derselben 
Stelle einwirken, so stumpft sich die Empfindlichkeit allmählich ab; in der Regel lässt sich aber dann von einer anderen Hautstelle sofort wieder ein erregender oder hemmender Effect auslösen.

Reizung des centralen Ischiadicusstumpfes mit starken Inductionsströmen erweist sich in der Regel in gleichem Sinn wirksam.

Lässt man ganz schwache Ströme auf den Nerven wirken (am besten unterbrocbene Kettenströme), so kann man oft sehr deutlich den anregenden Einfluss derselben constatiren.

Nach Ablauf der ersten meist erheblich verstärkten Athmung oder einer etwas verlängerten Pause macht sich in der Regel eine bedeutende Beschleunigung der Athemfrequenz geltend, die unter Umständen so hochgradig werden kann, dass sie die normalen Werthe um mehr als das Doppelte übersteigt, wobei dann die Pausen fast völlig verschwinden.

Nach Beendigung der Reizung stellt sich nur ganz allmählich wieder die ursprüngliche Frequenz ein.

Ganz ähnliche Wirkungen kann man übrigens gar nicht selten auch dann beobachten, wenn eine Hautstelle in kurzen Intervallen (alle 1-2 Secunden) durch Beribhrung mit einem zarten Pinsel schwach gereizt wird.

Oft äussert sich der Erfolg in diesem Falle nur in einer immer zunehmenden Beschleunigung der Atbmung, die bisweilen geradezu excessive Werthe erreicht und der Zahl der einwirkenden Reize annähernd gleichkommen kann.

Dasselbe Resultat vermochte ich iibrigens auch an grosshirn. losen Thieren zu erzielen.

Da man von allen Hautstellen des Rumpfes und der Extremitäten ganz gleiche respiratorische Wirkungen erhält, so kann man den für die Säugethiere geltenden und von $\mathrm{K}$ n 011 neuerdings auch für den Frosch nachgewiesenen Satz auch auf die Reptilien ausdehnen, "dass nämlich eine schwache Reizung beliebiger sensibler Hautnerven von einer erregenden Wirkung begleitet ist, die sich nicht so sehr in rascherem Verlauf und grösserer ex- resp. inspiratorischer Amplitude der einzelnen Respirationsbewegung äussert, als vielmehr in einer oft recht erheblichen Steigerung der Frequenz".

Bei Anwendung stärkerer Reize tritt im Allgemeinen mehr die Hemmung und Verlangsamung in den Vordergrund.

Plötzliche Beschattung der Augen ruft bei Eidechsen eine Verlangsamung der Athemfrequenz hervor, plötzliche Beleuchtung 
steigert dieselbe umgekehrt. Da dies Phänomen nur bei Vorhandensein beider Hemisphären des Grosshinrs auszulösen ist, so scheint es psycho-reflectorisch bedingt zu sein.

Akustische Reize (Klatschen der Hände, Anschlagen an eine Metallglocke) wirken im Allgemeinen äusserst schwach und stumpfen sich ausserordentlich rasch ab. In der Regel ruft die akustische Erregung eine etwas längere Pause hervor mit nachfolgender dauernder Steigerung der Frequenz; oft freilich lässt sich ein nennenswerther Effect überhaupt nicht erzielen, und regelmässig wird er vermisst nach Exstirpation des Grosshirns.

Sehr charakteristisch ist auch bei den Reptilien die athmungshemmende Wirkung der Reizung der Endausbreitungsgebiete des Nervus trige min us in den Anfangstheilen des Respirationstractus. Man beobachtet dann in der Regel einen bald kürzeren, bald längeren Stillstand der Athembewegungen, dem meist eine Reihe flacherer und vor Allem durch längere Pausen getrennter Athmungen folgen. Die Hemmungswirkung dieser Nerven ist zweifellos mebr ausgesprägt, als die erregende anderer Sinnesnerven; in der Regel geniigt schon ein leichter und nur kurzdauernder Reiz, um eine deutliche Wirkung hervorzurufen, die den Reiz selbst oft beträchtlich iiberdauert.

Taucht man eine Eidechse mit dem Hiuterkörper in Wasser, das etwas über Zimmertemperatur erwärmt ist, so bleibt die Athmung nach einem vorïbergehenden Stillstand im Wesentlichen unverändert; sie wird aber sofort gehemmt, sobald die Schnauze bespült wird. Der Stillstand dauert oft ziemlich lange, dann folgen in grösseren Intervallen leichte Kehlbewegungen und abortive Athmungen, bei welchen fast immer der aktiv inspiratorische Phasentheil unterdrückt erscheint.

Einen ganz ähnlichen Erfolg hat auch Einathmen von Chloroform, während Ammoniak und Aether schwächer wirken.

Reizung der Schleimbaut des Rachens und der Mundböhle bewirkt ebenfalls längeren Stillstand der Atlımung, und die lange Athmungsruhe, die K n o 11 bei gewaltsamem Oeffnen der Mundhöhle am Frosche beobachtete, und die ebenso stets bei den Reptilien in Erscheinung tritt, glaube ich mit ihm gleichfalls auf eine Reflexwirkung vom Trigeminus aus zurïckfuihren zu dürfen.

Die Hemmungswirkung tritt immer sofort im Beginn der Reizung ein; jede begonnene Respiration wird augenblicklich cou- 
pirt; der Kehlkopf als Ganzes und das Zungenbein nehmen Ruhestellung ein, während der Schreibhebel bei graphischer Verzeichnung der Atbmung eine der Rubelage des Thorax entsprechende Horizontale verzeichnet.

Gleichzeitig tritt ein krampfhafter Verschluss des Sphincter laryngis ein. Stösst man in dem Moment, wo der Aditus laryngis sich maximal erweitert hat, einen dünnen Glasstab in den Kehlkopf hinein, so beobachtet man, wie zu erwarten war, ganz analoge Reflexerscheinungen; nach längerer Athemrahe treten dann ebenfalls abortive Respirationsbewegungen auf und zwar wieder im Sinne einer Unterdruickung der aktiv inspiratorischen Theilphase. Da der Reiz hier andauernd einwirkt, erfordert es meist lange Zeit, bis die Athmung wieder annähernd normal geworden ist.

Auch bei Thieren, deren Athmung durch Vagisektion ausserordentlich verlangsamt worden ist, lassen sich die eben geschilderten Reflexe von Haut und Schleimhäuten in ungefähr analoger Weise auslösen, und namentlich tritt die Steigerung der Frequenz sehr schön hervor, wenn eine und dieselbe Hautstelle wiederholt schwach gereizt wird.

Auch kann man jederzeit während der langen Pause reflektorisch eine oder auch mehrere Athembewegungen auslösen und so eine Athemfrequenz erzeugen, die sich der der normalen bis za einem gewissen Grade nähert.

Bei winterschlafenden Eidechsen, deren Respirationsapparat im Zustande völliger Unthätigkeit verharrt ${ }^{1}$ ), lässt sich, wenn man sie durch Erwärmung zum Erwachen bringt, leicht folgende Reihenfolge der Erscheinungen beobachten.

Das erste Zeichen des Wiedererwachens sind meist leichte Kehlbewegungen, die, anfangs kaum sichtbar, allmählich kräftigeren Contraktionen des Mundbodens weichen.

Dann folgen die ersten schwachen Respirationsbewegungen, welche anfangs noch der aktiven Inspirationsphase entbehren, die erst einige Zeit später die Athmung in normaler Weise ergänzt.

Um diese Zeit offnet das Thier die Augen, der vorher erloschene Cornealreflex lässt sich von neuem nachweisen. Der Unterkiefer, den man bei tiefer schlafenden Thieren oft, seiner Schwere

1) Es ist interessant, dass Fano von einer periodischen Athmung winterschlafender Schildkröten zu berichten weiss. 
folgend, nach unten gefallen vorfindet, ist schon vorher wieder durch Muskelaktion dem Oberkiefer angepresst worden, und das Thier leistet dem Versuch, das Maul zu öffnen, energischen Widerstand.

Jetzt lassen sich auch schon Reflexe von der Haut auf das Athemcentrum deutlich auslösen; in der ersten Zeit fast ausschliesslich Kehlbewegungen, erst später typische Respirationen. Ganz allmählich erwacht schliesslich auch die Reflexerregbarkeit der übrigen willkïrlichen Muskulatur und nach und nach gewinnt das Thier die Herrsehaft über seine Glieder völlig wieder.

Es ist hier vor Allem die Thatsache hervorzuheben, dass die Kehlbewegungen früher auftreten und sich auch reflektorisch im Allgemeinen leichter auslösen lassen, weil man diese Erfahrung auch sonst sehr häufig zu machen Gelegenheit hat; leichte Hautund Vagusreize, die im Uebrigen keine Wirkungen zeigten, lösen oft eine oder eine Reihe von Kehlbewegungen aus, woraus man schiessen muss, dass das ihnen vorstehende Centrum im Allgemeinen ein leiehter erregbares sein muss, als das eigentliche Athemcentrum.

\section{G. Das Athemcentrum und die Kellathmung der Reptilien.}

Kaum dürfte es in der Physiologie eine zweite seit alten Zeiten soviel und von so verschiedenen Standpunkten aus erörterte Frage geben, wie die nach der Lage und der Natur des Athemcentrums. Seit Le gallo i s' (50) berïhmter Entdeckung des beherrschenden Einflusses, welchen bei allen Wirbelthieren die Mcdulla oblongata auf die Athmung ausizbt, und seit F l o u rens (51) in seinem "Noeud vital" die Stelle näher begrenzte, deren Zerstörung in jedem Falle ein dauerndes Erlöschen der Athembewegungen und damit früher oder später den Tod des Thieres zur Folge hat, ist dieses Thema stets ein Lieblingsgegenstand physiologischer Forschung geblieben.

Leider kann man aber ungeachtet der ungeheuren darïber vorliegenden Literatur nicht sagen, dass in allen Punkten erwünschte Klarheit herrscht, und selbst die Existenz eines Athemcentrums in der Oblongata gehört in neuester Zeit wieder zu den vielumstrittenen Fragen.

Gerade in Bezug auf diesen letzterwähnten Punkt möchte es scheinen, dass Untersuchungen an Kaltblütern viel eher sicheren 
Aufschluss versprechen, als die bisher stets mit Vorliebe benützten Warmbluiter. Ist doch die Widerstandsfähigkeit des centralen Nervensystems eine unvergleichlich viel grössere als dort. Wie sich indessen aus den folgenden Mittheilungen ergeben wird, sprechen die Resultate durchaus zu Gunsten der ä̀lteren Anschauung, wonach der Med. oblongata in der That eine beherrschende Rolle bezüglich der Innervation des ganzen Athemmuskelapparates zuzuschreiben ist.

Eine weitere Frage bezieht sich auf die Natur des die normalen Athembewegungen auslösenden Reizes.

Ausgehend von Erfahrungen, welche sich fast ausschliesslich auf die bei Warmbliutern gegebenen Verhältnisse beziehen, und im Himbliek auf die unleugbare Thatsache, dass das Blut und speciell der wechselnde Gasgehalt desselben hier nicht nur bei der Auslösung des ersten Athemzuges, sondern auch im späteren Leben eine iuberaus wichtige Rolle spielt, hatte man sich vielfach die Ansiebt gebildet, dass überhaupt die rhythmische Innervation von Seiten des Athmungscentrums durch den "Blutreiz" verursacht sei.

Am unzweideutigsten findet sich diese Anschaung wohl in dem 1862 erschienenen Buch von Rosenthal (52) über die Athembewegungen ausgesprochen. Es werden hier dieselben nicht in dem Sinne als automatische bezeichnet, dass das Athmungscentrum vermöge ihm als solchem innewohnender Eigenschaften aus sich selbst thätig sein müsste, vielmehr würde es erst vom Blute aus die Anregung zu seiner Thätigkeit empfangen.

Es konnte nicht fehlen, dass mit der fortschreitenden Erweiterung der Kenntnisse auf unserem Gebiete diese Annahne sich sebr bald als unhaltbar erweisen musste. $\mathrm{Hall}$ e r (53).

„Etiam evulso corde potest respiratio superesse" sagt bereits

V o l k m a n (54) entfernte bei einer jungen Katze (ebenso bei Hunden) ausser Gehirn und Vagi noch die Lungen mit Schonung der Zwerchfellnerven und sah die Athmung noch vierzig Minuten weiter bestehen, obwohl hierbei doch der Kreislauf vollständig unterbrochen war.

Auch Markwald hat gelegentlich solche Beobachtungen machen können; so sah er bei einem Hunde, welcher nach einem Blutdruckversuche durch einen Stich in's Herz getödtet worden 
war, Athmungen weiter gehen, obwohl das Herz flimmerte und die künstliche Respiration unterbrochen war.

Hierauf wurde das Aortensystem von der Carotis aus mit Paraffin injicirt, welches, wie die Autopsie lehrte, alle Hanptäste gefuillt hatte. Dessen ungeachtet machte der Hund noch mehrere Minuten lang Athmungen in regelmässigen Intervallen.

Aeusserst interessant ist ferner eine hierher gehörige Beobachtung desselben Forschers an einem winterschlafenden Murmelthiere, wo nicht, wie bei Reptilien in diesem Zustande, die Athmung anscheinend ganz aussetzt, sondern zwar äusserst verlangsant, trotzdem aber regelmässig fortdauert. Frappirend ist die A ehnlichkeit der Curvenbilder, die er bei Verzeichnung von einem

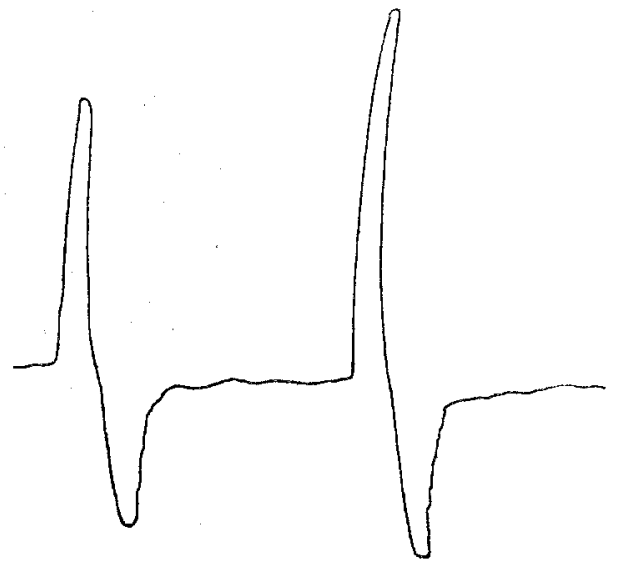

Fig. 6.

Athmungstypus eines winterschlafenden Murmelthieres (nach Markwald).

Seitenende der Trachealkanüle aus gewann, mit jenen der normalen Reptilienathmung (Fig. 6). Bezuiglich der Deutung derselben möchte ich mich allerdings der Auffassung Markwald's nicht anschliessen, sondern der Vermuthung Ausdruck geben, dass es sich in beiden Fällen im Wesentlichen um die gleiche Folge von Erscheinungen handelt. Nicht eine aktive, sondern viel mehr eine passive Exspiration würde demnach den Uebergang zur Ruhestellung des Thorax vermitteln.

Durch Eröffnung beider Carotiden liess dann Markwald das Thier sich verbluten und schnitt schliesslich auch noch das Herz heraus.

„Trotzdem börte die Athmung nicht auf. Die Athemzüge folgten sich vielmehr regelmässig weiter und zwar noch eine halbe Stunde lang im Intervall von einer Minute; nur waren die Respirationen flacher und länger, zumal die aktive Exspiration weniger ausgesprochen und sehr lang bingezogen. Das ausgeschnittene 
Herz pulsirte ebenfalls noch eine Zeit lang weiter, 5-6 mal in einer Minute."

Dies Experiment ist für uns übrigens auch deshalb noch besonders lehrreich, weil es an einem gewissermaassen kaltblïtig gewordenen bomoiothermen Thiere ausgefuhrt wurde und beweist, dass in diesem Falle auch beim Warmblüter die Excitationserscheinungen der hämorrhagischen oder der Gasdyspnoe fehlen.

Es spricht dies, wie man sieht, sehr zu Gunsten der schon früher geltend gemachten Annahme, dass der Unterschied in den Erscheinungsformen der Gasdyspnoe bei Warm- und Kaltblïtern kein prinzipieller genannt werden kann, sondern nur auf der grossen zeitlichen Verschiedenheit in der Entwickelung der der Erregung zu Grunde liegenden dissimilatorischen Prozesse bei Störungen des nutritiven Gleichgewichtes beruht.

Ros e nth a l selbst zeigte endlich, dass Athembewegungen auch auftreten, wenn an einem apnoisch gemachten Thier (Kaninchen) unter Fortsetzung der Lufteinblasungen die zum Gehirn aufsteigenden Gefässe verschlossen werden, und ebenso gelingt es leicht, sich von dem Vorhandensein von Athembewegungen an abgeschnittenen Köpfen zu überzeugen.

Des Weiteren ist mit Pflüg e r darauf hinzuweisen, dass die meisten so iiberaus lebhaft athmenden Insekten iberhaupt gar kein gefärbtes Blut besitzen, und dass auch Frösche, deren Blut durch $0,6 \%$ Kochsalzlösung ersetzt wurde, noch lange ganz regelmässige Athembewegungen erkennen lassen, und dasselbe kann man jeder Zeit mit Leichtigkeit an Reptilien bez. Eidechsen sehen, deren Circulation durch Aussehneiden des Herzens vollständig und dauernd unterbrochen ist.

Es kann demnach nicht der geringste Zweifel dariber bestehen, dass dem Athmungscentrum an s i ch (autochthon) die Fähigkeit zukommt, Erregungsimpulse in sich zu entwickeln und auszusenden, und dass es in dieser Beziehung durchaus mit anderen rhythmisch thätigen Organen und Organelementen (Herz, Flimmerbewegung etc.) vergleichbar erscheint. Die eigentliche Ursache der Entwickelung von Reizen innerhalb der centralen Nervensubstanz ist aber nicht sowohl im Gasgehalt ihrer unmittelbaren Umgebung, als vielmehr in Stoffwechsel derselben begrïndet und demgemäss natürlich auch von der normalen Ernährung resp. der Blutversorgung abhängig. 
Im gleichen Sinne äusserte sich später auch Rosenthal (56) (Cap. Athmung in Hermann's Handb. p. 272), indem er die Vorstellung eines von a us en auf die nervösen Apparate einwirkenden Reizes ganz aufgiebt und "die Vorgänge in den Ganglien des Gehirns an chemische Prozesse gebunden sein lässt, welche von der Beschaffenheit des Blutes abhängen, das in den Capillaren circulirt. Wenn dieses Blut reichlich mit Sauerstoff versehen ist, so sind die Vorgänge andere als im entgegengesetzten Falle".

„Darnach ist also das Blut nicht dir ekt als Reiz aufaufassen in dem Sinne, dass obne dasselbe die Reizung nicht zu Stande kommen könne, sondern nur als die Bedingung, von welcher das Zustandekommen des Reizes, wenn man diesen Ausdruck überhaupt noch gebrauchen will, abhängt. Und wenn diese Bedingungen sich o h $\mathrm{ne}$ Blut in der Nervensubstanz in der nämlichen Weise entwickeln, als bei sanerstoffarmem Blut, so müssen die Erscheinungen in beiden Fällen dieselben sein." (1. c. p. 272.)

Bei der äusserst mangelhaften Kenntniss, die wir z. Zeit noch von der eigentlichen Natur der chemischen Stoffwechselprozesse innerhalb der centralen Nervensubstanz besitzen, erscheint es kaum am Platze, sich in weitere Spekulationen über das Wesen derselben und die Ursache rhythmischer Reizauslösung im Athmungscentrum einzulassen. Im Grunde lässt sich zur Zeit hieriber ebensowenig etwas Sicheres aussagen, wie in allen anderen Fällen rhythmisch ablaufender Erregungserscheinungen.

Dazu kommt. bei der Reptilien- (und Vogel-)Athmung noch der weitere complicirende Urnstand, dass es sich hier nicht nur um eine regelmässige Abwechselung von Ruhe und Thätigkeit eines in funktioneller Beziehung einheitlichen Nervenapparates handelt, wie es wenigstens unter normalen Verhältnissen bei dem Athemcentrum der Säugethiere der Fall ist, wo die Exspiration in der Regel rein passiv verläuft, sondern um ein völlig gleichwerthiges Wechselspiel zwischen In- und Exspiration, wobei der a $k \mathrm{t}$ ive Charakter der letzteren in jedem Falle deutlich hervortritt.

Man wird dies vorläufig kaum in anderer Weise deuten können, als durch die Annahme einer in bestimmtem Sinne coordinirten Thätigkeit verschiedener Theile des, ,A themeentrums", ohne dass man dabei etwa mit Be rnstein (57) an eine qualitativ verschiedene Reizursache fiir das „In- und Exspirationscentrum" denken miisste. Besonderes 
Gewicht möchte ich mit Rücksicht auf gewisse seiner Zeit von J. G a d (58) geäusserte Anschaungen auf den Umstand legen, dass, sofern man die Athmung der Reptilien (und Vögel) mit berücksichtigt, durchaus kein Grund vorliegt, den der In- und Exspiration vorstehenden Nervenmechanismen eine ganz verschiedene Werthigkeit beizumessen in dem Sinne, „dass Ganglienzellen mit der genügenden Empfindlichkeit gegen den normalen Blutreiz uur in Inspirationscentren und nicht in Exspirationscentren vorkommen".

Im Gegentheil wird man hier, wie ich glaube, mit genau derselben Berechtigung von einem automatischen Exspirations- wie von einem automatischen Inspirationscentrum sprechen dürfen.

Die Erscheinungen der Dyspnoe durch Verschlechterung der Lüftung der Med. oblongata, auf welche $G$ a d besonderes Gewicht legt, indem hierbei stets eine überwiegende Vermehrung der In spirationsanstrengung sich entwickelt, lassen sich in unserem Falle allerdings nicht geltend machen, da, wie gezeigt wurde, eine Verstärkung der Athembewegungen bei Reptilien unter diesen Umständen überbaupt nicht erfolgt. Indessen ist dies bei $V \ddot{o} g$ eln jederzeit und zwar gleich im $B$ e $g$ in $n$ der Dyspnoe nachweisbar.

Es wurde oben schon bemerkt, dass Langendorff (8) bei seinen Bestrebungen, das Athemcentrum zu decentralisiren, auch bereits Reptilien (Eidechsen) in das Bereich seiner Untersuchungen gezogen hat. Da man erwarten durfte, dass alle jene Störungen, welche bei Warmblütern das Hervortreten der automatischen Funktion primärer (spinaler) Athemmuskelcentren verhindern resp. erschweren sollten, bei Kaltblütern in viel geringerem Grade sich bemerkbar machen würden, so schienen Versuche an solchen in der That sehr aussichtsreich. Leider entsprechen die Erfolge keineswegs den gehegten Erwartungen, und ich muss L a $\mathrm{n}$ ge $\mathrm{n}$ d orff auf Grund meiner eigenen Erfahrungen durchaus widersprechen. Ich werde dieselben im Folgenden, soweit sie sich auf die nach Durchschneidungen und Exstirpationen im Bereich der oberen Abschnitte des Centralnervensystems hervortretenden Folgeerscheinungen beziehen, übersichtlich zusammenstellen.

Die Exstirpation des Grosshirns lässt sich bei Eidechsen fast ebenso leicht wie bei Fröschen und anch in ganz ähnlicher Weise ausführen. Man fixirt das Thier in Bauchlage, hält mit der linken Hand den Kopf fest und entfernt mittels einer feinen Knochen- 
zange vorsiehtig das Schädeldach. Nach Blosslegung des Grosshirns umfasst man mit einem flachen breiten Haken die eine Hemisphäre von unten und hebt sie sanft empor; wobei durch den Zug gleichzeitig auch die andere mit gehoben wird; man sieht dann auf die Oberfläche des Mittelhirns und den Ort, wo die Hemisphären des Grosshirns mit der Umgebung verbunden sind. Nachdem man durch leichte Reinigung mit Huilfe eines nassen Wattebausches noch einmal das Operationsfeld ïbersichtlich gemacht, führt man ein feines spitzes Messer zwischen Mittelhirn und Unterfläche des Grosshirns ein, und indem man den Messerriicken anfangs gegen die seitliche Schädelwand richtet, führt man die Schneide in einem raschen Zug nach der anderen Seite, gleichzeitig die Spitze in die Tiefe bohrend, bis sie die Basis des Schädels berïhrt.

Man thut hierbei gut, das Messer in einer schrägen Richtung zu fuihren, sodass die Spitze nicht senkrecht, sondern in einer Ebene gefïhrt wird, die man sich von hinten oben nach unten vorn gelegt denkt, weil sonst leicht die vordersten basal gelegenen Theile des Mittelhirns mit in den Bereich des Sehnittes gelangen.

Der trennende Schnitt ist von intensiven Reizerscheinungen seitens der gesammten Körpermuskulatur begleitet, die sich weniger in tonischen resp. klonischen Krämpfen, als vielmehr in Bewegungen äussern, die coordinirten Reflexen gleichen.

Es ist verständlich, dass dieser letztere Theil der Operation unter keinen Umständen ohne Eröffnung grösserer arterieller und venöser Blutbahnen durchgefiihrt werden kann. Das sicherste Mittel, um der abondanten Blutung in kiirzester Zeit Herr zu werden, besteht in der an den trennenden Schnitt sich sofort anschliessenden raschen Ausräumung der gesammten Grosshirnmasse and darauf folgenden Tamponirung der Höhle mit Watte.

Eine äusserst bequeme Methode, um fast ohne irgend welchen Blutverlust Grosshirn and Mittelhirn zu entfernen, stellt die folgende Operation dar:

Man führt den einen Arm einer dünnen, aber scharfen, einfachen Scheere in die Mundhöhle nach hinten und stellt ihn so, dass die Schneide dem harten Gaumen anliegt, und zwar senkrecht zur Längsaxe der Gaumenplatte; die andere Branche wird dann dem äusseren Schädeldach angedrüekt; man sucht nun 
einen Punkt, der ca. $2 \mathrm{~mm}$ vom hintersten Schädelpol entfernt ist; ein einziger kräftiger Scheerenschlag bewirkt eine völlige Trennung des vorderen Schädels sammt den in ihm enthaltenen Gehirntheilen von den hintersten Parthien.

Wie man sich leicht iiberzeugen kann, ist durch den Schnitt das Grosshirn und Mittelhirn vollkommen ausgeschaltet; manchmal ist auch das Kleinhirn mit betroffen, seltener die hinterste Parthie des Mittelhirns stehen geblieben, die dann leicht noch nachträglich entfernt werden kann. Ein kleiner Wattebausch, den man jetzt vor die weite Wunde legt, verhindert fast jeden Blutverlust, wobei man allerdings sich hüten muss, die jetzt frei sichtbare Glottisöffnung mit zu verlegen.

Es ist selbstverständlich, dass jede Verletzung oberhalb der M. oblongata gelegener Hirntheile anch die normale Athmung stets für längere oder kürzere Zeit störend wird beeinflussen müssen.

Ich habe die Erfahrung gemacht, dass, wenn man der Blosslegung des Gehirnes den trennenden Schnitt unmittelbar nacbfolgen lässt, der Eingriff viel schwerer ertragen wird und weit länger dauernde Störungen des normalen Athemrhythmus zur Folge hat, als wenn man zweizeitig operirt. Ich pflegte daher später immer mehrere Stunden zwischen den beiden Akten der Operation, Trepanation und Exstirpation verstreichen zu lassen.

Die der Exstirpation folgenden Störungen der Respiration sind mannigfaltiger Art, Perioden in sich ungleicher Athmungen spielen hierbei die wichtigste Rolle und werden durch lange Pausen von einander getrennt; dann findet man auch zeitweise abortive Athmungen, bei denen entweder der aktiv-inspiratorische, seltener der aktiv-exspiratorische Phasentheil eliminirt ist, eventuell wohl auch kurze Stadien einer gesteigerten Frequenz, die bald ins Gegentheil umschlagen können, kurz alle nur möglichen Abweichungen vom normalen Typus, die sich deutlich genug als Folgewirkung der schweren Hirnreizung, wie sie sich auch in den uibrigen Erscheinungen auf dem Gebiete der gesammten Körpermuskulatur ausprägt, erweisen.

Sind alle der Operation unmittelbar folgenden Reizungserscheinungen abgeklungen, so gewinnt die Athmung eine ausserordentliche Regelmässigkeit und behält diesen Charakter bei, so lange das Thier lebt.

Fast immer macht sich eine erhebliche, $d$ a $u$ e r $n d$ e Steige- 
rung der Respirationsfrequenz bemerkbar, die indessen nur selten so hohe Werthe erreicht, wie man unter gleichen Umständen bei Vögeln findet.

Es scheint sich hier um eine ähnliche Erscheinung zu handeln, wie bei der bekannten Steigerung der Reflexerregbarkeit nach Exstirpation der Grosshirnhemisphären (die übrigens auch bei Eidechsen immer sehr überzeugend hervortritt).

Bei den überaus störenden Schwankungen der normalen Athemfrequenz der Reptilien können natürlich alle Beobachtungen iiber irgend welche Abweichungen von der Norm nur dann als voll beweisend gelten, wenn die Unterschiede über die Grenzen der gewöhnlichen Schwankungen hinausgehen.

Gelegentlich findet man, dass längere Reihen normaler Respirationen in ziemlich regelmässigen Intervallen vion Athmungen mit durchaus abweichendem Charakter unterbrochen werden.

In einem Falle, von dem Fig. 23 Taf. III einen Ausschnitt darstellt, handelte es sich um ein Thier, bei dem der das Grosshirn abtrennende Schnitt eine ganz gewaltige Steigerung der Frequenz hervorgebracht hatte, wodurch die sonst vorhandenen Ruhepausen, wie in der Aethernarkose, ganz in Wegfall kamen.

Von Zeit zu Zeit schieben sich nun zwischen Reihen normaler Athmungen eigenthümlich complicirte Athembewegungen ein, indem eine regelrechte, aktive Exspiration nicht sofort, sondern allmählich in Inspiration ïbergeht, wobei der Schreibhebel eine nach unten leicht convexe Curve oberbalb der Ruhelinie verzeichnet.

Dann erfolgt ein rapider Abfall noch unter das Niveau der vorausgegangenen inspiratorischen Scheitel, dem sofort eine energische Ausathmung sich anschliesst, welche den Hebel meist über die normale exspiratorische Gipfelhöhe emporhebt. In der Regel folgt dann unmittelbar wieder eine Inspiration, die aber nur selten die Tiefe der vorhergehenden erreicht und ziemlich rasch in die normale Ruhelage, immer unter Bildung einer leichten Zacke, zurückgeht. Die nun folgende längere Pause wird meist durch eine in ihrer Form etwas abnorme Exspiration unterbrochen, worauf sich sehr bald der regelmässige Rhythmus wieder herstellt, um schliesslich früher oder später nenerdings atypischen Athmungen zu weichen.

Es ist sicher berechtigt, diese eben geschilderten eigenthïm- 
lichen Phänomene in Parallele mit den bei Aethernarkose zu beobachtenden Erscheinungen zu setzen und ihre Entstehung auf an sich nicht näher definirbare Zustandsänderungen des centralen Nervenapparates zurückzuführen; jedenfalls bürgt ihre Inconstauz bei den verschiedenen Thieren und ferner die Thatsache, dass sie nach einiger Zeit verschwinden können, genugsam dafür, dass sie keineswegs als regelmässige Ausfallerschein ungen a ufgefasst werden diurfen, was ja a priori im höchsten Grade unwahrscheinlich wäre.

Nach Ausführung der Tracheotomie entwickelt sich dann in der Regel bald eine sehr ausgeprägte Kopfdyspnoe, während gleichzeitig auch die Kehlkopfbewegungen noch fortbestehen.

Durchschneidet man dagegen bei einer in mässiger Dyspnoe befindlichen Eidechse nach Ausschaltung des Gross- und Mittelhirns successive die Oblongata in der. Richtung von vorn nach hinten, so kommt man bald an eine Stelle, wo plötzlich die Bewegungen des Maules verschwinden, während die eigentliche Rippenathmung noch ungestört fortbesteht.

Mit Volkmann (54) darf man wohl hieraus den Schluss ziehen, dass die Athembewegungen in jedem Körpertheil augenblicklich aufhören, wenn dessen Verbindungen mit dem bulbären Athemeentrum unterbrochen worden sind.

Eine gegentheilige Anschauung wurde in neuerer Zeit insbesondere von Langendorff aufgestellt und, wie schon erwähnt, unter Anderem auch durch Versuche an Eidechsen zu stützen versucht.

Nach Lange n d orff (59) sind die motorischen Kerne der Athemmuskeln, die "Centren zweiter Projection", nicht nur reflektorisch erregbar, sondern automatisch thätig, während das bulbäre Centrum nur einen Hílfsapparat darstellen soll, ein respiratorisches Coordinationscentrum, das die coordinirten Thätigkeitsimpulse der eine $\mathrm{ph}$ y s i o log is $\mathrm{ch}$ e $\mathrm{E}$ in be it darstellenden spinalen Centren modificirt.

Eine Beobachtung bei Eidechsen scheint nun in unwiderlegbarer Weise für diese Anschauung zu sprechen.

„Durcbschneidet man bei einer kräftigen und lebhaften Eidechse im (Sommer) das Rückenmark dicht unterhalb der Medulla oblongata, so treten, nachdem bald längere, bald kürzere Zeit die Ath- 
mung stillgestanden hat, aufs Neue rhythmische Athembewegungen auf und dauern dann stundenlang fort.

Die Athmungen sind von den vor der Operation zu beobachtenden verschieden. Sie sind erstens langsamer, die Einzelathmungen folgen einander in Zwischenräumen von $1 / 2$ bis 1 Minute, selten in kürzeren, zuweilen in längeren Zeiträumen.

Sie bestehen ferner aus einer etwa im Laufe von 5 bis 10 Seeunden bis zum Maximum ansteigenden Exspiration und einer sich daran anschliessenden, erst mit grösserer, dann mit geringerer Geschwindigkeit erfolgenden Inspiration. Es folgt eine lange Inspirationspause, danach wieder die Ausathmung und so fort.

Hat die Inspiration vor der Pause nicht ihr Maximum erreicht, so geht der Ausathmung meistens noch eine kleine inspiratorische Senkung des Zeichenhebels unmittelbar voraus.

Auch ohne graphische Hiilfsmittel lassen sich diese Bewegungen durch Beobachtung des Brustkorbes leicht erkennen.

Nach dem, was eben über die normale Athmungsform der Eidechsen mitgetheilt worden ist, liegt also eine zweifellose Aenderung derselben vor. Die Aenderung ist aber keine sebr bedeutende, da sie im Wesentlichen auf einer nicht einmal erheblichen Abnahme der Steilheit der Inspiration und auf dem Fortfall des postinspiratorischen Partialcollapses beruht. Auf alle Fälle ist durch die mitgetheilten Versuche bewiesen, dass bei der Eidechse spinale Athemeentren bestehen, die ohne Hilfedes Kopfmarkes a tomatisch zu funktioniren und längere Zeit hind ureh die Athembewegungen zu erhalten im Stande sind."

Ich habe bereits erwähnt, dass ich ungeachtet ziemlich zahlreicher Versuche, die ich mit Rücksicht auf die schwebende Frage anstellte, auch nicht in einem einzigen Falle hoher Rückenmarkdurchschneidung Gelegenheit fand, mich von einer automatischen Spinalathmung zu überzeugen.

Die operirten Thiere liegen durchaus ruhig in der ersten der Durchtrennung folgenden Zeit da; $a b$ und zu kann man reflectorisch eine Contraktion von Thoraxmuskeln auslösen, ohne dass es aber auch in diesem Falle zur Entstehung einer längeren Reihe rhythmischer Athembewegungen käme; nur die Kopfathmung danert unter dem Bilde rhythmischer Bewegungen des Kehlkopfes fort, dessen Excursionen sich an der Halshaut deutlich ausprägen. 
Allmählich fängt dies Spiel an, seltener zu werden, indem sich mehr und mehr die charakteristischen Zeichen einer "Kopf-

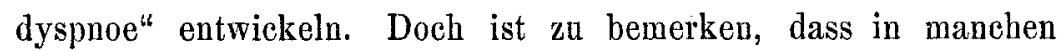
Fällen schon vor Eintritt dyspnoischer Erscheinungen ein Phänomen zur Beobachtung gelangt, welches vielleicht Langendorff mit zu seiner Auffassung Anlass gab. Plötzlich sieht man nämlich, wie der Thorax sich zusammenzieht, um sich sofort wieder auszudehnen. In diesem Zustande der Erweiterung verharrt er längere Zeit, bis ein ernenter Collaps mit anschliessender Lungen. füllung erfólgt.

Als ich zum ersten Mal dies Phänomen bemerkte, war ich auch versucht, an eine spinale Rippenathmung zu denken; die weitere Untersuchung ergab jedoch, dass es sich hier um etwas ganz anderes handelt.

Oeffnet man den Thorax eines Thieres nach Sectio bulbi, so sieht man trotzdem rhythmisch die Lunge an- und abschwellen, auch dann noch, wenn der Brustkorb in grosser Ausdehnung resecirt worden ist. Schon dieses Moment wäre eigentlich beweisend genug, um eine aktive Rippenbewegung ausschliessen zu können; noch frappanter wird die Erscheinung, wenn man das Riuckenmark ausbohrt. Das rhythmische An- und Abschwellen der Lungen besteht auch dann noch ungestört fort. Dagegen genügt ein einfacher Schnitt in die Trachea, um die Erscheinung sofort und dauernd zu beseitigen; ein Röhrchen, das beide Schnittenden verbindet, geniigt, um es wieder herzustellen.

Hieraus ergiebt sich unzweifelhaft, dass die Hebung des Thorax in diesem Falle als eine rein passive angesehen werden muss, bedingt durch die Blähung, welche die Lungen durch ibre plötzliche Füllung erfahren. Welchem Umstande diese letztere Erscheinung zuzuschreiben ist, wird weiter unten näher zu erörtern sein; hier soll nur noch beriicksichtigt werden, ob Langendorff's Beobachtungen sich etwa durch die beschriebenen Thatsachen er. klären lassen.

Wenn man auf den Thorax einen empfindlichen Fühlhebel aufsetzt, an einer. Stelle, die unter normalen Verhältnissen an Exspiration und Inspiration in gleicher Weise betheiligt ist und demnach ähnliche Bilder giebt, wie die pulmonalen Druckschwankungen bei Anwendung einer Trachealkanüle, dann erhält man Curven, wie in Fig. 24, Taf. III. Rasch sinkt der Hebel herab, der Ent- 
leerung der Lungen folgend, um sofort wieder emporzusteigen. Dann folgt eine Zeit der Ruhe, während der die Glottis geschlossen ist und die $1 / 2-1$ Minute andauern kann.

Die diesen Pausen entsprechenden geraden Linien der Curve liegen nicht immer in gleichem Niveau, wenn auch die jeweilige Höhendifferenz nur unbeträchtlich ist. Dies beweist, dass die Lunge bald mehr, bald weniger stark gefüllt wird, indem die Intensität der Schluckbewegungen nur annähernd constant ist.

Die Curve entspricht genau dem, was man auch ohne graphische Hülfsmittel leicht beobachten kann, d. h. einer Verengerung des Thoraxraumes mit unmittelbar nachfolgender Erweiterung. Auch die La $n$ ge e $\mathrm{d}$ o rff'schen Darstellungen "spinaler Athembewegungen" setzen sich in derselben Weise aus diesen beiden Faktoren zusammen; trotzdem aber ist der gesammte Habitus derselben so durchaus verschieden von den meinigen, dass ibre Identifizirung unmöglich erscheint, auch wenn Langendorff nicht ausdrücklich betonte, dass seine Curven, von der Trachealkantile aus aufgezeichnet" wurden. So sehe ich mich leider gänzlich ausser Stande, die beiderseitigen Differenzen zu erklären, muss aber auf Grund meiner Erfahrungen das Vorhandensein einer spinalen automatischen Athmung auch bei den Eidechsen durchaus in Abrede stellen.

Die beliebte Annahme einer durch die Operation gesetzten Choc- oder Hemmungswirkung, welcher die spinalen Centren unterliegen sollten, dürfte gerade in unserem Falle noch viel weniger am Platze sein, als bei Warmblütern, zumal es leicht gelingt, die operirten Thiere auch ohne künstliche Athmung lange am Leben zu erhalten, indem schon bald nach Ausfïhrung der hohen Ritckenmarksdurchschneidung jener andere Modus der Athmung einsetzt, durch welchen nach kurzer Zeit wieder ziemlich normale Verhältnisse geschaffen werden. Ich fand die Thiere unter Umständen noch am Tage nach der Operation lebend vor, wenn auch, bei der langen Dauer der Pausen und der wahrscheinlich nicht genügenden Lungenfüllung dauernd ein Zustand mässiger Dyspnoe besteht. Es würde dies aber für die Erregung der spinalen Athemcentren wohl nur günstig sein.

Wenn diese Erfahrungen, wie mir scheint, sehr entschieden zu Gunsten der alten Lehre von einem bulbären Athemcentrum zu sprechen scheinen, so soll damit keineswegs die Mög- 
lichkeit geleugnet werden, dass unter gewissen besonderen: Umständen, wie bei Säugethieren, so auch bei Reptilien die isolirten spinalen Athemmuskelcentren einzelne oder Gruppen von Athembewegungen auszulösen vermögen, deren reflektorische Entstehung aber im gegebenen Falle wohl kaum mit Sicherheit auszuschliessen sein dürfte.

Bekanntlich ist die Frage nach der automatischen oder reflektorischen Natur der rhythmischen, die normale Athmang bedingenden centralen Erregung auch in Bezug auf das bulbäre Centrum wiederholt Gegenstand der Erörterung gewesen.

Wenn schon von allgemeinen theoretischen Gesichtspunkten aus eine a utochthon e rlythmische oder arrhythmische Thätigkeit nervöser Centralorgane nicht ernstlich wird in Abrede gestellt werden können, so lässt sich doch gerade die von sensorischen Erregungen gänzlich unabhängige Automatie des bulbären Athemcentrums bei Reptilien sehr überzeugend nachweisen. Ich durchschnitt bei einer Eidechse zunächst beide N. vagi, worauf sofort die charakteristische enorme Verlangsamung (Pausenbildung) eintrat; hierauf durchtrennte ich das Rückenmark etwa in der Höhe des vierten Brustwirbels, wodurch zwar die abwärts vom Schnitt liegenden Rippenmuskeln gelähmt werden; doch ist der Zug der oberen Rippen genügend, um auch die unteren passiv zu heben. Es wurde sodann die Haut vom Rumpfe möglichst entfernt und durch einen im Niveau der unteren Brustapertur geführten Schnitt die ganze hintere Hälfte des Thieres entfernt.

Nach Resektion des Brustbeines wurden auch die schon vorher collabirten Lungen sowie sämmtliche Eingeweide entfernt. Man kann schliesslich anch noch die Halsmuskeln nebst Trachea und Oesophagus abpräpariren, sodass der Kopf eigentlich nur durch die nackte Halswirbelsäule mit dem Thorax noch zusammenhängt, ohne dass der bisherige Typus der Athmung irgend erheblich verändert wiirde.

Wird dann aber auch noch Gross- und Mittelhirn in der früher angegebenen Weise durch einen einzigen Scheerenschnitt mit den umgebenden Schädeltheilen entfernt, sodass die Med. oblongata eigentlich als einziger Ueberrest des ganzen Kopfes bestehen bleibt, so gewinnt die Athmung sofort einen durchaus veränderten Charakter. Si e ers cheint ganz a usserordentlich verlangsamt, wobei aber jede einzelne Athem- 
bewegungals durchaus normal zu bezeichnen ist. Während der Pausen, deren Dauer mehr als 2 Minuten betragen kann, befindet sich anfangs der ganze Thorax in einer eigentbümlich vibrirenden Bewegung, was sich später wieder verliert und wohl als direkte Reizwirkung aufzufassen ist (Fig. 25, Taf. IV).

$\mathrm{Ob}$ es sich bei dieser enormen Verlangsamung um den wahren Ausdruck des autochthonen Rhythmus der auslösenden Centralorgane handelt oder um eine choc-ähnliche Hemmungswirkung, lässt sich mit Sicherbeit $11 \mathrm{~m}$ so weniger feststellen, als auch die allmählich zunehmende Dyspnoe das Ihrige zur Verlangsamung des Athemrhythmus beitragen wird. Jedenfalls aber spricht die Thatsache der Fortdauer rhythmischer Athmungen nach so weitgehender Loslösung des Centralorgans aus seinen sämmtlichen peripheren Beziehungen sehr zu Gunsten einer wahren automati schen Thätigkeit desselben.

Auch an einem sonst intakten Thier bewirkt die doppelseitige Vagusdurchschneidung nach vorgängiger Abtrennung des Grossund Mittelhirns stets eine sehr viel stärkere Verlangsamung der Athmung als die Vagotomie an und für sich allein. Dies ist um so bemerkenswerther, als Durchschneidung des Gehirns an der oberen Grenze der Med. oblongata fast regelmässig zu einer mehr oder weniger beträchtlichen Besch leunig ung der Athemfrequenz führt, solange die Vagi erhalten sind. Erst die Durchtrennung der letzteren bedingt jene enorme Verlangsamung.

Auch bei Säugethieren hat man eigenthümliche Veränderungen eintreten sehen, wenn Gehirn und Vagi gleichzeitig entfernt wurden.

WährendMarkwald dann stets arrhy thmische Athemkrämpfe beobachtete, die langdauernd und in grossen Intervallen (1-3 pro Minute) einander folgten, sah L $0 \mathrm{w}$ y (60) nur eine rhythmische, ungewöhnlich verlangsamte und vertiefte Athmung $(2-4$ in der Minute); und Langendorff (61) konnte beide Beobachtungen an seinen Versucbsthieren machen; meist sah er Krämpfe, in seltenen Fällen dagegen auch regelmässig rhythmische Athmungen oder die ersteren allmählich durch letztere verdrängt; die Athmung war fast immer ausserordentlich verlangsamt.

Markwald betrachtet die normale rhythmische Athmung im Wesentlichen als einen reflektorischen durch die Vagi und die 
oberen Hirnbahnen ausgelösten Vorgang, wobei die antochthon im Centrum entstebenden Erregungen erst in passender Weise durch die centripetal zuströmenden Impulse geregelt würden. Das Athemcentrum sei zwar automatisch thätig, kann aber nur Athem kräm p fe auslösen. Die tonisch erregten Vagi oder die oberen Hirnbahnen sind zum Zustandekommen des Rhythmus nöthig; der Ausfall der ersteren kann durch die letzteren z. Th. gedeckt werden und umgekehrt; Langendorff dagegen glaubt, das die Atbemkrämpfe nicht durch den Fortfall der Hirnbahnen, sondern durch die mit ihrer Fortnahme verknüpften Verletzungen bedingt und daher im Wesentlichen als Reizerscheinung aufzufassen sind.

Dass es sich bei der an Eidechsen nach Entfernung des Gross- und Mittelhirns und doppelseitiger Vagotomie stets hervortretenden dauernden Herabsetzung der Athemfrequenz um eine wahre Ausfallerscheinung und nicht um eine Reizwirkung handelt, bedarf nach dem Mitgetheilten kaum noch besonderer Beweise und es lässt sich daher der Satz aufstellen, dass die Reptilien ein in der Gegend des Calamus scriptorius befindliches, a tomatisch thätiges und in sehr träger Rhythmik arbeitendes, respiratorisches Centralorgan besitzen.

Letzteresbesteht aus zweicoordinirten physiologischen Systemen, einem exspiratorisch und einem inspiratoriseb wirkenden, die beide ein anatomisch einheitliches Ganzes darzustellen seheinen - da derselbe Schnitt stets die Funktion beider a ufhebt-und in bestimmten, gewissermaassen associativen Beziehungen zu einander stehen müssen.

Schon wiederholt wurde im Vorstehenden jener eigenthümlichen Form der Athmung gedacht, die bei Eidechsen unter abnormen Bedingungen aufzutreten pflegt und in direkte Parallele zu der Schluckathmung der Frösche gesetzt werden kann. Währond man früher, im Gegensatz za allen anderen Reptilien, bei den Schildkröten eine durch die Contraktionen des Mundbodens bedingte Druckathmung annahm, weil ein physiologisches Aequivalent der Rippenbewegung nicht gefunden werden konnte, ist durch schon mitgetheilte Versuche später einwandfrei bewiesen worden, dass auch diese Thiere eine ganz reguläre Saugathmung 
besitzen. Damit schien eine scharfe Grenze zwischen dem Athernmechanismus von Reptilien und Amphibien gezogen zu sein, und P. Bert constatirte in seinem schon oft citirten Werke, dass von den Reptilien an aufwärts die primitive Schluckathmung verloren gegangen und durch die höher differenzirte Saugathmung ersetzt worden sei.

Heinemann war der erste, der gegen diese Anschaung Beobachtungen geltend machte, aus welchen sich unzweifelhaft ergab, dass wenigstens den Sauriern beide Respirationsmodi zu Gebote stehen. Er sagt hiertiber Folgendes:

„Legt man einer Eidechse durch Eröffnung des Thorax die Lungen bloss (Heinemann arbeitete meist an Iguana), so sieht man, wie das der Rippenrespiration beraubte Thier durch energische Druckbewegungen der Kehle reichlich Luft in die Lungen pumpt. Ist hiermit auch nicht bewiesen, dass dieser Modus der Respiration der gewöhnliche sei, so ist doch durch diesen einfachen Versuch die Möglichkeit, dass Eidechsen mit Hülfe der Schluckbewegungen athmen können, unwiderleglich festgestellt."

"Beobachtet man z. B. eine I guana in der Ruhe, so bemerkt man häufige Kehlbewegungen, welche aber von den Schluckbewegungen wesentlich verschieden sind; reizt man nun das Thier oder sucht man durch Druck mit beiden Händen die Respiration zu verhindern, so sieht man sofort energische Schluckbewegangen auftreten, welche mit solcher Kraft ausgefuhrt werden, dass trotz Gegendruck der Leib sich bis zum grösstmöglichen Grade aufbläht."

Man findet also bei den Eidechsen beide Respirationstypen vereinigt und sieht in wechselndem Spiele bald den einen, bald den anderen zur Anwendung kommen. Man muss nach Heineman n folgende Formen der Kehlbewegungen auseinanderhalten:

1. Leichte Kehlbewegungen, welche mit der Lungenrespiration nichts zu thun baben und die Pausen zwischen den echten Respirationsbewegungen ausfüllen.

2. Kehlbewegungen, welche die Respirationsbewegungen des Rumpfes begleiten und mit ihnen gleichsinnig oder fast gleichzeitig stattfinden, also Erweiterung des Kehlsackes bei Inspiration, Verengerung bei Exspiration; kommen bei Sauriern und Schildkröten vor. 
3. Echte Schluckbewegungen, welche fähig sind, die Lungenrespiration zu unterhalten. Nur bei Sauriern (und Schildkröten).

4. Affektbewegungen der verschiedensten Art bei Sauriern und Schildkröten. Hierher gehört das Aufrichten des für gewöhnlich gefalteten Kehllappens bei Iguana, das Aufblähen des in lebhaften Farben glänzenden Kehlsackes bei Anolisarten und andern.

Auch Carus spricht schon in seiner Zoologie davon, dass die Reptilien ihre geringen(?) Athembewegungen durch Schlingbewegungen unterstützen, und Langendorff hat ebenfalls durch Einlegen einer Canüle in das kopfwärts gelegene Ende der Trachea ein Durchstreichen von Luft durch dieselbe constatiren können.

Was zuerst die Kehlbewegungen der zweiten Gruppe Heinemann's betrifft, die also gleichsinnig mit der Thoraxathmung auftreten, so kann man sich leicht davon iuberzeugen, dass sie Bewegungen des Kehlkopfes als Ganzem ihre Entstehung verdanken; während der aktiven Exspiration erleidet der Larynx eine Lageverschiebung nach vorn, beim Nachlass der Contraktion gleitet er wieder in seine Ruhelage zurïck, um mit dem Eintreten der aktiven Inspiration über dieselbe hinaus nach rückwärts sich zu bewegen; bei Lösung des inspiratorischen Tonus geht er wieder in die Cadaverstellung nach vorn. Während dieser ganzen Bewegung ist die Glottis geöffnet; nach ihrem Ablauf schliesst sie sich sofort wieder. Die Vorwärtsbewegung bedingt gleichzeitig eine Verkleinerung der Mundhöhle, die Rïckwärtsbewegung dagegen eine nicht unerhebliche Erweiterung, und diesem Umstand ist es zu verdanken, dass man die Kehlbewegungen auch äusserlich beobachten kann.

Als bewegende Organe fungiren die an das Zungenbein sich ansetzenden Muskeln; der Sternohyoideus, Temporohyoideus u. s. w.; doch ist zu bemerken, dass die Zunge hierbei sich nieht mit bewegt, abgesehen von den hintersten Parthien, die durch den ihnen lose anhaftenden Kehlkopf passive Lageveränderungen erleiden.

Durchaus analogen Verhältnissen begegnet man auch bei den Schildkröten, weshalb ich hier nicht weiter darauf eingehen will; doch müssen die Schlangen noch kurz berïcksichtigt werden.

Heinemann hat völlig Recht, wenn er äusserlich sichtbare 
Kehlkopfbewegungen bei ihnen leugnet; de facto sind sie jedoch vorhanden und fallen nur deshalb bei äusserer Beobachtung nicht auf, weil mit ihnen keine Volumschwankungen der Mundhöhle verbunden sind. Dies hat vielleicht darin seinen Grund, dass die Rückwärtszieher des Zungenbeines dieses nicht nach hinten und aussen bewegen; denn die als M. atlanto-epistropheohyoideus und M. cervico-hyoideus bezeichneten Muskeln, welchen diese Funktion zukommt, und die an der Halswirbelsäule entspringen, müssen gleichzeitig bei ihrer Contraktion eher eine Einwärtsbewegung bedingen. Es existirt übrigens hier auch noch ein M. laryngo-hyoideus, der den Kehlkopf etwas zuriickbewegt, indem er ihn dem Zungenbeine nähert. Die wirklich sichtbare Kehlkopfbewegung ist jedoch bedingt durch die Bewegungen des Zungenbeines selbst.

Bei den Schlangen ist nun die Kehlkopfbewegung auch dadurch ausgezeichnet, dass n ur während derselben die Glottis geöffnet, während der Thoraxruhe dagegen geschlossen ist.

Dagegen weicht sie insofern von dem bei Sauriern und Schildkröten geschilderten Verhalten ab, als im Momente der Exspiration der geöffnete Keblkopf maximal nach rückwärts gezogen wird und hier durch Muskelkräfte bis zum Aufbören der aktiven Inspiration zurïckgehalten wird; mit dem Ende derselben kehrt er ebenso wie der Thorax in seine Ruhelage rasch zurück, wobei (vielleicht schon etwas vorher) Glottisverschluss eintritt. Charakteristisch ist hierbei also der Ausfall der nach vorn gerichteten Kehlkopfbewegung; es existirt zwar ein Vorwärtsbeweger des Zungenbeines, der M. genio- oder Maxillo-hyoideus; derselbe scheint aber offenbar nur für die Bewegungen der Zunge von Bedeutung zu sein; fraglich bleibt es schliesslich, ob der sogen. Vorwärtszieher des Kehlkopfes, dessen Name M. maxillo-laryngeus dic Insertionspunkte angiebt, nicht doch vielleicht unter normalen Verhältnissen eine Vorwärtsbewegung des Keblkopfes bei fixirtem Zungenbein bewirken kann; jedenfalls habe ich mich davon nicht sicher überzeugen können, und möglich ist es auch, dass dieser Muskel weniger die Funktion des Vorwärtsziehens, als des Emporheben s hat.

Anschliessend will ich noch bemerken, dass auch hier Dilatatoren und Constriktoren, allerdings meist kaum als besondere getrennte Muskeln, bestehen, sondern derart sich darstellen, dass 
ein einheitliches Fasersystem ganz allmähliche Uebergänge von der longitudinalen Richtung zur circulären und nmgekehrt zeigt, und dass dies Fasersystem alle Insertionspunkte am Kehlkopfe selber hat.

Wir kommen nunmehr zu der von Heinemann unter Nr. 1 aufgeführten Gruppe von Kehlbewegungen, die meist nur ziemlich oberfiächlich verlaufen und die Pausen zwischen den einzelnen Respirationen ausfüllen.

Die Form dieser Kehlkopfbewegungen ist durchaus dieselbe, wie bei den gewöhnlichen respiratorischen Bewegungen, d. h. sie bestehen in einem rhythmischen Vor- und Rückwärtsschwingen um die Ruhelage, nur dass ihre Intensität im Allgemeinen viel geringer ist; in Folge dessen sind auch die Volumschwankungen der Mundhöhle weniger ausgiebig und manchmal von aussen kaum sichtbar.

Sie sind im Allgemeinen recht häufig; bei sich sonnenden, ruhig liegenden Thieren ist oft die Thoraxathmung sehr verlang. samt, dagegen das Spiel der isolirten Kehlbewegungen ausserordentlich frequent. Ihr Verhalten bei Dyspnoe, sowie beim Er. wachen winterschlafender Thiere wurde schon frïher erwähnt.

$\mathrm{Zu}$ bemerken bleibt noch, dass leichte Vagusreize, welche die thorakale Athmung nicht beeinflussen, sehr regelmässig isolirte Kehlathmungen, oft auch eine ganze Serie derselben auszulösen im Stande sind; dagegen scheinen sie während der langen nach Vagotomie auftretenden Pausen ganz zu fehlen.

Im Frühjahr hatte ich Gelegenheit, einen ca. $1 / 2 \mathrm{~m}$ grossen Varanus niloticus zu beobachten, bei dem diese Kehlbewegungen ganz ausserordentlich schön zu beobachten waren. Bei diesem Thier hat die Athmung durchaus den Eidechsentypus; reizt man das Thier, so geht die unter normalen Verbältnissen geräuschlose Athmung mit einem exspiratorischen Zischen Hand in Hand; auch die.Inspiration ist von einem hörbaren Geräusch begleitet; in ähnlicher Weise ist auch die aktive Exspiration der gereizten Schlangen mit einem zischenden Tone verbunden, der den anderen Respirationsphasen aber fehlt.

Es scheint dieses Phänomen hauptsächlich durch eine geringere Glottisöffnung bedingt zu sein; hierfür spricht auch der Umstand, dass bei den Schlangen die hörbaren Exspirationen 
länger als die normalen sind; die Luft muss sich durch einen schmaleren Spalt nach aussen hindurchzwängen.

Auch die isolirten Kehlbewegungen können bei $\mathrm{Var}$ an us, wenn das Thier gereizt wird, einen kräftigen fauchenden Ton hervorbringen; dabei ist es vor allem die intensive Contraktion des Mundbodens, die die Luft aus den engen Nasenlöchern mit Macht hinaustreibt und die Entstehung des Geräusches veranlasst.

Bei Schildkröten ist es mir noch nicht gelungen, den $\mathrm{Cba}$ rakter dieser Kehlbewegungen mit Sicherheit festzustellen. Wenn man das Thier mit gewaltsam vorgestrecktem Kopfe fixirt, fallen sie meist sofort aus, und man kann stundenlang abwarten, ohne sie wieder erscheinen zu sehen. Beobachtet man aber ein ruhig schreitendes Thier, so ist es ausserordentlich schwierig, die Kehlhaut zu Gesicht zu bekommen, da Hals und Kopf meist nur sehr wenig über die Unterlage erhoben sind. Auch verwischt die starke gefaltete Haut das äussere Bild der Kehlbewegungen, das sich als eine Art ron Undulation des Mundbodens darstellt; ich bezweifle indess nicht, dass auch sie rhythmischen Kehlkopfbewegungen ihre Entstehung verdanken und denen der Eidechsen gleichwerthig sind.

Eine Erklärung dieser isolirten Kehlkopfbewegungen ist schwer zu geben.

Beim Frosch kann man bekanntlich zwei Arten rhythmischer Bewegungen unterscheiden.

"Bei der einen dieser Bewegungen ist an den Nasenfligeln nur eine ganz leichte, oft lediglich mit der Lupe wahrnehmbare Verschiebung, an den Flanken ein geringes Zucken, an der Kehlhaut dagegen ein wohl ausgeprägter Wechsel zwischen Einziehung und Ausdehnung, bei der zweiten ein deutliches Verengern und Erweitern der Nasenmundungen, ein starkes Einsinken und Vorwölben der Flanken und an der Kehlhaut eine kräftigere $\mathrm{Zu}$ sammenziehung und Aufblähung bemerkbar. . .

„Oeffnet man den Mund mit einer passenden Spreizvorrichtung oder macht man sich die Glottis respiratoria durch Abtragen eines Theiles des Schädels sichtbar, so sieht man, dass der Kehlkopf bei den den Kehlathmungen entsprechenden leichteren Schwankungen am Boden der Mundhöhle gleichfalls vor- und rückwärts gerichtete Schwankungen vollzieht, bei denen aber die Glottis 
fest verschlossen bleibt. Bei den Kehlathmungen findet also keine Luftzufuhr zu den Lungen statt."

„Die leichten Flankeubewegungen, die hierbei zu beobachten sind, erklären sich ebenso wie die, welche die eigentlichen Athembewegungen bei offener Mundhöhle begleiten, aus den Druckschwankungen, welche durch die Bewegungen des wie der Stempel einer Pumpe in der vorderen Brustapertur hin- und hergehenden Kehlkopfes und die Contraktion des bei tiefen Athembewegungen in Thätigkeit tretenden Musculus obliquus abdominis bewirkt werden, der in der vorderen Brustapertur sich kuppelförmig ïber die Lunge wölbt und von den Anatomen geradezu als zwerchfellartig bezeichnet wird" (19).

Während von We d enski i (62) die Ansicht ausgesprochen ist, es seien die von ihm "Oscillationen" genannten, bei der Lungenrespiration nicht betheiligten Kehlbewegungen des Frosches gänzlich aus der Reihe der Respirationsbewegungen zu streichen, betrachten sie andere Forscher, vor Allem Martin St. An g e (63) und $\mathrm{H}$ e in e mann als Reste der zurückgebildeten Kiemenrespiration.

Die Kiemen der Froschlarve erhalten durch die rhythmischen Volumschwankungen der Mundhöhle einen beständigen Zufluss frischen Wasser's, indem die Erweiterung eine Ansaugung, die Verengerung ein Austreiben des respiratorisch verbrauchten Wassers durch die Kiemenspalten bedingt.

Mit dem Uebergang des Larvenstadiums in das des fertig entwickelten Thieres fällt dann zwar die physiologisehe Bedeutung dieser Kehlbewegungen fort, doch bleiben sie selbst bestehen als eine Art physiologisches Rudiment.

$\mathrm{K}$ noll hat diese Bewegungen genauer untersucht, ohne dieser letzteren Hypothese Erwähnung zu thun. Nach ihm sind sie nur gewissermaassen der Ausdruck der schwächsten Erregung des Athemapparates, da bei ihnen nur die zur Zusammenziehung der Kehlhaut dienenden Petrohyoidei sich contrahiren und nicht einmal die Erweiterer der bei Ausschluss aller Muskelwirkung gescblossenen Glottis in Thätigkeit treten. Seiner Ansicht nach haben sie aber insofern eine gewisse Bedeutung für die Athmung, als die durch sie bedingten Druckschwankungen in der Leibesböhle wohl die Ventilation der Lungengefässe begünstigen dürften.

$\mathrm{H}$ e i n e m a n n dagegen verfolgt seine descendenztheoretische 
Hypothese noch viel energischer als $\mathrm{Mar}$ tin $\mathrm{St}$ t. A u ge etc.; da nach ihm die Lungenathmung einen viel complicirteren, sich erst während des Larvenlebens entwickelnden Muskelapparat erfordert, als die viel einfachere Kiemenathmung; da sich zu den Kehlbewegungen in verwickelter Weise Bewegungen der Kehlkopfund Bauchmuskeln (?) gesellen, da also, kurz gesagt, ein völliger Wechsel des Bewegnngssystems stattfindet, so glaubt er annehmen zu müssen, dass das Innervationseentrum für beide Zustände nicht dasselbe sei. Allmählich erst stellt das Kiemenathmungscentrum in Folge funktioneller Bedeutungslosigkeit seine Thätigkeitsäusserungen ein; aber wie die vergleichende Anatomie rudimentäre Organe kennt, so könnte die Physiologie rudimentäre Funktionen unterscheiden, die mit grosser Zähigkeit sich durch lange Entwickelungsperioden erhalten. Aus dieser Coexistenz zweier Innervationscentren, von denen das eine mehr und mehr im Laufe der phylogenetischen Entwickelung zurückgebildet wird, würde sich dann auf das Einfachste erklären:

1. dass Kehlbewegungen eines früberen Athemtypus auch dann noch fortdauern, wenn sie alle Bedeutung für die Athmung verloren haben,

2. dass diese Bewegungen völlig unabhängig sind von den echten Respirationsbewegungen, und dass sich beide zeitlich gegenseitig ausschliessen. Fur H e i n emann unterliegt es keinem Zweifel, dass die Kehlbewegungen von Amphibien und Reptilien rudimentäre ererbte Athembewegungen sind; bei den Eidechsen, nach ihm die ältesten unter den jetzt lebenden Reptilien, findet man neben der Schluckathmung Thoraxathmung und rudimentäre Kehlbewegungen, ebenso bei den Amphistänen; die jüngeren Krokodile und Schildkröten zeigen nur noch die letzteren, bei den Schlangen, dem jüngsten Zweige des Reptilienstammes, ist nur die Thoraxathmung noch vorhanden. Aber auch bei einem Hühnervogel Penelope sp. sah Heinemann solche rudimentären Athembewegungen.

Er vermuthet, dass sie einen, wenn auch beschränkten, Gasaustausch durch die Schleimhaut der Mundhöhle unterhalten, und dass sie durch Beförderung der Wärmeabgabe die Regulirung der Wärme begüunstigen." Er giebt an, dass bei P e n el o p e die nackte und sehr gefässreiche Kehle unter gewöhnlichen Verbältnissen sich ruhig verhält; bei starker Hitze aber versetzt sie der Vogel 
in lebhafte Schwingungen, sodass der Beobachter unwillkürlich den Eindruck erhält, es handele sich um Beförderung der $\mathrm{Ab}$ kühlung.

Alle diese Hypothesen sind gewiss sehr ansprechend, indem sie es anscheinend ermöglichen, eine phylogenetische Erklärung der Kehlbewegungen zu geben.

Indessen scheint bei diesen Spekulationen Vorsicht dringend geboten, und lässt sich durch eine genanere Analyse der Erscheinung sogar der Nachweis liefern, dass eine einheitliche Auffassung zur Zeit kaum möglich ist.

Während bei der eigentlichen ventilirenden Schluckathmung des Frosches (von der nach Knoll zumeist nur eine auf 2 oder mehrere nicht ventilirende Kehlathmungen oder auf eine längere Reihe der letzteren eine kleine Gruppe jener kommt) eine grössere Zahl von Muskeln der Mundhöhle betheiligt erscheinen, welche theils erweiternd, theils verengend wirken (Petrohyoideus ant. und post., Genioglossus und Geniohyoideus, Submaxillaris, Sterno- und Omohyoideus), Muskeln, deren Innervation neben den Volumänderungen der Mundhöhle gleichzeitig vor- und rückwärtsgerichtete Kehlkopfbewegungen bedingt, sind die sich einschiebenden, nicht ventilirenden Oscillationen lediglich das Resultat der Contraktion der Petrohyoidei anteriores, die die Mundböhle verengern und den Kehlkopf etwas nach vorn ziehen; die Erweiterung der Mundhöhle erfolgt dagegen rein passiv durch Erschlaffung der betreffenden Muskeln; die Kehlkopf bewegungen sind dabei unverhältnissmässig geringfügig.

Ganz anders ist dagegen das Verhalten dieser intercurrirenden Kehlbewegungen bei den Reptilien, deren Analogie mit jenen der Frösche $\mathrm{H}$ e in e m a n $\mathrm{n}$ behauptet. Bei ersteren haben dieselben genau denselben Typus wie jene, welche die gewöhnlichen Respirationen begleiten, indem der Kehlkopf um seine Ruhelage aktiv nach vorn und rückwärts bewegt wird.

Diese Bewegungen treten dabei sogar viel mehr in den Vordergrund, als die Verengerung und Erweiterung der Mundhöhle, während es beim Frosch gerade umgekehrt ist, indem hier der Kehlkopf nur wegen der nicht senkrecht, sondern etwas schräg gerichteten Zugkraft des Petrohyoidei etwas mit nach vorn gezogen wird.

Bei den Amphibien will ich einen Zusammenhang dieser 
nicht ventilirenden Oscillationen mit der zurïckgebildeten Kiemenathmung keineswegs in Abrede stellen; so verführerisch aber auch die Ausdehnung dieser Hypothese auf die höheren Vertebratenklassen erscheinen mag, so dürfte sie doch wohl kaum haltbar sein, und man wird in jenen Kehlbewegungen der Reptilien eben nur eine vom teleologischen Standpunkte aus zunächst wenig verständliche concomittirende Muskelaktion erblicken dürfen, die, vom Athemcentrum ausgelöst, der Athmung selbst, d. h. dem respiratorischen Gasaustausch direkt nicht dient. Nach allem Mitgetheilten wird man ferner annehmen muissen, dass die dabei betheiligten Muskelgruppen leichter ansprechen als jene, welche die Rippen bewegen, und schon auf Reize reagiren, bei welchen diese noch nicht erregt werden. So treten ja auch diese Kehlbewegungen in dyspnoischen Zuständen noch regelmässig auf, wenn das Athemcentrum in seiner Erregbarkeit bereits so gelitten hat, dass wirk. same, thorakale Athembewegungen nur noch in langen Intervallen hervortreten.

Dass aber andererseitseine wirkliche ventilirende Schluckathmang im selben Sinnewie beim Froseh a uch Reptilien, und zwarnichtnur den Sauriern, sondern, so oft dies auch geleugnet wurde, a uch den Schildkröten zukommt, darf als eine feststehende Thatsache bezeichnet werden.

Ehe ich jedoch auf die einschlägigen Verhältnisse näher eingehe, erscheint es wünschenswerth, die Druckathmung des Frosches kurz zu erörtern, weil dieselbe uns die nöthigen Anhaltspunkte für die Deutung der entsprechenden Befunde bei den Reptilien gewähren wird. Ich stütze mich hierbei im Wesentlichen wieder anf die schon mehrfach erwähnte Abhandlung von $\mathrm{Knoll}$, in welcher die einschlägigen Thatsachen sehr eingehend erörtert werden.

$\mathrm{K}$ no 11 unterscheidet mit $\mathrm{H}$ ein emann und Wedenskii vor Allem drei Formen der eigentlichen Schluckathmung des Frosches, die man als ventilirende, einpumpende (aufblähende) und rein entleerende bezeichnen kann und die oft in einer bestimmten Periodicität aufeinander folgen, indem sich der ventilirenden Athmung einpumpende Respirationsbewegungen und weiter eine Gruppe von rein entleerenden anschliessen.

Dieselben unterscheiden sich einmal durch die verschiedenen 
Fiullungszustände der Lungen, die bei ihnen zu beobachten sind, in besonders charakteristischer Weise aber durch die verschiedenen Formen der sie begleitenden Kehlkopfbewegnngen.

\section{Die ventilirende Athmug.}

Die Glottis öffnet sich hier unmittelbar vor Beginn einer nach aufwärts gerichteten Bewegung des Kehlkopfes, wobei Luft aus den Lungen durch die offenen Nasenlöcher bei schlaffer Kehle ausströmt. „Im Verlaufe der Vorwärtsbewegung des Kehlkopfes aber wird durch die vereinigte Wirkung der Zusammenziehung der Kehle und der Zunge, die sich bei der Contraktion der Kehlhaut gegen den harten Gaumen vorwölbt, Luft durch die offene Glottis in die Lungen gepresst, ein Vorgang, den schon $\mathrm{Cuvier}$ mit dem Spiel einer Druckpumpe verglichen bat."

Die Flanken sind demnach gegen Ende der Vorwärtsbewegung des Kehlkopfes vorgewölbt. Dann schliesst sich die Glottis und kehrt in diesen Zustand zurïck zur Ruhelage, während gleichzeitig die Nasenlöcher sich wieder erweitern.

\section{Die einpumpende (aufblähende) Athmung.}

Beobachtet man bei einem Thiere, das diese Athmung darbietet, den Kehlkopf, so sieht man, dass derselbe bei geschlossener Glottis sehr stark in gedehnter Bewegung nach rückwärts gezogen wird, dann sehr stark und jäh vorwärts steigt, sich erst im Verlauf der letzteren Bewegung öffnet und dann geschlossen zur Ruhelage zurückkehrt. Da bei der rückwärts gerichteten Kehlbewegung die Nasenlöcher unter unverkennbarer Muskelwirkung weit geöffnet werden, so muss eine relativ grosse Luftmenge in die Keble eingesaugt werden; da andererseits sich die Glottis erst bei der Vorwärtsbewegung des Kehlkopfes öffnet, während die Kehlhaut sich schon zusammenzieht und die Nasenlöcher kräftig verengert sind, so wird bei der vorwärts gerichteten Bewegung viel Luft in die Lungen aufgenommen werden, während nur wenig ausströmen kann. Es bleibt bei dieser Darlegung K n ol l's unsicher, ob das starke Vorwärtssteigen rein passiv ist, oder ob sich der Kehlkopf über die Ruhelage hinausbewegt, in Folge einer an die Erschlaffung der Erweiterer der Mundhöhle sich anschliessenden Contraktion der Verengerer derselben. 
3. Die entleerende Athmung

tritt nach vorbergängiger (aufblähender) Athmung ein und führt das Lungenvolumen wieder auf die Dimensionen bei der ventilirenden Athmung zurïck.

„Bei derselben öffnet sich die Glottis, während der Kehlkopf sich noch in Rube befindet, und dieser bewegt sich dann geöffnet mehr oder weniger stark nach rïckwärts und darauf unter allmählichem Glottisschluss nur sehr wenig nach vorwärts. Die Nasenlöcher klaffen während dieser Athmungsform und die Nasenflügel zeigen böcbstens eine ganz geringfügige Bewegung. Die Kehlhaut bläht sich zunächst ziemlich stark und zieht sich dann ganz leicht zusammen, sodass so gut wie gar keine Luft in die Lungen eingedrückt wird. - - ${ }^{*}$

Was nun die ventilirende Schluckathmung der Reptilien, d. h. der Saurier und Sehildkröten betrifft, so spielt dieselbe im Allgemeinen unter normalen Verhältnissen keine Rolle. Und wenn Heinemann sagt, dass er an gereizten Iguaniden regelmässig derartige Schluckbewegungen eintreten sah, ja, dass er an ihnen und auch bei Lacerta schon an ruhig athmenden Thieren beide Respirationstypen in wechselndem Spiel beobachten konnte, so kann ich dies, so weit meine Erfahrungen reichen, nicht bestätigen. Nur unter ganz besonderen Bedingungen sieht man nämlich diese merkwürdige Athmungsform in Erscheinung treten, und wenn ich auch glaube, dass ich nicht alle diese Bedingungen, unter denen es möglich erscheint, wirklich kennen gelernt habe, so sind doch im Folgenden gewiss die wichtigsten Fälle erwähnt, in welchen regelmässig and mit unfehlbarer Sicherheit das Auftreten der Druckathmung beobachtet wird.

Wie schon Heinemann fand, vermag eine sehr starke Compression des Thorax, die jede Erweiterung unmöglich macht und die Lungen auf kleinen Raum zusammenpresst, in vielen Fällen eine Schluckathmung oder auch mehrere auszulösen.

Sebr regelmässig beobachtet man ferner dasselbe bei Thieren, denen durch breite Spaltung der Thorax eröffnet worden ist. In dem Augenblicke, wo die Lunge sich stark retrahirt und als schlaffer Sack der Rückenwand anliegt, tritt regelmässig die erste Schluckathmung auf, und unwillkürlich erhält man den Eindruck, dass es sich hier um eine Reflexwirkung handelt. Die Lunge 
bläht sich anf nnd zwar recht erheblich, drängt selbst aus der breiten Wunde bervor und collabirt dann nach kurzer Zeit etwas allmählicher. Dann vergeht eine längere Zeit, bis eine neue Schluckathmung einsetzt.

Auch durch eine sich entwickelnde Dyspnoe lässt sich erfahrungsgemäss Schluckathmung auslösen, die dann ihrerseits im Stande ist, jene wieder annähernd zur Norm zurückzuführen.

Bei Eidechsen tritt die Dyspnoe wohl kaum jemals vor Ablanf der ersten Viertelstunde nach Beginn eines zu diesem Zwecke angestellten Experimentes ein; sie erreicht aber erst nach circa einer halben Stunde genügende Intensität, um Schluckathmungen auszulösen, zu einer Zeit, wo die Respiration bereits alle Charaktere der dyspnoischen Athmung in Gestalt der mannigfaltigen, früher geschilderten, concommittirenden Muskelbewegungen aufweist.

Der Verlauf der Erscheinungen ist hierbei folgender:

Durch lange Pausen getrennt erfolgen gedehnte, flache Inund Exspirationen, wie dies bereits früher geschildert wurde. Während jede Exspiration von einer mässigen Vorwärtsbewegung des Kehlkopfes begleitet wird, zieht sich bei der Inspiration der letztere maximal nach rückwärts, wodurch gleichzeitig eine beträchtliche Erweiterung der Mundhöhle bedingt wird. An Stelle der nun zu erwartenden passiven Zurückbewegung des Thorax in seine Ruhelage erfolgt aber im Gegentheil sofort eine weitere Ausdehnung desselben und die Beobachtung ergiebt, dass es sich hier um den Effekt einer Schluckathmung handelt, welche, der thorakalen Inspiration sich unmittelbar anschliessend, durch eine jähe Vorwärtsbewegung des Kehlkopfes und Verengerung der Mundhöhle charakterisirt ist.

Dies lässt sich noch deutlicher beobachten, wenn man die thorakale Athmung etwa durch Durchtrennung des Rückenmarkes unterhalb der Med. oblongata gänzlich ausschliesst. Nach einiger Zeit (15-20 Minuten), während deren lediglich die gewöhnlichen schwächeren Oscillationen der Kehle, begleitet von Larynxverschiebungen, zu beobachten sind, erfolgen scbliesslich auch hier jene eben geschilderten, sehr kräftigen Bewegungen des Kehlkopfes, welche für die wirksame Schluckathmung so charakteristisch sind.

Immer macht auch hier eine leichte Vorwärtsbewegung den Anfang, die zweifellos als der ausgefallenen thorakalen Athmung zugehörig zu betrachten ist. 
Das verhältnissmässig späte Hervortreten der Schluckathmung bei dyspnoischen Zuständen steht in einem auffallenden Gegensatze zu dem unmittelbaren Erfolge eines durch Eröffnung der Brusthöhle bewirkten Lungencollapses. Dass übrigens auch hier, wenigstens in den späteren Stadien, die allmählich sich entwickelnde Dyspnoe als auslösendes Moment mitwirkt, dürfte kaum zweifelhaft sein und wird unter Anderem durch das häufige Auftreten schnappender Kieferbewegungen bewiesen.

Hinsichtlich der Frequenz der Schluckathmungen sei bemerkt, dass dieselbe ganz ebenso wie die thorakalen Respirationsbewegungen von dem jeweiligen Zustande des Athemcentrums abhängen.

Wenn bei Eröffnung des Thorax die Vagi ausser Funktion gesetzt werden, so erscheinen beide Arten von Athmung in gleicher Weise verlangsamt. Wenn bei Dyspnoe die Frequenz der Rippenathmung auf zwei p. Min. gesunken ist, so erfolgen im Anschlusse auch nur zwei Schluckathmungen; und ist schliesslich die Erregbarkeit so weit gesunken, dass nur noch alle zwei oder drei Minuten je eine Rippenathmung ansgelöst wird, so ist anch die Schluckathmung entsprechend verlangsamt. Dagegen kommt es vor, dass im Verlaufe einer längeren Reihe typisch dyspnoischer, von Schluckathmungen begleiteter Thoraxrespirationen einige anscheinend ganz normale Rippenathmungen anftreten, an welche sich Schluckbewegungen nicht anschliessen.

Dass echte Schluckathmungen in typischer Form (neben einfachen oscillatorischen Kehlbewegungen) auch bei Schildkröten vorkommen, wurde früher schon erwähnt. Doch ist dies allerdings, wie meist auch bei den Eidechsen, nur unter gewissen abnormen Verhältnissen der Fall. Ich wurde auf diese wiederholt bezweifelte Thatsache zuerst bei einer Schildkröte aufmerksam, an welcher zu bestimmtem Zwecke das Bauchschild entfernt und dabei zufällig anch die Bauchhöhle eröffnet worden war. Es machte sich hierauf sofort ein auffallender Wechsel im Charakter der KehIbewegungen geltend, indem an Stelle der bis dahin ruhigen Oscillationen mächtige Ausbuchtungen und Einzichungen des Mundbodens auftraten. Dass durch dieselben in der That Luft in die Lungen gepumpt wurde, liess sich nach breiter Eröffnung der Bauchhöhle leicht constatiren, indem sich jene synchron mit den 
Schluckbewegungen hoben und senkten. Durchschneidung der Trachea machte dem Phänomen sofort ein Ende.

Ich muss ausdrïcklich bemerken, dass unter den erwähnten Umständen die Erscheinung der Schluckathmung bei Schildkröten keineswegs ganz constant auftritt oder sich doch erst in späteren Stadien bei weiter vorgeschrittener Dyspnoe bemerkbar macht.

Wenn man sich der verschiedenen Formen der Schluckathmung beim Frosch erinnert, so ist leicht zu erseben, dass weder die "ventilirende" noch die "entleerende" Athmung in Parallele gesetzt werden kann mit jenem Bewegungsmodus des Kehlkopfes, der bei Reptilien das Eintreten von Luft in die Lungen ermöglicht. Nur die "aufblähende" Athmung (K n oll (62)) des Frosches lässt sich zur Reptilien-Schluckathmung ungezwungen in Beziehung bringen. Zwar fehlt den Amphibien die kurze einleitende Vorwärtsbewegung des Kehlkopfes; aber wir haben ja gesehen, dass diese der vorhergehenden, thorakalen Respiration angehört. Auch dass sich bei den Reptilien der Kehlkopf. schon bei dieser ersten Bewegung öffnet, was beim Frosch erst im Laufe der letzten vorwärts gerichteten Phase der Fall ist, kann nicht auffallend erscheinen, da auch diese Oeffnung anfänglich nur Theilerscheinung einer thorakalen Respirationsbewegung ist.

Im Uebrigen verläuft die Schluckathmung bei den Eidechsen und Schildkröten einerseits, die aufblähende Athmung des Frosches andererseits nach demselben Typus. Fuir beide ist charakteristiseh die gedehnte enorme Rückwärtsbewegung des Kehlkopfes, weleher dieses sonst leicht zu beobachtende Organ dem in die Mundhöhle schanenden Beobachter fast in der Tiefe des Halses verschwinden lässt, für beide die jähe Vorwärtsbewegung des Kehlkopfes, in deren Verlauf sich die Glottis schliesst.

Es scheint auch verständlich, dass gerade jener energische Typus der Schluckathmung sich bei den Reptilien erhalten hat. Da dieselben bekanntlich keine beweglichen, verschliessbaren Nasenlöcher haben, so ist es leicht begreiflich, dass eine, sich der einfachen "ventilirenden" Athmung anschliessende Form kaum einen nennenswerthen respiratorischen Effekt erreichen würde, während die kräftigen einpumpenden Athmungen auch unter diesen Umständen noch ein gewisses Quantum Laft in die Lungen einzupressen im Stande sein miissen.

Ungeachtet der nahen Beziehungen zwischen Rippen- und 
Schluckathmung bin ich doch der Meinung, dass die "Centren" für beide nicht identisch sind, wenn sie auch sicher in engster Correlation zu einander stehen.

Der ganze Mechanismus der Schluckathmung des Frosches ist ein so völlig abweichender von dem der thorakalen Athmung der Reptilien, dass auch eine an a to $\mathrm{m}$ is $\mathrm{e}$ h e Verschiedenheit der Lage der auslösenden Centralorgane nicht unwahrscheinlich wird.

Hierfür darf man vielleicht auch den Umstand geltend machen, dass das Centrum für die Schluckathmung beim Frosche nicht, wie das "Athemcentrum" der übrigen Wirbelthiere in der Gegend des Calamus scriptorius, sondern mehr nach vorn gelegen ist.

vo n Wittich (64) sah schon nach Abtrennung am hinteren Rande der Zweihügel die Athmung dauernd erlöschen und verlegte demnach das Athemcentrum überhaupt jenseits der Medulla oblongata. Is noll dagegen konnte nur bei Schnitten, die bereits das verlängerte Mark selbst trafen, ein Aufbören der Athembewegungen konstatiren, allerdings in der Regel s ch o n bei Durcbse hneidung am hinteren Randedes Kleinhirnes.

In wenigen seltenen Fällen sah er wohl auch wie $S$ te in er (65) nach Schnittführung an dieser Stelle die Athmung fortbestehen, zumeist erlosch dieselbe aber darnach sofort, so dass er mit Flourens (51) und Valpian (66) zu der Annahme kommt, dass das Athemcentrum bei Fröschen im vorderen Theile der Medulla oblongata liegt, und die Ausnabmefälle, in denen die Athmung nach Durchschneidung am hinteren Rande des Kleinhirns fortbestand, dahin auslegt, dass keine haarscharfe Abgrenzung desselben besteht.

Es scheint mit Rücksicht hierauf wahrscheinlich, dass auch bei den Reptilien von einer derartig gelegenen Stelle aus die Schluckathmungen ausgelöst werden. Vielleicht gelingt es sogar an gentigend grossen Sauriern oder Schildkröten, bei denen man künstlich die Schluckathmung erzeugt hat, den experimentellen Nachweis einer Trennung beider Centren durch Durchschneidungsversuche der Medulla oblongata in verschiedener Höhe zu führen. Aber auch, falls dieser Versuch misslingen sollte, so wäre damit unsere Annahme doch nicht widerlegt, da manche Umstände es wahrscheinlich machen, dass die Automatie dieses Schluckcentrums nur eine bedingte ist, und dass zur Auslösung seiner Impulse von 
dem thorakalen Athemeentrum ihm zuströmende Erregungen nothwendig sind.

Das wenngleich nur bedingte Fortbestehen der primitiven Schluckathmung bei vielen Reptilien erscheint auch vom Standpunkte der Entwickelungslehre aus nicht ohne Interesse, indem es sich offenbar um eine in Rückbildung begriffene Funktion handelt, welche, bei den luftathmenden Amphibien allein wirksam, auf die Reptilien, die zuerst die Rippenathmung erworben haben, nur in sozusagen rudimentärer Form übergegangen ist und endlich Vögeln und Säugern gänzlich fehlt.

\section{Nachtrag.}

In wenigen Worten möchte ich noch einiger Thatsachen gedenken, die sich schwer in den Rahmen der vorliegenden Abhandlung einreihen liessen und die deshalb bier nocb kurze Erwähnung finden mögen.

1. Im Sommer 1884 hat A r o n s on (67) Versuche im Langend orff'schen Laboratorium angestellt über Apnoe bei Kaltblütern (Fröschen und Schildkröten) und neugeborenen Säugethieren.

Es gelang ihrn nie, bei diesen Thieren einen Athemstillstand zu erzielen und als Anhänger der "Blutapnoe" fuihrt er dies darauf zurïck, dass es bei den Poikilothermen. noch nicht zu einer strengen Trennung des arteriellen und venösen Blutes gekommen ist, einmal in Folge der entweder gar nicht vorbandenen oder doch unvollständigen Trennung der beiden Ventrikel und dann (bei Schildkröten) in Folge der Communikation der Pulmonalis und Aorta durch den Ductus Botalli.

Durch dieses Verhalten sei es bedingt, dass eben überhaupt das Blut sich nicht mit Sauerstoff sättigen kann, da dem arteriellen Blut sich immer solches beimengt, welches die Lungen iberhaupt nicht passirt hat. Aeholiche ungïnstige Verlältnisse würden auch bei den neugeborenen Säugethieren maassgebend sein, wo ebenfalls der Ductus Botalli noch nicht völlig obliterirt und das Foramen ovale noch offen sei.

Als überzeugter Anbầnger der Ansicht, derzufolge der apnoische Athemstillstand als eine Hemmungswirkung des Vagus aufzufassen ist, kann ich mich nach meinen Erfahrungen an Eidechsen der Meinung A rons on's nicht anschliessen. 
Was die Athmung des Frosehes betrifft, so ist es durchaus noch nicht erwiesen, dass auf sie der Vagus jenen gewaltigen Einfluss hat, den er mit dem Auftreten der thorakalen Athmung gewinnt.

Die Resultate sind hier keineswegs sehr ibereinstimmend, und $\mathrm{Kn} 01 \mathrm{l}$ ist es trotz seiner Bemühungen nicht gelungen, die reflektorische Selbststeuerung der Athmang beim Frosche einwandsfrei nachzuweisen.

Ein vielleicht in diesem Sinne zu deutender Vorgang bestand auch nach Vagisektion, wenn auch in abgeschwächtem Maasse, noch fort.

Ausserdem hat Vagusdurchschneidung bei Fröschen nicht, wie sonst überall in der Thierreihe, Verlangsamung, sondern nach M a r t i n (68) eine ganz ausserordentliche Beschleunigung der Athmung zur Folge. Ein Ausbleiben der Apnoe aber liesse sich sehr wohl durch Hemmungsinsufficienz des reflektorischen Nervenapparates erklären, der, selbst wenn er, wie es in der That der Fall zu sein scheint, bald erregend, bald hemmend eingreift, eine Nachwirkung der Erregung nicht zu Stande kommen lässt.

Aehnlich kann man auch das Ausbleiben der Apnoe bei Neugeborenen erklären durch eine mangelhafte Entwickelung der athmungshemmenden Funktionen dieses Nerven, wie man sie nach Soltmann's bekannten Versuchen über das Hemmungsnervensystem Neugeborener erwarten könnte. Die Thatsache, dass der Vagus iiberhaupt erregbar ist, und selbst bei schwachen Strömen Verlangsamung und bei stärkeren Stillstand erzielt wird, beweist noch nichts gegen die Vermuthung, dass, wenn auch eine Erregung möglich, eine $\mathrm{Nachwirk} \mathrm{ang} \mathrm{dóch} \mathrm{aus} \mathrm{den} \mathrm{eben} \mathrm{geschilderten}$ Grïnden nicht eintritt.

Ich wïrde diesen Erklärungsversuch nicht gegeben haben, da er fast gekünstelt gegenüber der einfachen A ro n s on'schen Hypothese erscheinen muss, wenn ich nicht die sichere Beobachtung des Vorkommens der Apnoe bei Eidechsen gemacht hätte, die hier ausserordentlich leicht zu erzielen ist; denn eine kurze Ventilation löst schon langdauernde Athempausen aus. Zur Stütze meiner Ansicht möchte ich noch anführen, dass Durchschneidung der Vagi ein Zustandekommen der Apnoe unter allen Umständen bindert.

2. Einen sehr abweichenden Athmungsmodus zeigt das Cha- 
mäl e on; ich hatte diesen Winter Gelegenheit, ein Thier dieser Art beobachten zu können, das allerdings für jeden experimentellen Eingriff ein Noli me tangere war.

Obwohl es fortdauernd bei hoher Temperatur gehalten wurde, war die Athmung enorm langsam (vielleicht alle halben Stunden einmal), wobei das Thier sich ausserordentlich aufblähte; ganz allmählich fällt dann der Thorax im Laufe vieler Minuten zusammen. Bekanntlich haben die Chamäleonten Luftsäcke, in die wahrscheinlich eine für längere Zeit genügende Quantität Luft aufgenommen wird. Der Grund dieser merkwürdigen Einrichtung beim $\mathrm{Ch}$ am äle on liegt vielleicht darin, dass eine lebhafte Respiration leicht Feinde und zur Beute dienende Insekten aufmerksam machen würde; und die ganze Organisation des Thieres ist ja darauf gerichtet, möglichst unbemerkt zu bleiben. Es wäre sehr interessant, die hier offenbar sehr stark modificirten Verhältnisse einmal genauer zu untersuchen.

Uebrigens ist zu erwähnen, dass man, wenn auch selten, an Chamäleonten den sonst ganz ruhigen Mundboden sich mehrmals hintereinander lebhaft contrahiren sieht. Unter dem Einfluss dieser Contraktionen bläht sich das Thier in einer Weise auf, die noch stärker als die gewöhnliche inspiratorische Erweiterung imponirt. Auch das Cham $\ddot{a} l$ e on besitztdemnacheine Schluckat h m ung.

\section{Literaturverzeichniss über die Athmung der Reptilien.}

1) Paul Bert, Leçons sur la Physiologie Comparée de la Respiration. Paris 1870.

2) Emil Blanchard, Recherches anatomiques et physiologiques sur le système tégumentaire des Reptiles (Sauriens et Ophidiens). Annales des sciences naturelles. 4. Sẻrie. Zoologie 1861.

3) Leydig; Die in Deutschland lebenden Arten der Saurier. Tübingen 1872.

4) J. Julien, Sur la respiration des Psammodromes; Comptes Rendus 1873. pag. 585.

5) Bronn's Klassen und Ordnungen des Thierreiches. Abtheilung Reptilien. Leipzig 1890. 
6) Heinemann, Ueber die Athembewegungen der Reptilien. Pflüger's Archiv Bd. 15. 1877.

7) - Ueber nicht der Lungenathmung dienende sogenannte oscillatorische Kehlbewegungen bei Amphibien, Reptilien und Vögeln. Dasselbe Archiv Bd. 34. 1884.

8) Langendorff, Kleine Mittheilungen zur Athmungslehre. Archiv für Anatomie und Physiologie 1891.

9) Haro, Mémoire sur la respiration des Grenouilles, des Salamandres et des Tortues, Annales des Sciences Naturelles 1842. Serie II. T. XVIII.

10) Pannizza, Observations Zootomico-Physiologiques sur la respiration chez les Grenouilles, les Salamandres et les Tortues, Annales d. Sc. nat. Zool. III. Ser. T. 3. 1845.

11) Weir Mitchell and Morehouse, Researches upon the anatomie and physiologie of respiration in the Chelonia; Smithsonian Contribution to Knowledge; March 1864. Auszug in Annal. des Sciences nat. Zool. 5. Série. t. III. p. 211. 1865.

12) Townson, Observations physiologiae de Amphibiis; pars prima de respiratione. Göttingen 1794 und Partis primae continuatio (Gottingae $1795)$.

13) Duvernoy, Note sur la manière dont les Tortues respirent. Bull. Soc. philom. T. III. pag. 279 an XIII.

14) Fano, Di alcuni metodi di indagine in fiosologia; Milano-Torino 1888. p. 20.

15) R. Regnard et R. Blanchard, Comptes Rendus de la Soc. Biol. 1880. 7. Série. II. p. 197 u. p. 180 u. p. 259.

16) Schlegel, Essay sur la physionomie des serpents. Amsterdam 1837.

17) Heinemann, Ueber den Respirationsmechanismus der Rana esculenta und die Störungen desselben nach Durchschneidung der Nervi vagi. Archiv für pathologische Anatomie und Physiologie. Bd. XXII. II. Folge. II. Band.

18) Fischer, Die Gehirnnerven der Saurier. Hamburg 1852.

19) Knoll, Beiträge zur Lehre von der Athmungsinnervation, 8. Mittheilung. Sitzumgsber. d. Wiener Akad.

20) Langendorff, Kleine Mittheilungen zur Athmungslehre. Archiv für Anatomie und Physiologie 1888. p. 304.

21) - Kleine Mittheilungen etc. Dasselbe Archiv. 1891. Nr, 4.

22) Sibson, On the Mechanism of Respiration. Philos. Transact. Part. 17. p. 501.1846.

23) Gegenbaur, Lehrbuch der vergleichenden Anatomie.

24) Hermann's Handbuch der Physiologie. IV. Band. II. Theil. Leipzig 1882.

25) Lehrbuch der praktischen vergleichenden Anatomie von Vogt und Y u ng. 2. Bd. p. 640. Braunschweig 1892.

26) Milne-Edwards, Leçons sur la physiologie et l'anatomie comparée de l'homme et des animaux. Paris 1857. Bd. II. p. 395. 
27) Laborde, Compt. rend. de la soc. biol, 1884. 8. Série I. p. 305.

28) Bojanus, Anatome testudinis europaeae 1819-1821.

29) Sokolow und Luchsinger, Zur Lehre von dem Cheyne-Stoke'schen Phänomen. Pflüger's Archiv Bd. XXIII. S. 183.

30) Langendorff, Studien über die Innervation der Athembewegungen. Dritte Mittheilung. Ueber periodische Athmung der Frösche. Du Bois Arch. 1881.

31) Siebert, Die Respiration des Frosches im Verhältniss zur Ciculation. Inaugural-Dissert. 1880. Königsberg.

32) Ackermann, Deutsches Archiv für klinische Medizin. 1866. October.

33) Gad, Ueber Wärmedyspnoe. Sitzungsberichte der Würzburger phys.med. Gesellschaft. 1881.

34) Mertschinsky, Beitrag zur Wärmedyspnoe. In,-Diss. Würzburg 1881.

35) Langendorff, Ueber die in Folge von Athmungshindernissen eintretendén Störungen der Respiration. Pflïg er's Archiv Bd. 39. p. 233.

36) Silher, On the to-called heat-dyspnoe. Journal of Physiologie Vol. II. p. 191.

37) Charbonelle-Salle, Sur le mécanisme de la respiration chez les Chéloniens. Compt. rend. Acad. d. Sciences. 1883, p. 1803.

38) Compt. rend. Soc. de biol. Par. 1888. 8. s. o. p. t. 2. 51-56.

39) Compt. rend. Soc. de biol. Par. 1889. 9. s. i. 470.

40) Compt. rend. Soc. de biol. Par. 1869. 4. s. v. 22.

41) Journal de l'anatom. et physiol. Paris 1869. v. 113-139.

42) Proc. Zool. Soci. London 1879. p. 649.

43) Knoll, Ueber die Athmungsinnervation. Separatabdruck aus den Verhandlungen des Congresses für innere Medizin. Wiesbaden. V. Congress.

44) Knoll, Beiträge zur Lehre von der Athmungsinnervation. 5. Mith. Sitzungsber. d. Wiener Academie. Bd. 102. Jahrg. 1885. III. Abth.

45) Mosso, Periodische Athmung und Luxusathmung. Du Bois' Archiv 1886. Supplementband S. 59.

46) Langendorff, Untersuchungen über das Verhalten der die Athmung beeinflussenden Vagusfasern gegen Kettenströme. Du Bois' Archiv Bd. 59. 1895.

47) Meltzer, Vagus und Geschlecht. Centralblatt für die mediz. Wissenschaft. 1882. Nr. 28.

48) - Die athemhemmenden und athemanregenden Nervenfasern innerhalb des Vagus in ihren Beziehangen zu einander und zum Athemmechanismus. Archiv f. Anat. und Physiol. 1892. S. 360.

49) Kauders, Ueber den Einfluss der elektrischen Reizung der N. vagi auf die Athmung. Dasselbe Archiv Bd. 57. S. 333 .

50) Le Gallois, Recherches sur le principe de la vic. Paris 1812.

51) Flourens, Verschiedene Abhandlungen in den Comptes Rendus von $1851,1858,1862$. 
52) Rosenthal, Die Athembewegungen und ihre Beziehungen zum N. vagus. Berlin 1862.

53) Haller, De respiratione experimenta. Lausanne 1746.

54) Volkmann, Ueber die Bewegungen des Athmens. Müller's Archiv 1841. p. 337.

55) Markwald, Die Athembewegungen und deren Innervation beim Kaninchen. Zeitschr. für Biologie Bd. XXIII. N. F. Bd. V.

56) Rosenthal, Kap. Athmung in Hermann's Handbuch p. 272.

57) Berustein, Ueber die Einwirkung der Kohlensäure des Blutes auf das Athemcentrum. Du Boi s' Archiv 1882, p. 313.

58) God, Ueber automatische and reflektorische Athemcentren. Du Bois' Archiv 1886. p. 388.

59) Langendorff, Du Bois' Archiv 1887.

60) Löwy, Experimentelle Studien über das Athemcentrum in der Medulla oblongata und die Bedingungen seiner Thätigkeit. Pflüger's Archiv Bd. 42. p. 257. 1888.

61) Langendorff, Studien über die Innervation der Athembewegungen. 11. Mittheil. Du Bois' Archiv 1888.

62) Wedenskii, Ueber die Athmung des Frosches. Dies Archiv Bd, 25. 1881.

63) Martin St. Ange, Recherches sur les organes transitoires et la métamorphose des Batraciens. Ann. d. Sc. nat. 1S31. t. XXIV.

64) von Wittich, Ueber die Beziehungen der Medulla oblongata zu den Athembewegungen der Frösche. Virchow's Archiv 1866. Bd. 37.

65) S teiner, Untersuchungen über die Physiologie des Froschhirnes. Braunschweig 1885.

66) Vulpian, Centre respiratoire. Bull méd. Paris 1887. i. 531-533.

67) Aronson, Ueber Apnoe bei Kaltblütern und neugeborenen Säugethieren. Du Bois' Archiv 1885.

68) Martin, The normal respiratory movements of the frog. (Journal of Physiologie. 1878-79. Vol. I.)

\section{Hanpttheil.}

Die Athmung der Vögel.

I. Die Enpnoe der Vögel.

Graphisehe Darstellung der normalen Respiration von Vögeln habe ich nur bei Bert (1), und Knoll (2) in einer Abhandlung uiber "Myocarditis und die übrigen Folgen der Vagussektion bei Tauben" finden können. Die Bert'schen Curven, 
die von Enten, Hühnern and Tauben stammen und mittels Tambours von der Trachea ans gewonnen wurden, zeigen sehr wenig Charakteristisches, eine lückenlose Anreihung von Inspirationen und Exspirationen, wobei die letzteren im Allgemeinen etwas langsamer verlaufen, bisweilen derartig, dass sie sich aus einem steileren, der vorausgegangenen Inspiration sich anschliessenden, und einem zweiten flacheren Curvenstück zusammensetzen, wodurch die Curve eine ungefähr in der Mitte liegende Einknickung erfährt.

Viel complicirter sind die von $\mathrm{Kn}$ oll mitgetheilten, mittels der Athemflasche gewonnenen Curvenbilder, welchen im Allgemeinen auch die von mir, ebenfalls an Tauben, erhaltenen entsprechen. Im Vergleich zu den Reptilien sowohl wie anch zu den Säugethieren ist der Verlauf der normalen Respirationsbewegungen der Vögel ein ausserordentlich vielgestaltiger, weniger bei dem einzelnen Thier, das in der Regel wenigstens während der Zeit des Versuches einen einheitlichen Typus darbietet, als bei verschiedenen Individuen derselben Species.

Bisweilen weehselt die Form der Athmung innerhalb weniger Stunden in der auffälligsten Weise und kann unter sonst ganz gleichen Verhältnissen an einem Tage einen ganz anderen Charakter darbieten, als am vorhergehenden und folgenden.

Dieser Wechsel der Form und die Complicirtheit der einzelnen Curvenbilder erschwert ihre richtige Deutung in ausserordentlich bohem Grade.

Die auffallende Empfindlichkeit des sehr complicirten respiratorischen Mechanismus der Vögel gegen jedwede Störung, welche wesentlich in den eigenartigen mechanischen Verhältnissen der Athmung begründet zu sein scheint, lässt, wie schon $\mathrm{Kn}$ oll 1 bemerkt, die grosse Mannigfaltigkeit des Athmungstypus bis zu einem gewissen Grade begreiflich erscheinen, indem offenbar alle jene störenden Eingriffe, welche zum Zwecke der graphischen Verzeichnung nothwendig sind; wie z. B. Fixation des Thieres, das Einlegen der Trachealkaniule u. s. w., die Athmung mehr oder weniger tiefgreifend beeinflussen.

Es ist unter diesen Umständen nicht leicht zu entscheiden, welche und ob itberhaupt eine der mannigfachen Curvenformen als Ausdruck der eigentlichen normalen Athmung anzusehen ist.

Schon die einfache Inspektion macht es aber zweifellos, dass es sich bei den Vögeln (Tauben), wie bei Reptilien, um ein rhyth- 
misch abwechselndes Spiel exspiratorisch und inspiratorisch wirkender Muskeln handelt. Führt man nach Entfernung der Federn einen Sehnitt durch die Haut des Bauches vom distalen Ende des Sternums nach unten (hinten) und präparirt dann die Haut nach rechts und links ab, so kann man mit Leichtigkeit die kräftigen Contraktionen der Bauchmuskulatur beobachten und zwar nicht nur, wie Knoll angiebt, in Form eines zuckungsartigen "Vorschlages vor der unmittelbar hierauf folgenden Inspiration“, sondern als eine, schon vor dieser gleich näher zu erwähnenden Zuckung beginnende, verhältnissmässig langsame Contraktion.

Auch bei graphischer Verzeichnung von der Trachea aus lässt sich in jedem Falle leicht die Thatsache constatiren, dass die Bewegungen des Thorax um eine seiner Ruhestellung entsprechende Mittellage erfolgen. Es ergiebt sich dies ohne Weiteres aus dem Umstande, dass die Abscisse, welche der Schreibstift des in Ruhelage befindlichen $M$ ar e y'schen Tambours zeichnet, eine horizontale Linie darstellt, die $\mathrm{zw}$ is $\mathrm{ch}$ e $\mathrm{n}$ den in- und exspiratorischen Gipfeln, und zwar in der Regel näher den ersteren verläuft. Eine aktive Exspiration ist demnach nicht nur vorbanden, sondern sie ist in der Regel sogar das maassgebendere Moment für die Excursionsweite der Thoraxbewegung.

So einfach wie bei den Reptilien gestalten sich nun allerdings die Verhältnisse bei den Vögeln niemals, indem hier jene durch die Pausenbildung bedingte Uebersichtlichkeit der Curvenform fast immer fehlt, welche es dort, wie gezeigt wurde, ermöglicht, in jedem Falle sofort die Ruheláge des Thorax zu erkennen.

Zwar findet man auch bei den Vögeln kürzere Athempausen, doch ist die Stellung des Thorax, bei welcher sie auftreten, keineswegs eine gleichbleibend constante, und die ihnen entsprechende Linie verläuft bald über, bald unter dem Niveau der Ruhelinie.

Es ist in Folge dessen auch nicht immer ganz leicht, den aktiv in- oder exspiratorischen Charakter eines gewissen Curvenabschnittes mit genügender Sicherheit festzustellen. Oft beobachtet man, dass der Hebel in jähem Aufstieg den exspiratorischen Gipfel erreicht, worauf aber nicht sofort ein Absinken zur Ruhelinie erfolgt, sondern eine kurze Pause entsteht, während der Schreibstift in wechselnder Höhe über jener eine Horizontale verzeichnet (Fig. 26-32, Taf. IV, vergl. auch K n oll 1. c. Taf. I Fig. 2, 3, 4).

Bisweilen verläuft dieselbe der Ruhelinie (Abscisse) so nahe, 
dass kaum noch eine Differenz zu bemerken ist. Die so entstehenden Pausen fallen demnach unzweifelhaft in die exspiratorische Phase der Athmung, wenn man jede Lage des Schreibstiftes oberhalb der Abscisse als exspiratorisch und umgekehrt bezeichnen will.

Unter allen Umständen wird man solche Pausen als exspiratorisch bezeichnen müssen, wenn der vorübergehende Stillstand auf der Höh e der Exspiration erfolgt. Ist dies aber nicht der Fall, tritt vielmehr die Pausenbildung erst dann ein, wenn die exspiratoriseh wirkenden Muskeln bereits wieder theilweise erschlafft sind, so handelt es sich thatsächlich eigentlich um eine partielle (passive) Inspiration (Fig. 33, 34, 36, Taf. IV).

So beschreibt auch K noll (l. c.) Fälle, wo „der Nachlass der exspiratorischen Kräfte nach einem sehr starken Exspirationsstoss zunächst $z \mathfrak{u}$ einem weniger steilen Abfallen der Curve führt. Vor dem jäheren, durch die Inspiration bedingten Absinken folgt dann noch ein nahezu horizontal verlaufendes kurzes Curvenstück" (vergl. K noll l. c. Taf. I, Fig. 1).

Wenn man bei einer Taube die Brust- und Bauchmuskulatur freilegt und dadurch, dass man den breiten M. pectoralis major auf unblutigem Wege durch stumpfe Zerreissung des ihn mit der Nachbarschaft verbindenden fettreichen Bindegewebes zurïckschiebt, einen grösseren Theil des Thorax freilegt und siehtbar macht, so sieht man, wie fast unmittelbar an die aktive Inspiration sich eine Contraktion der Bauchmuskulatur anschliesst, und zwar besonders der seitlichen Parthien derselben. Es handelt sich dabei ohne Zweifel vor Allem um den M. obliquus abdominis externus, der mit vier bis sechs Zacken von den Processus uncinati oder der vorderen Fläche der entsprechenden oberen Rippen entspringt; die Bauchpartie liegt an der Seitenwand des Bauches, wo sie den vorderen Theil des inneren schiefen Bauchmuskels, sowie ein Stück des Rectus und Transversus bedeckt und entweder fleischig oder sehnig an den vorderen Theil des Os pubis inserirt. Die dem Sternum zugekehrte Seite beider Portionen geht in eine breite sehnige Membran über, die sich an den Seitenrand des Sternum anheftet und in der Linea alba mit der der anderen Seite verschmilzt (3). Da seine Fasern schräg von aussen nach innen verlaufen, und zwar in einer Ebene, die nur wenig zur Horizontalen geneigt ist, so ist eine ausgesprochene Wirkung auf die Rippen sehr verständlich; er verengt den transversalen Durchmesser, wäh- 
rend der sterno-vertebrale weniger beeinflusst erscheint. Die Contraktion dieses Nuskels ist mit vollster Deutlichkeit zu beobachten; sie ist ziemlich langdauernd, steigt zu einem gewissen Maximum an, um dann wieder nachzulassen. Man denkt, die Exspiration sei zu Ende, da sieht man plötzlich um die Medianebene gruppirte Muskelfasern sich contrahiren, die wohl in erster Linie dem Rectus angehören, jenem Muskel, dessen Existenz von Vic q d'A z y r (4) geleugnet, jetzt bei allen Klassen nachgewiesen ist, der, breit und relativ kurz, sich fleischig an den hinteren Rand des Sternums ansetzt und in der Mitte des Bauches in eine breite am Os pubis sich inserirende Sehne übergeht. Die erwähnte Contraktion, welche sozusagen als Nachschlag der aktiven Exspiration auftritt, nicht aber, wie K noll meint, den aktiven Theil der Exspiration allein ausmacht, verläuft ausserordentlich rasch (zuckend). Deutlich sieht man unter ihrem Einfluss das Sternum sich einziehen, sodass seine distale Spitze der Wirbelsäule sich nähert; unmittelbar darauf bewegt sich das Brustbein schon wieder nach aussen und aufwärts, gehoben von der Kraft der nun in Aktion tretenden Inspiratoren. Die anfangs sehr energische Inspirationsbewegung wird bald etwas verlangsamt, und es kann sogar, wie bei der Exspiration, zu einer kurzen inspiratorischen Pause kommen. Oft sieht man dann noch vor dem Ende der Inspiration bereits wieder die Zusammenziehung des Obliquus externus beginnen, welche eine neue aktive Exspiration einleitet.

Ich habe diese Vorgänge an. Thieren mit freigelegter Muskulatur wiederholt betrachtet, weil durch das dichte Federkleid hindurch eine genügende Einsicht sehr erschwert wird, eine direkte Inspektion aber unumgänglich nothwendig ist zur Deutung der complicirten Curvenbilder.

In allen diesen Fällen habe ich dieselben eben geschilderten Beobachtungen machen können, in denen ich deshalb nicht anstehe, die normale Form ảer Tanbenathmung zu erblicken.

Oft genug gelingt es nun, bei tracheotomirten Thieren Curven zu gewinnen, die ein ziemlich exaktes Bild dieser Vorgänge liefern. Figur 27 u. 28 (vgl. auch Fig. 2, 3, 4 von $\mathrm{Knoll}$ ) dürfte am meisten diesen Anforderungen entsprechen. Man erkennt, wie hier in raschem, exspiratorischem Ansteigen der Schreibhebel eine bestimmte Höhe erreicht, die allerdings bei den verschiedenen Respirationsbewegungen nicht ganz in einem Niveau liegt. Dann 
erfolgt eine kurze Zeit der Ruhe, während welcher die exspiratorisch wirkenden Muskeln entweder in maximaler Contraktion verharren, wobei ein horizontales Plateau entsteht, oder langsam etwas ersehlaffen, wodurch eine leichte Senkung der Pausenlinie bedingt wird.

Unmittelbar anschliessend erfolgt dann jene oben erwähnte zuckende Contraktion der Banchmuskeln, als deren graphischer Ausdruck die mehr oder weniger hohe spitze Zacke gelten muss, welche das Ende der (exspiratorisehen) Pause markirt. Die sich unmittelbar anschliessende passive Inspiration geht wie bei Reptilien meist ohne sichtbare Grenze in die aktive Inspiration über, an deren Ende sich wieder eine kurze (inspiratorische) Pause anschliesst.

Mit Rücksicht auf den eben geschilderten Verlauf der Athmung, den ich als der Norm am meisten sich nähernd bezeichnen möchte, gelingt es unschwer, auch alle anderen in ibrer Form so sebr variablen Curvenbilder zu deuten. Die nahe Beziehung des durch Fig. 28 Taf. IV dargestellten Athmungstypus za dem eben geschilderten ist ohne Weiteres ersichtlich; dentlicher noch als dort zeigt sich hier die zuckende Contraktion der Bauchmuskulatur, was in noch auffälligerer Weise an dem Curvenausschnitt Fig. 26, Taf. IV hervortritt.

Hier zeigt sich die spitze Zacke von dem Anfangstheil der aktiven Exspiration durch eine nur wenig oberbalb der Ruhelinie verlaufende, der beginnenden Erschlaffung der exspiratorisch wirkenden Muskeln (bes. des Obliquus abdominis) entsprechende, geneigte Linie scharf getrennt. Die Ruhestellung des Thorax wird durch die horizontale Gerade bezeichnet, welche während der zeitweisen Unterbrechung der Verbindung zwischen dem Marey'schen Tambour und der Trachealkaniule gezeichnet wurde.

In diesem Falle konnte ich mich durch gleichzeitige Beobachtung des zeichnenden Hebels und der vorher freigelegten Banchmuskulatur mit aller nur wünschenswerthen Sicherheit überzeugen, dass die Contraktion des Obliquus schon eintrat, bevor der Thorax in die der Abscisse entsprechende Ruhelage zurückgekehrt war.

Auch der in Figur 31 und 32 wiedergegebene Respirationsmodus dürfte nach dem Gesagten leicht verständlich sein.

Oft genug kann man beobachten, dass die der Inspirationsphase vorausgehende "vorschlagsartige" Zacke überhaupt ganz 
verschwindet, und nicht selten finden sich beim selben Thiere alle Uebergänge von starker Ausbildung bis zum völligen Fehlen, sei es, dass dieser Theil der Exspiration wirklich ausfällt, wie es bisweilen den Anschein hat, oder dass die Zusammenziehung der Banchmuskulatur einzeitig und nicht, wie in der Mehrzahl der Fälle, zweizeitig erfolgt. Dann erbält man entweder Curven wie Figur 35, Taf. IV, wo Exspiration und Inspiration nur durch kurze Pausen auf den böchsten resp. tiefsten Punkten der Curven von einander getrennt sind, oder solche, bei welchen der exspiratorische Gipfel spitz erscheint und unmittelbar in die Inspiration übergeht. Mit grosser Regelmässigkeit findet man dieses Verhalten nach einseitiger und doppelseitiger Vagussektion, wobei ausserdem stets zu beobachten ist, dass der Hebel von seiner höchsten Exspirationsstellung erst schneller, dann langsamer zur Ruhelage absinkt, woranf erst die aktive Inspiration einsetzt. Hierdurch erhalten die den Vagustypus repräsentirenden Curven das Gepräge einer ausserordentlichen Regelmässigkeit, worauf später noch zurïckzukommen sein wird.

Im Allgemeinen kann man sagen, dass das in einem gegebenen Falle bestehende Verhältniss zwischen Exspiration und Inspiration beim selben Thiere während längerer Zeit constant bleibt, sodass eine solche Curvenreihe einen ziemlich regelmässigen Charakter zeigt.

Tritt z. B. ein partielles Erschlaffen der Exspirationsmuskeln vor dem zuckenden Nachschlag ein, so wiederbolt sich dieser Vorgang dann bei demselben Thier ungefähr in gleicher Weise bei jeder einzelnen Athmung; und wenn man die tiefsten Punkte der entsprechenden absteigenden Curvenlinien verbindet, so liegen dieselben annähernd in einer Geraden.

Fehlt jene Zacke, so ist dieser Ausfall für dasselbe Thier meist constant; fällt nach der aktiven Exspiration der Hebel erst langsam $a b$, um dann später plötzlich in steilerer Richtung nach unten zu sinken, so liegen die Punkte, wo diese gesteigerte Bewegungsgeschwindigkeit einsetzt, meist in ungefähr demselben Niveau, wie die zahlreich beigefïgten Curven, die so ziemlich alle von mir beobachteten Varietäten wiedergeben, zur Genüge beweisen. Ihr Studium lehrt auch, dass für die Inspiration mutatis mutandis dieselben Verhältnisse Gültigkeit haben (s. Fig. 26-34, Taf. IV). 
Sie sind es, die dem einzelnen Bild seinen regelmässigen Charakter sichern.

Die mannigfaltigen Abweichungen aber im Aussehen der verschiedenen Curven sind zurückzuführen auf das Vorhandensein oder Fehlen der oft erwähnten Zacke, auf den Umstand, dass sich dieselbe der Curvenlinie aufsetzen kann zu einer Zeit, wo die vorhergehende Contraktion der Exspirationsmuskeln eben ihren grössten Werth erreicht hat, oder am Ende eines exspiratorischen Gipfelplateaus oder endlich im Verlauf der sich anschliessenden Inspiration.

Sehr wesentlich kommt auch die Art in Betracht, wie die Inspiration in die darauffolgende Exspiration iibergeht. Unter Umständen kann, wie erwähnt, die letztere bereits durch aktive Contraktion der Bauchmuskeln beginnen, während die Inspiration noch im Gange ist; auch scheint es vorzukommen, dass eine Athmungsphase aktiv wird, bevor noch der Thorax zu seiner Ruhelage zurückgekehrt ist.

Der Ansicht von Knoll, der nur die zuckungsähńliche Zacke als Ausdrúck einer aktiven Exspiration betrachtet, kann ich mich nicht anschliessen, indem die Beobachtung der blossgelegten Banchmuskulatur in jedem Falle lehrt, dass sie sich in ihrer Gesammtheit in der Regel schon vor jener nachschlagsartigen Zuckung kräftig zusammenzieht, sodass sicher ein viel grösserer Theil der exspiratorischen Phase rein a $\mathrm{kt}$ i $\mathrm{v}$ ist.

Bei der Verzeichnung der Carven muss man bei Vögeln gewisse Vorsichtsmaassregeln beachten, welche bei Reptilien nicht, oder doch nicht wesentlich, in Betracht kommen.

Schaltet man nämlich in den Verlauf des den Tambour mit der Trachealkanïle verbindenden Schlauches in der sonst üblichen Weise eine Athmungsflasche von entsprechenden Raumverhältnissen ein, so sieht man sehr rasch eine allmählich zu den höchsten Graden sich steigernde Dyspnoe eintreten, wodurch eine nur einigermaassen längere Aufzeichnung unmöglich gemacht wird. Schon K n o ll (2) ist dies aufgefallen, und er war genöthigt, immer nach Verzeichnung nur weniger Curven die Versuche zu unterbrechen.

Wenn es darauf ankommt, die Form der Athemschwankungen des intrapulmonalen Druckes mit möglichster Genauigkeit festzustellen, so bleibt in der That kein anderes Mittel iubrig, und man hat nur dafür zu sorgen, dass die Verbindung zwischen der Ath- 
mungsflasche und der Trachea des Thieres durch möglichst kurze und weite Schlauchstücke vermittelt wird, um die Entwickelung einer "Rohrdyspnoe" thunlichst zu verzögern. Handelt es sich aber darum, die Athmung während längerer Zeit ununterbrochen graphisch zu verzeichnen, so empfiehlt es sich mehr, eine T-Canüle zu benützen, deren einer Schenkel mit dem Tambour, der andere mit der Trachea in Verbindung steht, während an das dritte freie Ende ein kurzer Gummischlauch angesteckt wird.

Durch Verengerung des letzteren hat man es ganz in der Gewalt, die Höhe der zu verzeichnenden Curven beliebig abzustufen. Unter diesen Umständen macht sich Dyspnoe niemals in störender Weise bemerkbar.

Was die Frequenz der normalen Athmung betrifft, so ist dieselbe eine ausserordentlich inconstante; sie bewegt sich bei Tauben im Allgemeinen zwischen dreissig and sechszig in der Minute, doch kommen auch grössere oder geringere Werthe, obgleich selten, vor. Jeder Eingriff steigert die Zahl der Athemzïge oft in's Excessive.

Schmerzen bewirken eine kurze Pause mit anschliessender starker Beschleunigung; ebenso wirkt Fixation und vor Allem das Einlegen einer Trachealkanüle.

B ert hat auch für die Vögel, ähnlich wie bei Reptilien, Sängethieren, Fischen ete., Untersuchungen angestellt uiber die respiratorische Frequenz bei verschiedenen Arten und die auffallende Thatsache festgestellt, dass die Vögel nnverhältnissmässig langsamer athmen als die Säugethiere. Die grossen Vögel athmen mit einer erstaunlichen Langsamkeit; der Pelican und der bengalische Marabout viermal in der Minute, der Condor sechsmal, Zahlen, die unter den Säugetbieren nur bei den grössten Species vorkommen.

Die geringste Frequenz zeigt der neuholländische Casuar, welcher in der Ruhe nur zwei bis dreimal pro Minute athmet.

"C'est la un premier fait, curieux en lui-même et que ne permettait pas d'attendre la reputation d'énergique respiration justement méritée par les Oiseaux."

Die normalen Athembewegungen werden von bestimmten Bewegungen der Plicae ary-epiglotticae begleitet, die allerdings nur recht geringfügiger Natur sind. Bei der Inspiration weichen sie 
etwas auseinander, bei der Exspiration näbern sie sich wieder ein wenig, doch nie in dem Grade, dass ein völliger Verschluss der Glottis eintritt, falls nicht, wie K n oll sagt, Hustenstösse oder Schluckbewegungen intercurriren.

Auch bei den Tauben ist, ähnlich dem Verhalten bei Reptilien und Säugethieren, die Cadaverstellung des Kehlkopfes eine $\mathrm{O}$ e f $\mathrm{f}$ n u n gs st el l u ng, und man erhält durch die Beobachtung durchaus den Eindruck, dass es sich auch hier um eine den Athembewegungen entsprechende rhythmische Schwingung der Plicae ary-epiglotticae, um eine Mittellage handelt. In einigen Fällen konnte ich die Beobachtung machen, dass die Kehlkopfränder ihre jeweilige exspiratorische oder inspiratorische Stellung nicht in einer kräftigen Bewegung erlangten, sondern durch eine Reihe rasch auf einander folgender Contraktionen, die die Kehlkopfränder in eine Art zitternde Vibration versetzten.

Hierbei handelte es sich stets um Thiere, die durch starken Blutverlust schon erheblich geschwächt waren, und zwar ging diese abweichende Bewegungsform Hand in Hand mit analogen Vorgängen in den eigentlichen Respirationsmuskeln; die Curven hatten dann ein eigenthümlich gezacktes Aussehen.

Der Kehlkopf als Ganzes zeigt bei normaler Athmung eigentlich gar keine Lageveränderung ${ }^{1}$ ); manchmal glaubt man ein schwaches inspiratorisches Vorwärtsrücken und eine exspiratorische Riickwärtsbewegung wahrzunehmen, doch ist dies, wenn iuberhaupt vorhanden, minimal, und $\mathrm{K}$ n o 11 leugnet es vollständig.

In die Innervation der Larynx tritt neben dem N. vagus noch der Hypoglossus ein. Der hier in Frage kommende Ast der letz-

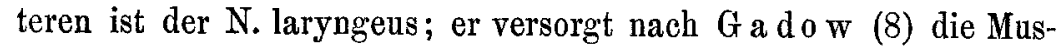
keln des oberen Kehlkopfes und die letzteren mit dem Zungengeriist und mit der Trachea und Furcula verbindenden Muskeln.

Dabei steigt der Nerv an der Seite der Luftröhre herab und innervirt schliesslich sämmtliche Muskeln des unteren Kehlkopfes.

Der Nervus vagus, um dessen wesentlichste anatomische Ver-

1) Doch kann man oft genug die Beobachtung machen, dass namentlich bei jungen erregten Thieren ein sehr kräftiges Muskelspiel am Kehlkopf sich entwickelt, welches durchaus dyspnoischen Charakter trägt (s. u.), ohne jedoch dyspnoisch bedingt $z u$ sein. Dasselbe geht früher oder später in die normale Form der Kehlkopfbewegung über. 
hältnisse gleich hier zu erwähnen, begleitet die Vena jugularis interna während ihres Verlaufes am Halse, nachdem er vorher hoch oben die Carotis gekreuzt hat. Oberhalb des Zungenbeines verbindet ihn eine starke Anastomose mit dem Hypoglossus.

Streckenweise ist er mit dem Nervus glosso-pharyngeus durch eine Bindegewebsscheide verbunden, ohne dass jedoch ein Fasernaustausch vorzukommen scheint.

Am Oesophagus entlang verlaufend tritt er zwischen dem Plexus brachialis und der Arteria carotis in die Brusthöhle, krenzt den Bronchus derselben Seite und verzweigt sich dann auf Lunge, Herz und Intestinaltractus in complicirter Weise. Wo er sich dem Bronchus nähert, gehen von ibm ausser den Rami pulmonales der Ramus recurrens s. laryngeus ab, welch' letzterer das untere Ende der Luftröhre und den Oesophagus versorgt; sein Rest tritt als Ramus cardiacus zum Herzen.

Es scheint demnach, dass der Ramus laryngeus N. hypoglossi die sensible und motorische Innervation des gesammten oberen Kehlkopfes besorgt. In der That kann man den Vagus in seinem ganzen Verlaufe am Halse blosslegen und an dem höchsten überhaupt erreichbaren Punkt in nächster Nähe des Schädels durehtrennen, ohne überhaupt nur die geringsten Störungen im Muskelspiel des Kehlkopfes hervorzubringen; im Gegentheil bewirkt Vagisektion, wie später genauer zu schildern sein wird, eine ganz ausserordentliche Thätigkeitssteigerung der gesammten laryngealen Muskulatur. Knoll (2) giebt an, dass er bei Tauben und Hiuhnern einen feinen Vagusast aufgefunden bat, der ebenso wie der R. laryngeus hypoglossi, in der Höhe des Znngenbeines abzweigt und in den Kehlkopf ubbergeht. Motorische Elemente scheint dieser Nerv nicht zu führen. $\mathrm{Z}$ a n d e r (27) nimmt freilich an, dass gewisse Folgeerscheinungen der Vagisektion am Kehlkopfe darauf zurückzufïhren seien, dass durch diesen Eingriff gewisse, von rückwärts verlaufende Vagusfasern ausgeschaltet werden, welche sich unter normalen Verbältnisssen an der Innervation betheiligten und Muskeln versorgten, welche in antagonistischem Gegensatz zu den vom Hypoglossus innervirten stünden. Hiervon aber später. Sicher ist, dass auch nach Vagisektion an den verschiedensten Stellen die Sensibilität des Keblkopfes erbalten bleibt, während Durchschneidung des Hypoglossus die Sohleimbaut des Larynx anästhetisch macht und die Mobilität aufbebt. 
Es sei hier noch eine kurze Beschreibung des oberen Kehlkopfes der Vögel und seiner einfachen Muskulatur eingefügt, die ich im Wesentlichen aus Bronn's „Klassen und Ordnungen des Thierreiches" (8) entlehne. Er liegt binter der Zungenwurzel, öffnet sich dureh die Stimmritze in der Mundböhle und wird durch den sogenannten Kiel oder Stiel des Zungengerüstes gestützt, den ein starkes Band mit dem ventralen Kehlkopfknorpel verbindet. Die Rima glottidis ist ein länglicher Spalt; eine Epiglottis ist meist nicht vorhanden oder höchstens durch eine jeder knorpeligen Grundlage entbehrende quere Hautstelle angedeutet. Das knorpelige, theilweise verknöcherte Gerïst des Kehlkopfes besteht meist aus sechs Stiicken, dem ventralen Hauptstück, wahrscheinlich dem Cricoid der Säugethiere entsprechend, an das sich nach binten und dorsalwärts je ein kleiner Knorpel von halbkreisförmiger Gestalt anschliesst; ferner das zwischen den beiden letzteren befindliche Procricoïd (nach F iu r bringer), das an seinem vorderen oberen Ende jederseits eine Gelenkfläche für die beiden Cartilagines arytenoideae besitzt. Diese beiden umgeben beweglich die Stimmritze; an sie setzen sich auch der M. sphincter s. compressor und der M. dilatator laryngis an, die durchaus dem Kehlkopf selbst angehören; beide entspringen rom Cricoid; doch setzt sich der erstere meist an der inneren, der letztere an der nach aussen gerichteten Fläche des Arytenoides seiner Seite an. Ausserdem scheinen noch unter Umständen Muskelbündelchen aufzutreten, die von einem Arytenoid zum anderen laufen, und zwar sowohl vorn als hinten.

Ihrer Natur nach werden natürlich auch sie als reine Constrictoren aufzufassen sein.

II. Der Mechanismus der Vogelathmung.

A. Der respiratorische Knochen- und Mnskelapparat der Vögel.

In vieler Beziehung sind die mechanischen Verhältnisse der Vogelathmung complicirter und schwerer zu beurtheilen, als jene der Reptilien oder gar der Säugethiere, bei welch' letzteren durch die Entwickelung eines ächten muskulösen Zwerchfelles das verwickelte Spiel der Rippenathmung mehr in den Hintergrund gedrängt wurde. 
Aus dem Jahre 1833 stammt eine „De avium respiratione“ betitelte kleine Arbeit (5), welche, z. Th. allerdings längst veraltet, doch bezüglich der mechanischen Verhältnisse der Thoraxathmung sehr klare und beachtenswerthe Angaben entbält. 1869 erschien dann im Archiv fur Anatomie und Physiologie eine Untersuchung von $\mathrm{M} \mathrm{ag} \mathrm{n} \mathrm{u} \mathrm{s}$ (3), welche in sehr eingehender Weise namentlich die respiratorischen Muskeln der Vögel behandelt, während $\mathrm{Sibs} 0 \mathrm{n}$ in seiner ausgezeichneten Abhandlung "Ueber den

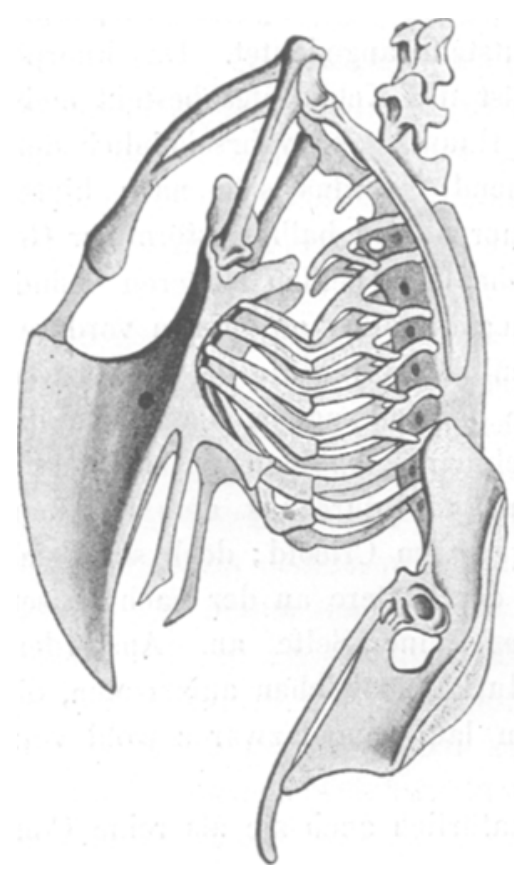

Fig. 7.

Thorax, Sehultergürtel nnd Becken von Ciconia (nach Gegenbauer).
Mechanismus der Respiration" die einschlägigen Verbältnisse in geradezu mustergiiltiger Weise auseinandersetzt, sodass sich etwas wesentlich Neues eigentlich kaum noch hinzufügen lässt (6).

Mit Rüeksicht auf spätere Erörterungen muss ich mir aber demungeachtet verstatten, die betreffenden Thatsachen, wenn auch in möglichster Kürze, übersichtlich darzustellen (vgl. Fig. 7).

Alle Vögel besitzen wahre und falsche Rippen. In typischer Weise sind die wahren Rippen ans zwei Hauptabschnitten zusammengesetzt: dem Dorsaltheile (eigentliche Rippe) mit dem Hamulus s. Processus uncinatus ${ }^{1}$ ) und dem Sternal theil e (Sternocostalknochen), welcher die Verbindung der ersteren mit dem Brustbein vermittelt.

Die Ossa sternocostalia, die den verknöcherten Rippenknorpeln der Reptilien (Saurier) und den Sternalknorpeln der Säugethiere analog sind, sind im Allgemeinen kürzer, als die platten

1) Derartige Fortsätze finden sich sonst nur bei Krokodilen und der uralten neuholländischen Saurierspecies Hatteria. 
Dorsalrippen, und nur die letzten zeigen ungefähr gleiche Länge wie diese. Sie sind schief nach vorn gerichtet und mit ihrem unteren Ende in eine an dem Seitenrande des Brustbeines ausgekehlte Rinne eingelassen, während ihr oberes Ende unter einem fast rechten Winkel an das distale Ende der entsprechenden Vertebralrippe stösst und mit diesem gelenkig verbunden erscheint.

Der Körper aller dieser Knochen ist cylindrisch und nur die sternalen Enden erscheinen kolbig verdickt, während (bei der Taube) das proximale Ende der beiden letzten Sternocostalknochen, die fast horizontal verlaufen, bedeutend abgeplattet ist.

Jede Rippe erscheint an den Brustwirbeln mittelst zweier abstehender Gelenkköpfe eingelenkt, der obere und hintere Kopf, das Capitulum, an dem Querfortsatz, der untere und vordere, das Tuberculum, an dem Wirbelkörper selbst, der seitlich dafür eine kleine Gelenkhöhle zeigt.

Das erste Rippenpaar setzt sich an den 3. Brustwirbel an. Etwa von der Mitte des Hinterrandes der 4 ersten Rippen springt ein nach hinten und unten gekrümmter, platter Fortsatz vor, dessen freies Ende sich der folgenden Rippe auflegt.

Man nimmt an, dass durch diese Hakenfortsätze (Processus uncinati) die Festigkeit des Brustkorbes wesentlich gesteigert wird.

Philomathinsky (l. c.) sagt: „Sunt autem hi processus ad respirationem auxiliandam (indem nämlich die bei der Inspiration gespannten Bänder, die sie locker an die Rippen befestigen, die Tendenz haben, beim Nachlass der Inspiration die gehobenen Rippen wieder in ihre Ruhelage zurückzuführen) eumque ad finem costis concessi, ut iis majus esset robur; ne vehementi pectoris compressione frangantur".(?)

Es giebt bei Tauben 3 Paare falscher, nicht an das Brustbein befestigter Rippen, ein vorderes und 2 hintere; sie sind nach demselben Plane gebaut wie die wahren Rippen, lenken sich auch auf dieselbe Weise mittels zweier Köpfe an die Wirbel an, sind aber kürzer und enden frei in den Muskeln.

Das B r u s t b e in hat, wie bei fast allen Carinaten, die Gestalt eines Schildes, das auf seiner gewölbten ventralen Fläche einen senkrechten Kamm trägt, an welchen sich die grossen Brustmuskeln anheften. Man kann sonach seine Gestalt im Ganzen mit der eines Bootes vergleichen, dessen Kiel der Kamm wäre. Der dorsalwärts ausgekehlte Körper des Brustbeinschildes zeigt einen, in Form 
eines Circumflexes ansgeschweiften Rand, dessen Witte nach vorn vorspringt. An diesen Vorsprung heften sich die das Rabenbein an das Brustbein befestigenden Sehnenbänder.

Der Vorderrand zeigt seitlich tiefe Auskeblungen, in welche die unteren Enden der Rabenbeine eingelassen sind. Die rerdickten Seitenränder des Brustbeinschildes sind vorn durch eine tiefe Rinne ausgekehlt, welche in je 5 Gruben zur Aufnahme der Sternokostalknochen abgetheilt ist. Nach vorn und hinten ist dieser Ausschnitt stark umwallt. Der vordere Wall springt nur wenig in dem sogenannten Costalfortsatze vor; der hintere dagegen setzt sich in eine lange abgeplattete Lamelle fort, die der hintere Seitenfortsatz genannt wird.

Hinter diesem ist der Brustbeinrand tief ausgeschnitten und scbweift sich dann zu einer Ecke aus, welche von einem kleinen Loche durchbrochen wird. Der Kamm bildet stets eine unmittelbare senkrechte Fortsetzung des Schildes auf der ventralen Mittellinie; sein unterer regelmässig gebogener Rand ist etwas verdeckt und läuft nach vorn in einen kurzen Sporn aus, an welchen das Gabelbein mittels einer kurzen aber starken Sehne befestigt ist.

Nach diesen nothwendigen anatomischen Details, welche ich dem Lehrbuch der vergleichenden Anatomie von $\mathrm{V}_{0} \mathrm{gt}$ und Y u $\mathrm{g}$ (7) entlehne, dürfte das Verständniss der der Athmung dienenden Thoraxbewegungen kaum erheblichen Schwierigkeiten begegnen.

Man sieht ohne Weiteres, dass der ganze Mechanismus sehr wesentlich von dem der Säugethierathmung abweicht, dagegen mit den bei Reptilien, insbesondere Sauriern, gegebenen Verbältnissen viel Uebereinstimmung zeigt.

Bei den Säugethieren bilden Rippen und Brustbein gewissermaassen ein starres Ganzes, das gemäss der Richtung der Drehungsaxen in den Costo-vertebral-Gelenken gehoben werden und sich auch seitlich erweitern kann. Die gelenkigen Verbindungen zwischen Sternum und Rippen sind derartig beschränkt, dass irgend ausgiebigere Bewegungen hier ziemlich ausgeschlossen erseheinen.

Ganz anders verhält es sich bei den Vögeln. Sowohl die Vertebral- wie die Sternalgelenke stellen, wie bereits $\mathrm{Mag} \mathbf{n}$ u s (1. c.) bemerkt, Ginglymi dar, in welchen die Bewegung um eine bei den ersten von vorn nach hinten, bei den letzteren quer von aussen nach innen gerichtete Axe erfolgt. Da starke Kapselbän- 
der eine Bewegung in anderer Richtung verhindern, so folgt, dass die Hauptaktion der Sternal- und Vertebralrippen in einer Hebung derselben besteht, während die Rotation nach aussen wesentlich eingeschränkt erscheint. Wohl aber ist diese in geringerem Grade möglich in dem Sternal- und Dorsalrippe verbindenden Gelenke, dessen Anordnung eine schwächere Aussenrotation zulässt.

Die Sternal- und Vertebralrippen verhalten sich, was die Form ihrer Bewegung anlangt, in gewissem Sinne antagonistiseh.

Während die Vertebralrippen von der Wirbelsäule aus nach vorwärts und abwärts ver. laufen, erstrecken sich die Sternalrippen von vorne nach rückwärts und abwärts (vergl. das Schema Fig. 8.); während bei der Hebung das distale Ende der Dorsalrippen sich von der Wirbelsäule entfernt, entfernt sich das an jene

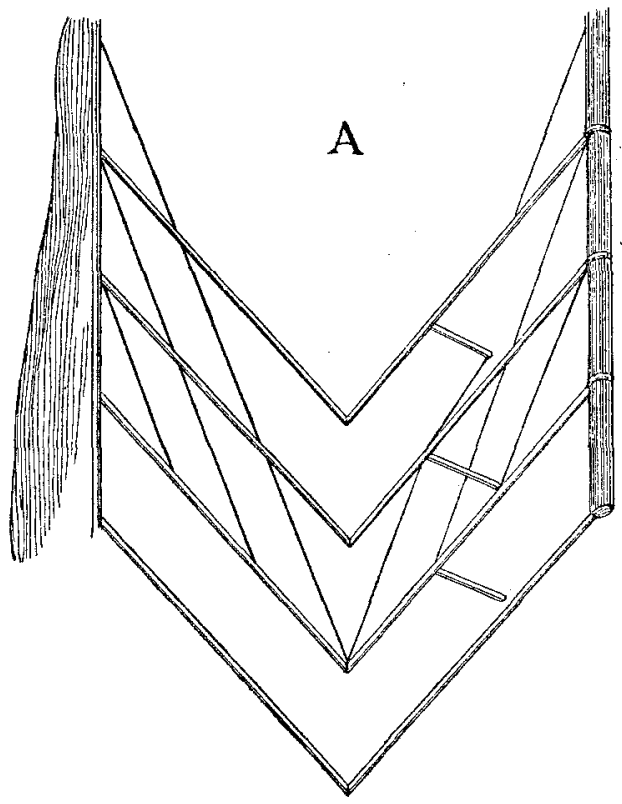

Fig. $8 \mathrm{~A}$.

Schema der Rippenbewegung bei Vögeln (nach Sibson) Exspirationsstellung. eingelenkte Ende der Ossa sterno-costalia umgekehrt vom Brustbein.

Die Folge davon ist, dass der Winkel, in dem beide Rippen firstartig zusammenstossen, und der in der Cadaverstellung praeter propter einen Rechten beträgt, zu einem stumpfen sich gestaltet, wodurch die Entfernung zwischen Wirbelsäule und Brustbein sehr erheblich vergrössert wird. Da nun die Wirbelsäule völlig starr ist und nicht nach rückwärts ausweichen kann, so folgt, dass, wenn die Rippen in der angegebenen Weise gehoben werden, das Brustbein nach vorn ausweichen muss. Dass dies in der That geschieht, davon uberzeugt man sich durch einen Blick auf den des Federkleides entblössten Thorax, und auch Fig. 8. A und B, der Sibson'schen Arbeit entlehnt, macht den Mechanismus sofort verständlich. 
Durch die Vergrösserung des von den beiden Rippenknochen eingeschlossenen Winkels wird also das Sternum nach auf- und vorwärts bewegt; aber diese Bewegung betrifft nicht alle seine Theile in völlig gleicher Stärke. Dies beruht auf folgenden Umständen:

Vor Allem kommt in Betracht, dass der Winkel, welchen die Sternal- und Vertebralrippen einschliessen, bei den vorderen ächten Rippen beträchtlich grösser ist, als bei den hinteren, so dass bei einer Hebung jener ein viel geringerer Spielraum gegeben ist. Je weiter man nach hinten geht, um so spitzer wird dieser Winkel, dessen Vergrösserung eben der maassgebendste Faktor ist. Dann aber ist die Thatsache von Wichtigkeit, dass die Gesammtlänge von

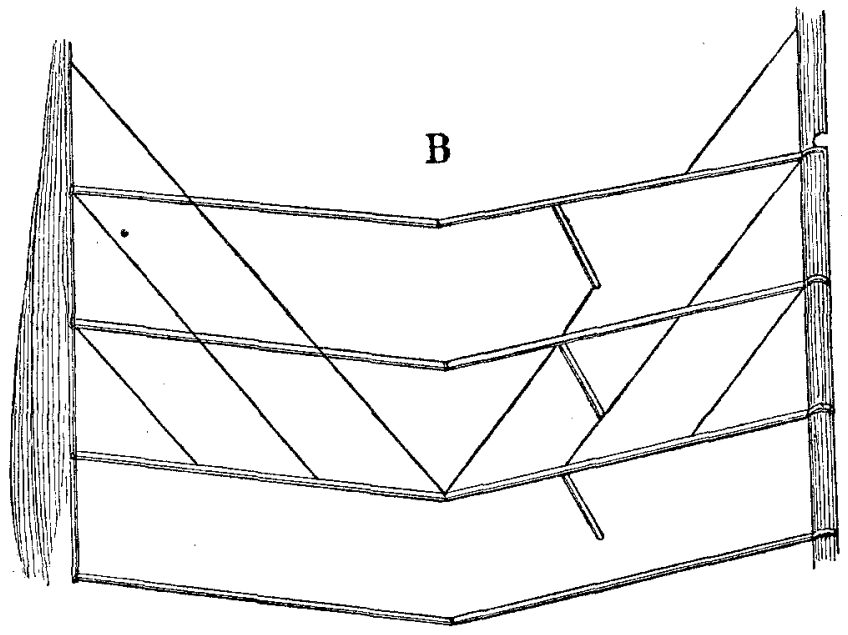

Fig. $8 \mathrm{~B}$.

Schema der Rippenbewegung bei Vögeln (nach Sibson) Inspirationsstellung.

Sternal- und Dorsalrippe vorn beträchtlich geringer ist als binten, so dass also auch aus diesem Grunde die hinteren Thoraxparthien eine grössere Erweiterungsfähigkeit erhalten müssen. Damit steht im Einklang, dass bei guten Fliegern, sowie auch bei gutlanfenden Vögeln, die Rippen sehr weit nach rückwärts verlaufen und so besonders geeignet erscheinen, den Brustraum, der in diesen Fällen durch das weit nach hinten reichende Brustbein von Haus aus schon sebr geräumig erscheint, noch bedeutend zu vergrössern und so Platz für die Füllung der ansehnlich entwickelten Luftsäcke zu schaffen ${ }^{1}$ ).

1) Die geschilderte Form der Rippenbewegung hat schon Philoma. 
Diesen Modus der Thoraxerweiterung durch in die Continuität der Rippen eingeschaltete Gelenke finden wir bei den Säugethieren nicht. Dagegen ist er, wie bereits erwähnt, bei gewissen Reptilien wenigstens angedeutet. Bei Sauriern schon sind die vorderen und hinteren Rippentheile in beschränktem Maasse gegen einander beweglich, wenn auch die Hauptbewegung sich analog dem Verhalten der Sängethiere in den Costo-vertebral-Gelenken dadurch vollzieht, dass in ihnen einmal die Rippen nach aufwärts gehoben und nach auswärts rotirt werden. Noch markanter aber findet man dies Verhalten am Chamäleon ausgeprägt, wo man am gänzlich unversehrten Thiere wäbrend der mäcbtigen Inspiration die Rippenwinkel sich nicht nur nach aussen bewegen, sondern auch deutlich sich vergrössern sieht.

Eine durchaus unbefriedigende Anschanung aber die Thoraxerweiterung hat $\mathrm{Magn} \mathrm{n}$ s entwickelt. Nach ihm ist die Bewegungsfähigkeit des Thorax als Ganzes eine äusserst geringfügige, „so dass man sie ruhig ignoriren kann, während dagegen die $\mathrm{M}_{0}$ bilität der einzelnen Theile derselben, speciell der Rippen und Brustbeinrippen, eine sehr ausgesprochene ist."

"Das sehr breite und starke Brustbein verhindert schon einmal durch seine bedeutende Entwickelung eine grössere Beweglichkeit, und andererseits fehlen ihm auch die bewegenden Muskeln. Heber des Brustbeins, wie wir sie bei den Sängethieren als Sterno-cleidomastoideus finden, entbehren die Vögel vollständig und mit ihnen natürlich anch die ausgiebigere Bewegung des Sternums nach dieser Seite hin ....

„Ich möchte nur eine Bewegung gelten lassen, und das ist ein Nachanssendrängen des Sternums, bedingt durch die Füllung der unter ihm liegenden Luftsäcke. Diese minimale Bewegungsfähigkeit des Brustbeins bietet den starken Flugmuskeln eine sichere, feste Basis zur Entfaltung ihrer Wirksamkeit."

„Cuvier vergleicht den Bau und die Bewegungen des Vogelthorax mit einem Blasebalg; die hintere Thoraxwand stellt die

tinsky richtig erkannt wenn er sagt: „Articulus vero mobilis illarum (sc. d. Sternalrippen) cum costis vertebralibus sub angulo obtuso, cuius apex deorsum et retrorsum spectat, dilatationem ampliorem thoracis admittit, ita ut tempore inspirationis os sternum a columna vertebrali, dum angulus obtusior redditur, satis superque remotum sit." 
eine unbewegliche Seite desselben dar, die vordere Wand, also das Brustbein, die andere, während die Seitenwände dem Leder desselben entsprechen, welches die Hauptbewegungen ausfülırt."

Aus unseren Darlegungen ergiebt sich ohne Weiteres, dass die Ausführungen von Magnus dem wirklichen Sachverhalt nicht entsprechen. Eine Hebung der Rippen, bei der sie sich gleichzeitig strecken, ist ja nur möglich durch Vorwärtsschieben des Sternums, das hierbei gleichzeitig gehoben wird. Hierin, nicht in irgend welchen direct angreifenden Muskeln, ist die Bewegungsursache des Brustbeins za suchen.

Den Antheil, den die Dorsalrippen an der Erweiterung der Leibeshöhle nehmen, wird vielfach sehr unterschätzt.

Die Gegenwart der Hakenfortsätze soll ihre freie Beweglichkeit direkt hemmen, so dass sie als starre oder fast starre Fortsätze der Wirbelsäule aufzufassen wären, zwischen denen die bewegenden Muskeln in Fortfall gekommen sind. Dies ist aber keineswegs in diesem Grade der Fall und hat höchstens für die den Wirbeln benachbarten Theile der Dorsalrippen Gültigkeit; ein Blick auf das Diagramm Fig. A ergiebt, dass eine kräftige Hebung namentlich der vorderen Portion der Spinalrippen eine mechanische Nothwendigkeit ist, und sowohl die hier stark entwickelten Muskeln als auch die Inspektion des lebenden Thieres geben unwiderlegliche Beweise. Wir werden später sehen, dass die kräftige Excursion gerade der Dorsalrippen das maassgebendste Moment bei der Füllung und Entleerung der langen darstellt.

Der Modus der Exspiration ergiebt sich nunmehr von selbst. Bei ihr spitzt sich der Rippenwinkel zu, in Folge dessen nähert sich das Brustbein der Wirbelsäule. Wie bei der Inspiration sich die Intercostalräume erweitern, verengern sie sich bei der Exspiration, und zwar derartig stark, dass meistens die zwischen den Sternalrippen liegenden Theile der Intercostalräume völlig zum Verschwinden gebracht werden, und die Rippen sich unmittelbar aneinanderlegen. Weniger markant ist die intercostale Verengerung zwischen den Dorsalrippen, obwohl auch hier, namentlich in den vorderen Parthien, ganz deutlich ausgeprägt.

Der respiratorische Muskelapparat.

Eine scharfe Trennung von Athemmuskeln und Extremitätenmuskeln (soweit sich letztere am Thorax ansetzen) lässt sich bei 
Säugethieren nur schwer durehführen, weil hier anch der Pectoralis major etc., je nachdem Thorax oder Oberarm das Punctum fixum darstellen, respiratorisch funktioniren können.

Da bei den Vögeln der Humerus nie in dem Grade festgestellt werden kann, dass er als Punctum fixum dienen könnte, so lässt sich hier eine Unterscheidung von Respirationsmuskeln und Flugmuskeln mit aller Sicherheit durchführen.

In die Gruppe der letzteren gehören die mächtigen Muskelmassen des Pectoris major, medius, minimus und quartus, sowie die von Schulterblatt und Wirbelsäule kommenden Muskeln. Sie scheiden deshalb von vornberein bei unserer Betrachtung aus, die sich naturgemäss in zwei Abschnitte gliedert, einer die Inspiratoren, der andere die Exspiratoren behandelnd.

Die Intercostales externi und interni mit ihrer auch hier strittigen Funktion sollen dagegen gemeinsam abgehandelt werden.

\section{x) Inspirationsmuskeln.}

1) Scaleni. Sie feblen bei Vögeln entweder ganz, oder sind jederseits auf einen langen, aber äusserst schwachen Muskel beschränkt, der nach $\mathrm{Mag} \mathrm{n} \mathrm{us}$ vom Processus transversus des vorletzten Halswirbels entspringt und sich am freien Ende der zweiten Rippe anheftet.

Dem Scalenus primus der Säugethiere entsprechend, ist er funktionell so gut wie gänzlich bedeutnngslos.

2) Musculusteres interprimam et secundum costam. Ein rundlicher schmaler Muskelbauch, der von der Spitze der ersten Rippe kommend sich breit an die zweite ebenfalls falsche - Rippe ansetzt; er bewegt die erste und zweite Rippe gegen einander; sicher ohne grössere respiratorische Bedeutung.

3) M us culi levatores costarum. Sie stellen mehr oder weniger selbständig gewordene Theile der Intercostales externi dar, von welchen sie für gewöhnlich sich nur sehr schwer sondern lassen. Als eine Reihe kleinerer Muskeln entspringen sie von den Rücken- und letzten Halswirbeln und inseriren sich mit distal- und caudalwärts gerichteten Fasern an Vorderrande der Costalrippe des nächstfolgenden Wirbels. Lateralabwärts fliesst ibre Insertion in der Gegend der Hamuli costales mit den M. intercostales externi zusammen. Sie entsprechen durchaus den 
Levatores breves der Säugethiere, während die Longi vollkommen fehlen. Ihre Funktion ist ganz eindeutig die der Rippenhebung, also eine inspiratoris che.

4) Sterno-costalis superior (Magnus): Ein kleines schwaches Muskelbündel, das nicht allen Genera zukommt (bei den Tauben vorhanden). Es zieht vom Processus lateralis superior sterni zur letzten Halsrippe hinüber, an deren hintere Fläche es sich anheftet.

„Es ersetzt dieser Muskel gleichsam die fehlende Brustbeinrippe und zieht seine Rippe leicht nach oben, funktionirt also als Inspirationsmuskel."

5) Serratus anticus major (Magnus) (Serratus superficialis, pars posterior, F ï r b r i $\mathrm{ng}$ e r) tritt in viel unbedeutenderer Entwickelung auf als bei den Säugethieren und entspringt im Allgemeinen mit 2-5 Zacken an der 3.-6. Rippe und deren Processus uncinati.

Seine Insertion ist der Ventral-Rand der Scapula, von deren unterem Winkel bis circa in ibre Mitte hinauf. Die Wirkung dieses Muskels auf die Rippen ist, wie Magn u s bemerkt, beim Vogel entschieden eine viel ausgesprochenere als bei den Säugern, wo er in erster Linie die Fixirung des Schulterblattes an den Thorax bewerkstelligt, während seine respiratorische Fähigkeit zweifelbaft erscheint. Ganz anders beim Vogel, „wo die Scapula so fest und innig sowohl an die Furcula wie auch an das Os coracoideum befestigt ist, dass an ein irgend erhebliches Abweichen derselben vom Thorax nicht gedacht werden kann."

„Seine Fasern verlaufen in seinen verschiedenen Parthien verschieden, die unteren und oberen Zacken verlaufen schräg, die oberen von unten nach oben, die unteren von oben nach unten; die Fasern seiner mittleren Parthien verlanfen dagegen fast horizontal." Daraus ergiebt sich, "dass die oberen Theile gemäss ihrer Richtung als Depressoren der oberen Rippen dienen, während die unteren als Heber der unteren Rippen funktioniren und dadurch gewissermaassen den Ersatz für die hier unvollkommener entwickelten Levatores costarum darstellen" ( $\mathrm{M} \mathrm{a} \mathrm{g} \mathrm{n} \mathrm{u} \mathrm{s} \mathrm{1.} \mathrm{c.} \mathrm{p.} \mathrm{224).}$

6) Serratus anticus minor (Serratus superficialis, pars anterior Fürbringer). Dieser Muskel dürfte wegen seiner anderen Innervation und seiner Insertion nicht am Coracoid, sondern am vorderen Theil des äusseren Scapularrandes, nicht als dem 
Serratus minor der Säuger identisch aufgefasst werden. Da er meist mit dem Serratus major durch eine Aponeurose verbunden ist oder selbst, wenn auch selten, direkt fleischig mit ihm zusammenhängen kann, so ist er besser als eine mehr oder weniger selbständig gewordene Portion des letzteren aufzufassen. Er inserirt sich an der ersten bis dritten Rippe, wo er theils ein-, theils zweiköpfig sich ansetzt; seine Wirkung ist nach Magnus ein starkes Heben der oberen Rip pen; freilich kann man am lebenden Thiere, wo man diesen Muskel sich zugänglich machen kann, eine Contraktion während der Inspiration nicht wahrnehmen.

7) M. sterno-coracoideus (s ubelavi us). „Es liegt dieser Muskel grösstentheils unter dem sternalen Ende des Os coracoideum verborgen, von dessen hinterer Fläche und dem Processus lateralis anticus sterni er zu der vorderen Seite der oberen Brustbeinrippen hinzieht oder an der vorderen Fläche des Sternums endigt." (Letzteres bei Columba.) Zweifellos kann er auf das Coracoid wirken, das er wenigstens in allen den Fällen an das Sternum fixirt, wo die Rippenzacken fehlen. Anders verhält es sich dagegen, wenn der Muskel an den Rippen seine Insertionspunkte findet; denn da die vorderen Rippen viel beweglicher mit dem Brustbein verbunden sind, als das Sternalende des Coracoids eingelenkt ist, so wird die Wirkung eine grössere auf die Rippen als auf die Coracoidea sein. Der Muskel erscheint deshalb in diesen Fällen zweifellos als ein Rippenheber (Gadow l. c. p. 225).

8) M. Sterno-costalis s. Triangularis sterni. Dieser kräftige Muskel befindet sich auf der Innenfläche der Brustbeinrippen. Er entspringt von der Innenfläche des vordersten Endes des Processus lateralis anticus sterni und spaltet sich in 3-6 Zacken (Columba 3), welche an die oberen Brustrippen gehen. Seine Wirkung ist sehr einleuchtend; indem er die Sternalrippen hebt und etwas nach anssen rotirt, erweitert er die Brusthöhle. Er ist ein Muskel, der dem Triangularis sterni der Säugethiere nur unvollkommen entspricht, und dessen kräftige Entwickelung mit der funktionellen Bedeutung der Sternalrippen in engstem Zusammenhang steht. Man erkennt in Diagr. 1 u. 2, dass, obwohl er eine den Levatores entgegengesetzte Faserrichtung hat, doch der Effekt seiner Contraction eine thorakale Erweiterung bedingen muss. Zu erwähnen ist schliesslich, dass zwischen ihm und dem Subclavius eine Art Wechselbeziehung besteht, indem bei schwa- 
cher Ausbildung des einen der andere um so kräftiger entwickelt erscheint, was sich leicht ans der gleichen Funktion beider Rippenheber erklärt.

\section{в) Exspirationsmuskeln.}

Der Musculus obliquas abdominis externus ebenso wie der Rectus abdomin is, der sich medio-ventral zwischen Obliquus externus und internus einschiebt, sind schon im ersten Capitel näher beschrieben worden. Der erstere spielt zweifellos bei der aktiven Exspiration die wichtigste Rolle, indem er die nach aussen gerollten und erhobenen Rippen berabzieht und nach innen drückt, und so den Rippenwinkel beträchtlich verkleinert. Es ist selbstverständlich, dass auch das Sternum, dem Zuge folgend, nach unten sinkt, gleichzeitig nach innen gedrüickt und mit seiner distalen Spitze der Wirbelsäule genähert wird.

Als Exspiratoren sind ferner noch folgende Muskeln zu erwähnen:

1) Musculus obliquus abdominis internus. Zwischen Externus und dem M. transversus entspringt er von der Mitte des Schambeines und dem Ilium und inserirt seine ventral- and kopfwärts aufsteigenden Fasern an der letzten echten Rippe, der Linea alba oder dem Aussenrand der Rectusaponeurose. Die nicht am Sternum artikulirenden hinteren Rippen durchsetzen ihn und theilen ihn in mehrere Parthien, so dass er gewissermaassen die Fortsetzung der Intercostales interni in die Lumbalgegend bildet. Er funktionirt als Herabzieher der Rippen und repräsentirt einen nicht unwichtigen Theil der Bauchpresse.

2) M. transversus abdominis. Der tiefste unmittelbar über dem Bauchfell liegende Muskel, entspringt er vom Schambein und Ileum und kann sich kopfwärts bis auf die Innenfläche einiger Rippen erstrecken. Als Senker der Rippen jedenfalls nicht sehr wichtig, bildet er einen nicht unwesentlichen Theil der Bauchpresse, welche für den Luftwechsel in den Luftsäcken von Bedeutung ist.

3) M. quadratus lumboram. Ein ganz unbedentender, früher vielfach übersehener dreieckiger Muskel, welcher in schräg von hinten und unten nach oben und vorn verlaufenden Fasern vom unteren Rand der letzten Rippe zum Darmbeinkamm hinüberzieht. Seine höchst unbedeutende Wirkung summirt sich zu der des Obliquus internus. 
4) Levator scapulae s. Serratus profundus: Es ist dies ein Muskel, der mit 2-5 Portionen von dem Querfortsatz des letzten Halswirbels und den ersten drei Rippen entspringt, um sich an der unteren Fläche der Scapula zu inseriren. Bei der unbedeutenden Beweglichkeit der letzteren und bei der Richtung seiner Fasern, die schräg von oben nach unten und hinten verlaufen, dürftè man vielleicht, wie Magnus meint, nicht mit Unrecht in ihm einen Depressor der oberen Rippen erblicken.

Die bei den Säugethieren so kräftig entwickelten Rückenmuskeln stehen bei den Vögeln auf einer äusserst niedrigen Stufe der Ausbildung. Man kann sie mit Stillschweigen übergehen, da eine Wirkung auf Rippe und Wirbelsäule, sowie ihr Einfluss auf die Respiration gleich Null zu setzen sind.

Nur der Sacro-lumbalis schickt einzelne schwache Zacken an die hintere Kante der Rippen, ohne aber von ihr Verstärkungsfascikel zu erhalten, während der Longissimus nach der Angabe aller Autoren zu den Rippen keine Beziehungen hat. Es bängt dies mit der starren Unbeweglichkeit des Brust- und Lendentheils der Wirbelsäule zusammen, welche eine stärker entwickelte Muskulatur überflüssig macht.

\section{y) Die Intercostalmuskeln.}

(Gadow l. e. p. 122 ff.). Ohne jeden Zweifel sind auch bei den Vögeln die Intercostales externi als Inspirationsmuskeln aufzufassen. "Sie sind auf den costalen Theil der Rippen beschränkt und reichen demnach von der Wirbelsäule bis zur Verbindung der Costal- und Sternalrippen.

Ihre Muskelfasern entspringen vom Hinterrande der Costalrippen und sind schräg caudal- und ventralwärts, oder abwärts gerichtet, um sich am Vorderrande der nächstfolgenden Rippe zu inseriren. Ihre Richtung stimmt demnach einigermaassen mit der des M. obliquus externus tiberein."

„Dureh die Processus uncinati werden die Intercostales externi in eine vordere und hintere Portion getheilt. Die vorderen oder distalen (von den Hamuli bis zu den Sternalrippen reichend) sind meistens viel stärker entwickelt, als die anderen mehr proximal oder dorsal gelegenen; am kräftigsten sind sie wiederum zwischen den ersten vordersten Rippen ausgebildet."

Um zu einem Verständniss der physiologischen Bedentung 
der Intercostales interni zu gelangen, muss man die zwischen Costal- und Sternalrippen liegenden Parthien dieser Muskeln strenge unterscheiden. Die zwischen den letzteren gelegenen Faserzitge werden allgemein als Inter-Appendiculares costarum bezeichnet und bilden eine einzige Schichte, welche am kräftigsten zwischen den vorderen Rippen entwickelt ist, während sie zwischen den unteren halb sehnig, halb fleischig, oder selbst rein aponeurotisch geworden sind. Ihre Faserrichtung hält zwischen den Externi (s. u.) und Interni die Mitte; denkt man sich jedoch die Sternalrippen in der Verlängerung der Costalrippen, den Winkel zwischen beiden zu $180^{\circ}$ vergrössert, so stimmen die Mm. interappendiculares mit den Intercostales interni überein (Gadow 1. c. p. 123).

Die eigentlichen $\mathrm{Mm}$. intercostales interni, die nach innen nur vom Transversus abdominis bedeckt werden, sind auf die distale Hälfte der Costalrippen beschränkt, erstrecken sich also dorsalwärts nur bis zu den Hamuli costales. Während sie zwischen den ersten zwei oder drei Rippen entweder nur sehr schwach entwickelt sind oder selbst gänzlich fehlen, zeigen sie zwischen den folgenden eine kräftigere Ausbildung. Sie entspringen vom Vorderrand der Rippen und inseriren sich ventral- und kopfwärts, also aufwärts gerichtet, am Hinterende der nächst vorderen Rippe. Ihre Faserrichtung ist daher mit der des Obliquus internus parallel und kreuzt sich mit der der Intercostales externi.

Während schon Tiedemann (9) die $\mathrm{Mm}$. interappendiculares und die eigentlichen Intercostales interni als Exspiratoren deutet und sie dem Triangularis sterni als Antagonisten gegenüberstellt, sprechen d'Alton (10) und Magnus ihnen eine inspiratorische Wirkung zu, und zwar aus folgenden Gründen:

1) Die Untersuchungen Henle's sollen für die Säugethiere die exspiratorische Funktion der Interni definitiv widerlegt, und, entgegen der alten Hamberger'schen Theorie, ihre inspiratorische Wirkung nachgewiesen haben.

2) Nur zwischen den oberen Sternalrippen finden sich die $\mathrm{Mm}$. interappendiculares deutlich ausgeprägt, während sie bei den unteren bis zum völligen Verschwinden zurłckgebildet sein können. „Soll nun“, fragt Magn u s (1. c. p. 218), „in diesem Falle eine bebende oder herabziehende Wirkung angenommen werden ?"

„Nehmen wir das Letztere an, so fehlen den unteren Brust- 
beinrippen die Depressoren vollständig, während sie an den oberen auftreten, ein Verbältniss, das aber ganz einzig dastände; gerade die unteren Rippen müssen ansgeprägte Herabzieher besitzen, bei deren Contraction sie fixirt werden, um so dè höher gelegenen Depressores einen festen Angriffspunkt zu geben und gleichzeitig die höher liegenden Rippen mit herabzuziehen."

"Ihr Faserverlauf entspricht vollkommen" dem eines sehr mächtigen Hebers dieser Rippen, des Triangularis, und verschmelzen sogar die oberen Intercostalmuskeln mit ihm. Wollte man sich nur nach der Faserrichtung und der Lage der Muskeln, ob sie an der äusseren oder inneren Thoraxwand liegen, in der Deutung ihrer Funktion richten, so müsste man den Triangularis, der an der inneren Brustwand liegt, und dessen Faserrichtung, entgegengesetzt der der Intercostales externi der wahren Rippen, fast gleich der der Intercostales interni verläuft, als einen inneren Zwischenrippenmuskel mit der Funktion eines Depressors deuten, woran aber bei dem Ursprung dieses Muskels vom oberen Ende des Seitenrandes des Brustbeins niemand denken wïrde."

Die Intercostales interni wären demnach nach d'Alton und Magnus als Levatores aufzufassen.

Hiergegen ist nun folgendes zu bemerken:

1) Die alte Hamberger'sche Ansicht von der exspiratorischen Wirkang der Intercostales interni ist noch keineswegs als widerlegt zu betrachten. Der alte Beweis dieses Forschers und zahlreiche in der Neuzeit hinzugekommene experimentelle Beobachtungen, die theilweise schon friher mitgetheilt worden sind, scheinen mir im Gegentheil auch für die Säugethiere die Annahme eines exspiratorischen Effektes fast sicher zu machen. Bei den Reptilien wenigstens ist mit absoluter Bestimmtheit die exspiratorische Funktion der Interni zu constatiren, wie frïher schon ausführlicher dargelegt worden ist.

Da hier dieselbe winklige Formation der Brustbein- und Costalrippen zu constatiren ist, wie bei den Vögeln, da ferner auch hier eine, wenngleich beschränktere Vergrösserung dieses Winkels die Erweiterung der Leibeshöble mitbedingt, so muss man, wenn uiberhaupt ein Analogieschluss in diesem Falle gestattet ist, die bei den Reptilie n gegebenen Verhältnisse mit den bei Vögeln za beobachtenden vergleichen, nicht aber als Maassstab der Beur- 
theilung den wesentlich verschiedenen Mechanismus der Säugethiere benuitzen.

2) Eine exspiratorische Funktion soll ausgeschlossen sein, weil die Intercostales interni den unteren Brustbeinrippen fehlen, während sie an den oberen Rippen vorhanden sind.

Demgegenüber ist zu bemerken, dass dasselbe auch von anderen exspiratorisch wirkenden Muskeln gilt, die sich ebenfalls nur an o b e re Rippen ansetzen und dieselben herabziehen, so beispielsweise der Levator scapulae und gewisse Theile des Serratus anticus major; und vor allem darf man doch nicht vergessen, dass eine mangelhafte Entwickelung der Externi an den unteren Rippen schon dadurch genügend erklärt werden kann, dass diese in den Bauchmuskeln das mächtigste exspiratorische Muskelsystem besitzen.

Was nun schliesslich die von Magnus hervorgehobene Uebereinstimmung der Faserrichtung der Intercostales interni mit jener des unzweifelhaft inspiratorisch wirkenden Triangularis anlangt, so sind doch die in beiden Fällen sehr wesentlich verschiedenen Insertionsverhältnisse der genannten Muskeln zu beruieksichtigen. Der Triangularis setzt sich an das als Punctum fixum fungirende Sternum an, während die Interni sich zwischen den beweglichen Rippen ausbreiten. Es ist an sich unzweifelhaft, dass diese Muskeln bei ihrer Verkürzung auf die obere senkend, auf die untere hebend einwirken miissen, und nur in der Anordnung dieser Muskeln kann das Moment gegeben sein, durch welches die eine oder andere dieser Wirkungen therwiegt. Ueber die Wirkung der Intercostales interni der eigentlichen Dorsalrippen schweigt Mag $\mathrm{nus}$ rollkom. men; für sie trifft aber gerade das zu, was er für bedeutungsvoll zur Beurtheilung der Funktion hält, dass sie sich nämlich in den unteren Intercostalräumen am kräftigsten entwickelt finden.

$\mathrm{Da}$ sie sich an dem distalen Theile, in der unmittelbaren Nähe des Rippenwinkels finden, so werden sie, wenn sie wirklich als Depressoren wirken, die Dorsalrippen herabziehen miissen.

Die Depression dieser Rippen aber muss, wie das Schema ohne Weiteres zeigt, auch die Sternalrippen herabziehen und den Winkel zwischen beiden Abschnitten verkleinern. Deshalb kann eine Depression der Sternalrippen erfolgen, ohne dass sie selber muskulös verbunden sind. Wir hätten dann einen Antagonismus in dem Sinne zu constatiren, dass an den oberen Rippen die 
zwischen den sternalen Theilen befindlichen Interni s. Interappendiculares, an den unteren die costalen Interni als Senker funktioniren und ihre Wirkung za einer gemeinsamen Depression summiren.

Ein eigentlich unwiderleglicher Beweis für die exspiratorische Wirkung der Interni lässt sich schliesslich auch auf vivisektorischem Wege führen. Beim todten Thiere sind die Rippen bis zu einem gewissen Grade einander genähert, ohne indess jemals einander zu bertihren. Athmet das Thier, so verengern sich bei der Exspiration die Intercostalräume beträehtlich, weniger die zwischen den Dorsalrippen gelegenen Parthien, die der Sternalrippen dagegen so beträchtlich, dass sie völlig verschwinden können und diese Rippen sich aneinander anlagern.

Trennt man jetzt, am distalen Rand des Sternums mit der Scheere entlang gehend, die Bauchmuskeln völlig los, so tritt demungeachtet diese Verengerung nach wie vor ein, selbst dann noch, wenn die oberen Rippen, die ja noch eigene, nicht intercostale Depressoren haben, mit der Knochenscheere resecirt wurden.

Hieraus folgt unmittelbar, dass die unteren Rippen aktir wirkende Exspirationsmuskeln haben müssen, die der Lage der Sache nach nur in den Intercostales interni bestehen können, welche, obwohl hier nicht zwischen den Sternalrippen sich aus. spannend, doch auch diese bis zur völligen Anlagerung aneinander herabziehen können.

Für die eigentlichen Interappendiculares lässt sich ein Beweis natürlich schwer erbringen, weil, wie erwähnt wurde, die exspiratorische Bewegung an den oberen Rippen auch noch durch andere Muskeln mitbedingt sein kann, deren operative Entfernung am lebenden Thier nicht wohl möglich ist. Das Verhalten der oberen Intercostales interni bei Reptilien, wo die Verhältnisse viel klarer und eindeutiger zu beobachten sind, lässt mich eine exspiratorische Funktion derselben auch bei den Vögeln muthmaassen. Ich glaube deshalb zu dem Satz berechtigt zu sein, dass iiberall in der Wirbelthierreihe die Interni Exspiratoren, die Externi Inspiratoren repräsentiren. 


\section{B. Die Lungen, die Luftsäcke und das Zwerchfell der Vögel.}

\section{a. Die Langen.}

Seit um die Mitte des 16. Jahrhunderts Coiter (12) zum ersten Male entdeckte, dass die Lunge der Vögel an ihrer Oberfläche perforirt ist, sind mit der Geschichte des Studiums des respiratorischen Apparates dieser Thiere die Namen der bedeutendsten Anatomen und Physiologen verknuiptt.

Hundert Jahre später beobachtete Harvey (13), dass die Oeffnungen an der Lungenoberfläche in grosse Säcke mit membranösen Wandungen führten, und abermals ein Jahrhundert später constatirten fast gleichzeitig der berühmte englische Physiologe Hunter (14) und der holländische Anatom Camper (15), dass die Luft sich nicht nur in den Lungen und Luftsäcken, sondern auch in das Innere der Knochen verbreitet. Seit dieser Zeit wurden durch eine grosse Reihe von Arbeiten allmählich die anatomischen Kenntnisse derartig vertieft, dass heute nach dieser Richtung wohl kaum noch wesentlich Neues sich hinzufügen liesse.

Cuvier (16), Sappey (17), Owen (18), Guillot (19), Huxley (20) und Campana (21) sind die Männer, die um die anatomische Aufklärang dieses complicirten Apparates sich das grösste Verdienst erworben haben, abgesehen von so vielen anderen Autoren, deren Aufzählung hier unterlassen werden kann.

Die Lungen der Vögel sind verbältnissmässig klein (durchschnittlich verhält sich ihr Gewicht zu dem des Gesammtkörpers wie 1:180), aber der Grösse der respirirenden Lungenoberfläche und der Dichtigkeit des Capillarnetzes wegen sehr leistungsfähig. Sie sind paarig, symmetrisch gelegen und am lebenden Thier lebhaft hellrosaroth gefärbt. In der dorsalen Brusthöhle neben dem Herzen und den Brustwirbeln liegend, erstrecken sie sich dorso-lateral bis zu den Sternalrippen, ohne aber je das Brustbein selbst zu erreichen, kopfwärts gelangen sie bis ungefähr zur ersten oder zweiten Rippe, während sie nach hinten bis zum oberen Nierenrande sich ausdehnen.

Die Vogellunge ist nie in Lappen gespalten, wie bei den Säugethieren; während aber ihre innere oder ventrale Fläche plan oder leicht concav gebogen, gleichzeitig glatt ist, ist die äussere oder dorsale convex und derartig in die correspondirenden Par- 
thien der Thoraxwand eingefügt, dass sie durch die Rippen tiefe querverlaufende Einkerbungen erbält. Mit der Hinterwand der Brusthöhle sind die Lungen durch lockeres Bindegewebe ziemlich eng verbunden, und es hält schwer, dieselben von den Zwischenrippenräumen ohne Zerreissung loszulösen 1 ).

Eigenthümlich und analogielos, wie die Lage und änssere Configuration der Lungen, ist auch der innere Bau des Organes. Ich gehe hier hinweg ïber die oft so merkwürdigen Formen der Trachea, die, mannigfach in Schlangenwindungen aufgerollt, theilweise innerhalb des Sternums gelegen sein kann, um lediglich das Verhalten der Lunge selbst darzustellen.

Der ans der Gabelung der Trachea hervorgehende Bronchus jeder Seite tritt medio-ventral an die betreffende Lunge heran und zwar in ihrem vorderen Drittel, verliert sofort seine nach aussen und etwas nach vorn gelegenen Knorpelhalbringe und bildet ganz im Eingang eine lokale Erweiterung, das Vestibulum.

Die intrapulmonäre Portion dieses Hauptbronchus behält nun im Allgemeinen die ursprüngliche Richtung bei und durchzieht die Lunge bis zu ihrem caudalen Ende, wobei sich das Lumen durch die Abgabe von Seitenbronchien allmählich verkleinert.

Am caudalen Lungenende geht er durch eine weite Oeffnung (Ostium posterius) in je einen der grossen abdominalen Luftsäcke über. Ungefähr in der Mitte seines Verlaufes sendet dieser Mesobronchium (Huxley) genannte Gang einen weiteren Zweigkanal zum hinteren ventralen Lungenrande $a b$, wo er sich ebenfalls in einen Luftsack öffnet (Ostium intermedium posterius).

Ausser diesem Hauptast giebt der Hauptbronchus gewöhnlich 10 Bronchien $\mathrm{zw}$ it er Ordnung ab, die mit grosser Regelmässigkeit derart angeordnet sind, dass vier von der Innen-, sechs von der Aussenwand entspringen. Die letzteren, Ectobronchia (Bronches costales, Sappey) genannt, gehen in lateraler und dorsaler Richtung zur Lungenoberfläche, während die ersteren, die Entobron chi en (Bronches diaphragmatiques, Sappey), ventralwärts zur Lungenperipherie hinziehen.

1) Milne Edwards (22) behauptet, die Lunge der Schildkröten sei ebenfalls dem Rückenschild adhärent: ich habe bei Emys europaea ihre volle Beweglichkeit und nach Oeffnung des Bauches den markantesten Lungencollaps beobachten können (Zurückziehen der Lunge nach hinten und oben).

E. Pflìger, Archiv f. Physiologie. Bd. 64. 
Alle diese Ento- und Ektobronehien geben nun, nicht dichotomisch, sondern radiär oder federförmig; wieder kleinere Röhren ab, die Bronchien dritter Ordnung oder $L$ ungen $p$ feifen (Parabronchia), welche sich zur Oberfläche der Lungen erstrecken, um dort blind zu endigen. „Ihre Eingänge sind, wie die Oeffnungen der Luftsäcke, durch Knorpelbogen gestätzt. Mit der anhängenden Gewebsmasse ist die einzelne Pfeife im Querschnitt meist hexagonal; ihr Lumen ist kreisförmig, von fester Bindegewebsmembran gestiitzt; es kann mit dem benachbarten Pfeifen anastomosiren, sodass also die Luft aus einem Theile der Lunge in einen anderen gelangen kann, ohne Vermittlung der grösseren Röhren und der Bronchien. In das Lumen der Pfeifen springen ringförmige Leisten vor, die dureh netzförmige bindegewebige Verbindungen und durch glatte Muskelfasern ein wabenförmiges Maschenwerk bilden. Die ziemlich dicken Wände der Pfeifen bestehen aus dem eigentlichen respiratorischen Gewebe und bilden die Hauptmasse der Lunge.

Aus jeder Wabe erstrecken sich nämlich feinste Röhrehen (Canaliculi aëriferi), zunächst rechtwinkelig und gerade, dann wellig gebogen und dichotomisch, zuletzt traubig anschwellend, sodass die Wand der Pfeife schwammig wird. Die Endanschwellungen entsprechen den Alveolen der Säugethiere." (Gadow 1. c. p. 748.)

Das Flimmerepithel, noch in den Pfeifen vorhanden, nimmt nach den Enden hin an Höhe ab und macht in den Canaliculi einem platten Epitbel Platz. Das dichte verfilzte Capillarsystem aber, das in die Zwischenräume der dendritischen Endverzweigungen eintritt, bedingt den lebhaften Gaswechsel, der in diesen Organtheilen stattfinden muss.

Während so die Ectobronchia allseitig blind endigen, ist dies bei drei der Entobronchien uicht der Fall. Auch sie, theils dorsalwärts, theils ventralwärts sich verzweigend, bilden Lungenpfeifen etc., genau wie die Costalbronchien; der Unterschied ist nur der, dass einer oder zwei Zweige sich mit freier Mündung an der ventralen Lungenfläche öffnen, um mit einem Luftsack zu communiciren. Diese Oeffnungen gruppiren sich in constanter Weise um die Eintrittsstelle des Hanptbronchus in die Lunge in einer Weise, die hier nicht näher ausgeführt werden soll. Nur erwähnen will ich noch, dass, während das erste Entobronchium zwei Oeffnun- 
gen hat (Ostium praebronchiale und subbronchiale), das zweite keine eigene Oeffnung besitzt, dagegen durch einen Verbindungszweig mit dem Ostium subbronchiale communicirt, während das dritte im Ostium intermedium anterius mit einem Luftsack in Verbindung steht; das vierte ist wie die Costalbronchien völlig blind.

\section{$\beta$ Die Inftsäcke.}

Die Luftsäcke können als Ausdehnungen der in die allgemeine Leibeshöhle gleichsam bruchsackartig eingestiilpten Erweiterungen bronchialer Wände aufgefasst werden. Aus diesem Grunde sind sie auch von einem dünnen Bauchfell, das sie vor sich berschieben, überkleidet. Sie bestehen aus fibrösem und fein elastischem Bindegewebe nebst weitmaschigen Capillaren, wäbrend die Innenfläche, in unmittelbarer Nähe der Bronchialöffnungen noch das Flimmerepithel der Bronchien zeigend, weiterbin nur mit einfachen Pflasterzellen ausgekleidet ist (iiber muskulöse Bestandtheile siehe später). Die Gefässe sind so spärlich, dass sie mit blossem Auge iiberhaupt nicht zu bemerken sind; erst die Injektion macht sie sichtbar.

Man hat sich lange über die Zahl dieser Säcke gestritten, weil viele Fortsätze, die sie ausschicken, als selbstïndige Luftzellen imponirten, und ist erst zu einer Einigung gelangt, nachdem man als einen einheitlichen Luftsack alle die mebr oder weniger von einander abgegrenzten Räume auffasste, welche durch denselben Bronchus mit der Lunge communiciren. Von diesem Gesichtspunkte aus kann man fünf Luftsäcke auf jeder Seite unterscheiden, welche oft durch Resorption der häutigen Zwischenwand unter einander zusammenhängen.

Diese Luftsäcke, deren Synonymie eine ziemlich verworrene ist, sind folgende:

1) Sacei s. cellulae praebrouchiales s. cervicales; entstammen dem Ostium praebronchiale und entsenden röhrenförmige Fortsätze zur Luftröhre, den grossen Gefässen des Halses, der Speiseröhre, in den Riickenmarkskanal bis in den Schädel und häufig in die Körper der Halswirbel selbst und nach rïckwärts in die Brustwirbel. Sie bilden ein elastisches Polster für die Halsorgane, blähen Hals und Nacken auf, unterstützen das Sträuben der Federn und sollen auch die Stimme verstärken (Pagenstecher, 24). 
2) Sacei subbronchiales s. interclaviculares. Fortsätze von ihnen dringen als Cellulae axillares mit den grossen Gefässen zur Achselgrube, legen sich theilweise zwischen Rippen und Schulter und treten in den Humerus ein; andere gelangen aus der Rumpfhöhle heraus um die Coracoide herum und pneumatisiren die Insertionen des Pectoralis und subclavius; wieder andere erstrecken sich nach der Innenfläche des Brustbeins, in das sie eintreten, oder umgreifen von hinten das Herz.

3) Sacei intermedi anteriores, communiciren mit dem Ostium intermedium anterius und stellen ein relativ kleines Luftreservoir dar, welches an Rippen und Lunge befestigt, mit freier Wand in die Bauchböhle sieht.

4) Sacei intermedii posteriores, entspringen aus dem Ostium intermedium posterius und sind ganz erheblich grösser als die vorher erwähnten, an die sie sich, nur durch eine Membran von ihnen getrennt, nach rïckwärts unmittelbar anschliessen. Sie sind mit ihrer Aussencircumferenz zum grössten Theil an die Rippen befestigt, doch steigen sie, nicht bei allen Arten, auch in die Bauchböhle hinab, an deren lateraler Muskelwand sie sich ebenfalls fixiren. Ihre innere Wand ragt frei in die Bauchhöhle hinein.

5) Sacei abdominales, hängen mit dem Ostium posterius des Hauptbronchus zusammen und besitzen bei weitem den grössten Volumeninhalt von allen Luftreservoiren. Sie steigen vom unteren Rande der Langen bis zur Beckenhöhle hinab, und während sie seitlich sich an die Bauchwand anlegen, umbüllen sie die Eingeweide, treten als Cellulae pelvicae in die Beckenregion, als Cellulae inguinales zwischen die $\mathrm{Mm}$. ilio-trochanterici und schliesslich in den Femur. Gerade bei ihnen hat man zahlreiche Unterabtheilungen aufgestellt, die aber mehr oder weniger künstlich sind und für uns kein wesentliches Interesse darbieten.

Während die Sacci intermedii anteriores et posteriores eine ganz bemerkenswerthe Straffheit ihrer Innenwandung zeigen, sind die Abdominalsäcke äusserst schlaffwandig; schneidet man in die ersteren ein, so collabiren sie nicht, da sie einmal an die Rippen fest fixirt sind, während andererseits die Innenwand straff gespannt ist; incidirt man dagegen die abdominalen Zellen, so fallen sofort die Wandungen zusammen, die keine Stiitze an der Um- 
gebung finden; dies gilt ebenso für die cervicalen und clavicularen Lufträume und ist wichtig für eine spätere Betrachtung.

Wenn man die Bauchsäcke aufbläst, so treten sie als mächtige Blasen hervor, die die Eingeweide weit vor sich herdrängen.

Est ist bemerkenswerth, dass unter normalen Verhältnissen der Grad der Ausdehnung geradezu minimal ist im Vergleich zu der denkbar grössten Entfaltung ihrer Wandungen.

Die Luftsäcke stehen in keiner Beziehung zur Lungencirculation; sie erhalten ibren arteriellen Blutzufluss aus Gefässen des Aortensystems und ergiessen das verbranchte Blut in benachbarte venöse Bahnen.

In dieser Beziehung ähneln sie gewissen luftsackartigen Bildungen der Schlangenlunge, die im letzten, oft sehr beträchtlichen Abschnitt, einen einfachen Sack ohne spongiöses Gewebe darstellt, also unmittelbar zur Respiration, d. b. zum Gasaustausch zwischen Luft und Blut nicht dienen kann.

Sonst findet man luftsackähnliche Bildungen nur noch bei den Chamäleonten. Die Lungen dieser Thiere, welche auch sonst einen complicirten Ban mit weitgehenderer Septenbildung aufweisen, als die der anderen Reptilien, besitzen an der Innenseite und dem Hinterrand zahlreiche fingerförmige Fortsätze, welche ebenso vielen blasigen Gebilden den Ursprung geben, die ihrerseits sich bis weit herab in die Bauchböhle erstrecken. Manchmal kann man beobachten, dass an Stelle der gewöhnlichen Rippenbewegungen kräftige Mundbodenkontraktionen treten, welche grosse Luftmengen in die Lungen einpumpen. Unter dem Einfluss dieser Schluckathmunge n bläht sich dann der Körper in einem Grade anf, der bei der gewöhnlichen Thoraxathmung nie erreicht wird, und wahrscheinlich ist es die stärkere Füllung der Luftsäcke, durch die dieser Effekt erreicht wird.

Dass diese Anhangsgebilde hier einen respiratorischen Nutzen gewähren, scheint mir zweifellos; sie e r m ögli chen den trägen Thieren so zu sagen ein Athmen auf Vorrath.

\section{$\gamma$. Das sogenannte Zwerchfell der Vögel.}

In der Brustbauchböhle des Vogels spannen sich in complicirter und nicht leicht verständlicher Weise Membranen aus, die das ganze Carum in bestimmter Richtung durchsetzen und 
in Unterabtheilungen trennen, welche von einander abgeschlossen sind.

Die Verhältnisse werden noch verwickelter dadurch, dass gewisse Theile dieser Scheidewände zu den Lungen in Beziehungen treten und muskulöse Elemente enthalten, wodurch eine Vergleichung und eventuelle Zuriickfiuhrung anf das Zwerchfell der Säugethiere herausgefordert wurde. So hat man denn, seitdem man sie überhaupt kennen gelernt hatte, diese Scheidewände als Diaphragmen zu bezeichnen sich gewöhnt, obwohl diese Benennung nicht eben als eine glïckliche zu bezeichnen ist; denn erstens entsprechen die Membranen nur zu einem Theil dem Zwerchfell der Säugethiere, und dann erweckt dieser Begriff eine Reihe geläufiger Vorstellungen, von denen man sich aber gerade, will man zu einem Verständniss der anatomischen Verhältnisse bei den Vögeln gelangen, möglichst frei machen muss.

Das "Zwerebfell" der Vögel ist am eingehendsten behandelt in einer Arbeit von Sappey: „Recherches sur l'appareil respiratoire des Oiseaux" ans dem Jahre 1846 und in einer neueren Abhandlung von Huxley: "On the respiratory organs of Apteryx" (1882) (17 u. 20).

Beide Forscher unterscheiden zwei verschiedene Diaphragmen, die wir jetzt gesondert betrachten miissen:

1. Das quere oder pulmonale Zwerehfell, pulmonary aponenrosis $\mathrm{Huxley}$; diaphragme antérieur Milne $\mathrm{Ed}$ wards, diaphragme pulmonaire Sappey.

Es entspringt neben dem ventrolateralen Rande der Lunge vom Thorax, zwischen dem zweiten und sechsten Rippenpaare und legt sich als breite Aponeurose über die freie Langenoberfläche; in der Medianebene des Körpers stösst es mit einem Septum zusammen, das medial und vertikal an den Wirbeln entspringt und als Mediastinum aufzufassen ist. Das pulmonale Zwerchfell legt sich fest auf die Lungenoberfläche namentlich um die Bronchialdurchbohrungen herum und scheidet die Lungen und ausserdem auch die cervicalen Luftsäcke von dem nach hinten gelegenen Theil der Leibeshöhle.

Nahe ihrem Ursprung von der Körperwand empfängt diese Aponeurose die schon von Perrault (25) als Lungenmuskeln erwähnten Muskelbündel. Sie entspringen als M. costo-pulmonales von den Vertebralrippen, etwas distal vom Abgang der Aponeu- 
rose, und häufig auch als M. sterno-pulmonales von dem Processus lateralis anterior sterni, um in schräger Richtung zur Aponeurose zu treten. Diese sämmtlich quergestreiften Muskelfasern werden durch Zweige der Intercostalnerven versorgt.

2. Das schräge oder abdominale Zwerchfell. Oblique septum $\mathrm{Huxley}$; diaphragme thoraco-abdominal Sappey; diaphragme postérieur Milne-Edwards).

Dieser Theil entbehrt vollständig der Muskeln (eine gegentheilige Behauptung Sappey's hat sich als irrig herausgestellt) und besteht ganz (Campana) oder fast ganz aus elastischen Fasern.

Es bildet einerseits die Fortsetzung des ventralen Randes des Mediastinum und breitet sich schräg durch die Bauchhöhle hin aus zu den Wänden derselben und dem hintersten oder untersten Rande des Brustbeins, ziemlich entfernt von der pulmonalen Aponeurose.

Medialwärts geht das schräge Zwerchfell zum Pericardium und verbindet sich mit diesem und der Medianlinie des Sternums.

Auf jeder Seite wird demnach ein weiter Raum folgendermaassen umschlossen: dorsal und lateral dureh das pulmonale Zwerchfell, medianwärts durch das Mediastinum, ventral und nach unten oder hinten durch das abdominale Zwerchfell.

Dieser Raum, von Huxley Subpulmonalraum genannt, wird wieder durch drei Septa in vier Loculi geschieden, von denen jeder einen postbronchialen Luftsack enthält.

Es ergeben sich demnach folgende Räume nach der Huxley'. schen Nomenklatur:

I. Cavum thoraco-abdominale.

A. Cavum respiratori um, nach vorn und dorsalwärts vom Septum obliquum.

1) Cavum palmonale, nach vorn vom Septum pulmonale, enthaltend die Lungen und praebronchialen Luftsäcke.

2) Cavum subpulmonale, zwischen Septum pulmonale und Septum obliquum, enthaitend die iubrigen vier Luftsäcke.

B. Cavum cardio-abdominale, nach hinten und ventral vom Septum obliquum, enthaltend das Herz und die übrigen Eingeweide.

Das pulmonale Zwerchfell entspricht so ziemlich der pars 
lateralis + sternalis des Diaphragma der Säugethiere, doch bestehen andererseits weitgehende Differenzen; einmal ist zu bedenken, dass das Zwerchfell der Vögel direkt die Lungen ïberzieht und sich fest mit ihnen verbindet; dann liegt das Herz ventralwärts von dem Zwerchfell, wie $\mathrm{Huxl}$ ey richtig betont, nicht kopfwärts von ihm; schliesslich muss man sich erinnern, dass der eigentliche Thoraxraum nicht kopf- sondern caudalwärts von dem Zwerchfell liegt. Der Raum, in dem sich bei Säugethieren die Lungen und das Herz befinden, enthält bei den Vögeln nur die Lungen und die cervikalen Luftsäcke, ohne, wie bei den Säugethieren mit dem Thoraxraum, d. h. dem Raum zwischen Rippen und Sternum vollständig zusammen zu fallen ${ }^{1}$ ). Dieser letztere Raum bleibt bei den Vögeln frei für die respiratorischen Appendices der vier noch restirenden Luftsäcke, und er würde der Bauchböhle der Säugethiere entsprechen, die nur hoch nach oben ausgebuchtet wäre und gleichzeitig das Herz mit einschliesst. Nun aber tritt bei den Vögeln noch das schräge oder abdominale Zwerchfell binzu, welches nur Theilen des Mediastinums der Säugethiere entspricht und im Wesentlichen eine dem Vogelorganismus eigenthümliche Bildung ist. Es ist derartig angebracht, dass es die Luftsäcke von dem noch übrigen Theil der Bauchhöble trennt, in der demnach das Herz und die Eingeweide liegen.

Gleichzeitig bedingt das zwischen Wirbeln und Brustbein in sagittaler Ebene ausgespannte Septum, welches theilweise mit dem abdominalen Diaphragma identisch ist, dass der rechte und linke Pulmonal- und Subpulmonalraum von einander getrennt, d. b. paarig sind, während der noch iibrig bleibende Theil der Bauchhöhle mit Herz und Eingeweiden unpaar ist.

Man hat daruber gestritten, ob ausser der an die Lungen befestigten A poneurose, die einen Theil des pulmonalen Diaphragmas darstellt, auch noch ein spezifischer Pleuraüberzug vorhanden wäre.

Diese Frage hat indessen nur ein speciell anatomisches Interesse, so dass sie hier nicht weiter erörtert zu werden braucht. Wichtig aber ist, dass weder zwischen Lunge und Zwerehfell. noch zwischen Lunge und Rippen ein Raum sich findet, der den

1) Aus diesem Grunde hat man wohl auch gesagt, dass die Lungen der Vögel ausserhalb der Brusthöhle lägen. 
Pleurasäcken der Sängethiere funktionell gleichzusetzen wäre, und dessen Druckschwankungen eine passive Ausdehṇung oder Verkleinerung der Lungen bedingen könnten.

\section{Der Gaswechsel in den Lungen und L u fts äcken.}

Wir haben im Vorhergehenden im Anschluss an die ausführliche Arbeit von $\mathrm{G}$ a d ow die wichtigsten anatomischen Verhältnisse des respiratorischen Apparates der Vögel dargeleg', soweit sie für das Verständniss seiner Funktion durchaus erforderlich sind.

Es fragt. sich nun, in welcher Weise der Gasaustausch in diesem complicirten Systeme von Lufträumen vor sich geht, von dem man bei vorurtheilsloser Betrachtung sehon a priori erwarten wird, dass mancher wichtige Unterschied auch in der Form seiner Thätigkeit gegenüber den Säugethieren sich ausprägen wird.

In Milne-Edwards' grossem Werke über die vergleichende Anatomie und Physiologie der Thiere and des Menschen findet sich neben einer breiten Darstellung der anatomischen Verhältnisse fast kein Wort darüber, wiẹ er sich den Luftwechsel in der Vogel-Lunge vorstellt.

Er bemerkt nur, dass dieselben an der dorsalen Thoraxwand angeheftet sind. Mán könne daher die normale Athmung des Vogels mit jener der Säugethiere vergleichen, wenn man sich vorstellt, dass hier durch eine pleuritische Entziundung eine Verklebung des parietalen und visceralen Pleurablattes auf der Dorsalund Aussenseite herbeigeführt würde.

Erweitert sich nun der Thorax, so wird er rein mechanisch die fixirten Theile mitziehen and deren Lufträume erweitern.

"Cela étant posé, il est facile de comprendre, que le résultat de la dilatation de la chambre respiratoire doit être le même, lorsque les poumons adhèrent aux parois de cette cavité, comme cela a lieu chez les Oiseaux, ou y sont suspendus librement, comme chez les Mammifères, les Sauriens et les Serpents."

Einen Fortschritt nach mancher Richtung, aber auch ganz unhaltbare Hypothesen finden wir bei S a p pe y (l. c.). Nach ihm kommt die Respiration in der Vogellunge wesentlich zu Stande durch Erweiterung oder Verengerung der Luftsäcke, während der parenchymatöse Theil, die eigentliche Lunge, nur sehr geringe 
Volumschwankungen zeigt, obwohl nach ihm der Gasaustausch, die "Hämatose" ausschliesslich in letzterer vor sich geht. Die Ventilation wird nämlich nach $\mathrm{Sappey}$ wesentlich von den mittleren Luftsäcken besorgt; es wird ihr Volumen anf ungefähr das achtfache des Lugenvolumens angeschlagen und gefolgert, dass trotz des anscheinend geringen Volumens der eigentlichen Lunge eine sehr energische Hämatose möglich ist. Er vergleicht die mittleren Luftsäcke mit einer Saugpumpe und die Lungen mit einem vascularisirten Sehwamme, der in die Bahn des Luftstromes eingeschaltet ist 1 ).

Gleichzeitig stellt er eine Hypothese auf, die deutlich genug das Bestreben zeigt, die Respiration der Vögel in analoger Weise zu erklären, wie die der Säugethiere.

Es wurde bereits mitgetheilt, dass sowohl vom Sternum aus, als auch von den Rippen her Muskelzüge auf die Lunge übergreifen und sich zum Theil anf der die ventro-mediale Oberfläche derselben überkleidenden Aponeurose ausbreiten.

Die ersteren stehen senkrecht zur Lunge, während die letzteren naturgemäss eine transversale Faserrichtung haben miissen.

„De cette disposition il résulte:

1) qu'au moment, où le thorax se dilate, la portion verticale du diaphragme est tendue soit par l'abbaissement du sternum soit par la contraction de ses fibres musculaires;

2) que la portion horizontale est également tendue, soit par la projection des côtes en dehors, soit par l'action de ses faisceanx contractiles;

3) que ces forces étant l'une verticale et l'autre horizontale, leur résultante se dirige obliquement en bas et en dehors.

4) que le diaphragme adhérent aux bronches inférieurs du poumon, au moment, où celui-ci s'abaissera pour se porter en bas et en dehors, les bronches correspondantes s'abaisseront aussi ct se dilateront;

5) que les bronches diaphragmatiques attirés en bas, entrâ̂neront dans la même direction le poumon, dont elles font partie,

1) „Le poumon peut être comparé à une éponge vasculaire, placée sur le trajet du courant atmosphérique. Les mailles de cette épouge s'entrouvrent devant le fluide régénérateur, moins pour l'attirer, que pour subir l'influence vivifiante de son contact" (17.1. p. 42). 
tandisque cet organe et les bronches, que recouvrent sa face supérieure, seront simultanément attirés en haut par l'écartement des côtes;

6) que l'organe pulmonaire placé ainsi entre deux puissances diamétralement opposées et obéissant à toutes deux, se trouve dans les conditions les plus avantageuses pour se dilater et attirer dans sa cavitẻ l'air atmosphérique ${ }^{1}$ )."

S a p p e y geht hier soweit, zu behaupten, "que ces réservoirs (nämlich die Luftsäcke) sont inutiles à la respiration".

Man versteht schwer, wie dieser letztere Ausspruch sich mit der anderen von ihm vertretenen Auffassung vereinigen lässt, wo eben die Ventilationsgrösse der Luftsäcke die conditio sine qua non für die Befriedigung des lebhaften Sauerstoffbedürfnisses bilden soll ${ }^{2}$ ).

Der S a p p e y'schen Anschaung von der inspiratorischen Wirkung des Zwerchfelles bei den Vögeln hat, soviel ich sehen kann, ausser $\mathrm{M}$ a $\mathrm{g} \mathrm{n} \mathbf{u}$ s kein anderer Forscher sich angeschlossen.

Aber die Entdeckung, dass die Lunge sich nur wenig ausdehnt, war gemacht und liess sich nicht mebr hinwegleugnen. Ja, man ging noch weiter und setzte die Volumvermehrung eigentlich gleich Null, da man bei den flach an die Brustwand sich schmiegenden Lungen auch durch die Rippenhebung kaum eine nennens. werthe Erweiterung für möglich hielt.

So trat die Bedeutung der Luftsäcke wieder in den Vordergrund und führte zur Aufstellung einer Theorie, die auf den ersten Blick des Räthsels Lösung zu enthalten schien und die auch von Sapp e $y$ bereits als Hülfshypothese mit angezogen worden war.

Schon im Jahre 1689 führte $\mathrm{M}$ e ry einige Experimente an Vögeln vor der Akademie der Wissenschaften in Paris ans, welche einen eigenthümlichen Antagonismus in der Füllung der Luftsäcke nachwiesen und die späterhin oft wiederholt und verschieden modificirt worden sind.

In den zwei thorakalen Luftsäcken, dem Saceus diaphragmaticus anterior und posterior, wird während der Inspiration die Luft verdünnt, während der Exspiration verdichtet; wenn man

1) Schon Hunter (1792) hat sich in ähnlichem Sinne geäussert.

2) „Dans les oiseaux, l'aspiration a donc son siège en de hors de l'organe de l'hématose." 
die Trachea zuschnürt und einen dieser Luftsäcke mit einem Manometer verbindet, so sieht man sebr schön, wie die Flüssigkeit während der Inspiration sich dem Luftsack nähert, während der Exspiration dagegen von jenem sich entfernt. Umgekehrt gestaltet sich das Verhalten, wenn man das Manometer mit einem der anderen Luftsäcke verbindet; dann wird das Quecksilber während der Exspiration angesangt und steigt während der Inspiration im freien Schenkel, d. h. diese Luftreservoire füllen sich wäbrend der Exspiration und werden bei der Einathmung theilweise entleert.

Einen ähnlichen Erfolg sieht man, wenn man den Femur amputirt und den Knochenstumpf mit einem M a r e y'schen Tambour verbindet; dann hebt sich der Schreibstift bei jeder Ausathmung und sinkt während der Inspiration.

Fibrt man das gleiche Experiment am Amputationsstumpf des Humerus ans, der sehr regelmässig pneumatisirt ist, so tritt dasselbe Phänomen in Erscheinung, Beweis, dass auch die vorderen Luftsäcke in ihrem Füllungszustande sich zu den thorakalen Luftsäcken antagonistisch verhalten.

"Motus itaque aëris in cellulis pectoralibus et extremitatibus alternus est, in cellulis vere abdominalibus et extremitatibus isochronus (5)."

Man dachte sich nun die Beziehungen dieser entgegengesetzten Füllungszustände zu dem Gaswechsel in den Lungen folgendermaassen: Bei der Inspiration wird nur ein relativ kleiner Theil der einströmenden Luft in die Lunge gelangen, der grössere Theil desselben tritt durch die Bronchialöffnungen in die intrathorakalen Luftsäcke. Nun aber ,contrahiren " sich wäbrend der Inspiration gleichzeitig die abdominalen und vorderen Luftsäcke, die ihrerseits Luft in die Lungen hineintreiben.

„The alternate expansion and contraction of the two sets of air cells causes currents of air to play continually through the spongy tissue of the lungs peculiar to birds, and to pass between the allmost naked capillaries, first described by Mr. Rain e y (in 1846).

The air-spaces between the capillaries are according to Mr. $R$ a in e $y^{\prime}$ s measurements, only $1 / 960{ }^{\text {th }}$ of an inch, and the quantity of air in them must soon be deprived of oxygen and saturated with carbonic acid. Hence the necessity of its continual change. 
This change is effected by constant streams of air that fan the capillaries in passing from one set of air-sacs to the other. The intricate courses, which the air takes in passing in and out of the air-cells and bronchial tubes of various orders is difficult to describe, especially without diagrams (11)."

Damit ist deutlich genug ausgesprochen, wie man sich die "Ventilation" der Lungen vorstellte. Während der Inspiration wird der Lunge gleichzeitig von der Trachea, von den abdominalen und vorderen Luftsäcken Luft zugefübrt. Man kann aber diesen Gedankengang noch weiter ausspinnen:

Während der Inspiration gelangte frische atmosphärische Luft in die thorakalen Reservoire, die sich nach hinten von der Lunge ausdehnen; während der Exspiration wird diese noch unverbranchte Luft nach vorn wieder durch die Lungen hindurchgetrieben, so dass auch während der Exspiration die Capillaren von einem sauerstoffreichen Gas. gemisch umspült werden.

Auch dieser Faktor würde dann eine "Ventilation" im Sinne der älteren Autoren sehr begünstigen, indem die Lunge beständig von frischer Luft durchströmt wird.

Der eben kurz skizzirte Ideengang findet sich am breitesten durchgefübrt in der grossen Arbeit von Campana (21). Die ganze hier entwickelte Theorie ist auf anatomisch-induktivem Wege gewonnen worden, eine Methode, deren "légitimité suspecte" der Autor selbst zugiebt.

Die wichtigsten Schlussfolgerungen sind folgende:

1. Die Lunge hat für die Bewegung der Athemgase keine Bedeutung, ibr Volumen bleibt immer constant.

2. Während der Inspiration tritt die Luft in die thorakalen Luftsäcke ein, ohne in das Lungenparenchym selbst einzudringen; gleichzeitig werden unter dem Einfluss der Contraction der umgebenden Muskeln die extrathorakalen Luftsäeke comprimirt, deren Inbalt theils in das Lungengewebe eintritt, theils ebenfalls in die thorakalen Reservoire.

3. Während der Exspiration dagegen entleeren sich die letzteren und lassen die in ihnen enthaltenen Gase theils in die extrathorakalen Luftsäcke strömen, theils durch die Trachea nach aussen, zum Theil aber auch in das eigentliche Lnngenparenchym.

Hieraus würde folgen, dass zur "Hämatose " während der In- 
spiration der Inhalt der extrathorakalen Luftsäcke verwendet wird, während der Exspiration dagegen der der intrathorakalen.

Da aber auch immer bereits verbrauchte Luft sich mit der neu eindringenden atmosphärischen Luft in den Luftsäcken mischt, so ist klar, dass die Lunge selbst niemals "l'air extérieur à l'état de pureté" erhält; „mais il est parcouru sans intermission et en sens alternatif, par un courant d'air de composition faiblement variable et venant tour à tour des réceptacles expirateurs et des réceptacles inspirateurs" (1. c. p. 231). Darin liegt nach Campana die höhere Vollkommenheit des Gasaustansches bei den Vögeln im Gegensatz zu den Säugethieren.'

Uebrigens vertritt dieser Forseher, wie hier anschliessend bemerkt werden mag, eine sonderbare und experimentell nach keiner Richtung hin gestützte Auffassung der Wirkung des pulmonen Diaphragma.

"Les poumons des oiseanx, tenus en distension permanente par les contractions alternes des réceptacles antagonistes, lesquelles se succèdent sans intermission, ne varient pas notablement de volume, ni pendant l'agrandissement, lni pendant le rétrécissement de l'enceinte eostale. L'action dilatante partielle, éprouvée par eux an moment de la contraction du diaphragme pulmonaire (contraction peu étendue, comparativement à celle du diaphragme des mammifères) a lie u pendant le rétrécissement de l'enceinte costale et l'expiration trachéale. Au point de vue du volume du poumon en général, l'action du diaphragme tendrait donc à annuler l'influence opposée des mouvements de l'enceinte costale; tandis qu'au point de vue du volume relatif des parties, le diaphragme pulmonaire dilaterait partiellement la surface ventrale des poumons, en même temps que l'enceinte costale tendrait à resserrer la surface dorsale, et inversement (1. c. p. 226)."

Ehe ich meine eigenen Anschauungen über das Zustandekommen des Gaswechsels in den Lungen der Vögel entwickele, möchte ich mit kurzen Worten noch einer alten Vorstellung Erwähnung thun, die von keinem geringeren als $\mathrm{Cuvier}$ ausgesprochen worden ist und späterhin auch von Milne-Edwards acceptirt wurde. Die Thatsache, dass die Luft bei den Vögeln nicht nur in den Lungen, sondern anch in und zwischen zahlreichen anderen Organen sich verbreitet, wird dahin gedeutet, dass: „indépendamment de la respiration pulmonaire il y a ici une re- 
spiration profonde presque diffuse, et c'est pour indiquer cette particularité tout à la fois anatomique et physiologique, qu'en caractérisant la classe des Oiseaux, Cuvier appelle ces Animanx des Vertébrés à respiration double $\left.{ }^{1}\right)^{*}$.

Diese Vorstellung ist sicher ganz unhaltbar; in den fast gefässlosen Wänden der Luftsäcke, sowie in den knöchernen Hohlräumen die anatomische Grundlage für einen irgend erheblichen Gasaustausch zu finden, daran dürfte heute wohl kaum noch Jemand enstlich denken.

Kaum glaublich ist es daher, dass ein neuerer, um die Anatomie des respiratorischen Muskelapparates der Vögel verdienter Autor diese längst verlassene Annahme wieder aufnimmt. In seiner oft citirten Arbeit sagt Magnus :

„Aus der festen Verbindung der Lungenflügel mit dem hinteren Theil der Rippen ergiebt sich natürlich, dass deren Ausdehnungsfälsigkeit eine nur beschränkte, ganz von der Beweglicblkeit dieses Rippentheiles abhängige, sein kann. Einigermaassen ausgeglichen wird dieses für die Capacität der Lungen so ungünstige Moment durch die Lungenmuskeln (d. h. die mehrfach erwähnten Zwerchfellmuskeln der Autoren), die durch ihre Contraktion die Lungen erweitern".

"Da trotz dieser herabgesetraten Funktionsfähigkeit der Lunge der ganze Stoffwechsel im Vogelorganismus doch ein sehr lebhafter und reger ist, so muss irgend ein Faktor in demselben wirken, welcher dieses ungünstige Moment neutralisirt. Einen solchen finden wir in dem System der Luftsäcke. Es haben dieselben nicht bloss den Zweck, durch Aufnahme von Luft den Vogelkörper zum Fluge zu befähigen, sondern sie ubernehmen auch einen grossen Antheil der Lungenarbeit; es geht in ihnen ein sebr lebhafterAustauseh zwischenden Blutgasen und der atmosphärischen Luft vor sich. Es istalso im Vogelorganismus der eigentliche Hauptzweck

1) Cuvier glaubte, dass die Luft anch in das subkutane Bindegewebe und in die parenchymatösen Organe sich ausbreite, und diese Anschauung ist es wohl gewesen, die dazu geführt hat, die "tiefe" Athmung in direkte Parallele zu der Tracheenathmung der Insekten zu stellen. Nur in sehr seltenen Fallen (Pelican etc.) sollen die Luftsäcke mit dem subkutanen Gewebe in direkter Communikation stehen (Milne-Edwards). 
der Lungen, die mit ihnen communieirenden L uftsäcke zu füllen, während ihre bei den Säugethieren so wichtige respiratorisehe Funktion hier mebr in den Hintergrund tritt. Die grösste geräumigste Luftzelle finden wir an den Seiten des Thorax bis in das Abdomen herabsteigen, und bedingt ihre wechselnde Füllung und Entleerung eine lebhaftere Bewegung der sie bedeckenden Brustwandung, also des vorderen Endes der Rippen und der Brustbeinrippen".

„Es erklärt also die Lage der Lunge und des grossen Brustluftsackes die grosse Beweglichkeit der Brustbeinrippen und des vorderen Theiles der wabren Rippen und die herabgesetzte Motilität des hinteren Theiles derselben."

Eine Kritik an dieser Auseinandersetzung zu üben, dürfte nach allem bisher Mitgetheilten wohl kaum nöthig sein.

Für eine richtige Auffassung der bei der Vogelathmung: in Betracht kommenden Verhältnisse des mechanischen Luftwechsels sind eine Reihe von Thatsachen von ausschlaggebender Bedeutung, welche sich experimentell ausserordentlich leicht feststellen lassen und im Folgenden zunächst kurz erwähnt werden sollen.

1. Der Gaswechsel hört bei Vögeln (Tauben) nichtauf, auch wenn sämmtliche erreichbaren L uftsäckezerrissen und soweit als möglichentfernt werden.

2. Die Zerreisung des sogenanten pulmonalen Zwerehfelles beeinflusstdie Respiration ebenfalls nicht in erheblichem Grade.

3. In keinem Theile der Brustbauchöble herrsetbei Ruhelagedes Thorax ein negativer Druek.

4. Bläst man einen Luftstrom in die Trachea, so füllen sich die Luftsäcke an, während die Lungen sich nur äuserst wenigausdehnen.

Führt man (wie dies Campana zuerst in ansgedehntem Maasse that) am todten Thiere von der Trachea aus eine Injektion der Lufträume unter schwachem Druck aus, indem man in dem Humerus eine Oeffnung anbringt, um der comprimirten Luft einen Ausweg zu. verschaffen, so füllen sich sehr bald die Luftsäeke prall an, während zunächst noch keine Spur der injicirten Masse in die 
Lungenalveolen oder auch nur in die grösseren Seitenbronchien eintritt.

Die Entfernung resp. Eröffnung der Luftsäcke bei Tauben ist sehr leicht auszuführen; man eröffnet die Bauchböhle und führt längs des distalen Randes des. Sternums die Scheere soweit wie möglich nach atssen und hinten; dadurch macht man das Sternum vollkommen beweglich und kann es emporheben, um sich einen geniigenden Einblick in den von Rippen und Brustbein umschlossenen Raum zu verschaffen.

Bei dieser Operation werden wohl immer die zartwandigen Abdominalsäcke angeschnitten und collabiren; dagegen kann man bei einiger Vorsicht die Brustluftsäcke intakt erbalten.

Man sieht ferner, ziemlich hoch oben, das Herz pulsiren und erkennt das vertebro-sternale Septum, dessen zwei Lamellen sich zum Cavum mediastinale auseinanderlegen, mit Herz, Aorta und Speiseröhre als Inhalt.

An den Brustluftsäcken, d. h. dem Saceus diaphragmaticus anterior und posterior, sieht man keine direkten Volumänderungen; während der Exspiration faltet sich die ventral nach innen schauende Wand leicht zusammen, während sie in der Inspiration sich wieder spannt; von einer eigentlichen Hervorwölbung ist dagegen nichts zu bemerken.

Durch diese Luftsäcke schimmern röthlich die Lungen hindurch, und wenn man die Wandungen der ersteren mit Messer und Pincette entfernt hat, stösst man auf jene aponeurotische Membran, die, theilweise muskulös, die ventrale oder innere Lungenfläche überzieht und mit ihr in innige Beziehnng tritt. Man kann diese iibrigens nur schwachen Muskelbündel von ihrer Insertion an Rippen und Brustbein los präpariren und die aponeurotische Membran von der Oberfläche der Lungen, wiewohl nicht ohne Schwierigkeit, wenigstens theilweise entfernen. Zerreisst man schliesslich noch die versebiedenen das Cavum sonst noch durchziehenden Septa und den Herzbeutel, so hat man künstlich einen einzigen grossen Hohlraum geschaffen, dessen unterer Theil von Leber und Darm erfüllt ist, während median und vorwärts das Herz an den grossen Gefässen aufgehängt erscheint und seitlich die Lungen als glatte, gänzlich nackte, scheibenartige Gebilde liegen.

Und trotzdem athmetdas Thier fort.

Allerdings hat sich eine dentliche Dyspnoe in der Zwischen- 
zeit eingestellt, aber diese dürfte ihren Ursprung mehr der Durchtrennung der wichtigsten Exspiratoren, der Bauchmuskeln, sowie ferner dem Umstand verdanken, dass man, um sich Zugang zu schaffen, während des ganzen Eingriffes, der übrigens fast ohne jeden Blutverlust verläuft, das Sternum stark nach anssen und oben zichen und fixirt halten muss, wodurch natürlich auch die Rippenbewegung sehr wesentlich beeinträchtigt wird.

Damit ist völlig einwandsfrei bewiesen, dass weder die Luftsäcke noch das sogenannte Diaphragma ${ }^{1}$ ) nöthig sind, um den Luftwechsel in den Lungenzu unterbalten, undesbleibt nichts anderes übrig, als in der direkten Einwirkung der Rippenbewegungen a uf die Lungen diemechanische Ursachedes respiratorischen Gaswechsels zu erblicken.

Hierfür ist vor Allem die eigenthümliche anatomische Lagerung der Vogel-Lungen zu beachten, die nicht, wie bei Säugethieren, der Thoraxwand frei verschiebbar und gleitend anliegen, sondern, wie schon erwähnt, mit ihr fest verwachsen erscheinen.

Wenn man sich am Cadaver die Vogellunge ansieht, so erscheint sie als flache Scheibe, die nur wenig über die Innenfläche der Thoraxwand erhaben erscheint.

Löst man sie jetat von ibrer Unterlage los, so ist man erstaunt über ihre relativ beträchtliche Dicke, die man bei der Betrachtung in situ kaum hätte voraussetzen können. Die Lunge ist demnach fast völlig vergraben in die Intercostalräume, und wo die Rippen in den Innenraum der Leibeshöhle vorspringen, bilden sie tiefe Einkerbungen in dem an diesen Stellen stark verdünnten Lungengewebe.

Wenn nun die Rippen sich bei der Exspiration, einander nähern - und diese Annäherung ist, wie man sich am lebenden Thier jeder Zeit überzeugen kann, eine sehr beträchtliche -, so werden die zwischen ihnen befindlichen Intercostalnischen stark

1) Am richtigsten dürfte wohl die Annahme sein, dass die Lungenmuskeln ebenso wie die um die Bronchialostien angebrachten Knorpelspangen

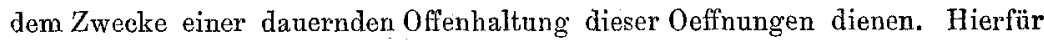
spricht vor allem der anatomische Umstand, dass gerade um diese Ostien herum sich die muskalösen Elemente in Form circulärer Wülste anläufen. 
verengt; die Lunge, fest fixirt, kann diesem Drucke nicht ausweichen und wird in Folge dessen zusammengedrückt; bei der In. spiration vertiefen sich die von den Rippen gebildeten Nischen, der Druek lässt nach, und das vascularisirte schwammige Lungenparenchym erweitert seine Poren, in die nun zur Ausgleichung. der Spannungsdifferenz Luft einströmt.

Man kann diese Compression übrigens leicht direkt beobachten, wenn man nach möglichst breiter Eröffnung der Brustbauchhöhle die Leber bei Seite schiebt, wobei zugleich die Art der Rippenbewegung sebr klar hervortritt; eine Ausdehnung oder Blähung der Lungen in dem Sinne, wie bei den Säugethieren, macht sich begreiflicher Weise niemals bemerkbar. Es ist leicht ersichtlich, dass, wenn unter den gegebenen anatomischen Verbältnissen die Lungenathmung bei den Vögeln nach demselben Princip erfolgte, wie bei Säıgethieren, für den erforderlichen Gaswechsel in sehr unvollkommener Weise gesorgt sein wiirde. Es ergiebt sich dies vor Allem aus der Berücksichtigung der grossen Verschiedenbeit des Widerstandes, welcher dem Eindringen der Luft einerseits in die Lungen, andererseits in die Luftsäcke entgegensteht. Bei der Weite der Communikationsöffnungen zwisehen beiden Organen ist ohne Weiteres klar, dass die durch die Trachea einströmende Luft ganz vorzugsweise in die Luftsäcke eiutreten würde, während die engen Alveolarröhren des Lungenparenehymes kaum gelüftet würden, sodass die ganze Vogel-Lunge lediglich einen Gasaustausch durch Diffusion vermitteln könnte.

Ich erinnere hier auch an das bekannte bei Säugethieren ausgeführte Experiment, durch eine künstlich vielfach durchlöcherte Lunge einen andauernden Gasstrom zu leiten; die einströmende Luft vermag dann eine wirkliche Ausdehnung nicht mebr zu erzielen. Den künstlichen Löchern entsprechen bei den Vögeln die weiten Bronchialöftinungen in die Luftsäcke; doch sind hier die Verhältnisse noch viel giinstiger, als in dem angezogenen Experiment, weil bei letzteren nicht die grössten Bronchien direkt mit der Aussenluft in Verbindung gesetzt werden; man denke sich den Hauptbronehus dureh die ganze Lunge verlaufend und frei nach aussen endigend; die Luft wird dann kaum noch in die sekundären Bronchien eintreten können, und bei den Vögeln baben wir fü $\mathrm{f}$. solche weite Oeffnungen.

Man ersieht hieraus, dass eine Hin- und Herbewegung der 
Luft innerhalb der häutigen Luftsäcke an sich nur wenig geeignet sein könnte, ohne das Hinzukommen einer ansaugenden Wirkung des Lungenparenchyms selbst, dieses ausgiebig zu ventiliren. Es erscheint aber natürlich nicht ausgeschlossen, ja sogar wahrscheinlich, dass neben dem oben geltend gemachten zweifellos wesentlichsten mechanischen Faktor der Lungenventilation auch die wechselnde Füllung der Luftsäcke als unterstützendes Moment des Gaswechsels in Betracht kommt.

Die verhältnissmässig grosse Entfernung jenes Theiles der Luftwege, in welchem bei Säugethieren ein di rekter mechanischer Luftwechsel stattfindet, von dem eigentlichen respirirenden Parenchym, innerhalb dessen lediglich Diffusionsvorgänge sich abspielen, bedingt natïlich auch einen relativ langsamen Gasaustausch, bei den Vögeln dagegen wird die Lunge als Ganzes comprimirt, sozusagen ausgedriickt, und hierin scheint die Möglichkeit einer noch rollkommeneren Lüftung gegeben zu sein, als bei den Säugethieren, sodass die Vogel-Lunge, weit entfernt, ein im Verhältniss zu der Säugethierlunge minderwertbig funktionirender Apparat zu sein, im Gegentheil viel vollkommener ist, theils durch die eigenthümliche Einlagerung in die Intercostalräume, theils durch das enorm entwickelte Capillarnetz ${ }^{1}$ ).

Das Experimentum crucis aber für unsere Annahme, dass der Gaswechsel nicht durch die Ventilation der Luftsäeke, sondern durch Volumschwankungen der Lunge selbst bedingt wird, liegt in folgender Erfahrung.

Entfernt man alle Luftsäeke in der oben geschilderten Weise und schnürt $n$ un die Trachea zusammen, so wird die dureb den A usfall der abdominalen Exspirationsmuskeln erzengte Dyspnoe keineswegs zur Asphyxie gesteigert, sondern das Thier behält unbegrenzte Zeit den geringen Grad von Athemnoth bei. Nur auf dem Boden unserer Anschaungen über das Zustandekommen des respiratorisehen Gaswechsels bei den Vögeln lässt sich dieses scheinbar so räthsel-

1) Vielleicht liegt in dieser hohen Vollkommenheit die Erklärung für die auf den ersten Blick so wunderbare Thatsache, dass die Vögel trotz ihres grösseren Sauerstoffbeduirfnisses eine erheblich geringere Athemfrequenz als die Säugethiere zeigen. 
hafte Phänomen erklären. Die durch die Operation mit der Aussenwelt in Communication gesetzten Bronchialöfnungen der medio-ventralen Lungenfläche ersetzen eben in vollkommenster Weise den Luftzufluss aus der Trachea; dureh sie wird dann die atmosphärische Luft inspirirt und die Exspirationsluft ausgetrieben.

Es fragt sich nun noch, wie die Volumschwankungen der Luftsäcke zu Stande kommen. Auch hier hat man, wie es scheint, ähnliche Beziehungen angenommen, wie sie zwischen Lungen- und Thoraxraum der Säugethiere gegeben sind. Man darf dies wenigstens daraus schliessen, dass über die Ursache des Zustandekommens der Erweiterung und Verengerung dieser Räume sich nirgends eine bestimmte Aeusserung findet.

Wenn wirklich die Bewegungsursache in beiden Fällen dieselbe wäre, so müssten natürlich auch die anatomischen Lageverhältnisse vergleichbar sein. Die Luftsäcke müssten sich luftdicht in dem Brustraum eingefitgt befinden, von der Thoraxwand vollkommen getrennt und an ihr verschiebbar. Ausserhalb der membranösen Säcke miisste dauernd oder wenigstens während der Inspiration ein geringerer als der Atmosphärendruck herrschen. Beides ist nachweislich nicht der Fall.

Figt man luftdicht in die Trachea einer todten Taube ein empfindliches Wassermanometer ein, so sieht man anch bei vorsichtigster, mit Schonung der Luftsäcke ausgeführter Eröffnung der Brustbauchböhle niemals eine merkliche Veränderung im Stande der Wassersänle eintreten.

Aber anch in anatomischer Beziehung lassen sich die thorakalen Luftsäcke nicht im mindesten mit den Lungen der Säugethiere vergleichen. Ein Theil ihrer Wandung wird durch die Brustwand selbst gebildet, der andere durch straffe Membranen, mittels deren die Luftsäcke untereinander und mit der Umgebung verbunden sind. $\mathrm{Da}$ sie sich ausserdem, wie leicht $\mathrm{zu}$ sehen, auch dann noch fiullen, wenn der Thorax breit eröffnet ist, so ergiebt sich von selbst die richtige Auffassung:

Dieden Rippenanliegende Wand dehnt sich mit aus, in dem Masse, als jene sieb heben, wodurch ein inspiratorisches Einströmen von Luft bedingt ist; senken sich die Rippen, so 
wird der Luftraum verkleinert, die Luft comprimirt und nach aussen gedrängt.

Es ist klar, dass diese Erweiterung nur in den Lufträumen stattfinden wird, die an die sich bewegenden Thoraxtheile angebeftet sind. Der hintere Brustluftsack liegt nun nicht bloss der Thoraxwand an, sondern heftet sich zum Theil auch an die Bauchwand an.

Es ist nun verständlich, dass, wenn der Thorax sich erweitert, vor Allem die ihm anliegenden Säcke Luft ansaugen werden, während aus den unteren, von der Erweiterung nicht direkt betroffenen abdominalen Luftkammern umgekehrt Luft nach oben strömen wird, ebenso wie von der Trachea her die Luft zum Ausgleich mit dem Atmosphärendruck herbeiströmt.

Die abdominale Portion des thorakalen Luftsackes würde also collabiren, während die thorakale sich erweitert, bis überall der gleiche Druck vorhanden ist; wenu sich die thorakale Portion dagegen verengert, so wird die Luft überallhin answeichen, nach der Trachea, nach der abdominalen Portion desselben Luftsackes und nach dem abdominalen und dem vorderen extrathorakalen Luftsacke.

Wenn jetzt wieder die thorakalen Luftsäcke sich erweitern, wird von überall her, wo ein stärkerer Druck herrscht, d. b. von der Trachea und den extrathorakalen Luftsäcken aus, Luft einströmen.

Hieraus erklärt sich auf das Einfachste das antagonistische Verhältniss in der Füllung der verschiedenen Luftsäcke ${ }^{1}$ ), indem die extrathorakalen wie Athemflaschen funktioniren, aus denen während der Inspiration Luft angesaugt wird, und in die während der Exspiration Luft eingepresst wird. Man weiss schon längst, dass, wenn man den Humerus eines Vogels spaltet und gleichzeitig die Trachea comprimirt, das Thier stundenlang am Leben erhalten werden kann; der hohle Knochen und der ihm verbundene Laftsack wirken dann eben als vicariirende Trachea. Die während der Athembewegungen in den Reservoiren circulirende Luft passirt natürlich dauernd die Lungen, da sie nur auf diesem Wege in

1) Dass übrigens dieser Antagonismus fïr die Vogelathmung ein unwichtiger Faktor ist, ergiebt sich schon daraus, dass es Vögel giebt, die überhaupt nur thorakale Luftsäcke besitzen. 
die verschiedenen Luftsäcke gelangen kann; sie vermag aber nur unter Beihülfe der erwähnten direkten Dehnung resp. Compression des Lungengewebes in die feinen Lufträume desselben einzudringen.

Der Hauptsache nach bildet den Inhalt der Luftsäcke wohl atmosphärische, auf Körpertemperatur erwärmte Luft und Wasserdampf; da jedoch bei der Lungenverkleinerung zweifellos Luft aus diesen in sie hineingelangt, so dürfte das Gasgemenge ziemlich kohlensäurereich sein.

Von dem Standpunkte aus, den wir gewonnen haben, dass die Luftsäcke respiratorisch so gut wie bedeutungslos sind, kann die Frage, ob den Luftsäcken eine eigene Beweglichkeit zukommt, für uns kein grosses Interesse mehr haben. Man hat da und dort in der Wand glatte Muskelfasern gefunden, ja G $\mathfrak{u}$ ill ot beschreibt am Axillarsack eine ganze Reihe von quergestreiften Muskelbiundeln, die, von benachbarten Körpermuskeln stammend, sich auf die Luftsackmembranen erstrecken und den Innenranm erweitern sollen, während die Contraktionen des darïberliegenden Pectoralis einen Reflex der im Sack enthaltenen Luft nach rückwärts bedingen.

Eberth (26) "vermisste Muskeln im Interclavicular- und Axillarsacke, im Sacke für das Herz, dem für den unteren Kehlkopf und dem grossen Abdominalsacke. Der über der Lange gelegene Iuftsack enthält gegen seinen Ansatz am Oesophagus sehr zahlreiche quere Muskelfasern, ja er besteht beim Huhn fast allein aus Muskeln, ebenso die ihm benachbarten Säcke."

Auch Campana nimmt eine durch Muskelcontraktion bedingte Verengerung der extrathorakalen Luftsäcke, während die mittleren erweitert werden oder inspiriren, an.

Es ist schwer zu sagen, welchem Zweck diese Einrichtung, wenn sie wirklich allgemein vorhanden ist, dient, zumal die eigentliche Bedeutung der Luftsäcke noch überhaupt keineswegs hinlänglich sichergestellt erscheint.

Alle bisher anfgestellten Hypothesen - und deren giebt es eine ganze Reihe - sind noch nicht exakt bewiesen, viele sogar äusserst unwahrscheinlich, und man kann sich nur den Worten Guillot's anschliessen: "Il vaut mieux peut-être se taire longtemps encore sur des fonctions que nous ignorons, et ne pas. se bâter de produire des idées anteriéures à toute espèce d'expérimentation. Que d'études restent encore à entreprendre sur la den- 
sité, sur les variations de la temperáture et sur la composition chimique de l'air contenu dans les réservoirs aériens. Que de conditions, que d'influences variées, dont l'action doit être étudiée, et qui malheureusement restent encore en dehors des limites de nos connaissances."

\section{Der Einfluss des N. vagus auf die Athmung.}

\section{A. Die Vagusdurchschneidung und ihre Folgen.}

Der Einfluss der Vagisektion auf die Atbmung der Vögel ist, soviel ich sehen kann, zuerst von B ert (1) zum Gegenstand einer wenn auch nur wenig eingehenden Untersuchung gemacht worden.

Drei Experimente an Enten, eines an einer Taube sind in seinem Werke erwähnt und durch Curvenbeispiele erläutert.

Diese letzteren stimmen, wie gleich hier bemerkt sein mag, mit denen gar nicht überein, die K n oll und auch ich regelmässig bei Tauben nach der in Rede stebenden Operation beobachten konnten.

Sektion eines Vagus ergab ihm meist eine längere oder kürzere Pause in fast reiner Exspirationsstellung, an die sich zunächst mehr oder weniger unregelmässige, meist verlangsamte Athmungen anschlossen, worauf sehr bald der normale Typus sich wiederberstellte und höchstens eine geringe Verlangsamung und etwas grössere Amplitude jeder einzelnen Athmung dauernd bemerkbar blieb.

Wurde nun anch der zweite Vagus durchschnitten, so trat neuerdings eine etwas längere exspiratorische Pause ein, nach deren Ablauf später Curven gezeichnet wurden, deren Form ganz auffallend an jene der normalen Reptilien-(Eidechsen-)Athmung erinnert.

Bei einer Ente konnte Bert ferner konstatiren, dass die am ersten Tage nach der Operation stark verlangsamte Athmung bereits am zweiten wieder ausserordentlich beschleunigt war.

Sehr eingehende Arbeiten iiber die Folgen der Vagusdurchschneidung wurden 1879 von $\mathrm{Z}$ ander (27) und 1880 von Knoll (2) veröffentlicht.

Beide Abhandlungen haben in erster Linie die Untersuchung: der allmählich, aber sicher zum Tode führenden Veränderungen 
zum Gegenstande, welche im Gefolge der doppelseitigen Vagussektion auftreten, liefern aber auch die ersten genaueren Mittheilungen über die dabei hervortretenden Athmungsstörungen.

Den Erfolg der Operation schildert Z a n d e r (1. e.) folgendermaassen:

„Die Zahl der Respirationen sinkt gleich nach der Operation sehr beträchtlich. Während ich an normalen Tauben im Durchschnitt 25-30 Respirationen in 1 Minute zählte, athmeten die Thiere unmittelbar nach der Vagotomie circa 5-10 Mal. Die Athmung wurde dyspnoisch. Die Dyspnoe steigt dann in den nächsten Stunden und die Frequenz geht noch weiter herunter. Schliesslich athmet das Thier nur 1-2 mal in der Minute.

Sehr charakteristisch ist das Bild, das die Vögel dabei bieten: Sie stehen ruhig auf einer Stelle; nach einiger Zeit schwanken sie von einer Seite zur anderen, der Hals beugt sich mit dem Kopf auf den Rücken; die Augen werden weit geöffnet; der Schnabel, die Mundschleimhaut werden cyanotisch; sie stirzen zu Boden oder überschlagen sich wohl gar; dann öffnet sich der Schnabel maximal; die Zunge wird weit vorgestreckt, eine tiefe Inspiration erfolgt; dann sind sie für einige Minuten ruhig und dasselbe Schauspiel spielt sich ron neuem ab.

Nicht immer ist die Dyspnoe so heftig; sie fehlt aber nie ganz.

Die Verlangsamung der Athmung wird nicht durch eine Verlängerung der Athemphasen, sondern hauptsächlich durch Athempa u sen bedingt; es tritt exspiratorischer Stillstand ein. Die Kohlensäure häuft sich im Blute an und reizt das Athemcentrum; eine tiefe Inspiration wird ausgelöst."

Die eingehendsten Untersuchungen über denselben Gegenstand verdanken wir Knoll (2), dessen Angaben ich in allen wesentlichen Punkten bestätigt fand. "Schon nach einseitiger Vagusdurchschneidung verlangsamt sich die Athmung der Versuchs. thiere (Tauben) bedeutend; ein Absinken der Respirationsfrequenz auf die Hälfte oder 2 Drittel der ursprünglichen Ziffer ist hierbei die Regel. Nach 2-3 Tagen ist jedoch die ursprüngliche Respirationsfrequenz gewöhnlich wiederhergestellt. Weit grösser und anhaltender ist die Verlangsamung, wenn beide Vagi durchschnitten sind."

In der Mehrzahl der Beobachtungen sank hiernach die. Athmung auf $5-7$ Athemzüge in der Minute, also auf $1 / 6$ bis $1 / 12$ der 
vorher gefundenen Ziffer, ab; doch constatirte $\mathrm{K} \mathrm{n}$ o $1 \mathrm{l}$ auch mehrmals ein Absinken auf 3 bis $3 \frac{1}{2}$ and zuweilen nur auf $10-15$ Respirationen in der Minute.

„Im Allgemeinen entsprach den relativ hohen Zahlen nach der Operation auch eine sehr hohe Frequenz der Respilation $\mathbf{v}$ o r derselben; doch war manchmal auch das Verbältniss ein abweichendes, in welchem Falle die Respirationsfrequenz nur auf $1 / 4-1 / 3$ absank."

Schon E i c b horst (28) hat behauptet, dass die unmittelbar nach der Vagusdurchschneidung sehr niedrig gewordene Athemfrequenz der Vögel im Laufe des zweiten Tages wieder normal wird, und auch Zander giebt an, dass die Athmung der Vögel in circa 24 Stunden nach der Vagussektion wieder erheblich rascher wird und erklärt dies in der Weise, dass die durch den Schnitt bedingte centripetale Reizung - welch' letztere nach Kohts and Tiegel (29) die Ursache der Verlangsamung der Athmung nach Vagussektion sei - innerhalb dieser Zeit -wieder abgeklungen ist $\mathbf{1}$ ).

Knoll war nicht in der Lage, diese Angaben durchaus zu bestätigen. Er beobachtete zwar auch oft eine merkliche Beschleunigung am ersten oder zweiten Tage nach der Operation; doch fand er bisweilen auch im Gegentheil die Atbmung später noch mehr verlangsamt, ,und stets war di e se lbe während der ganzen Beobachtungseit biszum. Todedes Versuchsthieres weit langsamer als vorder Opera$\mathrm{t}$ io $\mathrm{n}$ ".

Meine eigenen Erfahrungen stimmen hiermit durchaus überein and kann ich anstatt meiner Tabellen auf die von $\mathrm{Knoll}$ mitgetheilte Zusammenstellung von Respirationszablen verweisen (1. c. p. 11).

Es kann hiernach nicht zweifelhaft sein, dass es sich bei der nach doppelseitiger Vagotomie hervortretenden Verlangsamung der

1) Wenn man die von $Z$ ander vor und nach Vagotomie bis zum Exitus letalis aufgestellten Respirationsfrequenzen tabellarisch zusammenstellt, so ergiebt sich auch hier, dass die Respirationszahlen nach der Operation niemals den Normalwerth wieder erreichen, im Gegentheil in fast allen Fällen, weit geringer sind. Seine Ansicht über die Ursache der respiratorischen Verlangsamung wiederlegt sich dadurch von selbst. 
Athmung im Wesentlichen um eine ächte Ausfallerscheinung und nicht um die Folgen einer Reizwirkung handelt.

„Dass die Athemfrequenz der Versuchsthiere einige Zeit nach der Operation eine Zunahme erfährt, kann", wie Knoll richtig bemerkt, „ebensowenig befremden, als der Wechsel der Ziffern an den einzelnen Beobachtungstagen. Man braucht mit Bezug hierauf nur einerseits an die in thierischen und wohl iuberhaupt in allen Organismen bei Funktionsstörungen eintretenden regulatorischen Vorgänge za erinnern, und andererseits darauf hinzuweisen, dass in Folge der Vagussektion Störungen der Circulation und Veränderungen der Respirationsfläche zu Stande kommen, die ihrerseits auf das Athemcentrum in einer je nach ihrer Entwickelung differirenden Weise Einfluss nehmen miissen."

Aus dem. anatomischen Verhalten des $\mathrm{N}$. vagus ergiebt sich unmittelbar, dass durch seine Durchschneidung am Halse eind Lähmung des Kehlkopfes nicht bedingt wird: im Gegentheil er scheinen die Bewegungen desselben nach der Operation unvergleichlich stärker ausgeprägt, als unter normalen Verhältnissen ${ }^{\mathbf{1}}$ ). Während hier, wie schon erwähnt wurde, die Ligamenta ary-epiglottica nur sehr wenig umfangreiche Bewegungen ausfubren, legen sich nach der Vagusdurchschneidung die Ränder der Glottis fest aufeinander (was sonst nur bei Husten-, Schluck- und Reflexbewegungen durch Reizung der Larynxschleimhaut einzutreten pflegt) und öffnen sich nur während der Inspiration maximal. Während der Kehlkopf als Ganzes bei normaler Respiration so gut wie gar keine Bewegungen ausführt, steigt derselbe nach doppelseitiger Vagussektion bei dei Inspiration stark gegen den Schnabel empor und zieht sich bei der Exspiration nach unten zuriuck. Im Verlauf der ganzen Pause verharrt er unbewegt in der letźteren Stellung, d. h. im Tiefstand ( $\mathrm{K}$ n $\left.0 \mathrm{ll})^{2}\right)^{2}$.

1) Sektion nu? eines Vagus beeinflusst nach Knoll die Kehlkopfbewegungen gar nicht. Auch meine Beobachtungen lassen den Schluss zu, dass unilaterale Vagotomie, von geringen Störungen abgerechnet, bedeutungslos ist.

2) Doch habe ich eberso wie Knoll einmal beobachten können, dass die Pl. aryepiglotticae nicht während der ganzen Pausenlänge geschlossen blieben, sondern schon vorhèr auseinanderwichen und fast unmerklich in die Inspirationsstellung übergingen. Dabei vollzieht sich die Bewegung nicht energisch und einzeitig, sondern durch zitternde Rückwärtsbewegungen. Es 
Diesen veränderten Bewegungsmodus führt Zander darauf zurück, dass gewisse im $\mathrm{N}$. recurrens verlanfende Vagusfasern durch die Durehtrennung ausgeschaltet werden.

Mit Recht macht $\mathrm{Kn}$ oll gegen diese schwer verständliche Auffassung geltend, dass erstens einseitige Vagusdurchschneidung überhaupt keine deutlichen Veränderungen hervorruft, und dass andererseits auch elektrische Reizung des peripheren Vagusstammes erfolglos bleibt. Auch bei Reizung eines centralen Vagusstumpfes mit inducirten Strömen beobachtete er nur ein mit Stillstand der Athembewegung in Exspirationsstellung einhergehendes festes Aneinanderschliessen beider Falten und bei Verwendung starker Ströme stossweise heftige Gegenbewegungen derselben, welche an die hierbei auftretenden Hustenstösse gebunden schienen.

Es scheint viel richtiger, diese Bewegungen als dy s p n o i s ch bedingte aufzufassen; denn ganz dieselben Excursionssteigerungen kann man auch bei Thieren mit intakten oder nur einseitig durchtrennten Vagis beobachten, denen man die Trachea zugeklemmt hat.

Auch diese abnormen Kehlkopfbewegungen bleiben während der ganzen Lebenszeit der operirten Thiere bestehen, wenn auch die anfänglichen, begleitenden Symptome stärkster Athemnoth, in einem weiten inspiratorischen Oeffnen des Schnabels, krampfhaftem Vorstrecken des Halses und manchmal auftretenden Opisthotonus bestehend, meist schon nach 24 Stunden verschwunden sind. In der späteren Zeit sab übrigens Knoll diese Zeichen stärkster Dyspnoe wiederkehren, vielleicht bedingt durch entzïndliche Prozesse septischen Ursprungs in der Lunge oder durch die massenhafte Anstauung der Speisen im Kropfe, wodurch für die Athmung ein mechanisches Hinderniss gesetzt wird.

Bei sehr jungen Thieren ist die Vagusdurehschneidung meist in wenigen Stunden tödtlich, sei es, dass die an sich geringere Widerstandsfähigkeit gegen Dyspnoe und anderweitige Folgeerscheinungen der Operation daran Sehuld trägt, oder dass, wie P. B ert (1. p. 450) will, die noch nicht völlig ossificirten Ränder des Kehlkopfes bei jeder Inspiration sich zusammenlegen und so den Eintritt der Luft in die Trachea verhindern(?). Der Tod erfolgt stets unter den Erscheinungen der stärksten Suffocation (Krämpfe der Flügel-, Schultermuskulatur etc.).

handelte sich dabei übrigens um ein Thier, wo die Vagisektion fast einflusslos auf die respiratorische Frequenz geblieben war. 
Nicht nur in Bezug auf die Frequenz, sondern auch hinsichtlich des Typus der einzelnen Respirationsbewegung zeigen vagotomirte Tauben auffallende und bis zum Tode anhaltende Veränderungen, die meist sehon nach Durchschneidnng nur eines Nerven, sehr potenzirt dagegen nach doppelseitiger Vagotomie hervortreten.

Knoll (l. c. p. 12) erwähnt ausdrüeklich, dass bei vagotomirten Tauben die Trennung der Exspiration in einen passiven und aktiven Theil (d. h. nach unserer Auffassung der zuckungsähnliche Nachschlag der schon vorher aktiven Exspirationsbewegung) fast stets sichtbar, und beide Theile der Exspiration durch eine (exspiratorische) Athempause von beträchtlicher Länge von einander geschieden seien; indessen sprechen die von ihm selbst mitgetheilten Curven (vgl. l. c. Taf. I 2, 2a, 3, 3a, 3b, 2b) keineswegs zu Gunsten dieser Ansicht, indem die Zackenbildung am Ende jeder Pause entweder ganz fehlt oder nur schwach angedeutet erscheint, selbst wenn sie vorher am normalen Thiere sehr stark entwickelt war.

Ich habe, wie bereits friiher bemerkt wurde, die gleiche Thatsache regelmässig nach Vagotomie an Tauben zu constatiren Gelegenheit gehabt und Curven erhalten, welche auch sonst den von Knoll mitgetheilten durchaus entsprechen. Dieselben charakterisiren sich vor Allem dadurch, dass in der Mehrzahl der Fälle der absteigende Schenkel mehr oder weniger steil zu einem Plateau abfällt, welches sich namentlich nach Durchtrennung beider Vagi zu einer oft kolossalen Pause entwickelt, welche nach Knoll als eine exspiratorische zu bezeichnen sein wïrde (vgl. Fig. 37-39 Taf. IV und 40,41, 59).

"Wohl prägte sich jetzt auch am flacheren Abschnitt des inspiratorischen Theils der Curven eine erhebliche Verlängerung gegenüber dem gleichen Curvenabschnitte nach einseitiger Vagusdurchschneidung aus - allein diese Veränderung der Curven tritt ganz in den Hintergrund gegenïber der enormen Zunahme des flacheren exspiratorischen Curventheiles." (Kno11, l. c. p. 15.)

Unzweifelbaft kommen, wiewohl nur selten, nach Vagusdurchschneidung Pausen in tiefster Exspirationsstellung von beträcht licher Länge vor, indem sich das anch normaler Weise oft schon vorhandene kleine Gipfelplateau (Fig. 33-36) zu einer langen horizontalen Linie auszielıt, deren Ende dann wohl auch durch die 
bekannte, zackentörmige Erhebung ausgezeichnet ist (Fig. 42, Taf. IV und Knoll l. c. Fig. 7).

Indessen ist dies, wie gesagt, nur ausnahmsweise der Fall. Viel häufiger fällt, wie schon erwähnt, der exspiratoriscbe, ziemlich spitze Gipfel jäh oder „in sanfter Krümmung“ zu einem viel tiefer gelegenen Niveau ab, innerhalb dessen der Schreibstift während der Pause eine annähernd horizontale Linie verzeichnet, welche aber nach Knoll nicht ganz der "Rulelinie" (d. h. der vom Schreibhebel der M a re y'schen Trommel in der Ruhelage gezeichneten Linie) entspricht, sondern, wenn auch nur wenige Millimeter, ibber derselben verläuft. Ich selbst konnte mich in mehreren Fällen mit Sicherheit davon überzeugen, $d$ ass während der Pausen die wirkliche Rubestellung des Thoraxerreicht wird (vergl. Fig. 43 und 44, wo durch hohe Rückenmarksdurehschneidung dicht unterhalb der Med. oblongata die Thoraxathmung mit einem Male sistirt wurde).

Im Allgemeinen kann man sagen, dass je stärker die durch Vagotomie bedingte Verlangsamung ist, um so grösser die Wahrscheinlichkeit wird, dass die passive Inspiration, als deren Ausdruck der iuber der Abscisse gelegene Theil des absteigenden Curvenschenkels anfzufassen ist, in eine wirkliche Ruhepause im strengen Wortsinne - iibergeht.

Etwas abweichend sind die Beobachtungen, die Courre u r (37) an Hühnern gemacht hat. Es dürfte am besten sein, wenn ich diese betreffende Stelle hier wörtlich citire (1. c. p. 15).

1. Section unilatérale.

Au moment, où l'on effectue la section, l'animal présente une pause en expiration, qui résulte très probablement de l'excitation du nerf. Celle-ci est de peu de durée, et la respiration ne tarde pas à reprendro. Elle est d'abord un peu ralentie et irrégulière, mais cet effet n'est que passager, et au bout de quelques jours elle est complètement normale au point de vue du rhytme et de l'amplitude.

2. Section bilatérale.

Immédiatement après la double section, les monvements respiratoires deviennent beancoup plus rares ( 3 on 4 par minute au lieu de $35 \dot{a} 40$ ), et ils sont en même temps beancoup plus amples; l'inspiration est un peu allongée, l'expiration très brève, des pauses en expiration d'une durée de quinze secondes environ sépa- 
rent deux mouvements respiratoires. Un quart d'heure environ après, le nombre restant toujours le même, l'amplitude diminue beaucoup, et tombe même au-dessous de la normale. En même temps, on constate un certain changement dans la forme de la courbe: l'expiration reste toujours très brève, mais l'inspiration s'allonge notablement. Au bout de quatre ou einq jours, les mouvements sont devenus plus fréquents (doch erreichen sie auch nach Co u v re ur niemals aucb nur annähernd den Normalwerth), mais ont encore perdu en amplitude. L'inspiration reste tres allongée, mais l'expiration n'est plus si brève; parfois même elle s'alonge beaucoup, et se fait pour ainsi dire en deux temps. Ce type ce continue jusqu'à la mort.

Man sieht hieraus, dass in allen wesentlichen Punkten ziemliche Uebereinstimmung mit den Beobachtungen an Tauben besteht; auffallend ist nur, dass $\mathrm{Cou} v \mathrm{reur}$ stets Pausen in $\mathrm{reiner}$ Exspirationsstellung erhielt, d. h. auf der Höhe des exspiratorischen Scheitels, wobei freilich aus den beigegebenen Curvenaussehnitten kein Schluss auf den aktiven oder passiven Charakter der Ausathmungsbewegung zu machen ist.

\section{B. Die Folgen der Reizang des centralen Vagusstammes.}

Wie schon K noll bemerkt, ist die Blosslegung des N. vagus am Halse wegen der straffen, kaum zu trennenden Anheftung an die Venae iugulares und der zahlreichen schräg und quer in der vorderen Halsgegend verlaufenden Blutgefässe nicht ganz ohne Sehwierigkeit auszuführen.

Ich fand es am zweckmässigsten, den l in k e n Vagus sammt der Vene doppelt za unterbinden und zwischen den Ligaturen durchzuschneiden. Man kann dann leicht ohne Blutung ein mehrere Centimeter langes Stiick des Nerven frei präpariren und der Reizung zugänglich machen.

Benützt man inducirte Wechselströme eines Schlittenapparates, so besteht der gewöhnliche Erfolg in dem Auftreten von Pausen (wie sie auch von $\mathrm{Kn}$ oll bereits gesehen wurden).

Bei der Mehrzahl der Versuchsthiere erfolgt, wie Kn oll angiebt, dieser Stillstand nur in Exspirationsstellung. Stillstand in ti fster Inspirationsstellung kam uiberhaupt nicht zur Beobachtung. Bei zwei Versuchsthieren aber wurde bei einigen Reizversuchen die Exspiration kurz nach ihrem Beginne 
unterbrochen, und es kam zum Stillstand der Athmung in einer der tiefsten Inspirationsstellung genäherten Stellung.

Nach Beendigung der Reizung folgten gewöhnlich einige tiefere und beschleunigte Athemzigge, und hierauf stellte sich erst allmählich der ursprüngliche Athmungstypus wieder ein ( $\mathrm{K}$ n oll 1. e. p. 16).

Ich selbst hatte Gelegenheit, in zahlreichen Fällen den Erfolg der tetanisirenden Reizung des centralen Vagusstammes mit inducirten Wechselströmen zu beobachten und kann nur sagen, dass in der grossen Mehrzahl der Fälle der Stillstand der Athmung bei einer Thoraxlage erfolgte, welche der „Ruhelage“ entweder wirklich entsprach oder derselben doch mindestens sehr nahe kam.

Wie eine Vergleichung der Curven Fig. 45-47, 55, Taf. IV ohne Weiteres erkennen lässt, verläuft die Pausenlinie während der Dauer der Reizung im Allgemeinen im gleichen Niveau, wie die in Folge der Vagusdurchschneidung schon vorher vorhandenen, nach Knoll als exspiratorisch zu bezeichnenden Pausen.

Ich habe aber oben bereits die Gründe entwickelt, welche mich bestimmen, diese wenigstens in dem Falle, wenn sie gut entwickelt sind, für der Ruhestellung entsprechend zu halten.

Die Daner der möglichen Hemmung ist in rerschiedenen Fällen sehr wechselnd, bisweilen aber (Fig. 45, Taf. IV) sehr beträchtlich.

Unter allen Umständen schwächt sich bei Fortdauer der Reizung die Hemmungswirkung $a b$ und bricht, wie auch beim Vagusstillstand des Herzens, die autochthone, rhythmische Thätigkeit des Athemcentrums wieder durch.

Ein schönes Beispiel für diese Thatsache liefert Curve 46; man sieht, wie die Panse allmählich ganz flachen Athembewegungen Platz macht, in denen anfangs nur die aktive Exspiration deutlich ausgeprägt ist, während erst im weiteren Verlauf die aktive Inspiration zur Geltung gelangt.

Inspiratorische Pausen sind extrem selten; ich habe sie nur einmal bei einem Thier, das meist auch bei Reizungen reine Ruhepausen darbot, auftreten sehen.

Fig. 48, Taf. IV demonstrirt diese Verhältnisse. Der inspiratorische Tetanus ist während der Dauer der Reizung nicht von gleicher Intensität, sondern nimmt allmählich mehr und mehr ab. 
Schliesslich wird die Ruhelage wieder erreicht; nach einiger Zeit erfolgt eine neue Inspirationsbewegung, an die sich eine zweite inspiratorische Pause anschliesst, immer noch unter dem Einfluss des Stromes.

Während Knoll nur Pausenbildung als Reizerfolg beobachtet zu haben scheint, ist es mir, obschon nur selten, auch gelungen, Beschleunigung der Athmung zu constatiren.

Wie die Fig. 49-57, Taf. IV erkennen lassen, entwickelt sich dieselbe dann meist im Verlaufe einer länger anhaltenden tetanisirenden Reizung, welche anfangs oft noch ganz unverkennbare Hemmungswirkungen auslöst. Fast unmittelbar nach Beendigung, bisweilen sogar schon während der Reizung stellt sich die normale Frequenz wieder her.

Gleichzeitig mit der Beschleunigung ändert sich in der Regel auch die Form der einzelnen Curven nicht unerheblich. Sehr gewöhnlich macht sich eine Abschwächung der inspiratorischen Phase bemerkbar, während die Exspiration kaum beeinflusst erscheint, sodass die Curvengipfel nahezu in gleicher Höhe liegen.

Doch kommt auch das Gegentheil vor (Fig. 53, Taf. IV). In einzelnen Fällen gesellt sich zu einer gleich im Beginn der Reizung auftretenden Beschleunigung eine sehr erhebliche Verstärkung b e id e r Phasen der Athmung, sodass die Curven sich sowohl nach oben wie nach unten viel weiter iiber die Abscisse hinaus erstrecken als vorher (Fig. 53). Genau das Gegentheil (geringe Beschleunigung und sehr starke Abflachung der Athmung: durch enorme Verkìrzung der exspiratorischen Gipfel) erscheint in Fig. 54 ausgeprägt.

Um überhaupt mittels inducirter Wechselströme eine merkliche Wirkung auszulösen, muss man in der Regel die Rollen des Schlittenapparates einander ziemlich weit nähern.

Meist tritt bei langsamem Vorschieben die Wirkung ganz plötzlich und gleich in fast voller Entwicklung hervor (Fig. 54). Auch ist sehr bemerkenswerth, dass, so wechselnd auch bei verschiedenen Individuen die Reizerfolge sein mögen, bei einem und demselben Thier gewöhnlich eine sehr auffallende Constanz derselben sich geltend macht, selbst wenn die Reizstärke innerhalb. ziemlich weiter Grenzen verändert wird. War der erste Effekt eine Verlangsamung und Verkleinerung der Athembewegungen, so bleibt dieser Charakter in der Regel auch bei Verstärkung der 
Reizströme erhalten, seltener machen sich im einen und im anderen Falle auffallendere Abweichungen in der Form der Curven bemerkbar (Fig. 52).

Sehr häufig tritt nach Beendigung einer nicht zu kurzen tetanisirenden Reizung des centralen Vagus eine sehr auffallende Nachwirkung entweder im gleichen oder im en tg egengesetzte n Sinne der durch den Reiz selbst gesetzten Veränderung der Athmung hervor. Das Erstere, d. h. eine pos itive $\mathrm{Nach}$ wirk ung lässt sich am häufigsten bei Anwendung schwacher und mittelstarker Ströme beobachten, ohne dass aber irgend constante Beziehungen zwischen Intensität uud Dauer der Reizung und der darauffolgenden Nachwirkung sich erkennen liessen. Nur selten fehlt jede Andeutung einer solchen, indem die Athmung unmittelbar nach Beendigung einer Reizung ibren ursprünglichen Charakter wiedergewinnt.

Während nach den vorliegenden Angaben eine deutlich ausgesprochene n egative Nachwirkung bei Sängethieren nur nach starker Reizung hervortritt, gilt dies bei den Vögeln nicht, indem oft schon die schwächsten tiberbaupt wirksamen Ströme derartige Contrastwirkungen hervorzurufen im Stande sind. Als Beispiel sei auf die Fig. 45, 46, 55, Taf. IV verwiesen, wo es sich theils um Beschleunigung und Verstärkung der Athembewegungen nach einer vorausgehenden durch Reizung bedingten Pausenbildung oder Verlangsamung und Abflachung handelt, oder aber um das Gegentheil (Verlangsamung und Abflachung) nach vorhergehender Beschleunigung und Verstärkung.

Wie die vorstehend mitgetheilten Thatsachen zeigen, ist die Verschiedenheit und Inconstanz der Erfolge centraler Vagusreizung: unter Anwendung inducirter Wechselströme bei Vögeln nicht geringer, als bei Säugethieren.

Letzterenfalls sind neuerdings von Seite Grützner's (31) und insbesondere Langendorff's (32) Beobachtungen veröffentlicht worden, aus welchen hervorzugehen schien, dass mit Hülfe von Kettenströmen eindeutigere Resultate zu erzielen sind, und ich ging daher mit einiger Erwartung an die Untersuchung der entsprechenden Reizerfolge bei Vögeln; leider entsprachen, wie gleich vorweg bemerkt sein mag, die Resultate in vieler Beziehung nicht den gehegten Erwartungen.

Schliessung des a $\mathfrak{u}$ f ste $\mathrm{i} g$ ende $\mathrm{n}$ constanten Stromes und 
andauernde aufsteigende Durehströmung beeinflussen die Athmung bei Säugethieren im Sinne einer Hemmung, es erfolgt Athemstillstand in Exspirationsstellung oder verlangsamte Respiration. Die Oeffnung, nach Grützner ohne Einfluss, bat nach Langend o rff in der Mehrzahl der Fälle deutliche inspiratorische Wirkung, die sich entweder in einer Vertiefung der Inspiration ausprägt oder sich als kurzer Inspirationsstillstand darstellt.

Schliessung des absteigenden Kettenstromes ist im Allgemeinen von viel geringerer Wirkung und bleibt, wie Grützn er angiebt, oft ganz ohne jeden merklichen Einfluss. Im Falle ein Effekt hervortritt, ist er in s p iratoris ch.

Als Oeffnungsreizerfolg macht sich eventuell ein exspiratorischer Athemstillstand bemerkbar.

Wie dauernde Schliessung wirkt unter Umständen auch der unterbrochene $\uparrow$ oder $\downarrow$ Kettenstrom, wobei aber die Reizfrequenz von wesentlichem Belang ist.

Bei Tauben ist es mir leider nicht gelungen, derartige durchgreifende Unterschiede in der Wirkung der verschiedenen Stromesrichtungen nachzuweisen. Eines ist dagegen sicher, dass $d$ er anfsteigende Strom intensiver wirktals derabst eigende.

Als Stromquelle bediente ich mich in der Regel einer Chromsäure-Tauchbatterie, von der eine wechselnde Zahl von Elementen eingeschaltet wurde. Die feinere Abstufung der Stromesintensität erfolgte durch ein Du-Bois'sches Rheochord. Die Unterbrechung wurde durch rasch wiederholtes Schliessen und Oeffnen eines Quecksilberschlüssels mit der Hand bewerkstelligt.

Von einer Wirkung dauernder Schliessung konnte ich mich selbst bei Anwendung starker Ströme nur selten überzeugen und zwar ausschliesslich bei aufsteigender Richtung, während absteigende Richtung immer erfolglos blieb. Auch bestand ersterenfalls der Reizerfolg nicht in einer Hemmung oder Verlangsamung der Athmung, sondern im Gegentheil in einer nicht unerheblichen Beschleunigung, wobei zugleich in der Mehrzahl der Fälle die Curven niedriger und etwas im inspiratorischen Sinne verschoben erschienen (Fig. 56, 57).

Sehr viel ausgeprägtere Reizerfolge lassen sich mittels rasch unterbrochener Kettenströme erzielen und zwar sowohl bei aufsteigender, wie absteigender Richtung derselben. Auch hier gilt je- 
doch die Regel, dass aufsteigende Ströme wirksamer sind als absteigende.

Bei einer gewissen geringen Stromesintensität kann letzterenfalls die im Uebrigen gleichsinnige Wirkung sogar ganz fehlen oder sie erscheint nur schwach angedeutet (Fig. 58).

Mit zunehmender Reizstärke verschwindet dieser Unterschied mehr und mehr und wird schliesslich unmerklich, sodass sich aus dem jeweils hervortretenden Erfolg die Stromesrichtung nicbt mehr unmittelbar erkennen lässt.

Sehr häufig besteht auch hier der Reizerfolg in einer $\mathrm{He}$ m m u $\mathbf{n} g$ der Athmung, wobei einerseits die Frequenz sehr erbeblich abnimmt, vor Allem aber die exspiratorische Excursionsbreite des Thorax (die Curvenhöhe) ganz ausserordentlich vermindert erscheint. Diese Wirkung ist im Beginn der Reizung in der Regel am stärksten ausgeprägt und nimmt weiterhin allmählich ab (Fig. 58).

Bisweilen gilt dies nur von der Verlangsamung des Athemrhythmus, nicht aber auch bezüglich der Verkleinerung der exspiratorischen Amplituden, die vielmehr im Verlauf einer längeren Reizung noch weiter abnehmen können.

Langanbaltende ununterbrochene Pausen, wie sie bei Reizung mit inducirten Wechselströmen so häufig auftreten, habe ich durch den unterbrochenen Kettenstrom nie erzielen können. Dagegen beobachtet man sehr häufig ganz ausgeprägte Erreg ung $\mathrm{s}$ wirkungen, indem der Athemrhythmus während der Dauer der Reizung mehr oder weniger beschleunigt wird, wobei die einzelnen Respi. rationen entweder flacher als vorher oder umgekehrt in ihrem exspiratorischen Theil bedeutend verstärkt erscheinen. Seltener ist gleichzeitig auch die inspiratorische Phase stärker entwickelt, so dass die inspiratorischen Gipfel der Curven tiefer unter die $\mathrm{Ab}$ scisse herabreichen (Fig. 60, 61, 62, 63, Taf. V).

Sehr auffallend macht sich oft der Einfluss wechselnder Stromstärke geltend, indem unter sonst ganz gleichen Umständen verschiedenen Reizstärken bisweilen gerade entgegengesetzte Erfolge entsprechen.

So zeigt Fig. 61, Taf. $\mathrm{V}$ bei Anwendung von 4 Elementen eine merkliche Verlangsamung and bedeutende Abflachung der Athmung, während in Fig. 60 , Taf. $V$ bei 10 Elementen Beschleunigung uud Verstärkung als Reizerfolg hervortritt.

In noch schärfer ausgeprägter Weise, als bei Anwendung von 
Induktionsströmen, machen sich negative Nachwirkungen bei Reizung mit Kettenströmen bemerkbar, besonders in Form beschleunigter Respirationen, wenn während der Dauer der Reizung die Athmung verlangsamt und verflacht war.

Ueberblickt man das wechselvolle Bild der Erfolge centraler elektrischer Vagusreizung bei Vögeln, so findet man demnach folgende Möglichkeiten gegeben:

I. Reizung mitinducirten Wechselströmen.

1. Völliger Athmungsstillstand bei Ruhestellung des Thorax.

2. Inspiratorische Pausen (kurz und sehr selten).

3. Exspiratorische Pausen.

4. Verlangsamung und Verflachung.

5. Beschleunigung und Verflachung.

6. Verlangsamung und Verstärkung.

7. Beschleunigung und Verstärkung.

II. Reizung mit Kettenströmen.

1. Aufsteigende Schliessung bewirkt bisweilen Beschleunigung mit inspiratorischer Vertiefung und Verkürzung der Exspiration.

2. Auf- oder absteigend unterbrochener Strom kann

a) Verlangsamung und Verflachung,

b) Beschleunigung und Verflachung,

c) Beschleunigung und Verstärkung beider Athmungsphasen,

d) Beschleunigung mit vorwaltend exspiratorischer Verstärkung der Athmung geben.

So mannigfaltig sich daher die Reizerfolge auch gestalten, und so wenig sich ihr Charakter im einzelnen Falle voraussagen lässt, so constantbleiben dieselben wäbrend der Versuchszeit bei einem und demselben Thier.

Es gilt hier genau dasselbe, was Meltzer (33) schon bezüglich der Vaguserregung bei Säugethieren ausgesprochen hat: "Die Reizerfolge sind bei demselben Thiere durchaus nicht schwankender, regelloser Natur. Wenn man einmal den Vagus eines Thieres mit verschiedenen Stromstärken gereizt bat, so erlangt man für dieses Thier eine Reihe von Resultaten, die für das betreffende Thier als Norm, als Typus gelten kann. Die grossen Schwankungen in den Ergebnissen rühren vielmehr von der Ungleichheit der Reizerfolge bei verschiedenen Thieren her.

Also ein wesentlicher Theil der Verschiedenheit in den Er- 
gebnissen der Vagusreizungen rïhrt von der Verschiedenheit der Individualität der gereizten Thiere her."

Eine Constanz ganz anderer Art glaubt Bert in den Erfolgen seiner an Enten vorgenommenen Reizversuche zu erkennen. Er fasst das Resultat in folgendem Satze zusammen:

L'arrêt de la respiration a lieu, soit en inspiration, soit en exspiration dans les conditions identiques, selon le moment, où a été appliquée l'excitation.

La galvanisation du pneumogastrique, en d'autres termes, a arrêté les mouvements respiratoires au moment même, où elle à ètẻ appliquée."

Damit würde sich der Erfolg der Vaguserregung bei Tauben in direkte Parallele zu den bei Reptilien von Bert beobachteten Resultaten stellen. Mir selbst ist es weder in dem einen noch im andern Falle jemals geglückt, etwas Aehnliches zu sehen, und sehe ich mich gänzlich ausser Stande, die obwaltenden Differenzen zu erklären.

Ebenfalls mit meinen Versuchsergebnissen lebhaft contrastirend sind die Erfolge elektrischer Vagusreizung, über die Couvreur (l. c. p. 21 ) in seiner schon citirten Arbeit berichtet. $O b$ er in der Continuität des Nerven reizte oder seinen centralen Stumpf, ob der andere Vagus intakt oder durchschnitten war, immer erhielt er bei schwachen Strömen Beschleunigung, bei stärkeren dagegen inspiratorischen Stillstand der Athmung.

Même en prolongeant pendant longtemps l'excitation (15 secondes) on voit toujours l'effet inspiratoire prédominer; la courbe remonte bien un peu, mais au moment où l'on cesse l'excitation, e'est toujours une expiration violente qui se produit. Si l'on excite très longtemps (22 secondes), la respiration reprend, mais très courte et les sommets expirateurs restent au-dessous de la ligne générale des expirations. Cependant, quand on anesthésie l'animal, l'excitation du bout central provoque d'emblée un arrêt en expiration; mais l'effet est aussi le même quand le nerf est fatigué. Nous concluons done, en nous ralliant à l'opinion de Frédérieq, que le pneumogastrique renferme au cou des fibres inspiratrices et expiratrices, que les premières se fatiguent plus vite que les secondes, et qu'on peut les paralyser par les anesthésiques."

Gegenüber der enormen Vielgestaltigkeit meiner Versuchs- 
ergebnisse muss diese Constanz der Wirkungsweise höchst auffallend erscheinen. Leider macht Couvreur keine Mittheilung über die Art der verwendeten Ströme, und ebensowenig giebt er die benutzten Narcotica an, wenn auch die Bezugnahme auf Frẻdéric q die Annahme berechtigt erscheinen lässt, dass ihm das Chloral bei seinen Experimenten gedient hat, dessen bekannte Wirkung auf die inspiratorischen Vagusfasern von jenem Forscher genau studirt worden ist. Meinerseits muss ich aber ausdrücklich betonen, dass bei Tauben wenigstens die Einwirkung des Chlorals auf die Athmung eine von den Säugethieren total verschiedene ist. An eine anfängliche starke Steigerung der respiratorischen Frequenz schliesst sich bei tieferer Narkose ein Stadium an, das nicht durch exspiratorische Pausen, sondern im Gegentheil durch ausserordentlich spitz zulaufende exspiratorische Gipfel charakterisirt ist, während gerade die Inspiration gegen die Norm einen viel protrahirteren Verlauf nimmt; dass aber die Chloralnarkose auf den Erfolg der Vagusreizung auch nur den geringsten Einfluss hatte, habe ich nie constatiren können.

Couvreur geht indessen in dem Bestreben, direkte Analogien zwischen den Innervationsverhältnissen bei Vögeln und Säugethieren zu finden, noch viel weiter. Die bisher mitgetheilten Befunde galten nur für die Fälle, wo unterhalb des Abganges des N. laryngeus superior gereizt wurde (l. c. p. 22).

"Quand on excite le laryngé supérieur, ou bien le pneumogastrique au-dessus du point ou ce nerf se détache, l'effet n'est plus le même: c'est un effet expirateur qu'on obtient d'emblée. Cet effet est tellement marqué, que si l'on pratique l'excitation au moment d'une pause exspiratoire (animal à deux pneumogastriques coupés), une expiration forcée se produit immédiatement...

Nous sommes done forcés, d'après ces résultats, de nous ranger, au moins pour ce qui est des oiseaux, á l'opinion de Rosenthal et de la majorité des physiologistes allemands sur les mammiferès, à savoir que, au-dessous du laryngé supérieur l'effet de l'excitation du pneumogastrique est surtout inspirateur et surtout expirateur au contraire au-dessus de ce nerf."

Vor mehr als dreissig Jahren fasste Rosenthal (34) in seiner beriihmten Monographie das Resultat seiner Untersuchungen in folgenden Worten zusammen:

„Die Athembewegungen werden erregt durch den Reiz des 
Blutes auf das respiratorische Centralorgan. Der Uebergang dieser Erregung auf die betreffenden Nerven und Muskeln findet einen Widerstand, durch welchen die stetige Erregung in eine rbythmische Aktion umgesetzt wird. Dieser Widerstand wird durch die Einwirkung des Nervus laryngeus vermehrt; er wird vermindert durch die Einwirkung des N. vagus. Ein continuirlicher im N. vagus geleiteter Reiz vermehrt die Zahl der Athemziuge durch Verringerung jenes Widerstandes". Das Vorhandensein inspirationshemmender oder Exspiration hervorrufender Fasern im N. vagus unterhalb des Laryngeus sup. stellt er in Abrede und hält derartige Wirkungen für bedingt durch Stromschleifen und unipolare Abgleichungen auf den $\mathrm{N}$. laryngeus superior.

Im Jahre 1868 erschien dann die berühmte Arbeit von Hering und Breuer (35), in welcher der Nachweis geführt wurde, dass die Ausdehnung der Lungen reflektorisch die Inspiration bemmt und die Exspiration fördert, während umgekehrt der Lungencollaps die Exspiration hemmt und eine sofortige Inspiration hervorruft.

Diese Lehre, heute von vielen Autoren als richtig anerkannt, erfuhr später durch Ga d (36) eine Einschränkung, der zwar die Existenz inspirationshemmender und exspirationserregender Fasern zugiebt, inspirationsauslösende Fasern dagegen leugnet und so gerade das fallen lässt, was $\mathrm{R}$ o s e nthal durch lange Jahre mit grösster Energie verfocht.

Ich möchte mich hier nicht auf eine kritische Erörterung der von Gad und seinen Schülern vertretenen Anschauungen einlassen, obschon sich gerade auf Grund der in der vorliegenden Arbeit mitgetheilten Thatsachen begründete Einwände machen liessen. Es würde hierzu vor Allem eine viel eingehendere Untersuchung der auch bei Vögeln sehr auffallenden Erfolge "p hysiologischer Vagusreizung" durch Einblasen und Aussaugen von Luft in die Trachea nöthig sein, als ich sie bisher anzustellen Gelegenheit fand. Ich möchte aber dabei zugleich der Ueberzeugung Ausdruck geben, dass die wenigen Erfahrungen, welche ich in dieser Beziehung zu sammeln vermochte, mir durchaus den Eindruck machten, dass gerade die Untersuchung der Vogelathmung ausserordentlich geeignet erscheint, iuber die hier in Betracht kommenden Fragen grössere Klarheit zu verbreiten. Jedenfalls dürfte eine Weiterfüh- 
rung der Untersuchung in dieser Richtung sich besonders erfolgreich gestalten.

Sehr klar und eindeutig sind die Einwirkungen des Einblasens und Aussaugens von Luft auf die Kehlkopfbewegungen. Es wurde schon früher erwähnt, dass während der normalen Respiration der Kehlkopf eine, wie es scheint, inspiratorische Mittelstellung einnimmt, die sich nicht verändert, während die Plicae ary-epiglotticae sicb bei der Inspiration schwach nach aussen bewegen, bei der Exspiration sich dagegen ein wenig nähern. Bei dyspnoischen oder vagotomirten Thieren ändert sich dies Verhalten in auffälliger Weise, indem sich bei der Einathmung die Plicae aryepiglotticae weit von einander entfernen, während zugleich der Kehlkopf als Ganzes eine kräftige Vorwärtsbewegung erfäbrt, bei der Exspiration dagegen nach riickwärts gezogen wird, wobei sich der zwischen den Plicae befindliche weite Spalt bis zum völligen Schlusse verengert.

Diese Vorgänge kann man sich leicht durch Oeffnen des Schnabels vor Augen bringen und noch deutlicher gestalten, wenn man von einem vor dem Kopf des Thieres passend aufgestellten Spiegel Licht in die Mundhöhle reflektiren lässt. Bläst man nun nach Einlegen einer Trachealkaniule Luft in die Lungen, so beobachtet man sofort ein Zurückgehen des Kehlkopfes, während sich seine Ränder einander kräftig nähern. Die Aufblasung bedingt demnach eine ausserordentlich markante Exspirationsstellung des Kehlkopfes, und zwar in allen Fällen augenblicklich, mag sie im Moment der Exspiration oder Inspiration zur Einwirkung gelangen.

Diese Exspirationsstellung des Kehlkopfes bleibt dann so lange bestehen, als die Aufblasung andauert, und habe ich Pausen bis $\mathrm{zu}$ einer halben Minute beobachtet, selbst bei sebr jungen Tauben.

Oft kann man beobachten, dass der Erfolg der Aufblasung auch noch einige Zeit nachwirkt, indem die entstehende Pause erst etwas später durch eine inspiratorische Kehlkopfbewegung abge. schlossen wird. Wohl immer ist eine Nachwirkung in dem Sinne zu constatiren, dass die folgenden Respirationen stark verlangsamt sind, und dass dabei immer wieder der Kehlkopf in die Exspirationsstellung zurückkehrt, bis er allmählich erst die normale Mittellage wieder erreicht. Eine Beschleunigung habe ich als Nachwirkung nie auftreten sehen. 
Auch bei stark dyspnoischen Thieren tritt der Reflex äusserst prompt ein und die Hemmungswirkung ist dann nicht weniger stark ausgeprägt als unter ganz normalen Verhältnissen. Man braucht keineswegs sehr stark zu blasen; ein schwacher Luftstrom, der die respiratorischen Hohlräume gewiss kaum stärker als normal ausdehnt, genïgt, um die Hemmung mit aller Deutlichkeit in Erscheinung treten za lassen.

Legt man die Bauchmuskeln bloss, so kann man auch an ihnen durchaus entsprechende Beobachtungen machen. Doeh muss man gerade bier eine zu starke Aufblähung vermeiden, weil die ab. dominalen Luftsäcke sich sonst so stark hervorwölben, dass die Bauchrnuskeln zu sehr gedehnt und in ibrer Thätigkeit behindert werden.

Der Erfolg ist dann der, dass während der Aufblasung die Obliqui externi in deutliche und langgezogene Contraktion gerathen.

Oft tritt erst kurze Zeit nach Beginn der Aufblasung diese die Erregung der Exspiration bezeichnende Erscheinung ein; während anfangs die Muskeln noch erschlafft waren.

Ganz anderer Natur sind die Erfolge der Aussangung der Luftwege; junge Thiere eignen sich nicht besonders zu diesem Versuche, weil sie gegen den Eingriff sehr empfindlich sind und mit heftigen Körperbewegungen, mit Schluck- und Gegenbewegungen des Kehlkopfes auf eine irgend stärkere Saugung reagiren. Dagegen ist das Verhalten älterer Tauben stets constant. Der Kehlkopf steigt im Beginn des Saugens jäh nach vorn und öffnet sich maximal; jedoch entsteht nun keineswegs ein inspiratorischer Tetanus, der ihn längere Zeit fixirt hielte, sondern einen Moment später bewegt sich der Larynx schon wieder nach rïckwärts, um dann sofort wieder nach vorn zu schiessen. Dies Spiel wiederholt sich nun während der ganzen Dauer der Aussaugung; d. h. es tritt eine Beschleunigung der Athmung, mit sehr verstärkter Inspiration und verminderter Exspiration ein, was durchaus jenem Erfolge entspricht, den wir als einen häufigen Reizerfolg bei Anwendung des constanten und des unterbrochenen Kettenstromes haben auftreten seben.

Aehnlich wie bei den Säugethieren wird auch hier eine durch Aufblasung bedingte gedehnte Exspirationsbewegung durch Aussaugen momentan coupirt.

Aụch hier besteht eine Nachwirkung, wiewohl weniger ausge- 
prägt als bei der Aufblasung; leichte Beschleunigung und inspiratorische Kehlkopfbewegungen, die erst allmählichwieder verschwinden, zeichnen sie aus.

Der Erfolg der physiologischen Vagusreizung lässt sich demnach dahin zusammenfassen, dass Aufblasung die Inspiration hemmt und die Exspiration hervorruft, während umgekehrt Ausaugen die Exspiration hemmt und die Inspiration fördert.

Dass es sich dabei um einen Reflexvorgang handelt, beweist in einfacbster Weise die Sektion der Vagi: nach Durchschneidung beider Nerven ist das Phänomen dauernd verschwunden, während einseitige Durchtrennung die Erscheinung kaum beeinflusst.

Bei einem vagotomirten Thiere gelingt es niemals mehr, ausserhalb des spontanen Athmungsthythmus eine Inspiration oder Exspiration durch Aussaugen oder Auf́blasen auszulösen oder zu hemmen.

Es kann somit keinem Zweifel unterworfen sein, dass die Selbststenerung der Athmung in dem Hering-Breuer'schen Sinne für Vögel ganz ebenso Geltung hat, wie für die Säugethiere, und dürften die ersteren für die Demonstration der betreffenden Verhältnisse sogar bequemere Objekte darstellen, als diese.

Es erhebt sich nun die weitere Frage, ob die Lungen- oder die Luftsackdehnung die erwähnten Reflexe auslöst.

Berïcksichtigt man die bereits geschilderten anatomischen und mechanischen Verhältnisse der Vogelathmung, so wird man a priori mehr geneigt sein, die so ausserordentlich dehnbaren Luftreservoirs, gegen deren Volumänderungen jene der Lungen kaum in Betracht kommen, in erster Linie verantwortlich zu machen. Indessen lehrt eine genauere Untersuchung das Gegentheil.

Man kann die Luftsäcke, soweit als thunlich, zerstören, die Bauch- und Brusthöhle weit eröffnen, und trotzdem gelingt es noch immer, durch Einblasen von Luft in die Trachea, eine ganz exquisite Hemmung der Athembewegungen auszulösen, ohne dass sich die Lungen überhaupt merklich erweitern. Ich habe sogar vielfach den Eindruck erhalten, dass der Athmungsstillstand dann noch wesentlich leichter eintritt und länger anhält, als sonst.

Eine weitere sehr auffallende Erscheinung ist unter diesen Umständen auch die Gleichheit der Wirkung der Einblasung und d er A us saug u ng, indem Beides zunäcbst Athem- 
rthe bewirkt, die erst ganz allmählich in eine intensive Exspirationsanstrengung übergeht.

Eine Erklärung dieser auffallenden Verhältnisse zu geben, sehe ich mich zunächst gänzlich ausser Stande. Sicher ist nur, dass sie sich mit der derzeitigen Auffassung über die Entstehung der Lungenreflexe nicht völlig in Einklang bringen lassen. Ebenso sicher dürfte aber eine planmässige Weiterverfolgung dieser so leicbt zu machenden Beobacbtungen an Vögeln uns in der definitiven Lösung des Vagusproblemes einen Schritt vorwärts bringen können.

\section{Literaturverzeichniss über die Athmung der Vögel.}

1) Bert, Leçons sur la Physiologie Comparée de la respiration. Paris 1870.

2) Knoll, Ueber Myocarditis und die übrigen Folgen der Vagussektion bei Tauben, Prager Zeitschr. f. Heilkunde Bd. I. 1880.

3) Magnus, Physiologisch-anatomische Studien über die Brust- und Bauchmuskeln der Vögel. Archiv f. Anat. und Physiol. 1869, p. 207-235.

4) Vicq d'Azyr, Mémoires pour servir à l'anatomie des oiseaux. Mémoires de l'Academie Royale des Sciences. Paris 1772-1778.

5) Philomatinsky, De avium respiratione. Inaug.-Dissert. Dorpat 1833.

6) Sibson, On the mechanism of respiration. Phil. Transact. London 1846. p. $501-550$.

7) Vogt und Yung; Lehrb. d. vergl. Anat. Braunschweig 1892.

8) Bronn's Klassen and Ordnungen des Thierreiches. VI. Bd. IV. Abth.

9) Tiedemann, Anatomie und Physiologie der Vögel. I. p. 627.

10) d'Alton, De Strigum musculis commentatio, Halis 1837.

11) Drosier, On the functions of the air-cells, and the mechanism of Respiration. Ann. and Mag. of Natur. Histor. Bd. 17. London 1866. p. $313-316$.

12) Coiter, De avium aspera arteria, pulmonibus etc. (Externarum et internarum principalinm humani corporis partium tabulae atque anatomicae exercitationes, in fol. 1573. p. 131.)

13) Harvey, Exercitationes de generatione animalium 1651. exercit. 3.p. 5. 
14) Hunter, An account of certain Receptacles of Air in Birds, which communicate with the lungs and are lodged both among the fleshy Parts and in the hollow bones of those Animals. (Philos. Trans. 1774. t. LXIV. et Oeuvres t. IV. p. 250.

15) Camper, Mém. sur la structure des os dans les Oiseaux (Académie des sciences, Mém. des savants étrangers pour 1773. Paris 1776. t. VII. p. 328 .

16) Cuvier, Anatomie comparée, 1805. 1re édition. t. IV und Règne animal 2 édition. t. I.

17) S ap pey, Recherches sur l'appareil respiratoire des Oiseaux, 1847 und kurzer Auszug unter demselben Titel in Compt. rend. Ac. Sciences. Paris XXII (1846). p. 250, 508.

18) Owen, art. Aves (Todd's Cyclop. of Anatomy and Physiol, 1836. t. I.) und Anatomy of the Southern Apteryx. (Trans. of the Zool. Socie. of London. t. II.)

19) Guillot, Mémoire sur l'appareil respiratoire des Oiseaux. (Ann. des sc. nat., 1846. $2^{\mathrm{e}}$ série. t. V. p. 25.)

20) Huxley, On the respiratory organs of Apteryx; Proc. Zool. Soc. 1882. p. 560 .

21) Campana, Physiologie de la respiration chez les oiseaux etc. Paris 1875.

22) Milne Edwards, Leçons sur la Physiologie et l'Anatomie Comparée de l'homme et des animaux. t. II. 1857.

23) Marshall, Der Bau der Vögel. Leipzig 1895.

24) Pagenstecher, Allgem. Zoologie. t. III.

25) Perrault, Description anatomique de huit Autruches. (Mém. pour servir à l'histoire des Animaux. t. II. p. 142.)

26) Eberth, Zeitschr. für wissensch. Zool. XII. 1863.

27) Zander, Folgen der Vagusdurchschneidung bei Vögeln. Dies Archiv Bd. 19. 1879 .

28) Eichorst, Die trophischen Beziehungen der Nervi vagi zum Herzmuskel. Berlin 1879.

29) Kohts und Tiegel, Einfluss der Vagusdurchschneidung anf Herzschlag und Athmung. Dies Archiv Bd. XIII.

30) Head, On the regulation of Respiration. (Journal of Physiologie vol. X. Nos. I u. II.)

31) Grïtzner, Archiv f. Anat. und Physiol. 1878. Bd, 17. p. 238.

32) Langendorff, Untersuchungen über das Verhalten der die Athmung beeinflussenden Vagusfasern gegen Kettenströme. Du Bois' Archiv Bd. 59. 1895.

33) Meltzer, Die athemhemmenden und -anregenden Nervenfasern innerhalb des Vagus in ihren Beziehungen zu einander und zum Athemmechanismus. Archiv für Anat. und Physiolog. 1892. S. 360.

34) Rosenthal, Die Athembewegungen und ihre Beziehungen zum N. vagus. Berlin 1862 
35) Breuer, Die Selbststeuerung der Athmung durch den Nervus vagus. (Aus dem physiol. Laborat. d. k. k. Josephsakademie. 1868.)

36) Gad, Die Regulirung der normalen. Athmung. (Arch. f. Anat. und Physiol. 1880.)

37) Couvreur, Sur le pneumagastrique des oiseaux. (Annales de l'université de Lyon. t. II. 3e. Fascicule. Paris 1892).

\title{
Erklärung der Abbildungen auf Tafel III, IV und V.
}

\author{
T a fel III.
}

Fig. 1. Normale Athmung einer mit Kopfkappe versehenen Eidechse. Vorwiegen der aktiven Exspiration (aufsteigender Schenkel der Curve) über die aktive Inspiration (absteigender Curvenschenkel, soweit er nach abwärts von der der Cadaverstellung des Thorax entsprechenden Pausenlinie liegt).

Fig. 2. Wie in Fig. 1, nur prävalirt hier die inspiratorische Phase.

Fig. 3. Die Pausenlinien entsprechen der Cadaverstellung des Brustkorbes; die aktive Exspiration kräftig ausgeprägt, während die aktive Inspiration unterdrỉckt ist. Das Fehlen der letzteren ist ausserordentlich hänfig zu beobachten, namentlich in Zuständen verminderter centraler Erregbarkeit (z. B. im Herbst).

Fig. 4. Normale Respiration einer Eidechse unter Einschaltung einer Trachealkanüle; die Identität der Curve mit Fig. 1-3 ist ohne weiteres ersichtlich.

Fig. 5. Respirationscurve, von einem Alligator lucius (Trachealkanüle). Die Curve zeigt, ebenso wie

Fig. 6, von einer tracheotomirten Ringelnatter denselben Charakter wie Fig. 1, 2 und 4.

Fig. 7-10 incl. Ausschnitte einer Curvenreihe, die unter dem Einfluss einer sich allmählich steigernden Kohlensäuredyspnoe aufgezeichnet wurde. Charakteristisch ist die allmähliche Verminderung der exspiratori- 
schen und inspiratorischen Amplitude und die damit Hand in Hand gehende Verlängerung der A thempausen. .Die Curven können gleichzeitig als Paradigmata gelten für die Wasserstoff- und die hämorrhagische Dyspnoe.

Fig. 11-13 incl. Ausschnitte einer fortlaufenden Curvenreihe, zunehmende Wärmedyspnoe; hervorzuheben ist die im Anfangsstadium auftretende Bildung von Perioden und die allmählich ins Excessive sich steigernde Beschleunigung der Athmung.

Fig. 14 und 15. Verschiedene Formen periodischer Athmung, wie sie am normalen Thiere ausserordentlich häufig zur Beobachtung gelangen.

Fig. 16. Respirationscurve einer ätherisirten Lacerta. Der Ausschnitt stellt eine Periode dar, begrenzt von eigenthümlichen atypischen Athmungen, wie sie für diesen Zustand charakteristisch sind. Innerhalb der Perioden ist die allmähliche Amplitudenvergrösserung und das correspondirende Ansteigen der Frequenz bemerkenswerth.

Fig. 17. Dasselbe Thier nach starker Erwärmung. Die Athmung ist noch beschleunigter; Verkürzung der Perioden.

(Fig. 7-17 incl. bei Anwendung der Kopfkappe gewonnen.

Fig. 18. Tracheotomirte Eidechse; bei a Durchtrennung des linken Vagus. Enorme Verlangsamung, Verstärkung der inspiratorischen Amplitude und gleichzeitiger A usfall der aktiven Exspiration.

Fig. 19. Vom selben Thiere; eine Stunde später aufgenommen; die aktive Exspiration ist wieder aufgetreten, wenn auch noch schwächer als normal.

Fig. 20. Reizung des centralen Vagusstammes eines linksseitig vagotomirten Thieres mit mittelstarken Induktionsströmen. Die Durchschneidung des Nerven hatte in diesem Falle die Frequenz fast ganz unbeeinflusst gelassen; der Reiz (bei a), im Beginne einer aktiven Exspiration einwirkend, coupirt die letztere und lässt den Schreibhebel sofort zur Ruhelinie zurückfallen.

Fig. 21. Reizung des centralen Vagusstammes einer rechtsseitig vagotomirten Eidechse, in verschiedenen Phasen der Athmung; Pausen in Ruhestellung während der Dauer der Erregung.

Fig. 22. Reizung ( $a x$ und $b y$ ) mit dem aufsteigenden unterbrochenen Kettenstrom bei einer einseitig vagotomirten Eidechse; starke exspiratorische Wirkung; nach Beendigung der Reizung erfolgt eine stark vertiefte Inspiration und auch die folgenden Respirationsbewegungen sind noch im Sinne einer inspiratorischen Verstärkung beeinflusst.

Fig. 23. Athmung einer Eidechse mit exstirpirtem Grosshirn kurz nach der Operation: Lebhafte Beschleunigung; in annähernd constanten Inter- 
vallen schieben sich atypische Athembewegungen ein, welche der Curve den Charakter der Periodicität verleihen.

Fig. 24. "Schluckathmung" einer Eidechse, hervorgerufen durch hohe Rückenmarksdurchtrennung. Die Curve ist gewonnen durch Aufsetzen eines Fühlhebels auf die seitliche Thoraxwand. Die absteigenden Schenkel entsprechen dem Collapse der Lungen, die aufsteigenden der plötz* lichen Fuillung durch die Contralktion des Mundbodens, die Pausen der Dauer der Aufblähung.

\section{T a f e I IV.}

Fig. 25. Athmung einer Eidechse nach Exstirpation von Grosshirn und Mittelhirn und doppelseitiger Vagotomie. Nur $a$ und $b$ entsprechen typischen Athembewegungen, die sich dazwischen schiebenden eigenthümlichen Oscillationen des Brustkorbes sind nur vorübergehende Reizerscheinungen, enorme Verlangsamung der Athmung.

Fig. 26. Normale Respiration einer Taube; tracheotomirtes Thier. Die horizontale in der Mitte der Curve entspricht der Abscisse, gewonnen durch Abnahme des Trachea und Tambour verbindenden Schlauches.

Fig. 27-36. Normale Respirationscurven verschiedener Tauben. Doch stammt Fig. 33 von einem chloralisirten und Fig. 35 von einem enthirnten Thiere (in letzterem Falle ist die starke Beschleunigung bemerkenswerth). Ueber die Deutung der Curven siehe Text.

Fig. 37, 38 u. 39 . Respiration nach einseitiger Vagotomie.

Fig. 40 u. 41. Respiration nach doppelseitiger Vagotomie.

Fig. 42. Doppelseitige Vagotomie; seltener Athemtypus nach doppelseitiger Vagusdurchschneidung, ausgezeichnet durch die auf der Höhe der Exspiration stattfindende Pausenbildung.

Fig. 43. Doppelseitige Vagotomie; bei $x$ Durchschneidung des Rückenmarkes unterhalb der Medulla oblongata. Man erkennt, dass die an die passive Inspiration sich anschliessende Pause der Ruhestellung des Thorax entspricht. Aehnliche Verhältnisse zeigt auch

Fig. 44, die von einem einseitig vagotomirten Thiere gewonnen wurde. Auch hier bei $x$ hohe Rïckenmarksdurchschneidung.

Fig. 45. Doppelseitig vagotomirte Taube; bei a Reizung mit Induktionsströmen: erorme Pause in Ruhelage des Brustkorbes. Bei $b$ Unterbrechung der Reizung: Beschleunigung und exspiratorische Verstärkung.

Fig. 46-63. Sämmtlich von einseitig vagotomirten Tauben gewonnen.

Fig. 46. Faradische Reizung: Pause, die allmählich in flache und verlangsamte Respirationen übergeht. Nachwirkung im Sinne einer Beschleunigung. 
Fig. 47. Induktionsstrom; Chloralisirtes Thier, bei $x$ Beginn der Reizung. Der Hebel fällt allmählich zur Ruhelinie ab; als Nachwirkung exspiratorische Verstärkung and leichte Beschleunigung.

Fig. 48. Induktionsstrom; Reizung von $a$ bis $b$. Inspiratorische Pause, die in die Ruhestellung übergeht, worauf sich eine zweite Pause in Inspirationsstellung ausbildet. Als Nachwirkung Verstärkung beider Athemphasen und geringe Verlangsamung.

Fig. 49. Induktionsstrom (Schlittenapparat), allmählich zunehmende Frequenzsteigerung und Abflachung der inspiratorischen Phase.

Fig. 50. Induktionsstrom, anfänglich Verflachung und Ver]angsamung, dann Beschleunigung. Nachwirkung im Sinne einer Verlangsamung und Verstärkung von Ex- und Inspiration.

Fig. 51. Induktionsstrom: Anfangs Beschleunigung und leichte Abflachung namentlich der Inspiration; weiterhin nimmt die Frequenz und die Amplitude der Athmungen zu.

Fig. 52. Induktionsstrom:

bei $a$ : $20 \mathrm{~cm}$ Rollenabstand: Hemmung und Beschleunigung.

bei $c$ : $10 \mathrm{~cm}$ Rollenabstand: Hemmang und Verlangsamung.

In beiden Fällen als Nachwirkung Beschleunigung und Verstärkung beider Phasen.

Fig. 53. Induktionsstrom: Verstärkung beider Athemphasen. Anfangs Beschleunigung, dann Verlangsamung.

Fig. 54. Induktionsstrom: Hemmung, namentlich der Exspiration; mässige Beschleunigung. Als Nachwirkung Verstärkung der Exspiration.

Fig. 55. Indaktionsstrom: Pause. Als Nachwirkung Beschleunigung und Abflachung der respiratorischen Curvenschenkel.

Fig. 56. Reizung mit dem aufsteigenden constanten Strom, dauernde Schliessung, mässige Beschleunigung; Abflachung der Exspiration.

Fig. 57. Reizung mit dem aufsteigenden constanten Strom, dauernde Schliessung, inspiratorische Vertiefung; exspiratorische Verflachung, Beschleunigung.

Fig. 58. Reizung bei $a$ mit aufsteigenden, bei $c$ mit absteigenden unterbrochenen Kettenströmen, Hemmung beider Phasen; die geringere Wirkung des absteigenden Stromes sehr dentlich. Als Nachwirkung Beschleunigung und exspiratorische Verstärkung.

Fig. 59. Curve eines beiderseitig vagotomirten Thieres. Siehe Fig. 40-43 incl.

Tafel V.

Fig. 60. Reizung mit dem aufsteigenden unterbrochenen Kettenstrom. Beschleunigung und Verstärkung beider Athemphasen. 
506 Ernst Si efert: Ueber die Athmang der Reptilien und Vögel.

Fig. 61. Reizung mit dem aufsteigenden unterbrochenen Kettenstrom; dasselbe Thier; schwächerer Strom. Der Reizerfolg besteht in einer deutlichen Hemmungswirkung auf die Exspiration.

Fig. 62. Reizung mit dem $\uparrow$ unterbrochenen Strom. Starke Beschleunigung und Vertiefung besonders der Inspirationsphase.

Fig. 63. Reizung mit dem $\uparrow$ unterbrochenen Strom. Inspiratorische Vertiefung, Reduktion der Exspirationsphase und mässige Beschleunigung.

Fig. 26-63 mittels Trachealkanüle gewonnen.

Sämmtliche Curven sind von links nach rechts zu lesen. 